Sistema de Gerenciamento para a Integração em CC de Fontes Alternativas de Energia e Armazenadores Híbridos Conectados a Rede de Distribuição via Conversores Eletrônicos

Renan Fernandes Bastos

São Carlos

2016 

Renan Fernandes Bastos

\section{Sistema de Gerenciamento para a Integração em CC de Fontes Alternativas de Energia e Armazenadores Híbridos Conectados a Rede de Distribuição via Conversores Eletrônicos}

Tese apresentada à Escola de Engenharia de São Carlos, da Universidade de São Paulo, como requisito para obtenção do Título de Doutor em Ciências, Programa de Pós-graduação em Engenharia Elétrica.

Área de Concentração: Sistemas Dinâmicos.

Orientador: Prof. Dr. Ricardo Quadros Machado

São Carlos

2016

Trata-se da versão corrigida da tese. A versão original se encontra disponível na EESC/USP que aloja o Programa de Pós-Graduação de Engeharia Elétrica. 
AUTORIZO A REPRODUÇÃO TOTAL OU PARCIAL DESTE TRABALHO, POR QUALQUER MEIO CONVENCIONAL OU ELETRÔNICO, PARA FINS DE ESTUDO E PESQUISA, DESDE QUE CITADA A FONTE.

Bastos, Renan Fernandes

Sistema de Gerenciamento para a Integração em CC de Fontes Alternativas de Energia e Armazenadores Híbridos Conectados a Rede de Distribuição via Conversores Eletrônicos/ Renan Fernandes Bastos; orientador Ricardo Quadros Machado. São Carlos, 2016.

Tese (Doutorado) - Programa de Pós-Graduação em Engenharia Elétrica e Área de Concentração em Sistemas Dinâmicos -- Escola de Engenharia de São Carlos da Universidade de São Paulo, 2016.

1. Microrrede CC. 2. Eletrônica de Potência. 3. Bateria Chumbo-Ácido. 4. Ultracapacitores. 5. Geração Distribuída. 6. Gerenciamento de Energia. 7. Fontes Alternativas. 8. Controle Descentralizado. I. Título. 
Candidato: Engenheiro RENAN FERNANDES BASTOS.

Título da tese: "Sistema de gerenciamento para a integração em CC de fontes alternativas de energia e armazenadores híbridos conectados a rede de distribuição via conversores eletrônicos".

Data da defesa: 27/10/2016.

Comissão Julgadora:

Prof. Dr. Ricardo Quadros Machado

(Orientador)

(Escola de Engenharia de São Carlos/EESC)

Prof. Dr. José Carlos de Melo Vieira Junior

(Escola de Engenharia de São Carlos/EESC)

Prof. Dr. Marcelo Suetake

(Universidade Federal de São Carlos/UFSCar)

Prof. Dr. Claudionor Francisco do Nascimento

(Universidade Federal de São Carlos/UFSCar)

Prof. Dr. Marcelo Gradela Villalva

(Universidade Estadual de Campinas/UNICAMP)
Resultado:

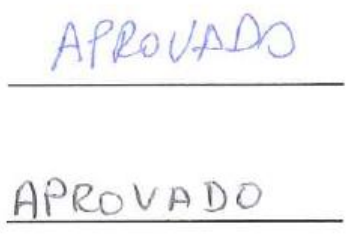

APROVADO

APCOVAJO

APROVADO

Coordenador do Programa de Pós-Graduação em Engenharia Elétrica: Prof. Associado Luis Fernando Costa Alberto

Presidente da Comissão de Pós-Graduação:

Prof. Associado Luis Fernando Costa Alberto 



\section{Agradecimentos}

Em primeiro lugar, agradeço a minha família pelo apoio, exemplo e pela minha formação como pessoa. Em especial aos meus pais e meus irmãos que me acompanharam nesta longa jornada. Aos meus avós Lalado, Leia, Niniza, aos meus tios, tias e primos que torcem por mim.

Aos amigos e professores da UFV, que toram possível o sonho chegar até aqui.

Aos amigos que fiz em São Carlos, que não daria para citar todos aqui, mas em especial os companheiros da Rep. Alabama, Goias, Rodolpho, Paulo, Fabão, Breno, Fabrício, Nuno, Ronaldo e Urso.

Muito obrigado aos companheiros de trabalho do LAC e LAFAPE, Amilcar, Giovani, Nilton, Fernando, Guido, Giann, Rodolpho, Cassius, Guilherme, Willian, Marina, Rafael e Klebber pela amizade, discussões, aprendizados e brincadeiras, aos quais sem eles este trabalho não seria possível.

Agradeço também a todos os funcionários do departamento de engenharia elétrica da USP pelas contribuições e pela boa vontade em sempre nos ajudar.

Ao Prof. Ricardo, pela confiança em mim depositada durante a execução deste trabalho, pelo incentivo, dedicação, paciência e amizade, obrigado por contribuir com a minha formação acadêmica. Agradeço também a professora Vilma, pela constante contribuição e suporte na pesquisa.

Aos professores, funcionários da Universidade de Aalborg e amigos que fiz em Aalborg, principalmente, Josep M. Guerrero, Tomislav Dragičević, Luiz Antônio de Souza Ribeiro e todos os que contribuíram de alguma forma durante o meu intercâmbio.

A UFOP e em especial aos professores do Departamento de Engenharia Elétrica da UFOP, que possibilitaram e apoiaram o meu processo de capacitação.

Agradeço a Escola de Engenharia de São Carlos pelas instalações e serviços, além do apoio financeiro do CNPq, Fapesp, processos 2013/20721-4 e 2012/12770-2 e Capes 88881.030370/2013-01. 

"Remember the IDEA, not the man, because a man can fail and be forgotten. But hundred years later an IDEA can still change the world" 



\title{
Resumo
}

\author{
BASTOS, R. F. Sistema de Gerenciamento para a integração em CC de fontes \\ alternativas de energia e armazenadores híbridos conectados a rede de distribuição via \\ conversores eletrônicos. 2016. 160p. Tese (Doutorado) - Escola de Engenharia de São Calos, \\ Universidade de São Paulo, São Carlos, 2016.
}

Esta Tese de doutorado visa o estudo e o desenvolvimento de topologias e técnicas de controle para a integração de fontes alternativas tais como, solar e eólica acopladas a um barramento comum em corrente continua $(\mathrm{CC})$ e conectá-las à rede de distribuição. $\mathrm{O}$ sistema contará também com elementos armazenadores como bancos de baterias e ultracapacitores, formando assim uma estrutura híbrida de armazenamento. Algoritmos de gerenciamento de energia serão implementados para que o perfil de injeção de potência na rede seja suave, eliminando as oscilações que são criadas, naturalmente, por fontes dependentes de fatores climáticos. Como consequência, os sistemas formados por fontes alternativas podem se tornar confiáveis e previsíveis, melhorando a capacidade de planejamento em um cenário cujos sistemas apresentem uma participação elevada na matriz energética. Duas metodologias de gerenciamento de energia são executadas neste trabalho, na primeira o ultracapacitor é gerenciado de modo a permitir a transferência de potência constante para a rede de distribuição em intervalos da ordem de minutos. A segunda estratégia se baseia no uso de banco de baterias combinado com ultracapacitores, formando uma estrutura híbrida de armazenamento. Nessa estrutura de gerenciamento, os armazenadores se comunicam entre si de forma a realizar um compartilhamento e filtragem de energia, fazendo com que transitórios de potência não sejam transmitidos para a rede de distribuição. Nesta estratégia, as baterias são responsáveis pelo fornecimento/absorção da potência média enquanto os ultracapacitores se encarregam dos transitórios. No segundo instante outras duas metodologias de divisão de carga são propostas para microrredes híbridas, contudo são baseadas em estratégias descentralizadas, ou seja, os armazenadores não se comunicam entre si para realizar o compartilhamento. Resultados experimentais e simulações irão comprovar a efetividade das metodologias de gerenciamento propostas.

Palavras-chave: Microrrede CC. Eletrônica de potência. Bateria de Chumbo-ácido. Ultracapacitores. Geração distribuída. Gerenciamento de energia. Fontes alternativas. Controle descentralizado 



\section{Abstract}

BASTOS, R. F. Energy management for integration of alternative sources and composite storage system connected to the grid. 2016. 160p. Tese (Doutorado) - Escola de Engenharia de São Calos, Universidade de São Paulo, São Carlos, 2016.

This Ph.D. dissertation aims the study and development of topologies and control techniques to integrate various alternative sources such as solar and wind, coupled to a direct current (DC) common bus and connect them to the distribution grid. Storage devices such as battery banks and ultracapacitors will form a hybrid storage structure that is responsible for the power supplying in periods in which the sources are unable (times of the day in which the light incidence is low or when the wind amount is scarce). Power management algorithms will be implemented so the alternative sources and storage devices exchange energy, in order to make smoother the power injection profile in the grid, eliminating the fluctuations that are created naturally by alternative sources. With a smooth power profile, energy management systems based on alternative sources may become more reliable and predictable, improving planning capacity in a scenario in which the renewable energy sources have a high penetration in the energy matrix. To obtain such a result, two power management methodologies are executed; the first one is based on ultracapacitors and aims to deliver constant power to the distribution network, even when the power production is zero. However, this technique allows constant power just for a few minutes, once the ultracapacitor capacity is limited. The second strategy is based on the bank of batteries combined with ultracapacitors, forming the hybrid storage system. In this management structure, the storage devices communicate with each other in order to perform a power sharing, resulting in a filtrated power profile delivered to the distribution network. In this strategy, the batteries are responsible to providing average power while ultracapacitors are in-charge of the transient power, sparing the batteries from supplying power peaks. In a second moment, two other load sharing methodologies are proposed for hybrid systems, but are based on decentralized techniques, i.e. storage devices do not communicate with each other to make the power sharing. Experimental and simulated results will prove the effectiveness of the control strategies and management methodologies.

Keywords: DC micro grid. Power electronics. Lead acid battery. Ultracapacitor. Distributed generation. Alternative sources. Decentralized control. 



\section{Lista de siglas e símbolos}

A - Área da turbina eólica.

CA - Corrente alternada.

CC - Corrente contínua.

$C_{p} \quad$ - Coeficiente de potência da turbina eólica.

C - Capacitor do barramento CC.

$C_{c a} \quad$ - Capacitor do filtro de saída do conversor CC-CA.

$C_{i n} \quad$ - Capacitor de entrada dos conversores CC-CC.

d - Duty cycle, ciclo de trabalho instantâneo dos conversores CC-CC.

D - Duty cycle, ciclo de trabalho dos conversores CC-CC em regime permanente.

$E_{B a t}$ - Energia total armazenada na bateria em A.h,

$E_{g} \quad$ - Energia mínima armazenada na bateria para início do algoritmo de injeção de potência constante.

$E_{m} \quad$ - Energia média armazenada na bateria.

$E_{S} \quad$ - Oscilação de energia na bateria.

$F_{c h} \quad$ - Frequência de chaveamento dos conversores.

$F P A$ - Filtro passa alta.

$F P B$ - Filtro passa baixa.

GD - Geração distribuída.

$G_{O L} \quad$ - Ganho de malha aberta da planta de controle.

$H_{i} \quad$ - Ganho do sensor de corrente do conversor CC-CA.

$H_{v} \quad$ - Ganho do sensor de tensãodo conversor CC-CA.

$i_{a} \quad$ - Corrente da fase A na saída do inversor.

$i_{\omega} \quad$ - Corrente injetada no barramento CC pelo aerogerador.

$i_{B a t} \quad$ - Corrente injetada no barramento CC pela bateria medida no lado de baixa tensão do conversor.

$i i_{\text {Bat }}$ - Corrente injetada no barramento CC pela bateria medida no lado de alta tensão do conversor.

$i_{b} \quad$ - Corrente da fase B na saída do inversor.

$i_{c} \quad$ - Corrente da fase $\mathrm{C}$ na saída do inversor.

$i_{d} \quad$ - Corrente de saída do conversor CC-CA no referencial síncrono $d q$.

$i_{f a} \quad$ - Corrente total gerada pelas fontes alternativas conectadas ao barramento CC.

$i_{g} \quad$ - Corrente entregue a rede no algoritmo de injeção de potência constante.

$I_{m p} \quad$ - Corrente de máxima potência do painel fotovoltaico.

$i_{q} \quad$ - Corrente de saída do conversor CC-CA no referencial síncrono $d q$.

$i_{\text {rede }} \quad$ - Corrente média drenada do barramento CC pelo inversor.

$i_{U C} \quad$ - Corrente injetada pelo ultracapacitor no barramento CC medida no lado de baixa tensão do conversor.

$i i_{U C} \quad$ - Corrente injetada pelo ultracapacitor no barramento CC medida no lado de alta tensão do conversor.

$k b \quad$ - Constante de escalonamento da corrente para divisão de carga aplicado na técnica descentralizada da bateria.

kc - Constante de escalonamento da corrente para divisão de carga aplicado na técnica descentralizada do UC.

ki - Constante integral do controlador de tensão da técnica descentralizada da bateria.

$K_{\text {int }} \quad$ - Constante integral do controlador de corrente dos conversores CC-CC.

$k p \quad$ - Constante proporcional do controlador de tensão da técnica descentralizada da 
bateria.

$K_{\text {prop }} \quad$ - Constante proporcional do controlador de corrente dos conversores CC-CC.

$L_{c a} \quad$ - Indutor de saída do conversor CC-CA.

$L_{c c} \quad$ - Indutor dos conversores CC-CC.

$L_{o} \quad$ - Indutor de acoplamento com a rede elétrica.

$m f$ - Margem de fase.

MPPT - maximum power point tracking, Algoritmo de busca do ponto de máxima potência.

PAC - Ponto de acoplamento comum.

$P_{f a} \quad$ - Potência gerada pelas fontes alternativas e entregue ao barramente CC.

$P I_{c} \quad$ - Controlador de corrente proporcional integral dos conversores CC-CC.

$P_{m p} \quad$ - Potência máxima desenvolvida pelo conjunto fotovoltaico.

PV - Painel fotovoltaico.

$P_{\omega} \quad$ - Potência mecânica da turbina eólica.

$P_{W_{m p}} \quad$ - Potência máxima desenvolvida pelo aerogerador.

$\rho \quad$ - Densidade do ar $1,225 \mathrm{~kg} / \mathrm{m}^{3}$

$R_{E Q} \quad$ - Resistencia equivalente do modelo simplificado das fontes alternativas em torno do ponto de máximo.

$R_{c a} \quad$ - Resistor do filtro de saída do conversor CC- CA.

$R_{L} \quad$ - Resistência parasita do indutor dos conversores CC-CC.

$S O C$ - State of Charge, estado de carga das baterias.

$T_{\omega} \quad$ - Torque da turbina eólica.

UC - Ultracapacitor.

$U C$ - Capacitância do UC

$v_{a} \quad$ - Tensão da fase A medida no ponto PAC.

$v_{b} \quad$ - Tensão da fase $\mathrm{B}$ medida no ponto PAC.

$v_{c} \quad$ - Tensão da fase $\mathrm{C}$ medida no ponto PAC.

$v_{c c} \quad$ - Tensão do barramento CC.

$V_{E Q} \quad$ - Tensão equivalente do modelo simplificado das fontes alternativas em torno do ponto de máximo.

$V_{m p} \quad$ - Tensão de máxima potência do painel fotovoltaico.

VSI - Voltage Source Inverter, inversor fonte de tensão.

$v_{\text {rede }} \quad$ - Tensão de referência medida na fase $\mathrm{A}$ da rede elétrica.

$v_{U C} \quad$ - Tensão terminal do ultracapacitor.

$v_{w} \quad$ - Velocidade do vento.

$W_{f a} \quad$ - Frequência fundamental da oscilação na potência gerada pelas fontes alternativas. que é igual a $1 / 24 \mathrm{~h}$.

$\omega_{F C L}$ - Frequência de corte em malha fechada.

$W_{m p} \quad$ - Velocidade na qual o aerogerador desenvolve a potência máxima.

$W_{\omega} \quad$ - Velocidade mecânica da turbina eólica.

$\vartheta \quad$ - ângulo da pá em relação ao eixo da turbina eólica

$\sigma \quad$ - Fator que relaciona a energia gerada pelas fontes alternativas e a energia armazenada na bateria. 


\section{Lista de Figuras}

Figura 1.1 - Irradiação média incidente durante 24 h................................................. 4

Figura 3.1 - Sistema completo para integração de fontes alternativas......................... 8

Figura 3.2 - Sistema eólico duplamente alimentado para conexão direta de gerador de indução

Figura 3.3 - Sistema eólico utilizando gerador síncrono............................................... 9

Figura 3.4 - Ângulo de inclinação da pá em relação ao eixo da turbina....................... 10

Figura 3.5 - Curva típica de $P_{\omega}$ versus $W_{\omega}$ da turbina para diferentes velocidades do vento, considerando o ângulo das pás fixo

Figura 3.6 - Coeficiente de potência para diferentes velocidades médias de vento, considerando o ângulo das pás constante

Figura 3.7 - Potência máxima de saída para diferentes velocidades do vento considerando o ângulo das pás fixo e turbina de raio $1 \mathrm{~m}$, de acordo com equação (3.5)

Figura 3.8 - Potência média de saída e coeficiente de potência para uma velocidade do vento fixa e variando o ângulo das pás.....

Figura 3.9 - Modelo generalizado de uma célula solar

Figura 3.10 - Curva característica corrente versus tensão de um módulo KC130TM, para diferentes níveis de irradiação.

Figura 3.11 - Curva potência versus tensão, módulo KC130TM, para diferentes níveis de irradiação

Figura 3.12 - Desgaste de uma bateria de chumbo-ácido em função da profundidade da carga.

Figura 3.13 - Efeito da temperatura na vida útil da bateria de chumbo-ácido.

Figura 3.14 - Estado de carga versus tensão de circuito aberto para uma bateria de chumbo-ácido.

Figura 3.15 - Método a dois níveis de tensão

Figura 3.16 - Tensão e corrente, método dois níveis.

Figura 3.17 - Diagrama de Ragone.

Figura 3.18 - Estrutura básica de um ultracapacitor 
Figura 3.19 - Comportamento da variável de controle e da potência, durante o regime permanente utilizando algoritmo MPPT por $\mathrm{P} \& \mathrm{O}$ com passo fixo.

Figura 3.20 - Método de busca por perturbação e observação.

Figura 3.21 - Conversores CC empregados na integração das fontes alternativas e dos armazenadores.

Figura 3.22 - Conversor Buck-Boost bidirecional e malha de controle utilizada na bateria e UC.

Figura 3.23 - Conversor Boost e malha de controle utilizada no PV e sistema eólico

Figura 3.24 - Sistema eletrônico e de controle do conversor CC-CA no modo conectado e isolado.

Figura 3.25 - Sistema de controle centralizado da tensão do barramento CC no modo conectado.

Figura 4.1 - Modelo simplificado equivalente do conversor Buck-Boost CC-CC acoplado as fontes alternativas ou armazenadores

Figura 4.2 - Conversor Buck-Boost adotado no instante chave $\boldsymbol{S} 1$ fechada e $\boldsymbol{S} 2$ aberta ou conversor Boost com a chave $S 1$ fechada e diodo da chave $S 2$ não conduzindo

Figura 4.3 - Conversor Buck-Boost adotado no instante chave S2 fechada e S1 aberta ou conversor Boost com a chave S1 aberta e diodo da chave S2 conduzindo.

Figura 4.4 - Diagrama de bode em malha aberta, malha fechada e malha fecha compensada $+P I_{c}$ da função de $\mathrm{TF} G_{c}(s)$

Figura 4.5 - Planta de controle do conversor CC-CA em modo conectado................ 36

Figura 4.6 - Planta do conversor CC-CA em modo ilhado....................................... 37

Figura 4.7 - Diagrama do algoritmo de sincronização............................................... 38

Figura 4.8 - PLL em funcionamento sincronizando com a rede............................... 39

Figura 4.9 - Atuação do PLL na frequência gerada para alcançar o sincronismo........ 39

Figura 5.1 - Estratégia de gerenciamento proposta por [67]................................... 44

Figura 5.2 - Estratégia de gerenciamento proposto com restauração contínua da tensão terminal do UC. 
Figura 5.3 - Sincronização entre o VSI e a rede de distribuição ou sub transmissão.. 45

Figura 5.4 - Tensão do VSI e da rede de distribuição no momento da conexão........ 47

Figura 5.5 - Corrente na fase "A" do inversor durante transitórios............................. 47

Figura 5.6 - Corrente da bateria e do UC................................................................. 48

Figura 5.7 - Tensão terminal do UC sendo restaurada pela estratégia proposta......... 48

Figura 5.8 - Potência de saída do aerogerador.......................................................... 49

Figura 5.9 - Tensão do barramento CC durante os eventos....................................... 49

Figura 5.10 - Potência de Saída do conjunto PV sob irradiação solar constante......... 50

Figura 5.11 - Tensão de saída do conjunto PV sendo controlado pelo algoritmo de busca MPPT P\&O. Irradiação solar ajustada constante em $1000 \mathrm{~W} / \mathrm{m}^{2}$ e $V_{m p}=$ $76 \mathrm{~V}$

Figura 6.1 - Circuito eletrônico considerado no modelo da microrrede com UC e bateria.

Figura 6.2 - Circuito eletrônico dos conversores bidirecionais dos UCs e baterias..... 56

Figura 6.3 - Microrrede com sistema descentralizado de controle onde os armazenadores não se comunicam.

Figura 6.4 - Técnica de controle dos UCs.............................................................. 58

Figura 6.5 - Técnica de controle das baterias...................................................... 58

Figura 6.6 - Representação gráfica da influencia do SOC na divisão de carga............. 60

Figura 6.7 - Corrente imposta pelas fontes alternativas $i_{f a}$ ao barramento CC e a resposta dos armazenadores $\left(i_{B a t}+i_{U C}\right)$ de forma a manter o equilíbrio................ 62

Figura 6.8 - Tensão do barramento CC................................................................. 63

Figura 6.9 - Resposta dos UCs e baterias frente à entrada $i_{f a}$ apresentada na Fig. 6.6 quando a constante de tempo dos filtros FPA e FPB é $\mathrm{T}=0,05 \mathrm{~s}$

Figura 6.10 - Resposta dos UCs e baterias frente à entrada $i_{f a}$ apresentada na Fig. 6.7 quando a constante de tempo dos filtros FPA e FPB são modificadas para $\mathrm{T}=$ $0,15 \mathrm{~s}$

Figura 6.11 - Comportamento dinâmico do SOC durante equalização da Bat1 e Bat2..

Figura 6.12 - Modelo do sistema completo em diagrama de blocos. 
Figura 6.13 - Modelo simplificado em diagrama de blocos

Figura 6.14 - Resposta do modelo em diagrama de blocos dada uma entrada com sucessivos degraus de $i_{f a}$

Figura 6.15 - Diagrama de bode do sistema da Fig. 6.13 em malha fechada para $G_{2}(s)=0$ (apenas UC), $G_{1}(s)=0$ (apenas bateria) e malha combinada UC e bateria

Figura 6.16 - Lugar das raízes para $K($ soc $)=1$ mostrando o polo mais crítico do sistema se movimentando para direita (região de instabilidade) à medida que $K(s o c)$ se reduz.

Figura 6.17 - Lugar das raízes para $K(s o c)=0,5$ mostrando o polo mais crítico do sistema se movimentando para direita (região de instabilidade) à medida que $K(s o c)$ se reduz

Figura 6.18 - Lugar das raízes para $K(s o c)=0,1$ mostrando o polo mais crítico do sistema se movimentando para direita (região de instabilidade) à medida que $K($ soc $)$ se reduz.

Figura 6.19 - Técnica de controle proposta para as baterias no sistema descentralizado com restauração do barramento CC......

Figura 6.20 - Perfil de corrente gerada $i_{f a}$ e tensão do barramento CC sendo restaurada para $250 \mathrm{~V}$.

Figura 6.21 - Tensão dos UCs, corrente dos UCs e corrente das baterias para um mesmo estado de carga

Figura 6.22 - Tensão do barramento CC, tensão dos UCs, corrente dos UCs e corrente das baterias para $\mathrm{SOC} 1=0,7, \mathrm{SOC} 2=0,4$.

Figura 6.23 - Tensão do barramento $\mathrm{CC}$, corrente $i_{f a}$, corrente das baterias e estado de carga das baterias, utilizando o modelo de SOC dinâmico da equação (6.7)

Figura 6.24 - Modelo em diagrama de blocos para o sistema híbrido com restauração da tensão do barramento CC.

Figura 6.25 - Resposta do modelo em diagrama de blocos para o sistema híbrido com restauração da tensão do barramento $\mathrm{CC}$, dado sucessivos degraus de $i_{f a} \ldots \ldots . . . .$.

Figura 6.26 - Diagrama de bode do sistema da Fig. 6.24 em malha fechada para $G_{2}(s)=0$ (apenas $\mathrm{UC}$ ), $G_{1}(s)=0$ (apenas bateria) e malha combinada UC e bateria.

Figura 6.27 - Lugar das raízes para $K($ soc $)=0,5$ mostrando o polo mais crítico que se movimenta para a região de instabilidade à medida que esta constante se reduz.. 
Figura 6.28 - Lugar das raízes para $K($ soc $)=0,1$ mostrando o polo mais crítico que se movimenta para a região de instabilidade à medida que esta constante se reduz.........

Figura 7.1 - Modelo simplificado analisando valores médios

Figura 7.2 - Irradiação solar média global durante 96 h seguidas.

Figura 7.3 - Velocidade do vento durante 96 h seguidas.

Figura 7.4 - Corrente média entregue ao barramento pelo aerogerador, painel fotovolotaico e a soma de ambas, respectivamente.

Figura 7.5 - Algoritmo de decisão para o algoritmo de gerenciamento baseado no $\mathrm{UC}$

Figura 7.6 - Algoritmo de gerenciamento baseado no UC, quando há a injeção de potência na rede ocorre em forma de constante por intervalos.

Figura 7.7 - Zoom aplicado na Fig. 7.6.

Figura 7.8 - Algoritmo de decisão modificado para o gerenciamento baseado no $\mathrm{UC}$.

Figura 7.9 - Algoritmo de gerenciamento modificado baseado no UC, com a injeção de potência na rede constante por intervalos

Figura 7.10 - Aumento da frequência de oscilação da corrente na rede pela redução do UC, $200 \mathrm{~F}$ para $100 \mathrm{~F}$ (Fig. 5.18).

Figura 7.11 - Estratégia de controle da bateria combinada com UC e referência do inversor conectado.

Figura 7.12 - Algoritmo de gerenciamento baseado na média da potência gerada e a constante de tempo do filtro é ajustada em $0,5 \mathrm{~h}$

Figura 7.13 - Energia média na bateria $\left(E_{m}\right)$ oscilação de energia $\left(E_{s}\right)$ e frequência da oscilação.

Figura 7.14 - Variação da oscilação de energia $E_{S}$ no banco de baterias com o aumento da constante de tempo.

Figura 7.15 - Resposta de $F_{n}(s)$ e $H_{n}(s)$ para a mesma frequência de corte 1 $\mathrm{rad} / \mathrm{s}$

Figura 7.16 - Corrente média entregue a rede usando filtros de ordem 1, 2 e 3 e frequência de corte $1 \mathrm{rad} / \mathrm{s}$

Figura 7.17 - Energia da bateria usando filtros de ordem 1, 2 e 3 e frequência de corte $1 \mathrm{rad} / \mathrm{s}$. 
Figura 7.18 - Filtragem da potência entregue a rede de distribuição ou sub transmissão para constantes de tempo $\mathrm{T}=0,5 \mathrm{~h}, \mathrm{~T}=3 \mathrm{~h}$ e $\mathrm{T}=8 \mathrm{~h}$.

Figura 7.19 - Energia total da bateria para constantes de tempo $\mathrm{T}=0,5 \mathrm{~h}, \mathrm{~T}=3 \mathrm{~h}$ e $\mathrm{T}=8 \mathrm{~h}$

Figura 7.20 - Comparação entre a potência gerada pelas fontes alternativas com a potência injetada na rede para uma constante de tempo $\mathrm{T}=3 \mathrm{~h}$

Figura 7.21 - Algoritmo de decisão empregado no gerenciamento baseado na bateria.

Figura 7.22 - Resposta do sistema para $I_{g}=2,6 \mathrm{~A}$ e $E_{g}=36 \mathrm{Ah}$. Destacando a energia média na bateria $E_{m}=38 \mathrm{Ah}$ e a oscilação de energia na bateria $E_{s}=40 \mathrm{Ah}$.

Figura 7.23 - Resposta do algoritmo de gerenciamento baseado na bateria para $I_{g}$ definido em 2.6 A (650 W de injeção constante) considerando $E_{g}=22 \mathrm{Ah}, E_{g}=30$ Ah e $E_{g}=50 \mathrm{Ah}$

Figura 7.24 - Resposta do algoritmo de gerenciamento para $i_{g}$ definido em 2,6 A (650 W de injeção constante) considerando $E_{g}=22 \mathrm{Ah}, E_{g}=30 \mathrm{Ah}$ e $E_{g}=50 \mathrm{Ah} . . . .$.

Figura 7.25 - Resposta do algoritmo de gerenciamento para $I_{g}=2,6$ A e $I_{g}=3,5 \mathrm{~A}$ quando $E_{g}=36 \mathrm{Ah}$

Figura 7.26 - Resposta do algoritmo de gerenciamento para $I_{g}=2,6$ A e $I_{g}=3,5 \mathrm{~A}$ quando $E_{g}=36 \mathrm{Ah}$

Figura 8.1 - Esquemático do sistema de processamento e atuação do protótipo

Figura 8.2 - Placas de condicionamento de sinais de tensão e corrente, respectivamente.

Fig. 8.3 - Banco de 30 UC Maxwell conectados em série e banco de 100 capacitores eletrolíticos (1000 uF cada) em paralelo...

Figura 8.4 - Banco de nove baterias Moura Clean 12MF36 de $12 \mathrm{~V}$ e 36 Ah conectadas em série

Figura 8.5 - Foto do protótipo construído com esquemático descritivo indicando cada

componente.

Figura 8.6 - Funcionamento do algoritmo PLL

Figura 8.7 - Corrente de 2 A pico (1,41 rms) nos terminais do VSI em fase com a referência 
Figura 8.8 - Redução de $V_{m p}$ em degrau.

Figura 8.9 - Aumento de $V_{m p}$ em degrau.

Figura 8.10 - Desconexão e reconexão de painéis fotovoltaicos na microrrede.

Figura 8.11 - Funcionamento do algoritmo de gerenciamento baseado no UC, alternando entre os limites de tensão $(75 \mathrm{~V}$ e $55 \mathrm{~V})$ e mantendo a corrente fixa por intervalos

Figura 8.12 - Detalhe durante o funcionamento do algoritmo de gerenciamento baseado no UC.

Figura 8.13 - Sistema de controle centralizado dividindo a carga em entre um conjunto de armazenadores híbridos dada uma entrada em degrau pelas fontes alternativas $\left(i_{f a}\right)$. Nota-se que a tensão do barramento é sempre restaurada para $250 \mathrm{~V}$ após os transitórios.

Figura 8.14 - Sistema de controle centralizado dividindo a carga em entre um conjunto de armazenadores híbridos dada uma entrada em degrau pelas fontes alternativas $\left(i_{f a}\right)$. Nota-se a restauração da tensão terminal dos UCs após cada transitório, graças a técnica proposta da Fig. 5.2.

Figura 8.15 - Sistema de controle centralizado dividindo a carga entre um conjunto de armazenadores híbridos dada uma entrada em degrau pelas fontes alternativas $\left(i_{f a}\right)$. Nota-se a entrega de potência a rede na forma filtrada em relação a $i_{f a}$, reduzindo o impacto destes transitórios no sistema de distribuição......

Figura 8.16 - Sistema de controle centralizado dividindo a carga entre um conjunto de armazenadores híbridos dada uma entrada em degrau pelas fontes alternativas $\left(i_{f a}\right)$. Nota-se a corrente da bateria se encarregando do déficit/superávit de energia necessário para manter a estabilidade, enquanto o UC se ocupa dos transitórios rápidos

Figura 8.17 - Sistema de controle centralizado dividindo a carga entre um conjunto de armazenadores híbridos dada uma entrada em degrau pelas fontes alternativas $\left(i_{f a}\right)$. Nota-se o detalhe da corrente entregue a rede crescendo de forma gradual, devido ao aumento repentino na energia gerada pelas fontes alternativas....

Fig. 8.18 - Expansão da técnica proposta no capítulo 5 quando mais baterias são conectadas ao sistema.

Figura 8.19 - Sistema de controle centralizado dividindo a carga em um sistema híbrido para uma entrada em degrau da corrente $i_{f a}$, onde duas baterias com estados de carga diferentes são conectadas, SOC1=0,8 e SOC2=0,4, dividindo proporcionalmente a carga e restaurando o barramento CC.

Figura 8.20 - Sistema de controle centralizado dividindo a carga em um sistema híbrido para uma entrada em degrau da corrente $i_{f a}$, onde duas baterias com 
estados de carga diferentes são conectadas, SOC1=0,8 e SOC2=0,4, dividindo proporcionalmente a carga e restaurando a tensão terminal dos UCs.

Figura 8.21 - Sistema de controle centralizado dividindo a carga em um sistema híbrido para uma variação em degrau da corrente entregue à rede.

Figura 8.22 - Sistema de controle centralizado dividindo a carga em um sistema híbrido para uma variação em degrau da corrente entregue à rede.

Figura 8.23 - Sistema de controle centralizado dividindo a carga em um sistema híbrido para variações em degrau da corrente entregue à rede.

Figura 8.24 - Técnica de controle descentralizado sem restauração do barramento CC dividindo a carga entre o UC e bateria, além de restaurar a tensão do UC...........

Figura 8.25 - Técnica de controle descentralizado sem restauração do barramento CC dividindo a carga entre o UC e bateria além da corrente total gerada pelos armazenadores.

Figura 8.26 - Técnica de controle descentralizado sem restauração do barramento CC dividindo a carga entre o UC e baterias, tendo as baterias diferentes estados de carga, $\mathrm{SOC} 1=0,7$ e $\mathrm{SOC} 2=0,4$.

Figura 8.27 - Técnica de controle descentralizado sem restauração do barramento CC dividindo a carga entre o UC e baterias, tendo as baterias diferentes estados de carga, $\mathrm{SOC} 1=0,7$ e $\mathrm{SOC} 2=0,4$.

Figura 8.28 - Técnica de controle descentralizado sem restauração do barramento CC dividindo a carga entre o UC e baterias, sendo a constante de tempo da técnica alterado de $T=0,05 \mathrm{~s}$ para $T=0,15 \mathrm{~s}$

Figura 8.29 - Técnica de controle descentralizado sem restauração do barramento CC dividindo a carga entre o UC e baterias, sendo a constante de tempo da técnica alterado de $\mathrm{T}=0,05 \mathrm{~s}$ para $\mathrm{T}=0,15 \mathrm{~s}$.

Figura 8.30 - Técnica de controle descentralizado sem restauração do barramento CC dividindo a carga entre o UC e baterias. Zoom durante o transitório mostrando a corrente entregue a rede se mantendo estável mesmo durante o transitório.

Figura 8.31 - Técnica de controle descentralizado sem restauração do barramento CC dividindo a carga entre o UC e baterias dada uma entrada que emula a geração de energia por uma célula a combustível..

Figura 8.32 - Técnica de controle descentralizado sem restauração do barramento CC dividindo a carga entre o UC e baterias dada uma entrada que emula a geração de energia por uma célula a combustível......

Figura 8.33 - Técnica de controle descentralizado sem restauração do barramento CC dividindo a carga entre o UC e baterias dada entrada em degrau de $i_{f a}$. Neste caso o SOC é emulado pela equação (6.7) de forma a reduzir a capacidade virtual das baterias. 
Figura 8.34 - Técnica de controle descentralizado sem restauração do barramento $\mathrm{CC}$ dividindo a carga entre o UC e baterias dada entrada em degrau de $i_{f a}$. Neste caso o SOC é emulado pela equação (6.7) de forma a reduzir a capacidade virtual das baterias

Figura 8.35 - Técnica de controle descentralizado com restauração do barramento CC dividindo a carga entre o UC e baterias para entrada em degrau de $i_{f a}$. Esta figura monstra o momento da sincronização inicial das duas baterias com o mesmo SOC.

Figura 8.36 - Técnica de controle descentralizado com restauração do barramento CC dividindo a carga entre o UC e baterias para entrada em degrau de $i_{f a}$. Esta figura monstra o momento da sincronização inicial de duas baterias com o mesmo SOC, além do comportamento do UC durante os transitórios

Figura 8.37 - Técnica de controle descentralizado com restauração do barramento CC dividindo a carga entre o UC e baterias para entrada em degrau de $i_{f a}$. Neste caso, ambas as baterias possuem o mesmo SOC....

Figura 8.38 - Técnica de controle descentralizado com restauração do barramento CC dividindo a carga entre o UC e baterias para entrada em degrau de $i_{f a}$. Neste caso, as duas baterias possuem estados de carga diferentes, $\mathrm{SOC} 1=0,7$ e SOC2=0,4.

Figura 8.39 - Técnica de controle descentralizado com restauração do barramento CC dividindo a carga entre o UC e baterias dada entrada em degrau de $i_{f a}$. Neste caso, as duas baterias possuem estados de carga diferentes, SOC1=0,7 e SOC2=0,4.

Figura 8.40 - Técnica de controle descentralizado com restauração do barramento CC dividindo a carga entre o UC e baterias para entrada em degrau de $i_{f a}$. Neste caso, as duas baterias possuem estados de carga diferentes, $\mathrm{SOC} 1=0,7$ e SOC2=0,4.

Figura 8.41 - Técnica de controle descentralizado com restauração do barramento

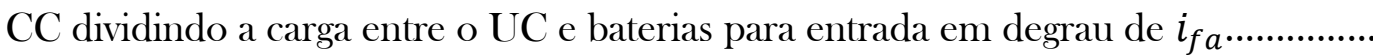

Figura 8.42 - Técnica de controle descentralizado com restauração do barramento

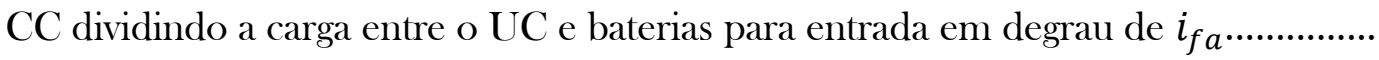

Figura 8.43 - Técnica de controle descentralizado com restauração do barramento $\mathrm{CC}$ dividindo a carga entre o UC e baterias para entrada em degrau de $i_{f a}$. Neste caso é mostrada a equalização das baterias de forma dinâmica usando a equação (6.7)

Figura 8.44 - Corrente entregue a rede pelo inversor.

Figura 8.45 - FFT do sinal de corrente na saída do inversor

Figura 8.46 - Composição harmônica normalizada do sinal de corrente na saída do inversor. 
Figura 8.47 - Zoom na Fig. 8.45 mostrando a composição harmônica da corrente.... 139 


\section{Lista de Tabelas}

Tabela 3.1 - Características dos Diversos Tipos de Baterias................................... 16

Tabela 4.1 - Parâmetros do Modelo em Pequenos Sinais.......................................... 35

Tabela 5.1 - Parâmetros do Modelo Funcional PV ................................................... 42

Tabela 5.2 - Parâmetros do Modelo Funcional do Aerogerador.............................. 42

Tabela 5.3 - Parâmetros dos Modelos da Bateria e UC.......................................... 42

Tabela 5.4 - Elementos Passivos Utilizados na Simulação....................................... 42

Tabela 5.5 - Descrição de Eventos Simulados........................................................... 45

Tabela 6.1 - Parâmetros do Modelos Simulado........................................................... 61

Tabela 6.2 - Parâmetros do Modelo Simplificado.................................................... 66

Tabela 8.1 - Componentes do Sistema Experimental.............................................. 108 



\section{Sumário}

1. Introdução.......................................................................... 1

2. Motivação do Trabalho e Objetivos da Tese................. 3

2.1 Motivação do Trabalho .................................................. 3

2.2 Objetivos …………………………………………..... 4

3. Sistema de Integração de Fontes Alternativas ............... 7

3.1 Integração em Corrente Contínua................................... 7

3.2 Aerogerador ……………………………………….. 8

3.3 Painel Fotovoltaico …………………………………..... 13

3.4 Banco de Baterias …………………………………..... 15

3.5 Ultracapacitores .......................................................... 20

3.6 Algoritmos de Busca do Ponto de Máxima potência ... 22

3.7 Interfaces de Potência ................................................... 24

3.8 Considerações Finais do Capítulo 3.............................. 29

4. Metodologias de Projeto ................................................... 31

4.1 Critério de Projeto dos Controladores .......................... 31

4.2 Conversores CC-CC ………………………………….. 32

4.3 Conversor CC-CA ………………………………….... 35

4.3.1 Operação em Modo Conectado ………………………. 35

4.3.2 Operação em Modo ilhado .......................................... 36

4.4 Controlador do Barramento CC …………………….... 38

4.5 Algoritmo de Sincronização PLL ................................. 38

4.6 Considerações Finais do Capítulo 4.............................. 40

5. Resultados Simulados ..................................................... 41

5.1 Simulação Eletrônica do Sistema de Integração de Fontes Conectado a Rede ............................................. 41

5.2 Considerações Finais do Capítulo 5.............................. 51

6. Sistema Híbrido Descentralizado de Divisão de Carga Entre UC e Bateria.......................................................... 53

6.1 Descrição e Motivação.................................................... 53

6.2 Estado da Arte...…………………………………….. 53

6.3 Modelo Matemático do Sistema Eletrônico................... 54

6.4 Controle Descentralizado para Microrrede Híbrida - 
sem Restauração do Barramento CC........................... 56

6.4.1 Resultados Simulados.................................................. 60

6.5 Controle Descentralizado para Microrrede Híbrida com Restauração do Barramento CC.......................... 70

6.6 Considerações Finais do Capítulo 6.............................. 80

7. Modelo Simplificado e Algoritmos de Gerenciamento de Energia................................................................. 81

7.1 Estratégia de Gerenciamento Baseado em UC de Alta Capacidade.................................................................. 84

7.2 Estratégia de Gerenciamento Baseado na Potência Média Gerada............................................................... 90

7.3 Considerações Finais do Capítulo 7............................. 104

8. Resultados Experimentais........................................... 105

8.1 Descrição da Bancada Experimental............................. 105

8.2 Testes e Ensaios........................................................ 108

8.2.1 Gerenciamento Baseado no UC de Alta Capacidade... 112

8.2.2 Gerenciamento Baseado na Potência Média Gerada em Sistema Centralizado de Controle........................... 114

8.2.3 Sistema de Armazenamento Híbrido e Controle Descentralizado de Divisão de Carga sem Restauração do Barramento CC.

8.2.4 Sistema de Armazenamento Híbrido e Controle Descentralizado de Divisão de Carga com Restauração do Barramento CC................................... 131

8.3 Considerações Finais do Capítulo 8............................. 140

9. Conclusões Gerais...................................................... 141

10. Propostas para Pesquisas Futuras.................................. 143

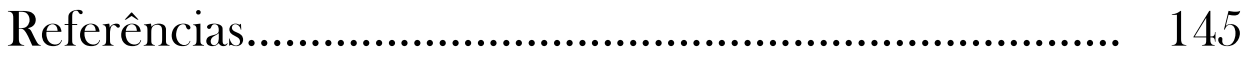

Apêndice A.............................................................. 151 


\section{Capítulo 1}

\section{Introdução}

Na última década, a atenção nas pesquisas relacionadas com a produção de energia elétrica ficou voltada para a busca de soluções energéticas que contribuíssem com o meio ambiente e que fossem alternativas para a limitada produção de energia por grandes centrais elétricas [1, 2]. Além da inviabilidade econômica e, principalmente, os impactos ambientais causados na construção de novas usinas têm feito com que os governos e os pesquisadores recorram a outros tipos de soluções para o decorrente problema de produção de energia, principalmente em regiões com baixo desenvolvimento econômico, social e em locais nos quais a energia produzida, pelas centrais elétricas, não seja suficiente devido ao crescimento da demanda, reduzindo investimentos por parte de órgãos governamentais, etc.

Dessa forma, devido ao aquecimento global e mudanças climáticas o interesse público e privado em se obter soluções ecologicamente corretas e com desenvolvimento sustentável têm recebido maior enfoque a nível nacional e mundial [3]. Nesse contexto, diversos pesquisadores que trabalham com a tecnologia de geração distribuída (GD) estão investigando aplicações de geradores fotovoltaicos, células de combustível ou geração eólica, além do uso de armazenadores de energia, como forma de minimizar os impactos ambientais causados pelas emissões de carbono [4]. Principalmente em países da Europa, América e Ásia os painéis fotovoltaicos e as células de combustível apresentam grande interesse nas pequenas gerações de energia para atender determinada carga ou injetar a potência excedente na rede.

Pode-se dizer que a GD é a geração de energia elétrica próxima do consumidor, dispensando de certa forma os sistemas de distribuição, ou seja, a utilização desse tipo de solução pode levar a reduções nas perdas de potência (para certas condições de carga) uma vez que a geração se encontra próxima à carga. Além disso, em geral, as células de combustível ou os arranjos fotovoltaicos produzem potência na ordem de quilowatts, sendo essa quantidade de potência gerada suficiente, por exemplo, para manter uma residência ou ser injetada na rede [5]. Desta forma, justificam-se as pequenas e micro gerações de energia próximas aos centros consumidores como alternativa a construção de grandes centrais elétricas [4].

Em vista disso, a GD decorrente do uso de fontes alternativas está sendo incentivada pelo governo federal por meio de órgãos como a ANEEL (Agência Nacional de Energia Elétrica) e Ministério de Minas e Energia com a finalidade de promover soluções para os 
problemas de fornecimento de energia. Nesse contexto, o governo federal lançou alguns incentivos através de leis e programas governamentais para o desenvolvimento e instalação de sistemas de GD que utilizam fontes alternativas de energia [6, 7].

Com a disseminação do uso de GDs e a sua conexão com a rede, diversas normas e padrões internacionais foram criados e adotados para minimizar os impactos causados principalmente nos sistemas de distribuição $[8,9,10]$. Como critério de qualidade da energia, a geração deve fornecer energia elétrica com baixas distorções harmônicas, ou seja, tensão com frequência e valor nominal compatível com o ponto da conexão entre a GD e a rede, além de sistemas antiilhamento que deverão ser capazes de desconexão em caso de contingências [11].

No Brasil, a partir de 17 de abril de 2012, a ANEEL lançou a resolução normativa no 482 no Diário Oficial da União, que estabelece: "as condições gerais para o acesso de microgeração e minigeração distribuída aos sistemas de distribuição de energia elétrica e do sistema de compensação de energia elétrica, além de mencionar outras providências", dando um prazo de 240 dias para as concessionárias se adequarem as alterações dessa resolução [12]. Sendo esta atualizada em 24 de novembro de 2015 pela resolução normativa 687.

Nesse contexto, o uso da GD conectada à rede de distribuição traz vários benefícios ao fornecimento de energia elétrica tais como: a melhoria dos níveis de tensão, redução das perdas de potência em projetos de cogeração, não agressão ao meio ambiente em plantas ecologicamente corretas, entre outros [13, 14, 15]. Entretanto, caso a inserção dessas novas fontes não seja feita de forma adequada, podem surgir problemas relacionados ao planejamento [16], controle e gerenciamento do sistema elétrico, uma vez que elas modificam a capacidade de curto-circuito da rede na qual elas são inseridas, causando mau funcionamento na coordenação de relés de proteção e diminuição da qualidade de energia [17, 18, 19].

Outro problema decorrente da má gestão da GD é o chaveamento dos taps em transformadores da distribuição e reguladores de tensão, que são ocasionados por variações de tensão, fluxo de potência reverso e modificações abruptas na potência gerada [20, 21, 22, 23], podendo comprometer tanto a vida útil desses dispositivos quanto à qualidade da energia no local no qual os mesmos são inseridos. 


\section{Capítulo 2 \\ Motivação do Trabalho e Objetivos da Tese}

\subsection{Motivação do Trabalho}

De acordo com os fatos apresentados no Capítulo 1, a produção de energia elétrica (próxima aos centros consumidores) feita através de fontes alternativas tais como, solar fotovoltaica e eólica, pode se tornar uma solução que venha a complementar o quadro geral de produção de energia de baixa e média escala devido ao limite operacional da capacidade de produção por grandes centrais elétricas.

Entretanto, sabe-se que estas fontes (fotovoltaica e eólica) são direta ou indiretamente derivadas da energia produzida pelo sol que incide sobre o planeta, Fig. 1.1, desta forma, elas possuem uma característica variável em relação à disponibilidade energética e que muitas vezes, não apresentam um alto grau de previsibilidade, dificultando a utilização deste tipo de geração em termos de disponibilidade de energia [24].

Assim, conhecendo a inconstância na geração utilizando fontes alternativas e na dificuldade em prever seu comportamento, torna-se complexa a utilização destas fontes como solução confiável, ou seja, a utilização deste tipo de solução é aplicável apenas em redes remotas, onde a rede elétrica da concessionária não está disponível e a qualidade da energia produzida não é de importância crucial ou estratégica.

Tendo em vista estas limitações e dificuldades na operação de geração de energia que empregam fontes alternativas, são buscadas formas de tornar esse tipo de solução mais confiável, apresentando uma disponibilidade mínima durante a sua operação, seja ela durante o dia ou à noite e que tal capacidade não seja dependente das condições climáticas. Podendo assim, ser considerada uma fonte confiável e disponível, deixando de ser apenas uma fonte ecologicamente correta, para se tornar uma alternativa viável.

Outra problemática relacionada à natureza variável e "aleatória” são as oscilações de potência. Essas causam variações na tensão da rede além de fluxo reverso em transformadores de distribuição, o que causa problemas de qualidade da energia, chaveamento de taps e reguladores de tensão, logo, uma estrutura que elimine ou suavize oscilações bruscas de potência na rede de distribuição possui grande impacto na qualidade da energia elétrica. 
Para se obter um funcionamento otimizado dos sistemas de GD, tanto a diversificação das fontes de energia quanto a utilização de armazenadores é necessária, fazendo com que os componentes desta microrrede se complementem, ou seja, trabalhem em sinergia de forma que a deficiência de um deles seja complementada pela característica dos demais dispositivos. Contudo, para se conseguir esta harmonia entre os armazenadores e as fontes, os algoritmos de gerenciamento e controle devem ser projetados para se obter o resultado esperado.

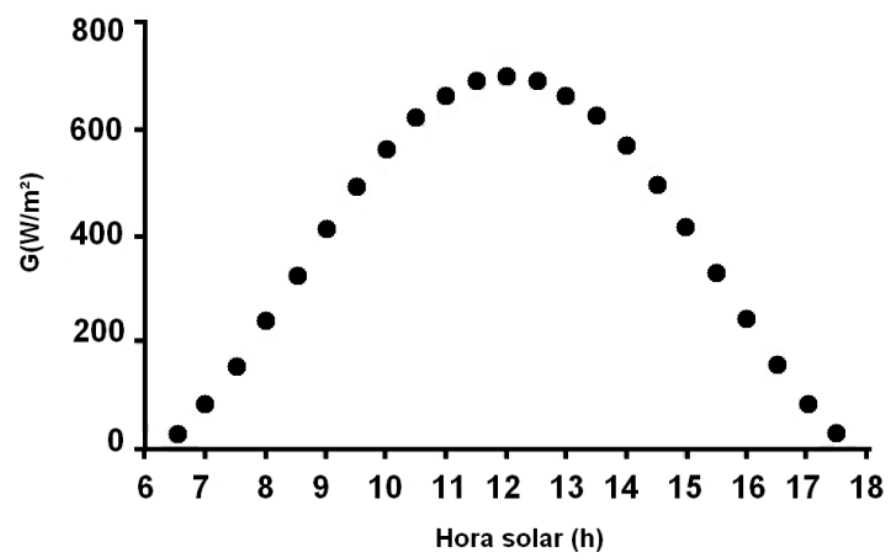

Figura. 1.1 - Irradiação solar média incidente durante 24 h [24].

\subsection{Objetivo}

Os objetivos gerais desta Tese de doutorado consistem no gerenciamento, controle e análise de uma microrrede $\mathrm{CC}$, quando a mesma opera de forma a integrar diversas fontes alternativas e armazenadores em um barramento comum. Para atingir uma maior autonomia e confiabilidade, a proposta traz, ainda, a inclusão de um VSI (inversor fonte de tensão) para a conexão com a rede elétrica, de forma que os índices de qualidade da energia no ponto de acoplamento comum (PAC) não ultrapassem os limites estabelecidos por normas nacionais e internacionais.

A abordagem principal deste trabalho é baseada na diversificação das fontes e no acoplamento das unidades geradoras a dispositivos armazenadores de energia como os bancos de bateria e ultracapacitores (UC). Tal diversificação fará com que a microrrede tenha a capacidade de eliminar ou suavizar as variações "aleatórias" de potência decorrente das alterações climáticas (sol e vento). Logo, o perfil de potência entregue à rede não apresentará a mesma característica aleatória da potência gerada pelas fontes alternativas, evitando ou suavizando problemas de qualidade da energia. 
Para que a microrrede funcione de forma a atingir todos os objetivos descritos nessa seção, propõe-se a utilização de dois sistemas de gerenciamento para os armazenadores. No primeiro caso, será usada uma estrutura de gerenciamento centralizada na qual os armazenadores se comunicam entre si através de uma rede de alta velocidade, enquanto que no segundo caso o gerenciamento será realizado de forma descentralizada, ou seja, a rede de comunicação não está disponível e os dispositivos são autônomos. Como opção de armazenadores é proposto o uso de UCs para a compensação dos transitórios de alta velocidade e baterias para suprir demandas em regime permanente.

Os objetivos específicos estão listados abaixo:

- Controlar a geração das fontes alternativas, solar fotovoltaica e eólica no ponto ótimo;

- Integrar as diversas fontes a um barramento CC comum para a formação de uma microrrede $\mathrm{CC}$;

> - Controlar o fluxo bidirecional de potência do barramento CC para os armazenadores;

$>$ - Projetar uma estrutura de controle e gerenciamento para os armazenadores de forma centralizada;

$>$ - Projetar uma estrutura de controle e gerenciamento para os armazenadores de forma descentralizada;

$>$ - Controlar a injeção de potência na rede mantendo os requisitos mínimos de qualidade da energia determinados por normas nacionais e internacionais;

- Eliminar ou suavizar os transitórios de potência decorrentes de alterações climáticas e/ou manobra de carga.

Contribuições do Trabalho:

Como contribuições deste trabalho que serão apresentadas nos capítulos a seguir, pode-se destarcar:

- Técnica de restauração contínua de UCs em microrrede com armazemadores híbridos;

- Técnica de divisão de carga descentralizada sem restauração do barramento CC;

$>$ - Técnica de divisão de carga descentralizada com restauração do barramento CC;

- Modelo simplificado da microrrede para análise energética;

- Técnica de entrega de potência constante a rede. 


\section{Capítulo 3}

\section{Sistema de Integração de Fontes Alternativas}

Neste capítulo são descritas as estruturas para integração de fontes alternativas e o detalhamento dos principais dispositivos utilizados na sua composição, juntamente com seus modelos matemáticos e principais características da microrrede. Sendo esta microrrede formada por aerogeradores, painéis fotovoltaicos, baterias, ultracapacitor, além de circuitos conversores CC-CC, CC-CA e os seus respectivos controladores.

\subsection{Integração em Corrente Contínua}

A Fig. 3.1 mostra o esquemático elétrico do sistema proposto para a integração e conexão das fontes alternativas na rede de distribuição. Dentre as principais fontes renováveis utilizadas optou-se por soluções nas quais usam painéis fotovoltaicos e aerogeradores, uma vez que tais fontes possuem como característica o baixo impacto ambiental, são renováveis e estão amplamente difundidas comercialmente.

Outro fator preponderante é a obtenção de uma microrrede com elevada autonomia na produção de energia elétrica. Para atingir tal objetivo, dois diferentes tipos de armazenadores serão incorporados, os bancos de baterias de chumbo-ácido e os ultracapacitores, uma vez que os mesmos possuem maior interesse econômico devido à sua modularidade, capacidade de regulação/controle, vida útil, entre outras qualidades quando os mesmos são comparados a outros dispositivos armazenadores, como os volantes de inércia e os hidretos metálicos. Contudo, supõe-se que a microrrede possa ser expandida pela inclusão de outros componentes de geração e de armazenamento, característica esta comum a qualquer sistema de distribuição.

Em termos de operação, as fontes alternativas serão controladas de forma a fornecer a maior potência útil disponível para um maior aproveitamento da geração, assim, torna-se imprescindível o uso de algoritmos de busca do ponto de máxima potência [25, 26, 27]. Os armazenadores, por outro lado, precisam apresentar um nível de otimização para que uma demanda mínima seja atendida garantindo assim, a operação e injeção de potência na rede a qualquer instante, independentemente das condições climáticas. Além disso, devido à diversificação dos armazenadores, espera-se que o dispositivo com maior densidade de energia se encarregue de suprir o regime permanente (baterias) enquanto que, o dispositivo com maior densidade de potência seja responsável pelos transitórios de carga (UC). Para mais detalhes à 
respeito de microrredes, topologias de controle e métodos de gerenciamentos em microrredes consulte $[28,29]$.

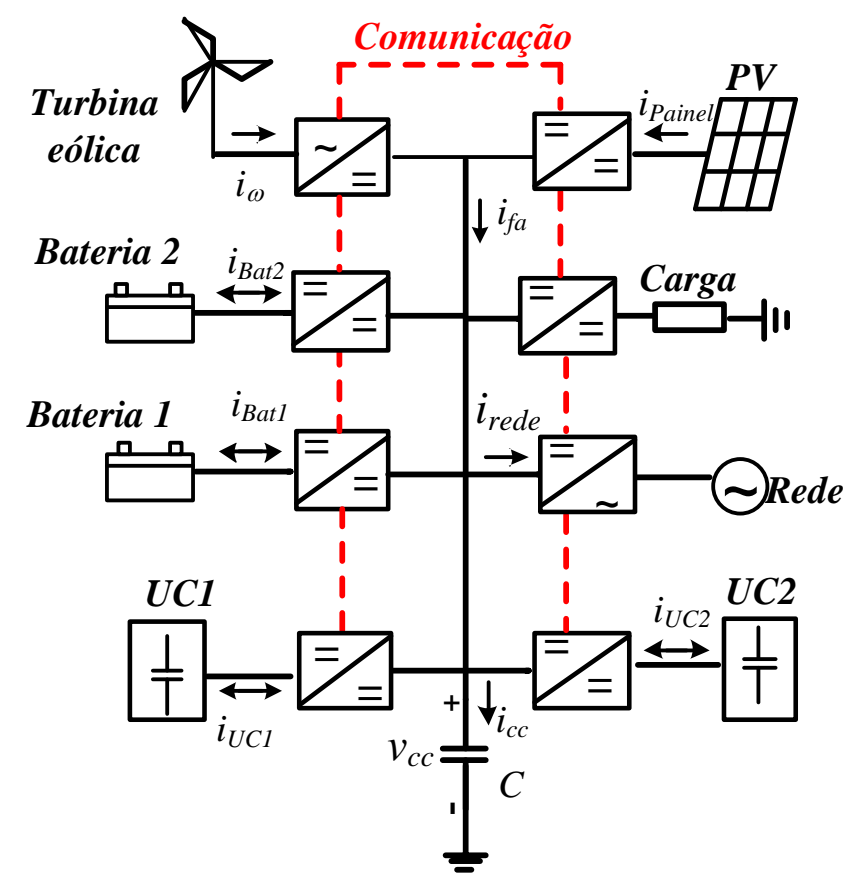

Figura 3.1 - Sistema completo para integração de fontes alternativas.

\subsection{Aerogerador}

A topologia básica de um aerogerador consiste na conexão de um conjunto de hélices acoplado a um gerador elétrico, podendo este corresponder a uma máquina de indução ou síncrona, tanto com enrolamento de campo quanto a ímã permanente no rotor.

Geradores eólicos utilizam, geralmente, máquinas de indução quando as aplicações requerem conexão com a rede de distribuição sem o uso de conversores entre o estator do gerador e a rede e sem a necessidade de algoritmos de sincronismo, Fig. 3.2 [30].

Por outro lado, se o sistema eólico utiliza geradores síncronos, o uso de conversores eletrônicos de potência elevada é indispensável, uma vez que toda a potência gerada é processada através deste conversor, Fig. 3.3. Entretanto, como o gerador síncrono está, indiretamente, conectado à rede de distribuição através de um conversor, o gerador não contribui com a corrente de curto-circuito do sistema de distribuição em caso de falha, devido às proteções de corrente na malha de controle do gerador [30].

Neste trabalho, será utilizado um gerador síncrono de acordo com a Fig. 3.3, devido ao fato das diversas fontes serem acopladas em um barramento CC comum para formar uma 
microrrede, desta forma a topologia apresentada na Fig. 3.3 se adequa ao tipo de microrrede CC que se utiliza neste trabalho.

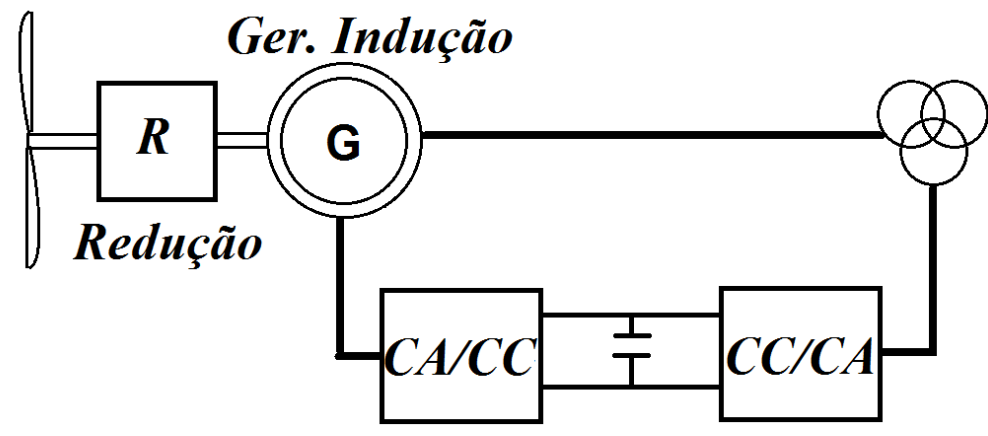

Figura 3.2 - Sistema eólico duplamente alimentado para conexão direta de gerador de indução [30].

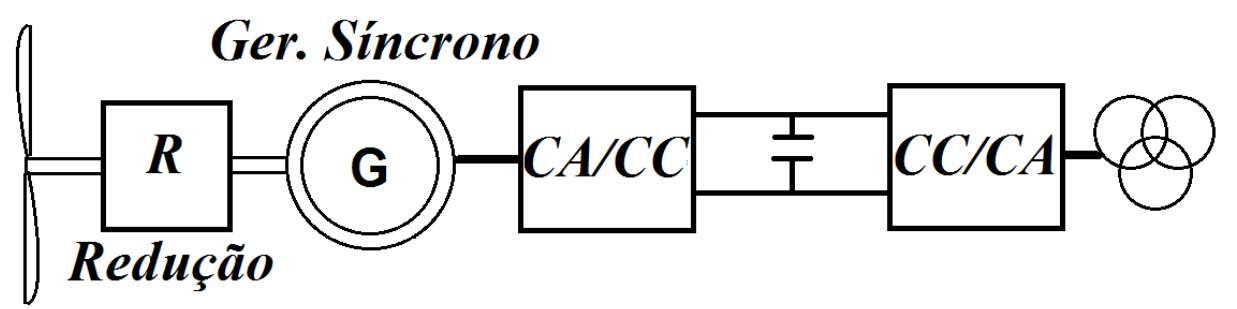

Figura 3.3 - Sistema eólico utilizando gerador síncrono [30].

As relações aerodinâmicas do gerador eólico (3.1) são relações conhecidas e documentadas [31, 32, 33, 34]. Em (3.1) $P_{w}$ é a potência extraída do vento (em W), $\rho$ é a densidade do ar, que ao nível do mar corresponde a $1,225 \mathrm{~kg} / \mathrm{m}^{3}, C_{P}$ é o coeficiente de potência, $v_{\omega}$ é a velocidade do vento que corta as pás $(\mathrm{m} / \mathrm{s})$ enquanto $A$ representa a área varrida pelo rotor (em $\mathrm{m}^{2}$, sendo $A=\pi R^{2}$ e $R$ o raio da pá). $\mathrm{O}$ torque aerodinâmico em Nm é definido de acordo com a equação (3.2) que relaciona o torque $\left(T_{\omega}\right)$ a potência extraída $\left(P_{\omega}\right)$ e a velocidade angular da turbina $\left(W_{\omega} \mathrm{em} \mathrm{rad} / \mathrm{s}\right)$. Isso implica que o torque aerodinâmico é o torque transmitido ao gerador quando não há caixa de redução ou quando a relação de redução é igual a 1 [34].

Já o coeficiente de potência alcança o seu valor máximo quando $C_{P}=0,593$ [35], o que significa que o rendimento máximo de uma turbina eólica é de 59,3\% (limite de Betz). Este limite é explicado pelas várias perdas aerodinâmicas advindas do formato, peso e demais variáveis construtivas da pá. Outra abordagem para $C_{P}$ é a utilização tabelada, o que torna o uso 
de métodos de interpolação imprescindíveis para se alcançar uma resolução satisfatória para o uso de $C_{P}$.

Uma outra possibilidade de utilização do coeficiente de potência é mostrada através do uso da equação (3.3), que define $C_{P}$ em função da velocidade do vento, das pás e o ângulo de ataque das pás [34].

Através da análise dos coeficientes de (3.3), é possível concluir que $C_{1}, C_{2} \ldots C_{6}$ dependem do tipo e da forma da turbina, ou seja, eles apresentam diferentes valores para cada tipo de topologia. Assim, os coeficientes propostos por [31] são $C_{1}=0,5, C_{2}=116, C_{3}=0,4$, $C_{4}=0, C_{5}=5, C_{6}=21$ (o fator " $x$ "não é utilizado, pois $C_{4}=0$ ).

Já a variável $\beta$ é definida de diferentes maneiras por [31, 32, 33], em [31] 1/ $\beta$ é calculado conforme é visto na equação (3.4), onde $\vartheta$ é o ângulo de inclinação em graus da pá em relação ao eixo de rotação da turbina, Fig. 3.4. Também em (3.4), é possível verificar que o coeficiente $\lambda$ é dependente da velocidade média angular em $\mathrm{rad} / \mathrm{s}$, raio da pá e da velocidade média em $\mathrm{m} / \mathrm{s}$, onde $\lambda=\frac{W_{\omega} R}{v_{\omega}}$.

$$
\begin{gathered}
P_{\omega}=C_{P} \frac{1}{2} \rho A v_{\omega}^{3} \\
T_{\omega}=\frac{P_{\omega}}{W_{\omega}} \\
C_{p}(\lambda, \vartheta)=C_{1}\left(C_{2} \frac{1}{\beta}-C_{3} \vartheta-C_{4} \vartheta^{x}-C_{5}\right) e^{-C_{6} \frac{1}{\beta}} \\
\frac{1}{\beta}=\frac{1}{\lambda+0,08 \vartheta}-\frac{0,035}{1+\vartheta^{3}}
\end{gathered}
$$

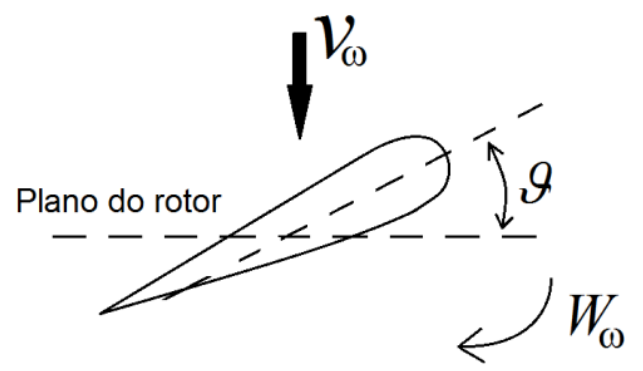

Figura 3.4 - Ângulo de inclinação da pá em relação ao eixo da turbina. 
A Fig. 3.5 mostra uma curva típica de potência extraída de uma turbina versus a velocidade angular da turbina para diferentes velocidades do vento quando o ângulo das pás é fixo. Quando essa figura é analisada, o ponto de máximo para cada valor de velocidade do vento é claramente definido, o que implica na necessidade de uso de métodos de busca do ponto ótimo de operação da turbina como o MPPT (maximum power point tracking) [36].

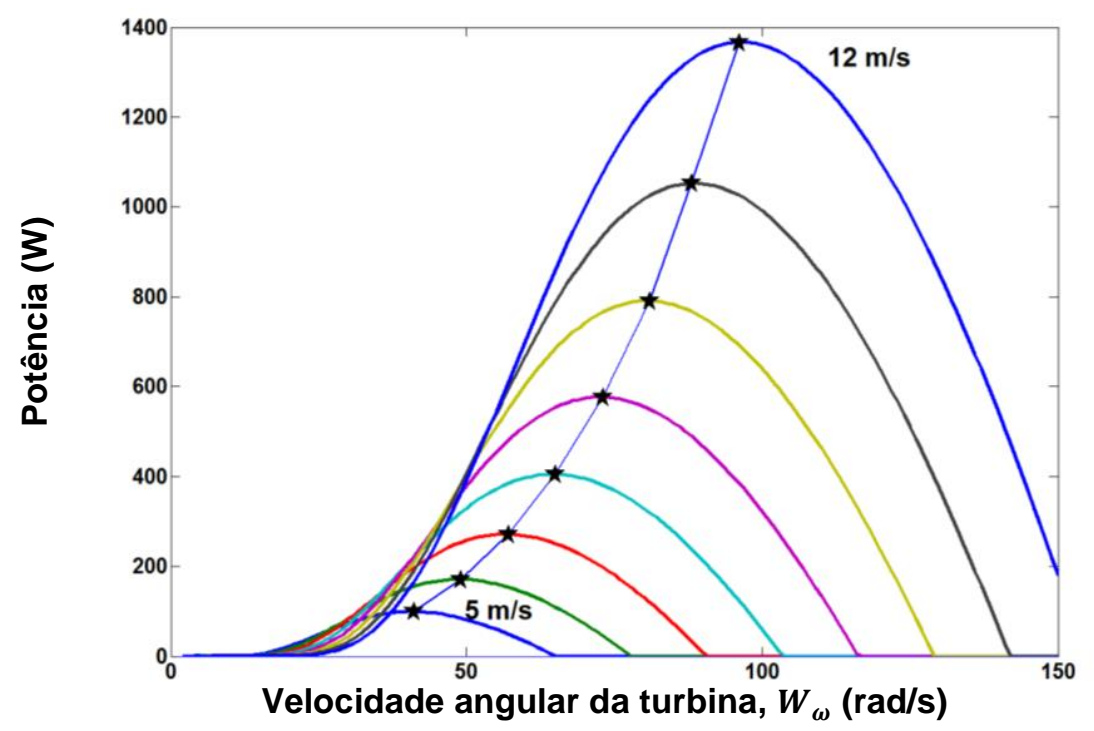

Figura 3.5 - Curva típica de $P_{\omega}$ versus $W_{\omega}$ da turbina para diferentes velocidades do vento, considerando o ângulo das pás fixo [36].

De acordo com as equações (3.1) a (3.4) pode-se extrair a Fig. 3.6, que representa o coeficiente de potência da turbina para diferentes velocidades do vento. Logo, nota-se que para cada velocidade do vento a turbina alcança o ponto de potência máxima em uma velocidade da turbina diferente, entretanto o $C_{P M A X}$ é sempre o mesmo, portanto a função que descreve a potência máxima de uma turbina eólica pode ser representada por (3.5), que indica que o valor da potência máxima extraída de uma turbina cresce de forma cúbica com a velocidade do vento que incide nas pás, quando o ângulo das pás permanece inalterado, Fig. 3.7.

$$
P_{\omega_{M A X}\left(v_{w}\right)}=C_{P M A X} \frac{1}{2} A v_{\omega}^{3}
$$




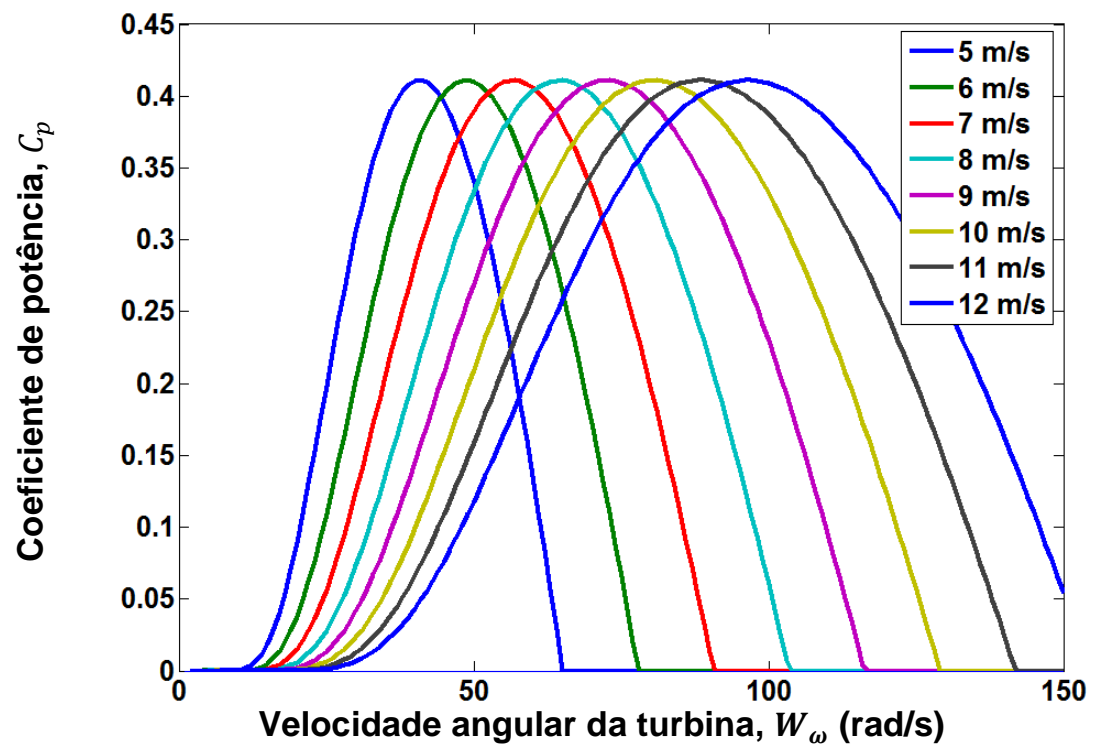

Figura 3.6 - Coeficiente de potência para diferentes velocidades de vento, considerando o ângulo das pás constante.

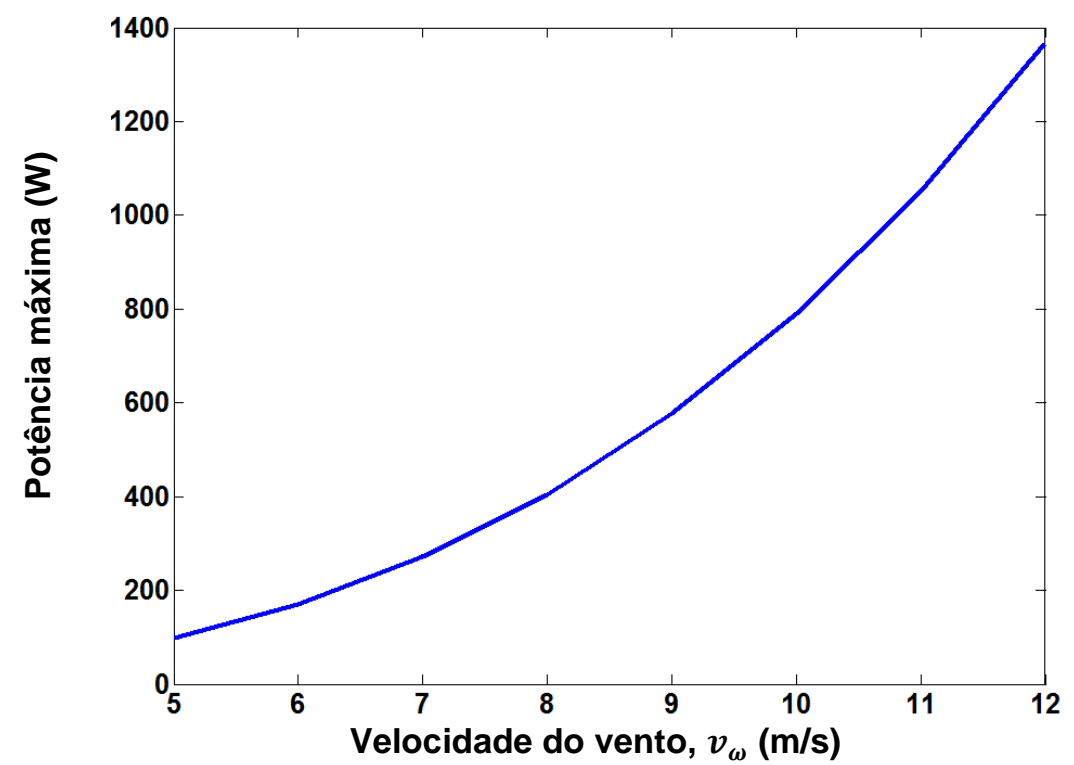

Figura 3.7 - Potência máxima de saída para diferentes velocidades do vento considerando o ângulo das pás fixo e turbina de raio $1 \mathrm{~m}$, de acordo com equação (3.5).

A Fig. 3.8 indica o enfeito do ângulo das pás no coeficiente de potência e na potência média de saída, para uma velocidade do vento fixa, ou seja, um aumento específico no ângulo das pás promove um deslocamento do ponto de máximo, além de uma redução da potência máxima da turbina. 

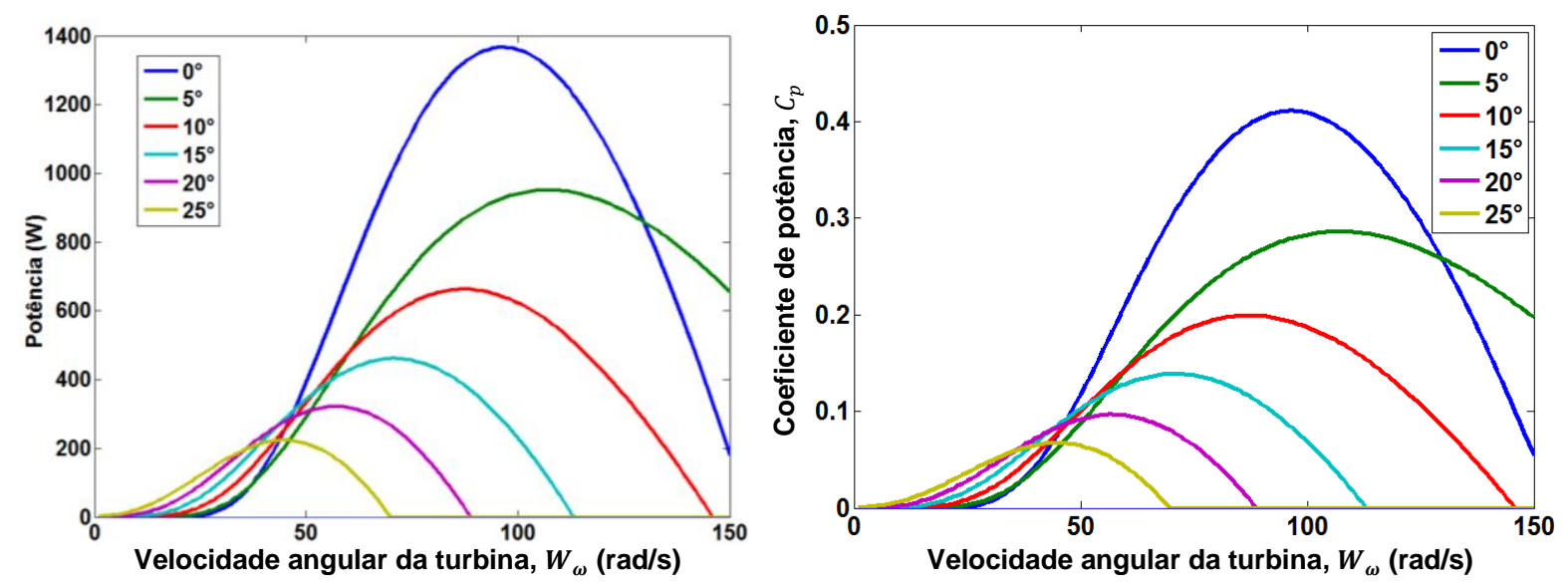

Figura 3.8 - Potência média de saída e coeficiente de potência para uma velocidade do vento fixa e variando o ângulo das pás.

\subsection{Painel Fotovoltaico}

O efeito fotovoltaico foi descoberto por Alexandre-Edmond Becquerel em 1839 que constatou a presença de uma diferença de potencial nos terminais de um semicondutor quando exposto a luz. A origem deste fenômeno está embasada no efeito fotoelétrico, que ocorre quando fótons atingem a superfície de um metal com energia suficiente para permitir a liberação dos elétrons [37].

A célula fotovoltaica é, basicamente, uma junção p-n de um semicondutor (normalmente de silício) que quando exposto à luz libera elétrons em torno de um circuito elétrico fechado. A taxa de elétrons gerados depende do fluxo de luz incidente e da capacidade de absorção do semicondutor [27].

O modelo generalizado da célula fotovoltaica é baseado na natureza da junção p-n e representa com precisão as células de silício cristalino através de uma fonte de corrente controlada pela luz incidente $\left(I_{p v}\right)$, resistências série e shunt $\left(R_{s}\right.$ e $\left.R_{p}\right)$ e um diodo $\left(D_{1}\right)$ que representa o efeito da recombinação das portadoras (Fig. 3.9). Esses cinco parâmetros do modelo generalizado variam de acordo com a temperatura e a irradiação, não sendo uma relação trivial, sobretudo em relação à irradiação. $\mathrm{O}$ valor de $R_{S}$ altera, principalmente, a corrente de curto-circuito do painel $\left(I_{s c}\right)$, enquanto $R_{p}$ altera a tensão de circuito aberto $\left(V_{o c}\right)$ $[25,38]$.

O modelo do painel fotovoltaico pode ser expresso pela equação (3.6), que é apresentada em [27, 38]. A função V-I que caracteriza um módulo fotovoltaico é não linear e transcendental (implícita), ou seja, a equação necessita de métodos iterativos para ser solucionada, porém todos os parâmetros necessários para sua solução são encontrados nos datasheets do fabricante [25]. 


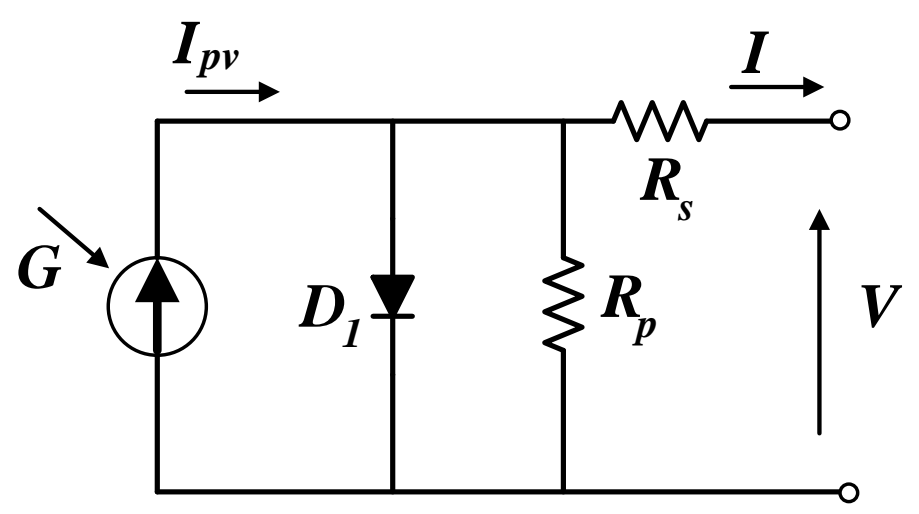

Figura 3.9 - Modelo generalizado de uma célula solar [38].

$$
I=I_{p v}-I_{0}\left[\exp \left(\frac{V+R_{S} I}{V_{t} a}\right)-1\right]-\frac{V+R_{S} I}{R_{p}}
$$

Onde, $I_{p v}$ é a corrente induzida pela luz, $I_{0}$ é a corrente de saturação do diodo, $a$ é o fator de idealidade do diodo, $R_{S}$ é a resistência série equivalente do módulo e $R_{p}$ é a resistência equivalente em paralelo do módulo, $V_{t}=N_{s} k T / q$ é a tensão térmica do painel com $N_{s}$ células conectadas em série, $k$ é a constante de Boltzmann [1,3806 $\left.10^{-23} \mathrm{~J} / K\right], T$ é a temperatura da junção p-n em $K, q$ é a carga elementar do elétron $\left[1,602176 \times 10^{-19} C\right.$ ]. Dessa forma, pode-se inferir que a corrente $I_{p v}$ depende tanto do nível de irradiação $(G)$, quanto da temperatura $(T)$ do painel, enquanto que $I_{0}$ depende somente de $T[38]$.

A Fig. 3.10 mostra a relação não linear entre a corrente e a tensão, enquanto a Fig. 3.11 mostra a relação entre a potência média de saída e a tensão, sendo que o ponto no qual a potência média extraída do painel é máxima está identificado por um ponto na curva. É nesse local que o algoritmo MPPT deve operar de forma a extrair a máxima potência gerada [25]. Apesar da relação entre a corrente e a tensão apresentar não linearidades, a relação entre a potência máxima extraída e a irradiação incidente apresenta um comportamento aproximadamente linear, ou seja, dobrando a radiação incidente, dobra-se a potência máxima de saída do painel, como pode ser notado pela Fig. 3.11. 


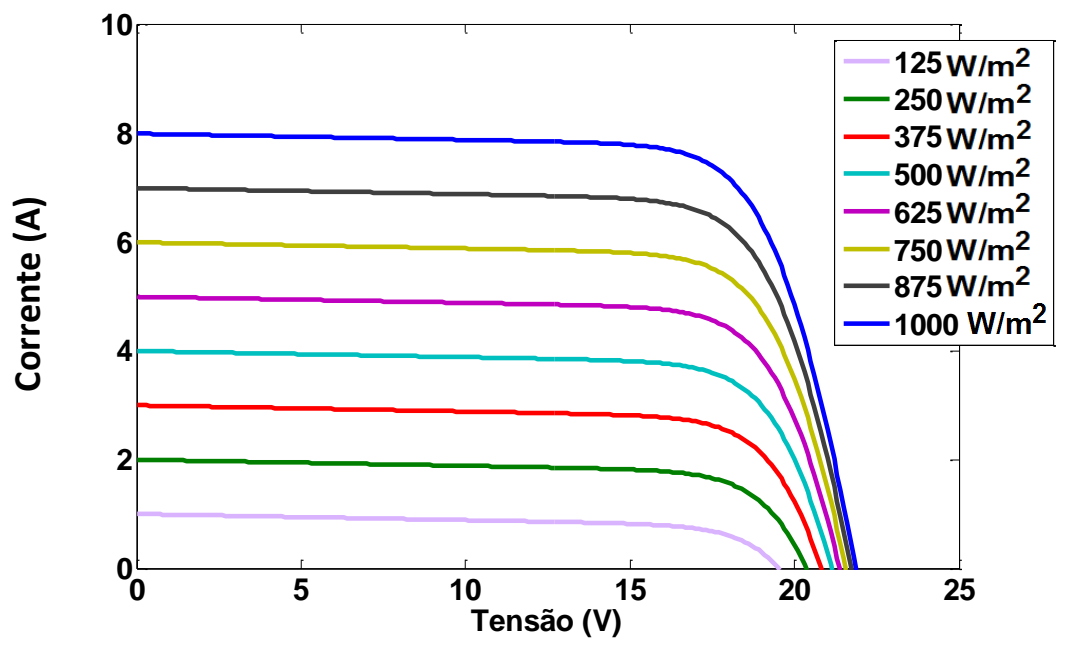

Figura 3.10 - Curva característica corrente versus tensão de um módulo KC130TM, para diferentes níveis de irradiação [25].

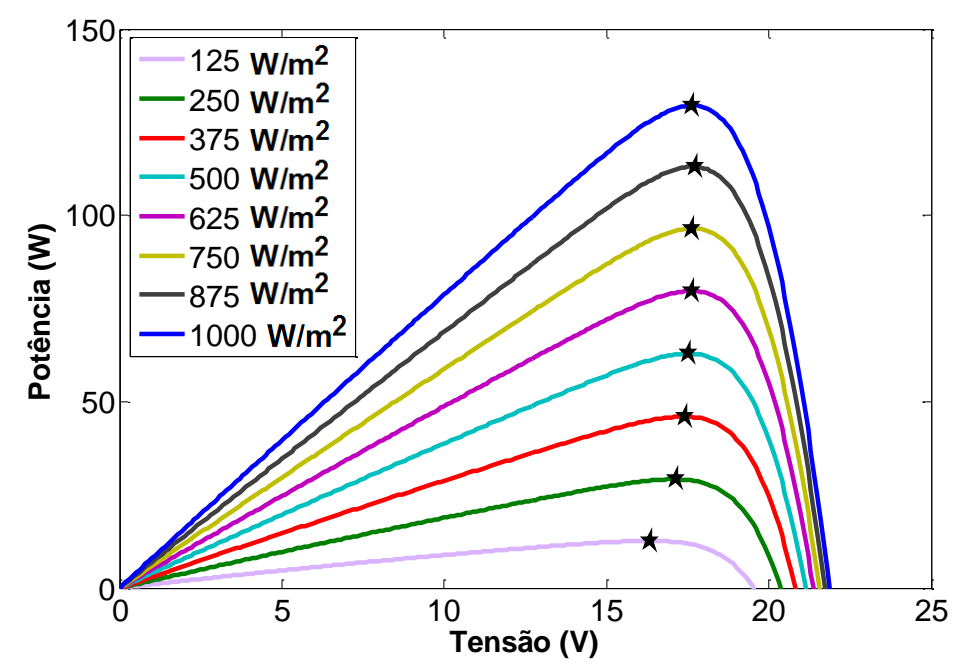

Figura 3.11 - Curva potência versus tensão, módulo KC130TM, para diferentes níveis de irradiação [25].

\subsection{Banco de Baterias}

A Tabela 3.1 mostra uma comparação entre os tipos mais comuns de baterias disponíveis comercialmente, destacando os principais atributos de desempenho e operação de cada uma.

As discussões nesse trabalho serão restritas às baterias de chumbo-ácido, pois as mesmas serão utilizadas no projeto devido ao seu baixo custo inicial, robustez e adequação à microrrede, no entanto, qualquer um dos tipos descritos na Tabela 3.1 poderia ser utilizado. A bateria de chumbo-ácido foi inventada em 1860 pelo francês Gastón Planté e desde que sua 
utilização se difundiu no início do século XX, poucas foram as alterações em sua composição, que é constituída, basicamente, de chumbo e ácido sulfúrico.

TABELA 3.1

CARACTERÍSTICAS DOS DIVERSOS TIPOS DE BATERIA [39].

\begin{tabular}{|c|c|c|c|c|}
\hline & Chumbo-ácido & Ni-Cad & "NiMh & Lithium-ion \\
\hline Custo inicial & Baixo & Médio & Médio & Alto \\
\hline Custo a longo prazo & Alto & Médio & Médio & Baixo \\
\hline Segurança & Boa & Boa & Boa & Boa \\
\hline Impacto ambiental & Alto & Alto & Médio/Alto & Médio/Baixo \\
\hline Ciclos & $200^{*}$ & 250 & $400-500$ & $400-600$ \\
\hline Tensão nominal (V) & 2 & 1,2 & 1,2 & 3,4 \\
\hline $\begin{array}{c}\text { Densidade de } \\
\text { energia }(W h / k g)\end{array}$ & 35 & 41 & 80 & 120 \\
\hline $\begin{array}{c}\text { Densidade de } \\
\text { energia volumétrica } \\
\left(\mathrm{Wh} / \mathrm{m}^{3}\right)\end{array}$ & 80 & 120 & 200 & 280 \\
\hline $\begin{array}{c}\text { Autodescarga por } \\
\text { mês (\%) }\end{array}$ & $<5$ & $<10$ & $<20$ & $<5$ \\
\hline Efeito memória & Não & Sim & Pouco & Não \\
\hline $\begin{array}{l}\text { Temperatura de } \\
\text { operação (ํㅡ) }\end{array}$ & $-15^{\circ} a+50^{\circ}$ & $-20^{\circ} a+50^{\circ}$ & $-20^{\circ} a+60^{\circ}$ & $-20^{\circ} a+60^{\circ}$ \\
\hline Peso & Pesada & Leve & Leve & Muito leve \\
\hline Tempo de carga & Longo & Médio & Médio & Curto \\
\hline
\end{tabular}

\section{* dependente da profundidade da descarga}

A bateria é um elemento que armazena energia elétrica na forma eletroquímica, isto é, uma bateria não produz energia, somente armazena [40]. Em baterias recarregáveis, o processo de carga e descarga pode ser repetido por centenas de vezes nos quais, para uma bateria de chumbo-ácido, o número de ciclos de carga e descarga é inversamente proporcional à profundidade da descarga, ou seja, o quanto a bateria é descarregada antes de ser carregada novamente (Fig. 3.12). A situação de operação mais danosa para uma bateria de chumbo-ácido é quando a mesma opera sob temperaturas elevadas, o que reduz sua vida útil (Fig. 3.13) entretanto aumenta sua capacidade de armazenamento [41, 42].

Até recentemente, o foco dos fabricantes estava voltado para a redução do custo de produção ao invés do aumento do desempenho, já que suas aplicações se limitavam a dispositivos utilizados na ignição de automóveis. Atualmente, o surgimento de novas tecnologias está proporcionando às baterias de chumbo-ácido de última geração atender uma nova gama de aplicações como: sistemas fotovoltaicos isolados da rede, sistemas de energia emergencial, sistemas de telecomunicação e etc, que são estruturas que necessitam de longos períodos ininterruptos de fornecimento de energia, ocasionando descargas profundas nas 
baterias, diferentemente de sistemas de ignição. Logo, os mesmos necessitam de baterias de ciclos profundos e com alta durabilidade, mesmo em condições adversas de temperatura, Fig. 3.13.

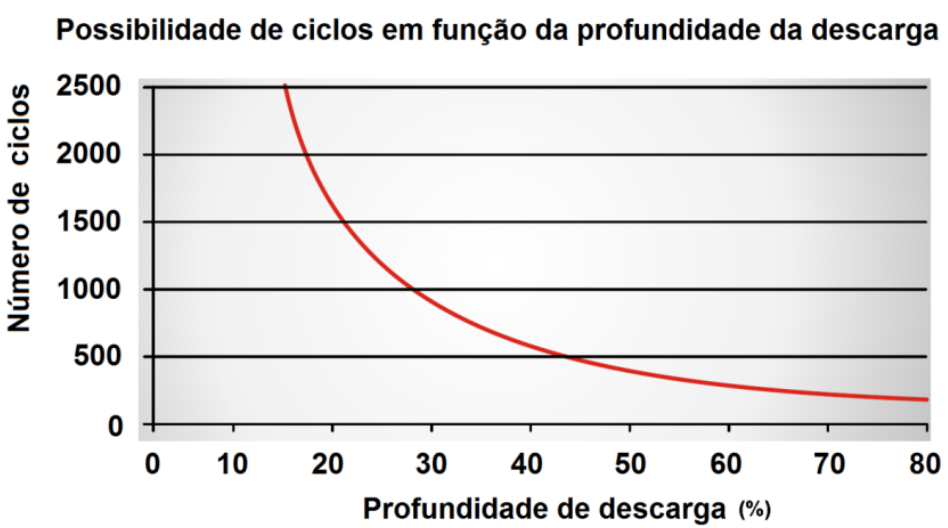

Figura 3.12 - Desgaste de uma bateria de chumbo-ácido em função da profundidade da carga [41].

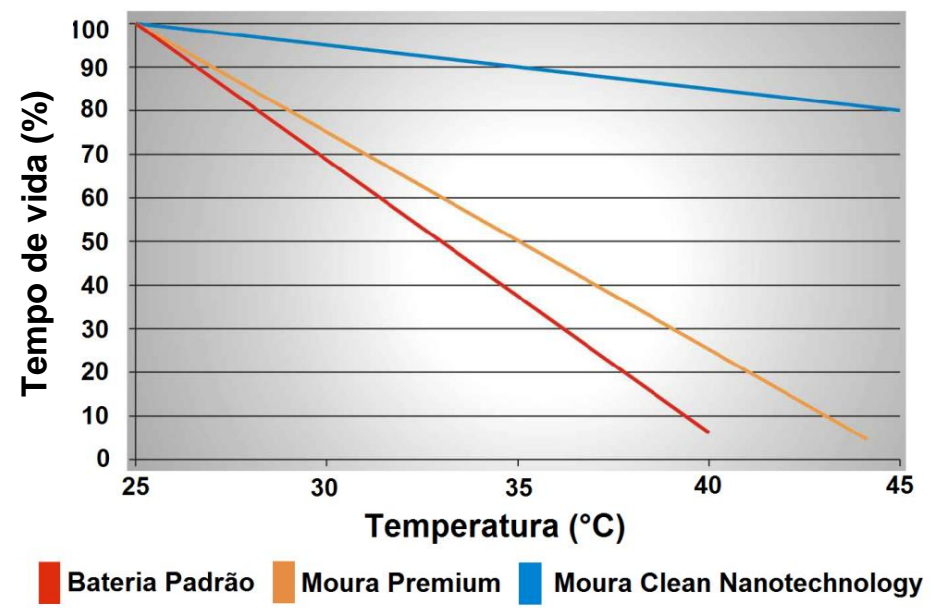

Figura 3.13 - Efeito da temperatura na vida útil da bateria de chumbo-ácido [41].

As baterias não são $100 \%$ eficientes, sendo este rendimento proporcional à corrente drenada ou injetada, uma vez que uma parte da energia é perdida na forma de calor nas resistências parasitas (internas à bateria). Dessa forma, o rendimento típico de uma bateria de chumbo-ácido é de $85 \%$ e de uma bateria de níquel-cádmio de 65\% [40].

Uma bateria típica de chumbo-ácido fornece em seus terminais, aproximadamente, 2,14 $\mathrm{V}$ por célula se completamente carregada [43], porém se a mesma não for utilizada sua capacidade se reduz devido à auto descarga. Assim, uma tensão de flutuação deve ser imposta 
nos terminais da bateria quando ela não estiver em operação, valor este em torno de $2,2 \mathrm{~V}$ por célula [40].

Por outro lado, um dos parâmetros mais importantes para avaliar uma bateria é o estado de carga state-of-charge (SOC), ele informa quanto de carga existe, o que evita sobrecargas ou descarregamentos excessivos, além disso, através desse parâmetro é possível o gerenciamento do processo de carga e descarga com maior precisão. O $S O C$ pode ser determinado medindo-se as tensões em circuito aberto nos terminais da bateria (no caso de baterias chumbo-ácido) ou através da medição da acidez do eletrólito, o que é complexo, pois as baterias são seladas [44].

Nesse contexto, a tensão de circuito aberto de uma bateria de chumbo-ácido quando, completamente, carregada está entre 2,12 e 2,15 V por célula ou 12,7 e 12,9 V por bateria. A $50 \%$ de carga ela possui $2,03 \mathrm{~V}$ por célula e 1,95 V quando, totalmente, descarregada $(0 \%$ de carga) [40, 44], ver Fig. 3.14.

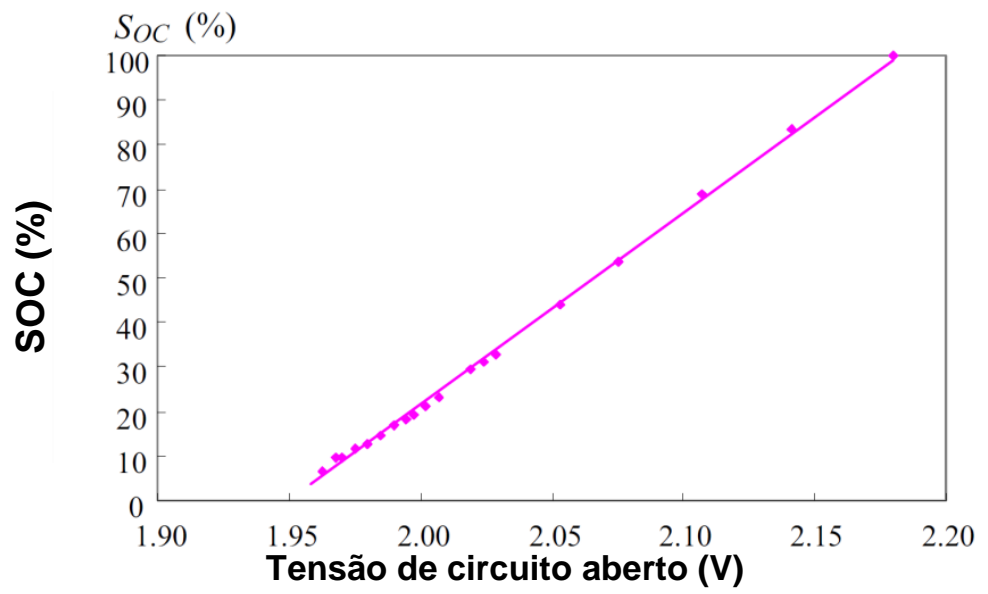

Figura 3.14- Estado de carga versus tensão de circuito aberto para uma bateria de chumboácido [44].

Os fatores relevantes para a carga de uma bateria são o tempo de carga disponível e o rendimento que se deve maximizar, porém ambos estão atrelados, uma vez que uma carga mais rápida requer uma corrente mais elevada, o que resulta em um rendimento menor, com isso, ambos devem ser tratados de forma a se obter um equilíbrio. Os limitantes do processo de carga são: a tensão terminal e a temperatura, já que tensões e temperaturas elevadas danificam e reduzem a vida útil da bateria [40].

Os principais métodos de carga descritos na literatura são cinco: corrente e tensão constante, potência constante, corrente pulsada e métodos mistos nos quais existem estágios de alternância entre os outros métodos [40, 45, 46, 47]. Dos métodos mistos utilizados, destaca-se 
o método a dois níveis de tensão. Este método se baseia na união das características dos métodos da corrente constante e do método da tensão constante, alternados de forma a utilizar as melhores características de cada um [40, 47], veja Fig. 3.15 e Fig. 3.16.

Supondo-se uma bateria, profundamente, descarregada, logo o processo de carga se inicia na primeira etapa, na qual uma corrente mínima controlada $I_{\min }$ é entregue a bateria evitando com isso, picos de corrente e formação excessiva de gases. Esta etapa é mantida até que a bateria atinja uma tensão mínima de trabalho $V_{\text {min }}$.

Ao ser alcançado $V_{\text {min }}$, a bateria inicia o processo de carga na segunda etapa, injetando a corrente de carga desejada $I_{\max }$. Com a injeção de uma corrente de carga elevada, a tensão tende a subir a uma taxa proporcional à corrente. No momento em que ela atinge o valor máximo permitido pela bateria $V_{s t}$, a terceira etapa é iniciada fixando este valor de sobre tensão na bateria.

A terceira etapa tem a função de reduzir o tempo de carga por meio da regulação de uma sobre tensão $V_{s t}$. Como a tensão é fixa, a corrente de carga inicia um processo de queda à medida que a bateria se aproxima da carga completa.

Ao ser atingida a carga completa, inicia-se a quarta etapa que possui a função de compensar a auto descarga da bateria aplicando uma tensão de flutuação $V_{f}$, uma vez que a bateria está carregada e não está em operação. Após o uso da bateria, caso o processo de carga se inicie com uma carga diferente de zero, o mesmo precisa ser reiniciado a partir da segunda etapa.

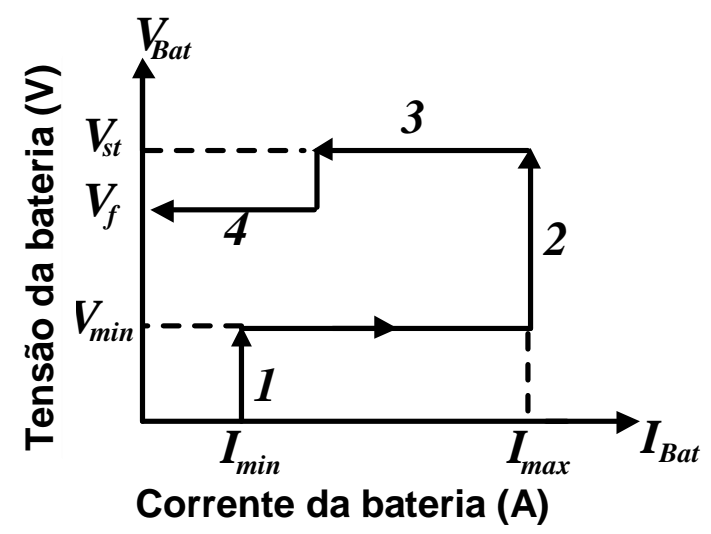

Figura 3.15 - Método a dois níveis de tensão [40]. 


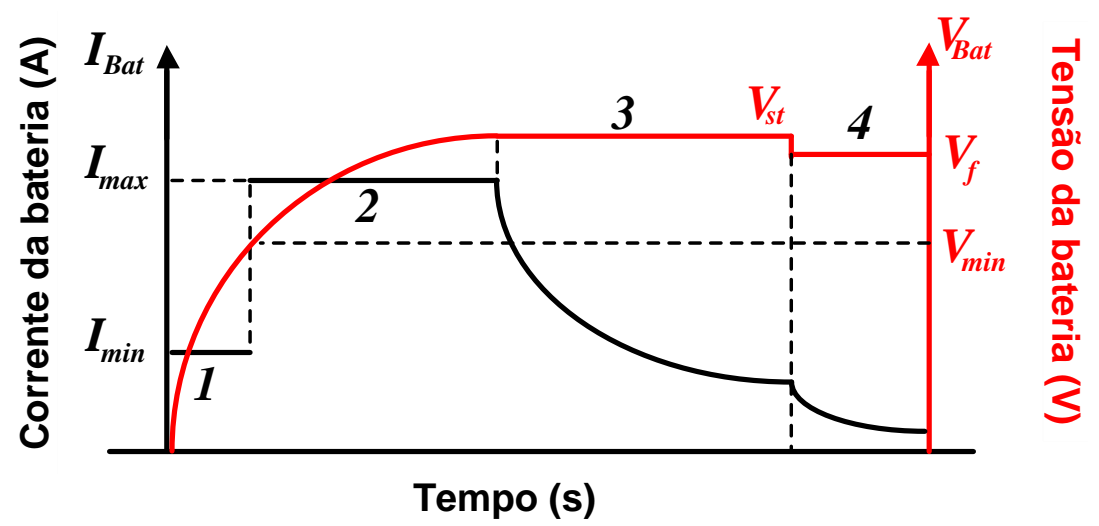

Figura 3.16 - Tensão e corrente, método dois níveis [40].

\subsection{Ultracapacitores}

A primeira geração de ultracapacitores disponível comercialmente apareceu no final da década de 70 e era utilizada, basicamente, em produtos eletrônicos, em razão da pequena tensão que as células de UC suportavam (inferior a 2,5 V). Com a possibilidade de modularização foi possível empregá-los em aplicações com tensões mais elevadas. Somente na década de 90 seu uso começou a se difundir, graças ao uso dos UC em veículos elétricos [48]. Neste tipo de aplicação, o dispositivo funciona como uma fonte de transferência rápida de energia, o que possibilita a compactação e a melhora de desempenho da estrutura de armazenamento e de conversão de energia [49].

O elevado custo dos UC ainda é um empecilho para uma ampla utilização do dispositivo, principalmente, aquelas que requerem níveis de tensão média ou elevada (> $50 \mathrm{~V})$. No entanto, em sistemas com múltiplas fontes de energia, ou seja, em conjunto com baterias ou células a combustível, podem resultar em soluções técnicas e econômicas mais viáveis [49, 50]. Em termos práticos, a utilização combinada destes armazenadores se torna interessante, pois estes dispositivos se complementam devido à diferente característica de cada um, ou seja, cada dispositivo apresenta uma densidade de energia e de potência diferentes, Fig. 3.17.

Logo, a bateria consegue fornecer um pacote de energia maior por um tempo mais elevado devido à sua grande densidade de energia, já os ultracapacitores podem entregar uma quantidade de energia menor, porém em um tempo muito reduzido, devido à sua alta densidade de potência. Assim, as baterias e células de combustível podem suprir regimes longos e com uma constância maior, enquanto que os UC podem suprir a demanda transitória e picos inesperados [49]. 


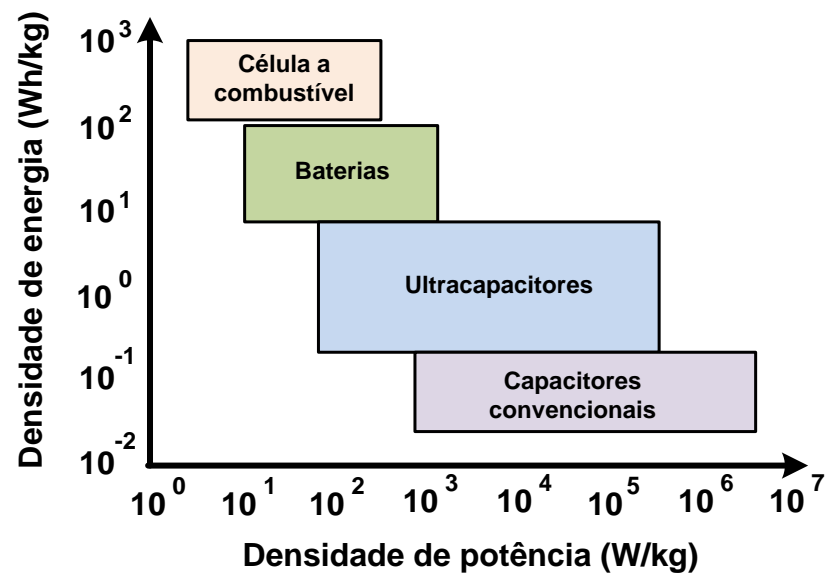

Figura 3.17 - Diagrama de Ragone [49].

Atualmente, os ultracapacitores são uma das tecnologias mais promissoras para melhorar a gestão, aumentar a eficiência, otimizar o desempenho e prolongar a durabilidade das estruturas de armazenamento e de geração de energia elétrica [49].

Em um capacitor de placas paralelas, o acúmulo de energia ocorre através do campo elétrico, devido à separação entre as cargas. $\mathrm{O}$ valor da capacitância é uma grandeza que reflete a capacidade do dispositivo em armazenar energia e depende somente de parâmetros dimensionais e da rigidez dielétrica. Os ultracapacitores ou capacitores eletroquímicos de dupla camada obedecem ao mesmo princípio, ou seja, o valor elevado de capacitância é alcançado graças à enorme área superficial dos eletrodos e à mínima distância entre as cargas [49, 48].

Atualmente, cada eletrodo do UC é composto por uma película metálica revestida por uma fina camada, em geral de carbono ativado, que possui imensa área superficial (alcançado pela elevada porosidade de seus nódulos microscópicos), condutividade elétrica, química inerte e baixo custo, Fig. 3.18. Entre dois eletrodos é interposto um material separador (papel, membrana ou fibra de vidro) que impede o contato eletrônico (condução de corrente) entre os eletrodos, mas permite o livre trânsito de cátions e ânions [51]. Além disso, o conjunto formado pelas camadas de carbono ativado e separador é encharcado por um eletrólito altamente condutivo (aquoso ou solvente orgânico) que provê, instantaneamente, alta concentração de íons móveis [52]. 


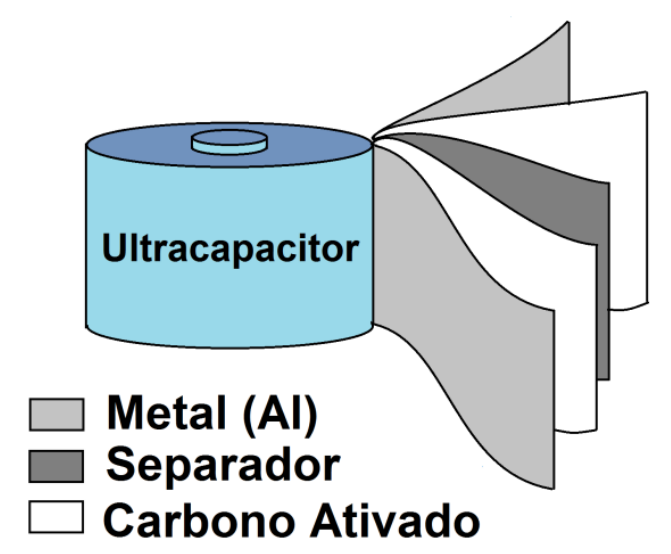

Figura 3.18 - Estrutura básica de um ultracapacitor [49].

O limiar de tensão para operação segura de uma célula de UC é determinado pela composição do eletrólito. Em um eletrólito aquoso a tensão é de $1 \mathrm{~V}$, enquanto que em um eletrólito de solvente orgânico a tensão é de 2,3 V. Excedido o limite haverá a eletrólise do eletrólito, ocasionando a formação de gases que danificará o dispositivo. Para alcançar tensões de operação mais elevadas, os UC são combinados em série, sendo que para distribuir uniformemente as tensões, são empregados circuitos de balanceamento de tensão. Estes circuitos podem ser passivos (resistores em paralelo), ativos (circuitos eletrônicos) ou uma combinação de ambos [48, 53, 54].

Em termos de comportamento dinâmico, o UC é um dispositivo "robusto" a variações bruscas e elevadas de corrente, não apresenta efeito de memória, trabalha em uma ampla faixa de temperatura e de tensão e apresenta tendência de custos decrescente.

O estado de carga de um UC pode ser, diretamente, obtido pela tensão nos seus terminais, uma vez que a energia armazenada em um capacitor é, diretamente, proporcional à capacitância e a tensão terminal ao quadrado [49]. Este fato torna sua operação simples, pois a determinação do estado de carga é direta, diferente de alguns tipos de baterias, como a bateria de chumbo ácido, por exemplo, cuja determinação do estado de carga é complexa [26].

\subsection{Algoritmos de Busca do Ponto de Máxima Potência (MPPT)}

Devido à característica dos painéis fotovoltaica $(\mathrm{P}$ vs $\mathrm{V})$ e dos aerogeradores $(\mathrm{P}$ vs $\mathrm{W})$, para se obter um maior aproveitamento da potência gerada e para se conseguir um aumento da eficiência, ambos os dispositivos necessitam de algoritmos para a busca do ponto ótimo de operação (MPPT), uma vez que esses algoritmos possuem como meta a determinação do 
ponto de operação de maior produção de energia. Para a obtenção de tal objetivo, encontramse hoje, na literatura, diversos tipos de algoritmos que são classificados em três principais categorias: algoritmos baseados em modelo, algoritmos baseados em treinamento e algoritmos MPPT de busca [37] [55] [56].

Os algoritmos baseados em modelo dependem de um equacionamento matemático para o cálculo do ponto ótimo logo, a determinação do ponto ótimo é obtida, diretamente, pela solução da equação definida pelo modelo em questão [37].

Por outro lado, nos algoritmos que utilizam treinamento, é necessário um banco de dados para que se possa realizar o treinamento e em seguida, obter um comportamento semelhante ao encontrado em um dispositivo real tanto durante a busca quanto durante operação em regime permanente. Dentre as principais técnicas de busca baseadas em treinamento, é possível mencionar os métodos cujo princípio de funcionamento usa lógica fuzzy ou redes neurais. Entretanto, esses métodos requerem maior poder computacional e dispensam o uso de modelos matemáticos complexos [57].

Já os algoritmos de busca que são baseados em regras heurísticas não requerem o conhecimento prévio das características do sistema, uma vez que um reduzido número de medidas é feitas (tensão e corrente no caso do painel fotovoltaico) e de acordo com as informações contidas nessas medidas, uma decisão é tomada em relação à variável de controle.

Os métodos mais difundidos, na literatura, são o Perturbação e Observação (P\&O) e o Condutância Incremental [27, 36, 37]. A Fig. 3.19 mostra o comportamento da variável de controle e da potência de saída utilizando o método P\&O, enquanto que a Fig. 3.20 mostra o fluxograma do algoritmo para execução do método MPPT por P\&O [26].

É importante observar, na Fig. 3.19, que para o conjunto de painéis fotovoltaicos a variável de controle " $V$ " é representada pela tensão terminal do painel enquanto que, para o gerador eólico, a variável de controle " $V$ " é a velocidade da turbina [36, 37]. Nessa mesma ilustração, $V_{m p}$ representa o valor de " $V$ " no ponto ótimo $\left(P_{m p}\right)$ e $\Delta V$ é o passo da variável de controle em torno do ponto ótimo. 


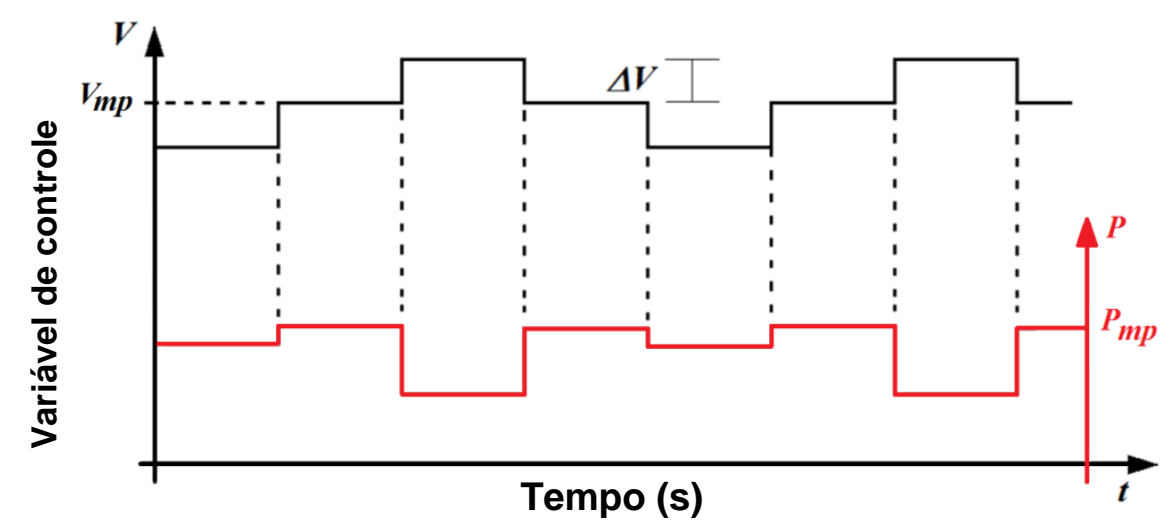

Figura 3.19 - Comportamento da variável de controle e da potência, durante o regime permanente utilizando algoritmo MPPT por P\&O com passo fixo [26].

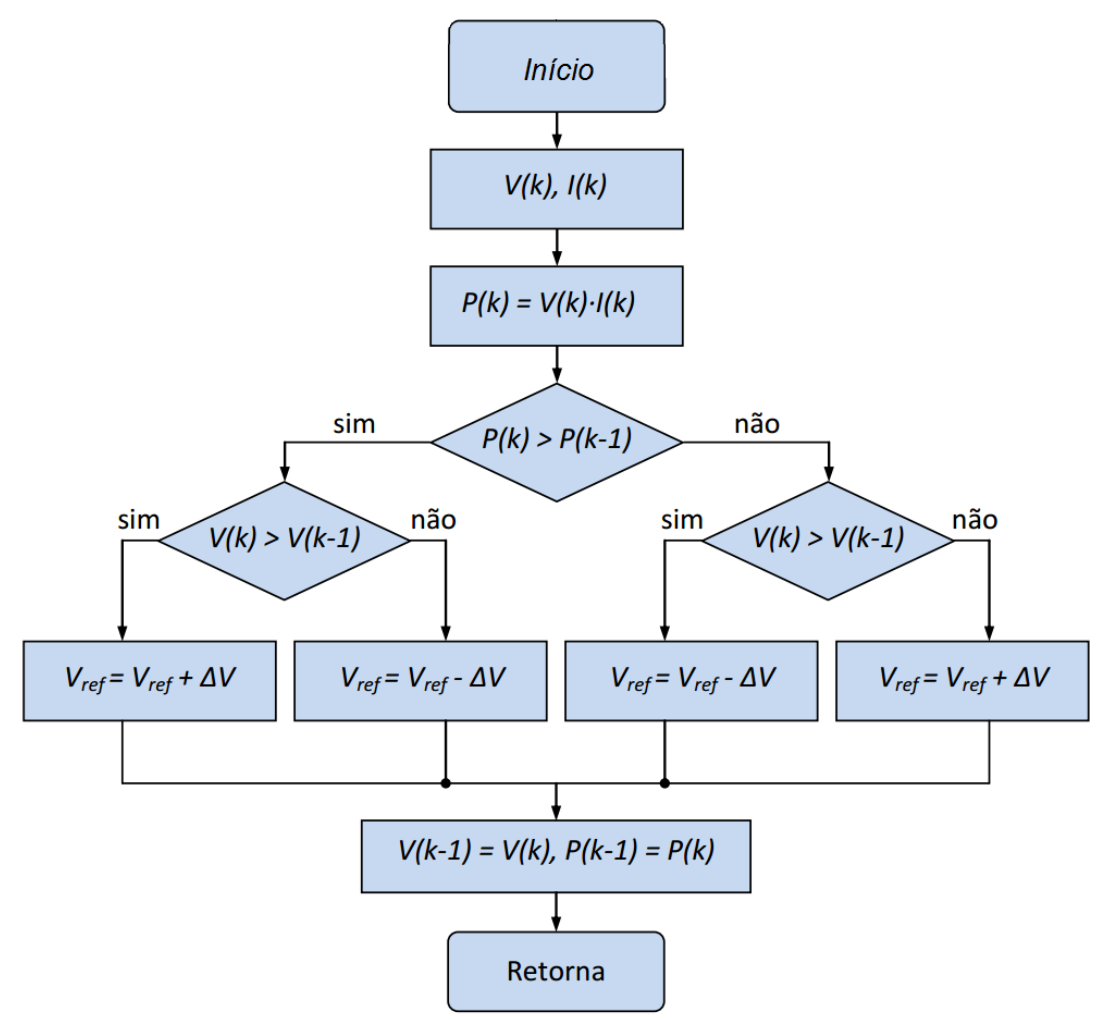

Figura 3.20 - Método de busca por perturbação e observação [25].

\subsection{Interfaces de Potência}

A Fig. 3.21 ilustra a estrutura eletrônica responsável pela conversão da energia das diferentes fontes alternativas e pela integração delas em um barramento $\mathrm{CC}$ comum a todas [58] [59]. Esta topologia se resume a dois conversores Boost, sendo usados como interface do aerogerador e do conjunto fotovoltaico, além de dois conversores Buck-Boost bidirecionais utilizados no gerenciamento dos elementos armazenadores (Baterias e Ultracapacitores). A necessidade de conversores bidirecionais é decorrente da natureza bidirecional dos armazenadores, hora armazenando energia e hora fornecendo. 


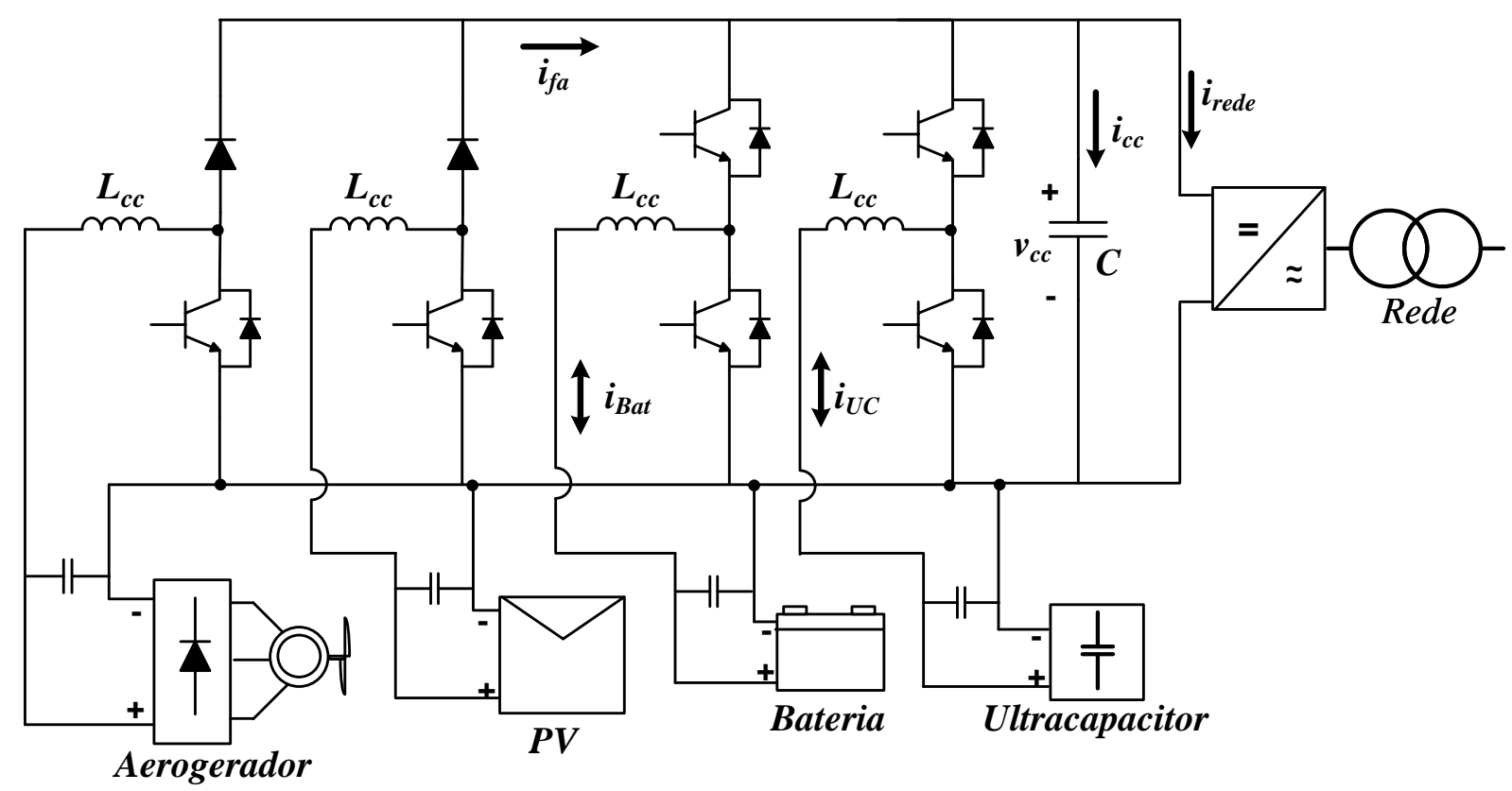

Figura 3.21 - Conversores CC empregados na integração das fontes alternativas e dos armazenadores [58] [59].

A Fig. 3.22 mostra o conversor Buck-Boost bidirecional utilizado para comandar os armazenadores e sua malha de controle, onde as chaves eletrônicas são acionadas de forma complementar, permitindo o fluxo de corrente em ambos os sentidos. Nessa mesma figura, $P I_{c}$ é a estrutura de controle usada para regular tanto a corrente de carga quanto de descarga dos armazenadores.

Já a Fig. 3.23 mostra o controlador PI usado no controle das fontes alternativas, juntamente com o algoritmo de busca MPPT, que gera a referência necessária para que o circuito alcance a máxima potência ( $v_{\text {painel }}^{*}$ no caso do painel e $w_{\omega}^{*}$ no caso do aerogerador) [36, 37]. Para o conjunto de painéis fotovoltaicos são medidas a tensão terminal $\left(v_{\text {painel }}\right)$ e corrente instantânea de saída $\left(i_{\text {painel }}\right)$, já para o aerogerador são medidas a tensão terminal $\left(v_{\omega}\right)$, corrente instantânea de saída $\left(i_{\omega}\right)$ e a velocidade angular do eixo $\left(W_{\omega}\right)$. Para o caso do aerogerador, pode-se incluir uma malha interna de corrente $\left(P I_{c}\right)$ em cascata com a malha externa de velocidade, de forma a aumentar a controlabilidade da microrrede.

A Fig. 3.24 mostra o conversor CC-CA, juntamente, com suas malhas de controle, sendo que a malha de controle ilhado atua em condição de contingência ou em operação isolada, de forma a gerar uma tensão no PAC (ponto de acoplamento comum) dentro dos parâmetros de qualidade determinados pela norma IEEE 1547. No entanto, a malha de controle em modo conectado, busca impor corrente controlada na rede de forma a maximizar 
a potência ativa mantendo assim, os parâmetros de qualidade de energia [60].

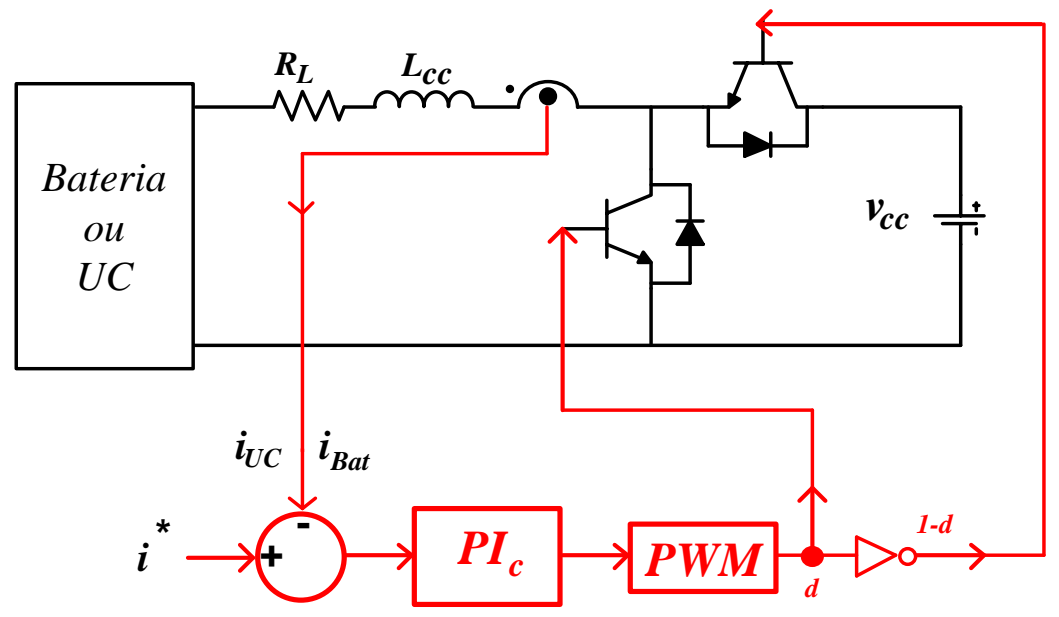

Figura 3.22 - Conversor Buck-Boost bidirecional e malha de controle utilizada na bateria e UC [26].

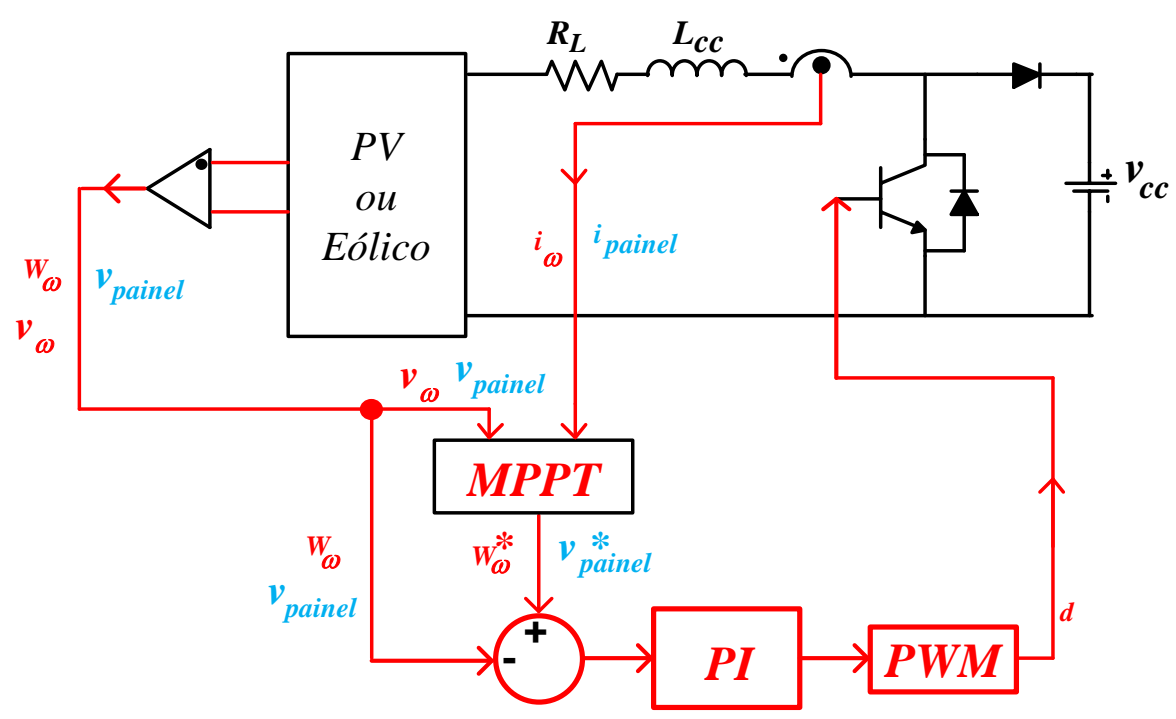

Figura 3.23 - Conversor Boost e malha de controle utilizada no PV e sistema eólico [27, 26]. 


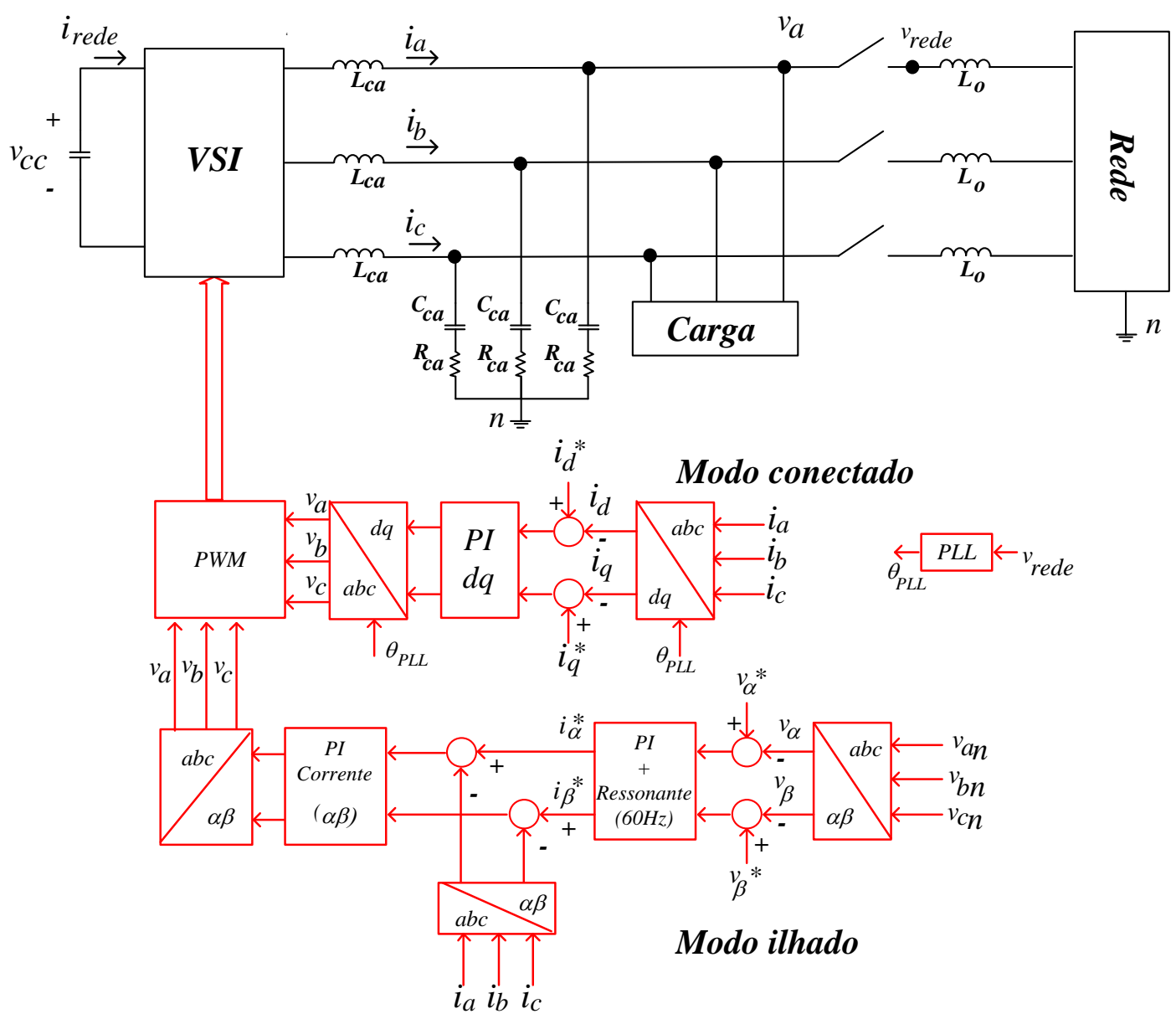

Figura 3.24 - Sistema eletrônico e de controle do conversor CC-CA no modo conectado e isolado [60].

Para a estrutura de integração de fontes que está sendo apresentada nesse trabalho, espera-se que toda a potência gerada pelas fonte alternativas, em um determinado momento do dia, seja disponibilizada ao barramento $\mathrm{CC}$ logo, para alcançar tal requisito, a estrutura de controle e gerenciamento de cada fonte precisa operar junto ao ponto de máxima potência. Dessa forma, o controle da tensão do barramento CC fica a cargo dos armazenadores, que devem suprir/absorver prováveis falta/excesso de energia na microrrede, mantendo a estabilidade e a disponibilidade de energia para o inversor Fig. 3.25.

Assim, a presença de apenas um tipo de armazenador (UC ou bateria) pode acarretar em grandes oscilações ou instabilidades do barramento CC uma vez que, tais dispositivos são complementares em termos de operação, ou seja, UCs suprem os transitórios e as baterias o regime permanente.

Por outro lado, a corrente da rede é controlada pelo algoritmo de gerenciamento, podendo assumir valores constantes ou variáveis, dependendo da estratégia aplicada e que será discutida nos próximos capítulos dessa Tese de doutorado. 
A Fig. 3.25 apresenta uma microrrede com controle centralizado, cujos geradores e armazenadores se comunicam em alta velocidade, de forma a manter a estabilidade do barramento $\mathrm{CC}$, controlam a entrega de potência para a rede de distribuição e a potência gerada pelas fontes alternativas.

Em regime permanente, para que a tensão no barramento $\mathrm{CC}$ seja constante, o somatório das potências no barramento deve ser zero (3.7) bem como, a derivada da tensão do barramento, logo a corrente média que flui no capacitor do barramento CC deve ser zero (3.8).

Assim, quando a corrente das fontes $\left(i_{f a}\right)$ e/ou a entregue a rede $\left(i_{\text {rede }}\right)$ for submetida a algum tipo de variação decorrente de alguma alteração nas condições climática ou manobra de carga $\left(i_{L o}\right)$, restará aos armazenadores $\left(i_{B a t}+i_{U C}\right)$ atuar sobre a corrente injetada no barramento de forma a manter a igualdade em (3.8).

Desta forma, o controlador da tensão $v_{c c}$ deve produzir uma referência de corrente que deverá ser sintetizada pelos conversores CC-CC dos armazenadores, responsáveis pelo controle da tensão do barramento $\mathrm{CC}$, impondo assim a corrente necessária a ser drenada/injetada para que a condição de estabilidade seja alcançada, Fig. 3.25.

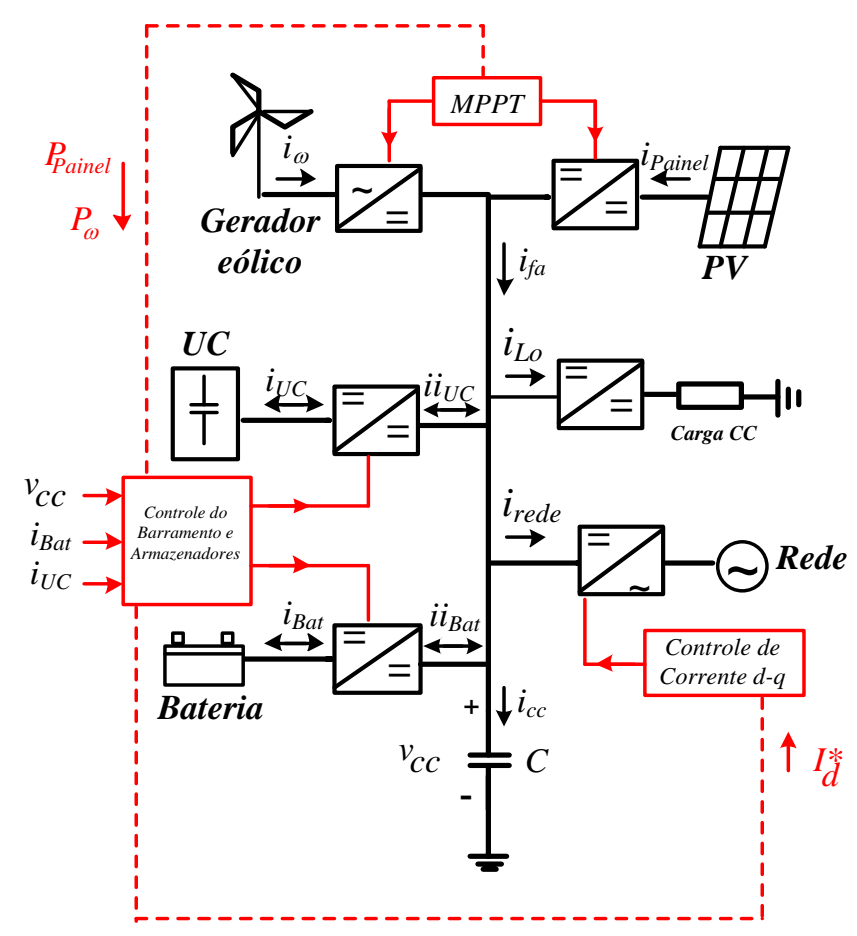

Figura 3.25 - Sistema de controle centralizado da tensão do barramento CC no modo conectado.

$$
\begin{gathered}
P_{B a t}+P_{U C}+P_{f a}-P_{r e d e}-P_{L o}=0 \\
i i_{B a t}+i i_{U C}+i_{f a}-i_{\text {rede }}-i_{L o}=C \frac{d v_{c c}}{d t}=0
\end{gathered}
$$




\subsection{Considerações Finais do Capítulo 3}

Neste capítulo foram apresentadas as topologias eletrônicas e de controle que são utilizadas na integração das fontes alternativas junto ao barramento CC e a conexão com a rede de distribuição. Para que a integração seja efetiva, as fontes alternativas são comandadas por algoritmos de busca do ponto de máxima potência, enquanto os armazenadores se encarregam da estabilização do barramento, tendo na rede de distribuição uma corrente que será dependente do método de gerenciamento, que será discutido nos próximos capítulos deste trabalho. 


\section{Capítulo 4 \\ Metodologias de Projeto}

No presente capítulo será apresentada e discutida a metodologia de sintonia dos controladores que serão utilizados nos conversores de potência, tanto CC-CC quanto CC-CA, que foram descritos no Capítulo 3. Esta metodologia é baseada na frequência de corte em malha fechada, margem de fase e utiliza os modelos de pequenos sinais.

\subsection{Critério de Projeto dos Controladores}

Para o projeto dos ganhos dos controladores empregados nos conversores CC-CC e CC-CA, é utilizada uma metodologia baseada na margem de fase $(m f)$ e frequência de corte $\left(\omega_{F C L}\right)$ [27, 61, 62, 63]. Inicialmente, através do modelo da planta a ser controlada é determinado o ganho de malha aberta $\left(G_{O L}\right)$ da malha requerida, sendo esta malha de tensão ou corrente. Assim, o controlador é dimensionado de acordo com a velocidade de compensação em malha fechada.

Para esse projeto, a frequência de corte de malha fechada é determinada de acordo com a frequência de amostragem/chaveamento e é baseado em [38, 62, 63] que sugere que, para esse caso, seja posicionada uma década abaixo da frequência de amostragem e que a margem de fase não seja menor que $50^{\circ}$ e maior que $70^{\circ}$ respectivamente.

Depois de definir o ganho de malha aberta e os valores de projeto, o ganho proporcional $\left(K_{\text {prop }}\right)$ é calculado por (4.1). Tendo em mãos o valor de $K_{\text {prop }}$, o ganho integral $\left(K_{\text {int }}\right)$ é calculado de acordo com $(4.2)$ [62,63].

$$
\begin{gathered}
K_{\text {prop }} \frac{G_{O L}}{\omega_{F C L}}=1 \\
K_{\text {int }}=K_{\text {prop }} \frac{\omega_{F C L}}{\tan (m f)}
\end{gathered}
$$




\subsection{Conversores CC-CC}

Inicialmente, para o projeto dos controladores dos conversores CC-CC, deve-se obter a planta em pequenos sinais do circuito, linearizada em torno do ponto de operação e que é determinada através da análise em espaço de estado (4.3) e (4.4) [26, 27, 64], sendo $D$ o ciclo de trabalho em regime permanente, $\boldsymbol{X}$ o vetor de estados em regime permanente e $\boldsymbol{U}$ o vetor de entradas.

$$
G(s)=C[s \mathrm{I}-A]^{-1}\left[\left(\boldsymbol{A}_{1}-\boldsymbol{A}_{2}\right) X+\left(\boldsymbol{B}_{1}-B_{2}\right) U\right]+\left(\boldsymbol{C}_{1}-C_{2}\right) X
$$

onde

$$
\begin{aligned}
\boldsymbol{A}=\boldsymbol{A}_{\mathbf{1}} \boldsymbol{D}+\boldsymbol{A}_{\mathbf{2}}(1-D), \boldsymbol{B} & =\boldsymbol{B}_{\mathbf{1}} D+\boldsymbol{B}_{2}(1-D), \boldsymbol{C}=\boldsymbol{C}_{\mathbf{1}} D+\boldsymbol{C}_{\mathbf{2}}(1-D) \\
\boldsymbol{X} & =-\boldsymbol{A}^{-1} \boldsymbol{B} \boldsymbol{U}
\end{aligned}
$$

As matrizes $\boldsymbol{A}_{\mathbf{1}}, \boldsymbol{A}_{\mathbf{2}}, \boldsymbol{B}_{\mathbf{1}}, \boldsymbol{B}_{\mathbf{2}}, \boldsymbol{C}_{\mathbf{1}}$ e $\boldsymbol{C}_{\mathbf{2}}$ podem ser determinadas resolvendo-se as equações diferencias dos circuitos em questão. Tomando o conversor Buck-Boost bidirecional, este será modelado e sua planta extraída para a sintonia dos controladores aplicados nas fontes alternativas e armazenadores.

A Fig. 4.1 mostra o diagrama do modelo padrão que será adotado para todos os conversores CC-CC utilizados neste trabalho, sendo considerado o barramento CC estável com um valor fixo e representado por uma fonte constante, $v_{c c}$. Tanto os conversores Buck-Boost bidirecionais utilizados nos armazenadores quanto os conversores Boost utilizados nas fontes alternativas apresentam as mesmas matrizes de estado, contudo, a corrente do indutor só assume valores positivos no caso do conversor Boost, circulando assim pela chave $S 1$ e pelo diodo da chave $\mathbf{S 2}$. Já pelo conversor Buck-Boost bidirecional pode circular tanto corrente positiva quanto negativa, devido ao chaveamento complementar das chaves $S 1$ e $S 2$.

A fonte alternativa será considerada como um modelo simplificado e linearizado em torno do ponto de interesse (ponto de máxima extração de potência) representado por $V_{E Q} \mathrm{e}$ $R_{E Q}$. Informações adicionais em relação a este modelo podem ser encontradas em [27, 37]. No caso da bateria e do UC, o mesmo modelo é utilizado, sendo $V_{E Q}$ a tensão do armazenador e $R_{E Q}$ a resistência interna série. 


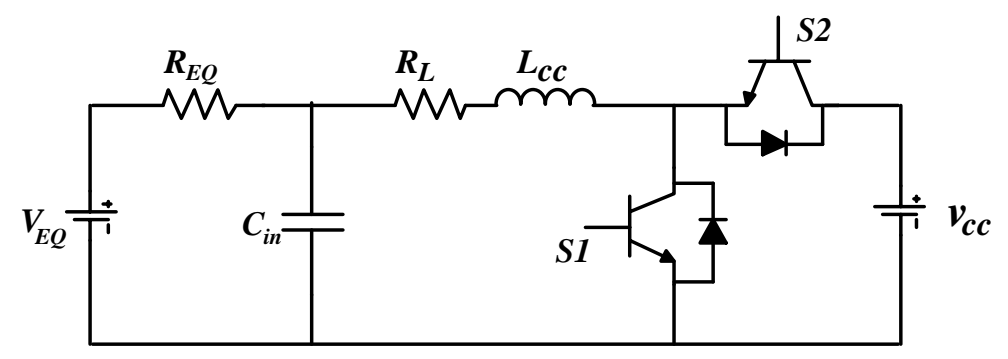

Figura 4.1 - Modelo simplificado equivalente do conversor Buck-Boost CC-CC acoplado as fontes alternativas ou armazenadores.

A Fig. 4.2 mostra o circuito no instante em que a chave $S 1$ está fechada e $S 2$ está aberta. Abaixo são apresentadas as matrizes de estado na forma $\dot{\boldsymbol{x}}=\boldsymbol{A}_{\mathbf{1}} \boldsymbol{x}+\boldsymbol{B}_{\mathbf{1}} \boldsymbol{u}$, e $\boldsymbol{y}=\boldsymbol{C}_{\mathbf{1}} \boldsymbol{x}$. Para o conjunto fotovoltaico $\boldsymbol{C}_{\mathbf{1}}=\left[\begin{array}{l}0 \\ 1\end{array}\right]$, pois deseja-se controlar a tensão de saída dos painéis, já para o controlador da bateria, UC e aerogerador, $\boldsymbol{C}_{\mathbf{1}}=\left[\begin{array}{ll}1 & 0\end{array}\right]$, uma vez que o interesse é na corrente de saída do armazenador.

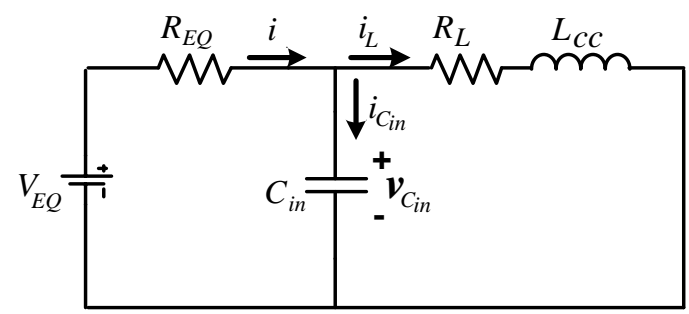

Figura 4.2 - Conversor Buck-Boost adotado no instante chave $\boldsymbol{S} 1$ fechada e $\boldsymbol{S} 2$ aberta ou conversor Boost com a chave $S 1$ fechada e diodo da chave $S 2$ não conduzindo.

$$
\begin{gathered}
{\left[\begin{array}{c}
\frac{d i_{L}}{d t} \\
\frac{d v_{c_{i n}}}{d t}
\end{array}\right]=\left[\begin{array}{cc}
-\frac{R_{L}}{L_{c c}} & \frac{1}{L_{c c}} \\
-\frac{1}{C_{i n}} & -\frac{1}{R_{E Q} C_{i n}}
\end{array}\right]\left[\begin{array}{c}
i_{L} \\
v_{c_{i n}}
\end{array}\right]+\left[\begin{array}{cc}
0 & 0 \\
0 & \frac{1}{R_{E Q} C_{i n}}
\end{array}\right]\left[\begin{array}{c}
v_{c c} \\
V_{E Q}
\end{array}\right]} \\
y=\left[\begin{array}{ll}
1 & 0
\end{array}\right]\left[\begin{array}{c}
i_{L} \\
v_{c_{i n}}
\end{array}\right]
\end{gathered}
$$

A Fig. 4.3 mostra o circuito no instante em que a chave $S 2$ está fechada e $S 1$ está aberta ou chave $S 1$ aberta e diodo da chave $S 2$ conduzindo. A seguir são apresentadas as matrizes de estado na forma $\dot{\boldsymbol{x}}=\boldsymbol{A}_{\mathbf{2}} \boldsymbol{x}+\boldsymbol{B}_{\mathbf{2}} \boldsymbol{u}$, e $y=\boldsymbol{C}_{\mathbf{2}} \boldsymbol{x}$, sendo que para o conjunto fotovoltaico $\boldsymbol{C}_{\mathbf{2}}=$ [0 1], pois deseja-se controlar a tensão de saída dos painéis, já para o controlador da bateria, UC e aerogerador, $\boldsymbol{C}_{\mathbf{2}}=\left[\begin{array}{ll}1 & 0\end{array}\right]$. 


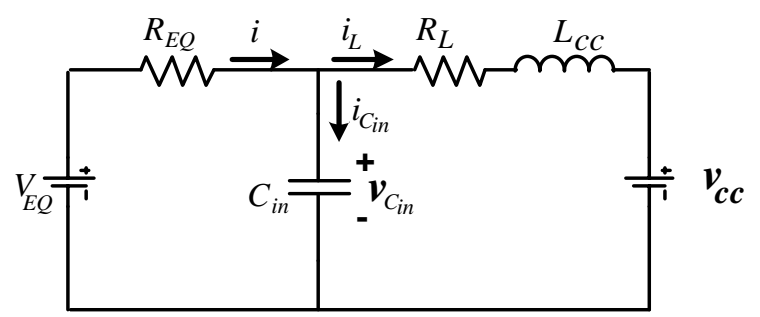

Figura 4.3 - Conversor Buck-Boost adotado no instante chave $\boldsymbol{S} 2$ fechada e $\boldsymbol{S} 1$ aberta ou conversor Boost com a chave $S 1$ aberta e diodo da chave $S 2$ conduzindo.

$$
\begin{gathered}
{\left[\begin{array}{c}
\frac{d i_{L}}{d t} \\
\frac{d v_{c_{i n}}}{d t}
\end{array}\right]=\left[\begin{array}{cc}
-\frac{R_{L}}{L_{c c}} & \frac{1}{L_{c c}} \\
-\frac{1}{C_{i n}} & -\frac{1}{R_{E Q} C_{i n}}
\end{array}\right]\left[\begin{array}{c}
i_{L} \\
v_{c_{i n}}
\end{array}\right]+\left[\begin{array}{cc}
-\frac{1}{L_{c c}} & 0 \\
0 & \frac{1}{R_{E Q} C_{i n}}
\end{array}\right]\left[\begin{array}{c}
v_{c c} \\
V_{E Q}
\end{array}\right]} \\
y=\left[\begin{array}{ll}
1 & 0
\end{array}\right]\left[\begin{array}{c}
i_{L} \\
v_{c_{i n}}
\end{array}\right]
\end{gathered}
$$

Usando a equação (4.3), (4.5) e (4.7) tem-se a função de transferência do conversor CCCC para o controle de corrente no indutor (4.9). De forma a representar uma bateria ou UC com resistência interna de condução muito baixa, é considerada uma tensão média de entrada do armazenador $V_{E Q}=80 \mathrm{~V}$ e resistência $R_{E Q}=0,01 \Omega$. Para representar o aerogerador ou painel fotovoltaico basta ajustar os mesmos parâmetros $\left(R_{E Q}\right.$ e $\left.V_{E Q}\right)$ para cada modelo.

De posse da função de transferência (FT) (4.9), seus respectivos controladores podem ser sintonizados de acordo com o método descrito por (4.1) e (4.2) na seção 4.1, cuja frequência de corte do sistema em malha fechada é posicionada 1 década abaixo da frequência de chaveamento do conversor CC-CC. Utilizando os parâmetros da Tabela 4.1, é possível projetar os ganhos do controlador $P I_{C}$ para os armazenadores, que são apresentados na mesma na tabela.

A Fig. 4.4 apresenta o diagrama de bode da função $G_{c}(s)$ utilizando os parâmetros da Tabela 4.1, onde é apresentado o diagrama do sistema em malha aberta, malha fechada sem compensação e malha fechada compensada pelo controlador $P I_{c}$. Nota-se uma redução da banda-passante do sistema em malha fechada, quando o mesmo é compensado pelo $P I_{c}$, de forma a atender os parâmetros de projeto. 
TABELA 4.1

PARÂMETROS DO MODELO EM PEQUENOS SINAIS

\begin{tabular}{cc}
\hline \hline Símbolo & Valor \\
\hline$R_{L}$ & $0,1 \Omega$ \\
$C_{\text {in }}$ & $1000 \mathrm{uF}$ \\
$R_{E Q}$ & $0,01 \Omega$ \\
$V_{E Q}$ & $80 \mathrm{~V}$ \\
$V_{c c}$ & $250 \mathrm{~V}$ \\
$L_{c c}$ & $10 \mathrm{mH}$ \\
$K_{\text {int }}$ & 10 \\
$K_{\text {prop }}$ & 0,15 \\
$F_{\text {ch }}$ & $12 \mathrm{kHz}$ \\
\hline \hline
\end{tabular}

$G_{c}(s)=\frac{\widehat{T}_{L}(s)}{\widehat{d}(s)}=\frac{V_{c c}\left(C_{i n} R_{E Q} s+1\right)}{s^{2} R_{E Q} C_{i n} L_{c c}+s\left(L_{c c}+C_{i n} R_{E Q} R_{L}\right)+R_{E Q}+R_{L}}$

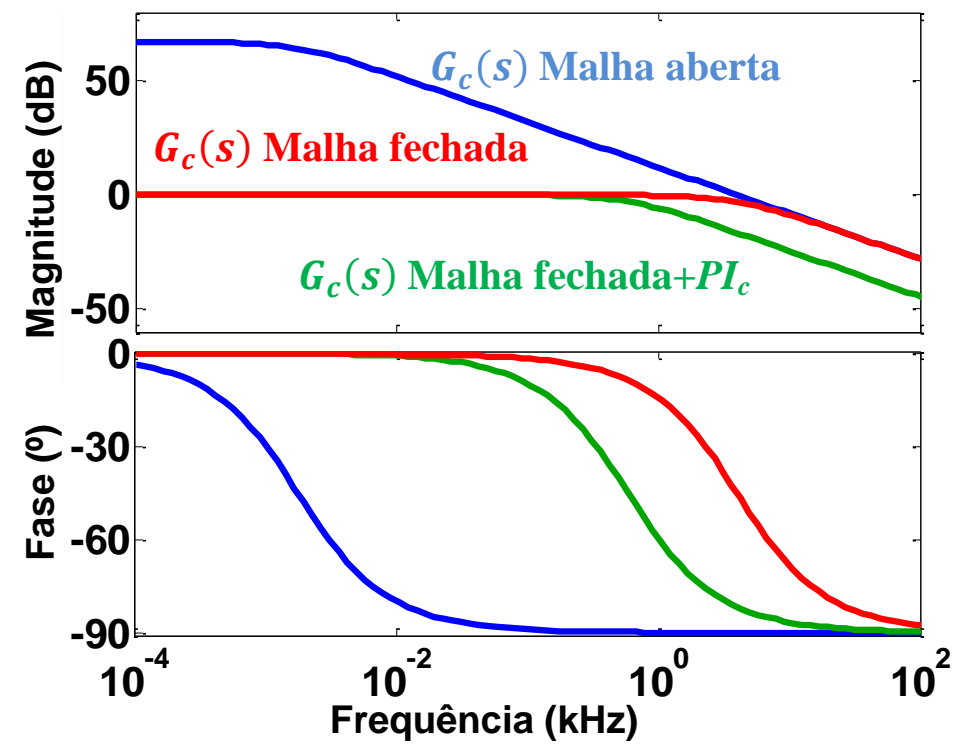

Figura 4.4 - Diagrama de bode em malha aberta, malha fechada e malha fecha compensada + $P I_{c}$ da função de TF $G_{c}(s)$.

\subsection{Conversor CC-CA 4.3.1 Operação em Modo Conectado}

A planta do sistema de controle para o conversor CC-CA em modo conectado é mostrado na Fig. 4.5. Sendo que o termo $V_{c c} / 2$ representa o ganho do conversor CC-CA, o filtro de corrente na saída do conversor é representado por 1/( $\left.s L_{c a}\right)$ e $H i$ é o ganho do sensor de corrente [27, 60, 63, 65]. 
$\mathrm{Na}$ modelagem deste conversor eletrônico em coordenadas $d q$ surge um produto cruzado entre a variável $d$ e $q$, gerando assim um acoplamento entre as variáveis, o que em teoria não permitiria o controle independente das fases. Contudo, assim como afirmado e utilizado em [27], a ausência de um termo de desacoplamento tem efeito imperceptível no controle das correntes, fazendo com que o diagrama de controle por fase possa ser representado pela Fig. 4.5.

Para a obtenção dos ganhos do controlador de corrente $\left(P I_{i_{-} d q}\right)$ é necessário definir a margem de fase da malha de corrente $\left(m f i_{-} d q\right)$, a frequência de corte em malha fechada $\left(F_{C L i-} d q\right)$ e o ganho em malha aberta (4.10) da malha em corrente [63].

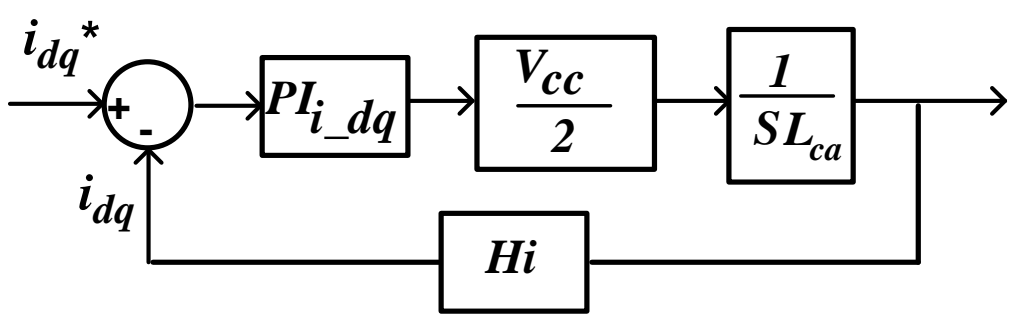

Figura 4.5 - Planta de controle do conversor CC-CA em modo conectado [60, 27].

$$
G_{O L i_{-} d q}=\frac{V_{C C}}{2} H i \frac{1}{L_{c a}}
$$

O ganho proporcional $\left(K_{p_{-} i_{-} d q}\right)$ e o integral $\left(K_{i_{-} i_{-} d q}\right)$ do controlador $P I_{i_{-} d q}$ de corrente são definidos conforme as equações da seção 4.1, representados por (4.11) e (4.12) [62].

$$
\begin{gathered}
K_{p_{-} i_{-} d q}=2 \pi \frac{F_{C L i_{-} d q}}{G_{O i_{-} d q}} \\
K_{i_{-} i_{-} d q}=2 \pi \frac{K_{p_{\_} i_{-} d q} F_{C L i_{-} d q}}{\tan \left(m f i_{-} d q\right)}
\end{gathered}
$$

\subsubsection{Operação em Modo Ilhado}

A planta do sistema de controle para o conversor CC-CA no modo ilhado é mostrado na Fig. 4.6, onde as leituras e os controladores estão em coordenadas $\alpha \beta 0$ [60]. Nessa mesma figura, $H v$ é o ganho do sensor de tensão e $1 /\left(s C_{c a}\right)$ representa o filtro da tensão terminal do conversor CC-CA. 
Análogo ao digrama para controle da corrente mostrada no item anterior, a estrutura descrita na Fig. 4.6 possui a mesma funcionalidade, diferenciando-se daquela mostrada na Fig. 4.5 em relação ao eixo de referência usado, ou seja, na Fig. 4.6 é usado o eixo de referência estacionário $\alpha \beta$ enquanto que, na estrutura em blocos mostrada na Fig. 4.5, é utilizado o eixo de referência síncrono $d q$

Assim, após usar os procedimentos de projeto do item 4.3.1 para projetar a malha interna em corrente, define-se a margem de fase da malha de tensão $\left(m f v_{-} \alpha \beta\right)$, a frequência de corte em malha fechada $\left(F_{C L v_{-} \alpha \beta}\right)$ e o ganho em malha aberta (4.13) de tensão para então, calcular os ganhos proporcional e integral do controlador de tensão $\left(P I_{\mathcal{V}_{\_} \alpha \beta}\right)$ via equações (4.14) e (4.15), respectivamente.

Para tal tarefa, a malha de controle em corrente é considerada como um ganho, pois na frequência na qual o controle de tensão é projetado, o atraso associado ao controlador de corrente é desprezível [65]. Outra consideração feita reside na frequência de corte da planta de tensão, que deve ser posicionada uma década abaixo da frequência de corte da malha de corrente. Isto se torna necessário para desacoplar as duas plantas de controle, minimizando a influência de uma sobre a outra $[63,60]$.

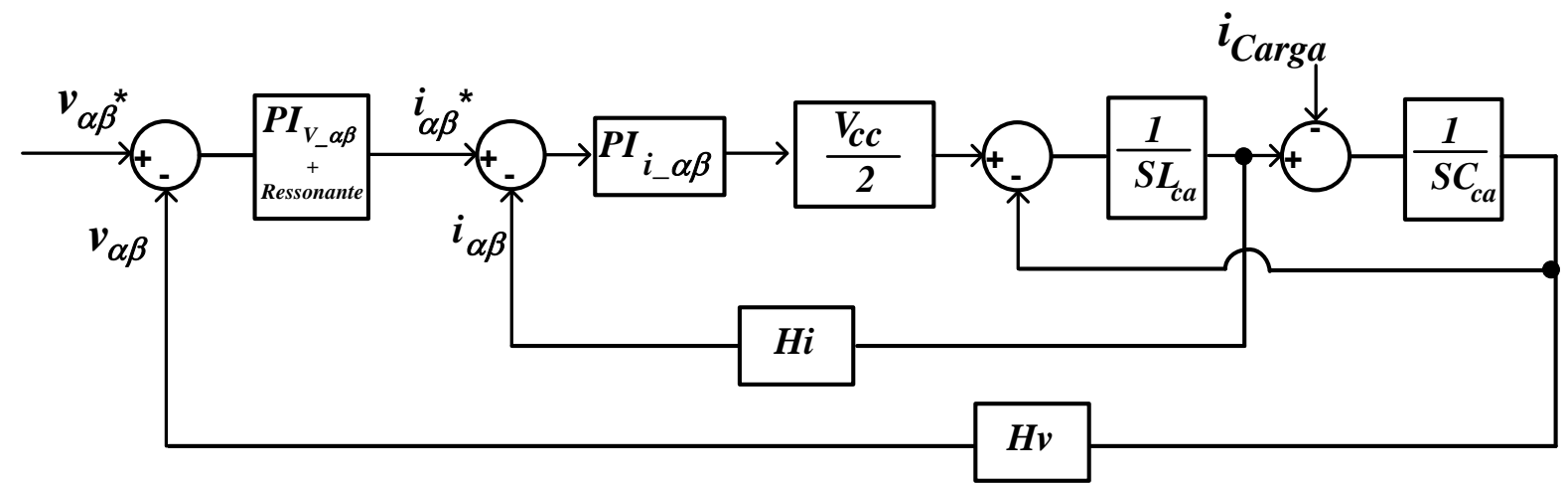

Figura 4.6 - Planta do conversor CC-CA em modo ilhado [60].

$$
\begin{gathered}
G_{O L v_{-} \alpha \beta}=G_{O L i} \frac{1}{C_{C a}} \frac{H v}{H i} \\
K_{P_{-} v_{-} \alpha \beta}=2 \pi \frac{F_{C L v_{\_} \alpha \beta}}{G_{O L v_{-} \alpha \beta}} \\
K_{i_{-} v_{-} \alpha \beta}=2 \pi \frac{K_{p_{-} v_{-} \alpha \beta} F_{C L v_{-} \alpha \beta}}{\tan \left(m f v_{-} \alpha \beta\right)}
\end{gathered}
$$




\subsection{Controlador do Barramento CC}

De forma similar ao apresentado nos itens de projeto dos controladores do conversor CC-CC e CC-CA, a sintonia do controlador da tensão do barramento CC é feita utilizando as equações da seção 4.1, tomando como o modelo do sistema em malha aberta $1 /(s C)$ [65]. Isto indica, que a dinâmica e velocidade para estabilizar a tensão do barramento é dependente da capacitância do barramento CC.

\subsection{Algoritmo de Sincronização PLL}

A Fig. 4.7 mostra o diagrama do algoritmo de sincronização [66, 27]. De acordo com [66], devido às altas frequências de amostragem, o sistema em malha fechada pode ser reduzido à forma canônica de segunda ordem como mostrado em (4.16).

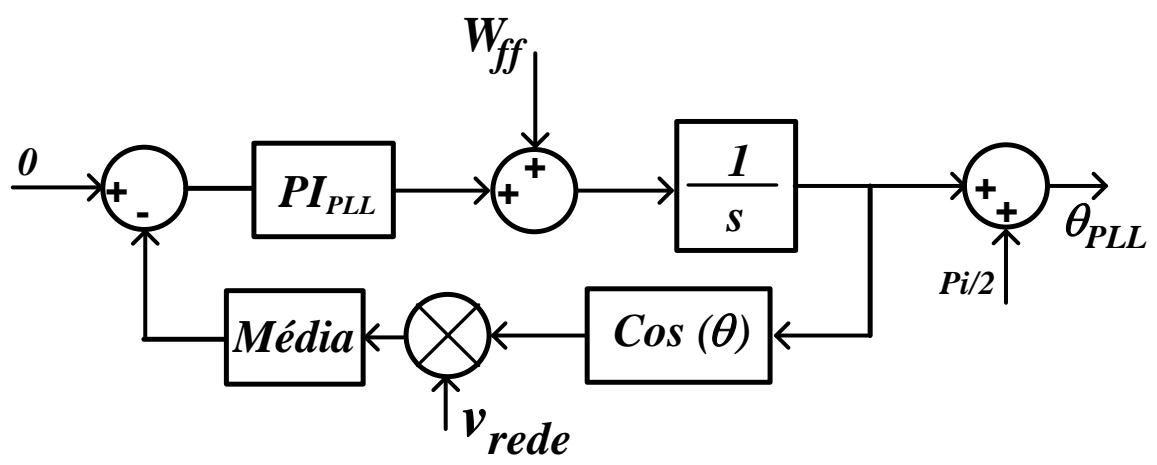

Figura 4.7 - Diagrama do algoritmo de sincronização [60].

$$
H_{c l}=\frac{K_{p \_p l l} s+K_{i \_p l l}}{s^{2}+K_{p_{-} p l l} s+K_{i} p l l}=\frac{2 \xi \omega_{n} s+\omega_{n}^{2}}{s^{2}+2 \xi \omega_{n} s+\omega_{n}^{2}}
$$

Desta forma, $K_{p_{-} p l l}$ e $K_{i_{-} p l l}$ podem ser ajustados de acordo com (4.17) e (4.18), respectivamente $[60,66]$.

$$
\begin{gathered}
K_{p_{-} p l l}=2 \xi \omega_{n} \\
K_{i \_p l l}=\omega_{n}^{2}
\end{gathered}
$$


Observa-se que manipulando $\omega_{n}$ a velocidade da planta é alterada, ou seja, deixando a planta mais rápida, aumenta-se a sensibilidade ao ruído, por outro lado deixando a planta mais lenta o algoritmo se torna mais imune aos ruídos, contudo, aumenta-se o tempo de convergência do método. A Fig. 4.8 mostra a sincronização via a cossenoide de referência produzida pela rede de distribuição, enquanto a Fig. 4.9 mostra a frequência sendo ajustada pelo PLL de forma a sincronizar a microrrede com a rede de distribuição.

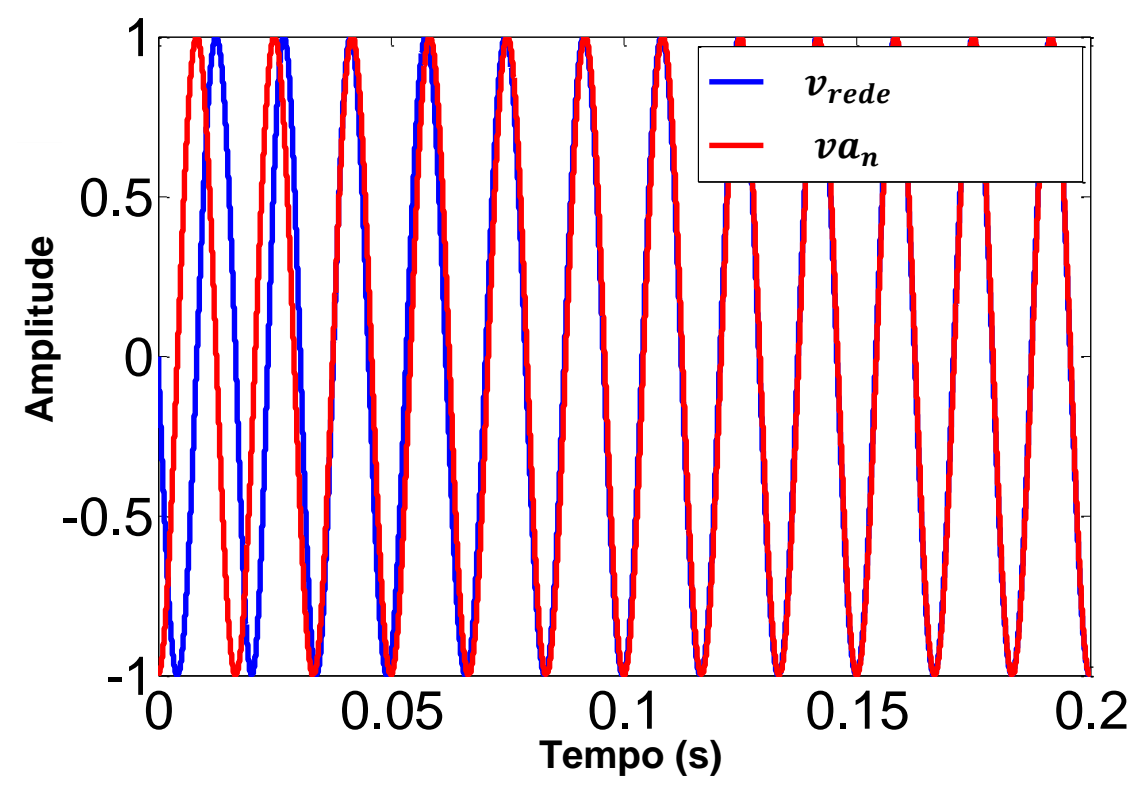

Figura 4.8 - PLL em funcionamento sincronizando com a rede.

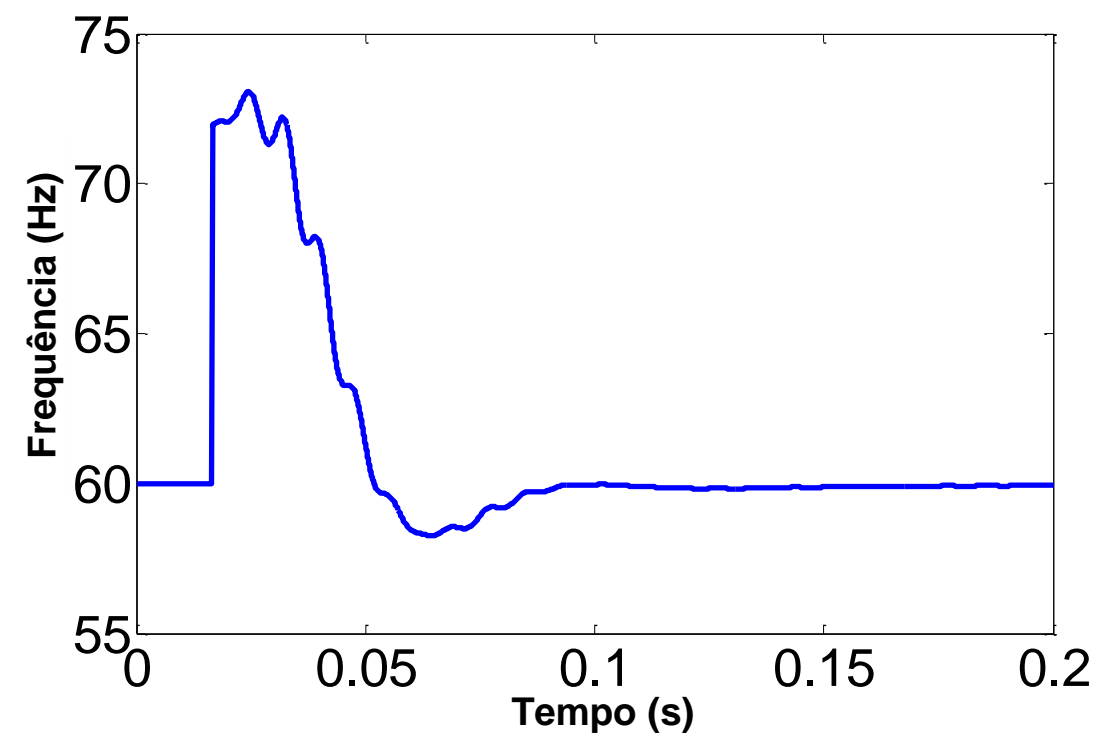

Figura 4.9 - Atuação do PLL na frequência gerada para alcançar o sincronismo. 


\subsection{Considerações Finais do Capítulo 4}

Neste capítulo foram apresentados os modelos e os métodos de sintonia para as estruturas de controle apresentadas no Capítulo 3, cujos métodos são baseados na frequência de corte e na margem de fase. Os modelos dos conversores CC-CC foram obtidos utilizando uma representação em pequenos sinais, enquanto para o conversor CC-CA em modo conectado é utilizado um modelo simplificado (eliminando-se o acoplamento entre as variáveis $d$ e $q$ ), representado pelo ganho do inversor e os filtros de saída do conversor. Foi também apresentada a estrutura de sincronismo PLL, cujos ganhos do $P I_{P L L}$ alteram a velocidade de resposta e imunidade ao ruído do algoritmo. 


\section{Capítulo 5 Resultados Simulados}

Neste capítulo serão apresentados os resultados simulados da microrrede completa, apresentada na Fig. 3.25, quando uma estrutura de gerenciamento centralizada controla todos os conversores. Nesta etapa, será executada a simulação eletrônica dos controladores, conversores de energia, fontes alternativas e armazenadores, ou seja, é testada a capacidade da microrrede na produção de energia a partir das fontes alternativas, injetando potência na rede e controlando a carga dos armazenadores. Assim, é possível aferir a performance das malhas de controle e dos ganhos das mesmas, cujos métodos de projeto foram descritos no Capítulo 4.

\subsection{Simulação Eletrônica da Microrrede CC Conectada à Rede}

Nesta seção, serão apresentados os resultados simulados do modelo chaveado do sistema completo para a integração de fontes alternativas conectadas à rede, apresentado na Fig. 3.25. Nesta estrutura eletrônica, as fontes alternativas (PV e aerogerador) e os armazenadores (bateria e UC) são conectados ao barramento CC através de conversores CC-CC não isolados, conforme apresentados no Capítulo 3.

Toda a simulação foi realizada no Software PSIM 9.3, sendo que as malhas de controle analisadas nos capítulos anteriores foram implementadas em forma de código (linguagem $\mathrm{C}^{++}$), através do bloco de execução $C$ Block. Já os modelos da bateria, UC, PV e aerogerador foram utilizados os modelos disponibilizados nas bibliotecas do PSIM, sendo os mesmos parametrizados de acordo com os dispositivos reais presentes no laboratório.

As Tabelas 5.1, 5.2 e 5.3 apresentam os dados utilizados na configuração dos modelos. Em termos de painéis fotovoltaicos, é mostrada corrente $\left(I_{m p}\right)$, tensão $\left(V_{m p}\right)$ e potência $\left(P_{m p}\right)$ no ponto de máxima potência gerada. Já para o aerogerador, é mostrada a velocidade angular $\left(W_{m p}\right)$ e a potência nos terminais do gerador $\left(P_{W m p}\right)$, ambas junto ao ponto de máxima

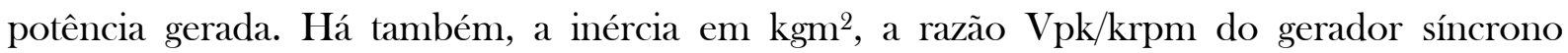
(representa a tensão de pico gerada nos terminais da máquina para cada mil rpm) e a velocidade do vento incidente sobre as pás. 
TABELA 5.1

PARÂMETROS DO MODELO FUNCIONAL PV

\begin{tabular}{ccc}
\hline \hline \multicolumn{3}{c}{ PV } \\
\hline$V_{m p}(\mathrm{~V})$ & $I_{m p}(\mathrm{~A})$ & $P_{m p}(\mathrm{~W})$ \\
\hline 76 & 8 & 608 \\
\hline \hline
\end{tabular}

TABELA 5.2

PARÂMETROS DO MODELO FUNCIONAL DO AEROGERADOR

\begin{tabular}{ccccc}
\hline \hline \multicolumn{5}{c}{ Aerogerador } \\
\hline$W_{m p}(\mathrm{rpm})$ & $P_{\omega_{m p}}(\mathrm{~W})$ & $\begin{array}{c}\text { Inércia } \\
\left(\mathrm{kgm}^{2}\right)\end{array}$ & $\mathrm{Vpk} / \mathrm{krpm}$ & $v_{\omega}(\mathrm{m} / \mathrm{s})$ \\
\hline 400 & 1000 & $2 \mathrm{e}^{-3}$ & 300 & 14 \\
\hline \hline
\end{tabular}

TABELA 5.3

PARÂMETROS DOS MODELOS DA BATERIA E UC

\begin{tabular}{cc}
\hline \hline Bateria & $\mathrm{UC}$ \\
\hline$V_{\text {Bat }}(\mathrm{V})$ & $U C(\mathrm{~F})$ \\
\hline 100 & 0,4 \\
\hline \hline
\end{tabular}

Os parâmetros utilizados nos elementos passivos dos conversores CC-CC e CC-CA foram inseridos de acordo com os elementos disponíveis no laboratório e são apresenta na tabela 5.4. Com o intuito de reduzir a tensão de trabalho do barramento $\mathrm{CC}$, foi utilizado um transformador abaixador $(110 \mathrm{Y}-220 \Delta)$ para acoplamento do conversor CC-CA com a rede, $\operatorname{logo}$ a tensão de trabalho entre fase e neutro no $P A C$ foi reduzida para $63,5 \mathrm{~V} \mathrm{rms}$ ou $89,81 \mathrm{~V}$ pico.

TABELA 5.4

ELEMENTOS PASSIVOS UTILIZADOS NA SIMULAÇÃO

\begin{tabular}{cc}
\hline \hline & Elementos \\
\hline$L_{c c}$ - Indutância dos conversores CC-CC & $10 \mathrm{mH}$ \\
\hline$R_{L}$ - Resistência parasita do indutor & $0,1 \Omega$ \\
\hline$C_{i n}$ - Capacitor de entrada dos conversores CC-CC & $1000 \mathrm{uF}$ \\
\hline$C$ - Capacitor do barramento CC & $1000 \mathrm{uF}$ \\
\hline$L_{c a}$ - Indutor de saída do VSC & $5 \mathrm{mH}$ \\
\hline$C_{c a}$ - Capacitor do filtro RC na saída do VSC & $30 \mathrm{uF}$ \\
\hline$R_{c a}$ - Resistor do filtro RC na saída do VSC & $10 \Omega$ \\
\hline$L_{o}$ - Indutor de acoplamento com a rede & $2 \mathrm{mH}$ \\
\hline Frequência de chaveamento & $12 \mathrm{kHz}$ \\
\hline \hline
\end{tabular}

De forma a gerenciar uma microrrede híbrida, ou seja, com a presença de elementos armazenadores de energia (Bateria e UC), é necessário o uso de uma técnica de gerenciamento que faça com que os transitórios de potência sejam supridos pelos UC enquanto que, a 
operação de regime permanente fique a cargo das baterias, para que se possa aproveitar ao máximo a característica de cada dispositivo da microrrede.

Em [67] é utilizada uma abordagem na qual a corrente de referência da bateria é caracterizada pelo valor filtrado da corrente consumida pela carga menos a corrente gerada pela fonte alternativa, ou seja, a bateria fornece à carga a média do déficit de potência, enquanto que o UC fornece os picos de corrente, Fig. 5.1. Em outras palavras, a bateria fornece as variações de corrente em baixa frequência, enquanto o UC, devido à sua alta densidade de potência, fornece os surtos de corrente.

Como alternativa à estratégia aplicada em [67], é proposta a estratégia da Fig. 5.2, na qual é adicionado um termo a corrente do UC para a restauração da sua tensão terminal, evitando que ela se desvie, demasiadamente, da referência $v_{U C}^{*}$ após cada surto de corrente.

Na estratégia proposta por [67], a tensão do UC é livre para variar até que atinja um limite superior/inferior. Uma vez atingido um dos limites, uma descarga/recarga é acionada, contudo, durante este procedimento o armazenador (UC) se torna vulnerável a surtos de corrente, uma vez que ele se ocupa, exclusivamente, da recuperação de sua tensão terminal. Outra clara desvantagem, é que este tipo de estratégia requer UCs com grande capacidade e alta densidade de energia, para suportar os seguidos picos de corrente sem que a tensão atinja o limiar mínimo/máximo em um curto intervalo de tempo.

Na estratégia proposta, Fig. 5.2, é adicionado um termo (negativo) a corrente do UC. Este termo, por sua vez, é proporcional ao erro da tensão terminal e é processado através de um limitador e de um filtro passa-baixa, que possui como tarefa, limitar e atrasar o processo de restauração da tensão. Tal procedimento é necessário para que a restauração seja suave e somente possa ser iniciada após o fim do surto de corrente entregue pelo UC.

O uso desta técnica permite o uso de UC com reduzidas capacitâncias (menores que 1 F) sem a necessidade de parada para recuperação de tensão, uma vez que a tensão é continuamente restaurada. No entanto, recomenda-se o casamento das constantes de tempo da estratégia proposta, Fig. 5.2, de forma que a constante de tempo do restaurador seja maior ou igual à constante do filtro que gera a referência da bateria. Assim, a estrutura de controle nunca inicia a restauração do UC durante os surtos de corrente, ou seja, tal procedimento somente é iniciado após o final do transitório da bateria. 


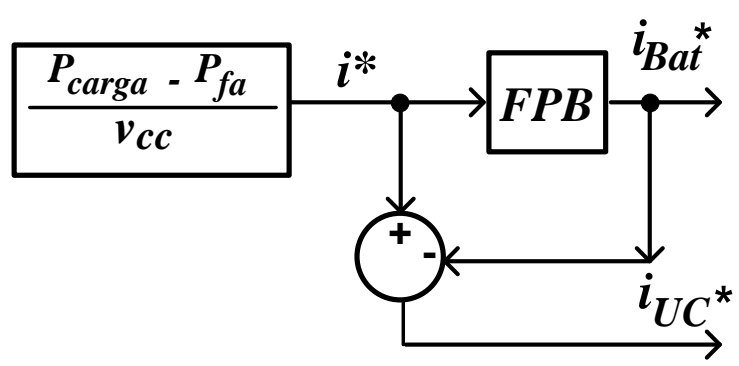

Figura 5.1 - Estratégia de gerenciamento proposta por [67].

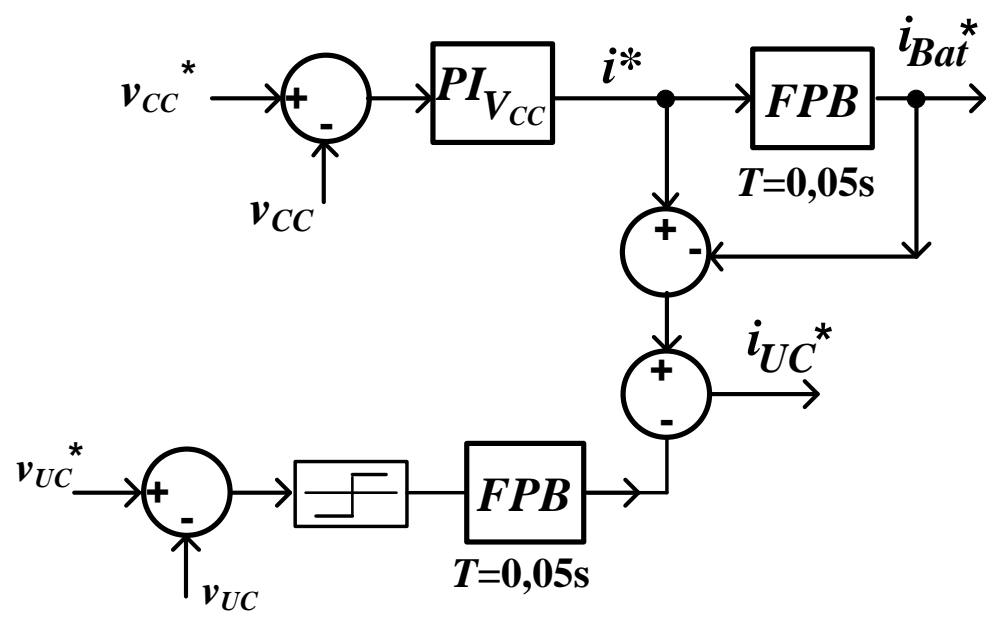

Figura 5.2 - Estratégia de gerenciamento proposto com restauração contínua da tensão terminal do UC.

A Fig. 5.3 mostra a inicialização da microrrede no modo de controle ilhado, ou seja, modo de controle em tensão. Juntamente com esta topologia de controle, é possível notar que o algoritmo PLL é capaz de sincronizar a tensão gerada pelo conversor e a tensão da rede de distribuição.

Nessa mesma figura, a amplitude da tensão produzida pelo conversor alcança o valor desejado em no máximo 2 ciclos enquanto que, o erro de fase é zerado em cerca de 10 ciclos de rede. Assim, conclui-se que o modo de controle em tensão é necessário na condição ilhada, pois a rede não se encontra presente, logo cabe ao inversor impor uma tensão com amplitude e frequência fixxa, além de gerar baixa distorção harmônica.

A Fig. 5.4 apresenta o momento da conexão física entre o $P A C$ e a rede, cujo modo de controle do inversor é alterado, passando a controlar a corrente (controlador em coordenadas $d q)$, diferentemente do acontecia no instante anterior no qual, o conversor era gerenciado em modo de controle de tensão (controlador em coordenadas $\alpha \beta$ ). $\mathrm{O}$ modo de controle em corrente passa a ser necessário neste instante, uma vez que as variáveis de interesse passam a ser a potências ativa e reativa fornecida à rede, o que é garantido pelo controlador de corrente em coordenada $d q$. 
De forma a avaliar o desempenho dos controladores da microrrede, uma série de eventos são produzidos e a estabilidade da mesma é colocada à prova. A Tabela 5.5 descreve os eventos gerados nos resultados das Figuras 5.5 a 5.11 .

TABELA 5.5

DESCRIÇÃO DE EVENTOS SIMULADOS

\begin{tabular}{cc}
\hline \hline Evento & Tempo $(\mathrm{s})$ \\
\hline Sistema conectado com $i_{d}^{*}=6 \mathrm{~A}$ & 0,0 \\
\hline Incremento de $i_{d}^{*}=6 \mathrm{~A}$ para $i_{d}^{*}=12 \mathrm{~A}$ & 0,9 \\
\hline Aumento da velocidade do vento de 12 para $14 \mathrm{~m} / \mathrm{s}$ & 2,2 \\
\hline Redução de $i_{d}^{*}=12 \mathrm{~A}$ para $i_{d}^{*}=8 \mathrm{~A}$ & 3,2 \\
\hline Redução de $i_{d}^{*}=8 \mathrm{~A}$ para $i_{d}^{*}=2 \mathrm{~A}$ & 4,2 \\
\hline \hline
\end{tabular}

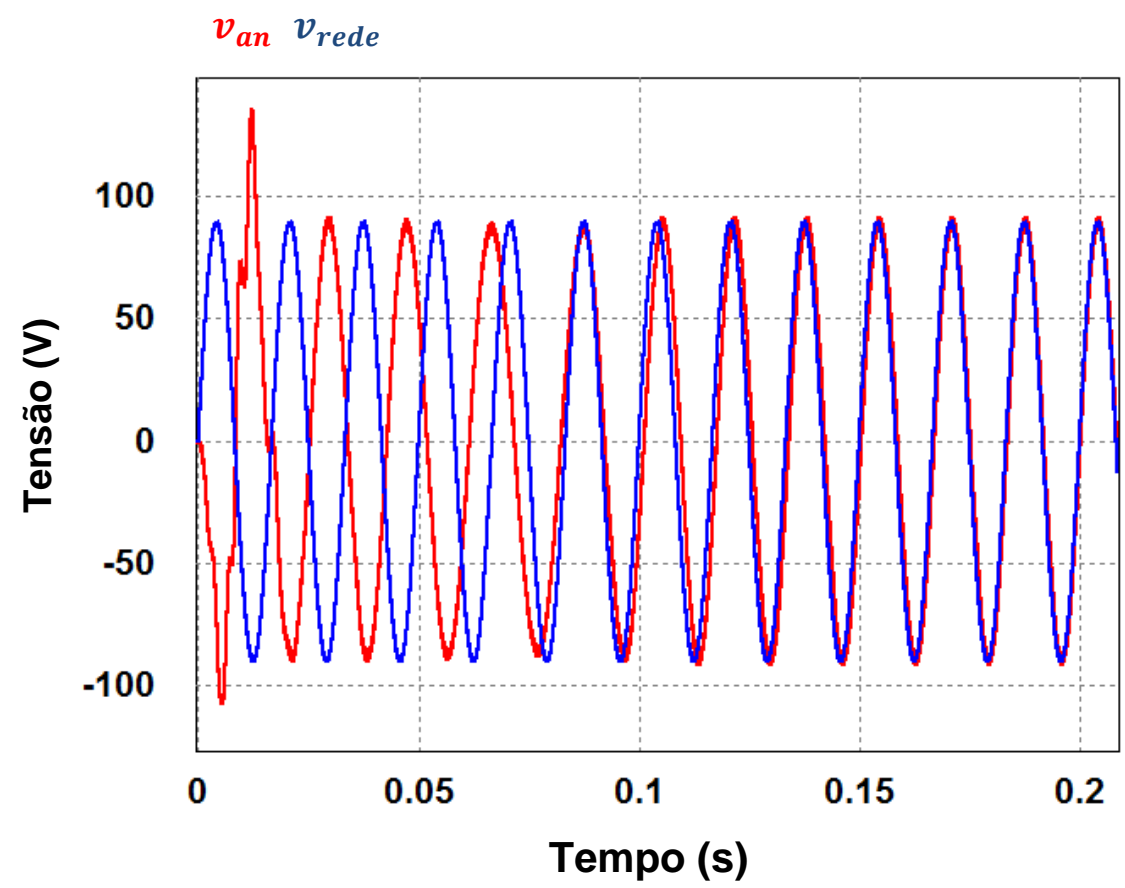

Figura 5.3 - Sincronização entre o VSI e a rede de distribuição ou sub transmissão.

Para analisar a versatilidade do algoritmo de gerenciamento sob diferentes pontos de operação ou "pacotes de potência” entregue à rede de distribuição, são realizadas rápidas transições nas amplitudes das correntes que circulam através das fases do inversor, Fig. 5.5 (apenas a corrente através da fase "A" $\left(i_{a}\right)$ do VSI é mostrada). Em termos de eventos, eles acontecem, especificamente, em 0,9 s com alteração da amplitude da corrente do inversor de 6 A para $12 \mathrm{~A}$, em 3,2 s de $12 \mathrm{~A}$ para $8 \mathrm{~A}$ e em 4,2 s de 8 A para $2 \mathrm{~A}$, respectivamente. 
Uma vez que a variação da corrente que circula através da rede distribuição cria um desequilíbrio na equação (3.7), é necessário que o mesmo seja compensado por outro elemento do circuito CC, neste caso pela bateria e pelo UC. Assim as perturbações produzidas pela corrente da rede de distribuição são transferidas aos armazenadores, que compensam as alterações de potência, Fig. 5.6.

Nota-se, ainda, que os picos gerados durante os transitórios são compensados pelo UC enquanto que, a potência média é fornecida pela bateria, ou seja, em regime permanente o UC fornece corrente nula para a rede de distribuição. Ao final do transitório, nota-se uma alteração suave no sentido da corrente do UC, para que este restaure sua tensão. Esta mudança no sentido da corrente é causada pela técnica de restauração da tensão (Fig. 5.2), absorvendo toda a energia fornecida por ele durante o transitório, Fig. 5.7, logo a energia média no UC é sempre constante em regime permanente.

A Fig. 5.8 mostra a potência de saída do grupo aerogerador, quando o mesmo é submetido a uma rajada de vento que altera a velocidade do vento de $12 \mathrm{~m} / \mathrm{s}$ para $14 \mathrm{~m} / \mathrm{s}$ no instante 2,2 s e, consequentemente, modifica a velocidade com que as pás giram. Novamente, pode-se notar que este desequilíbrio afeta a corrente dos armazenadores, que são os agentes responsáveis pela estabilidade do barramento, Fig. 5.6. Assim, a oscilação de potência produzida pelo aerogerador é toda transferida ao UC, que é encarregado dos eventos de alta velocidade, enquanto o excesso de energia gerado em regime é direcionado à bateria.

Na Fig. 5.8 é possível, também, observar a busca da máxima potência nos terminais do aerogerador imposta pelo algoritmo de busca do ponto de máxima potência durante o evento em análise (rajada de vento). De acordo com (3.5) e os parâmetros do modelo do aerogerador, espera-se uma potência máxima de 1000 W a 14 m/s e 629 W a 12 m/s, conforme análise da Fig. 5.8.

Além de refletirem sua influência sobre os armazenadores, todos os eventos citados, também, produzem oscilações no barramento $\mathrm{CC}$, que podem ser vistas na Fig. 5.9, cujas oscilações máximas chegam a $20 \mathrm{~V}$ de sobressinal para situações críticas, como variações em degrau da potência injetada na rede de distribuição. 


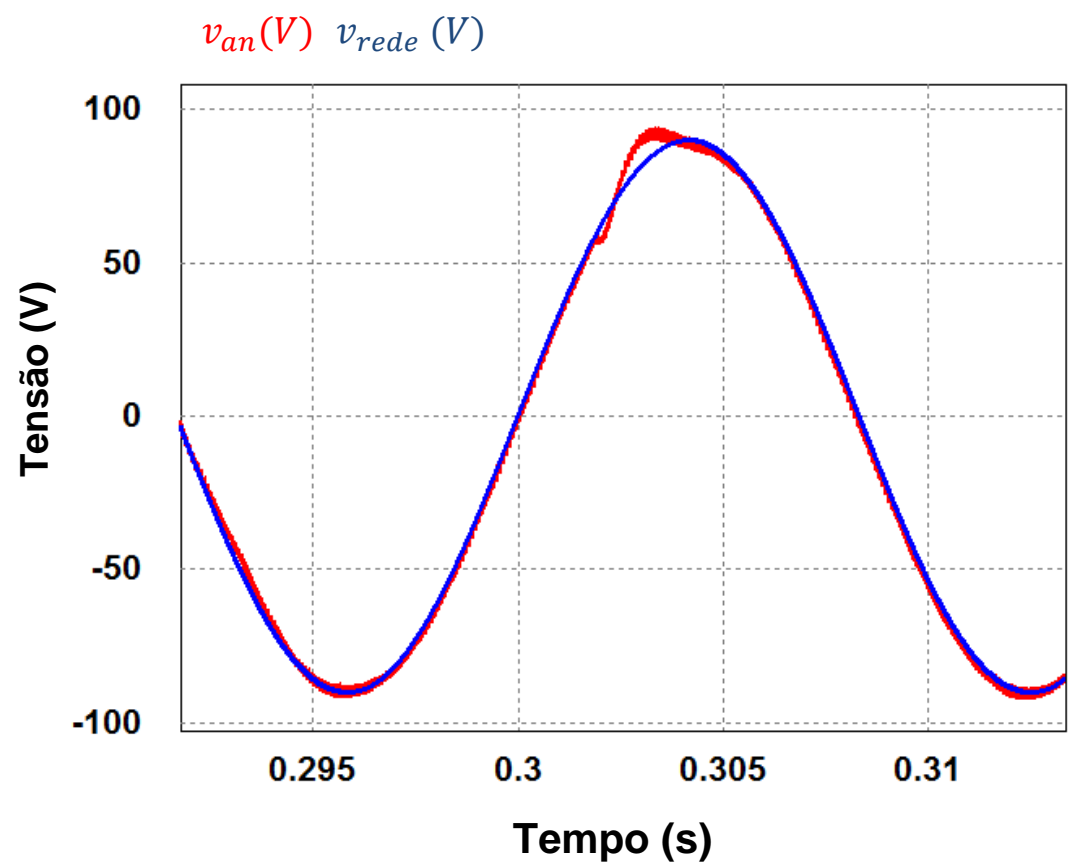

Figura 5.4 - Tensão do VSI e da rede de distribuição no momento da conexão.

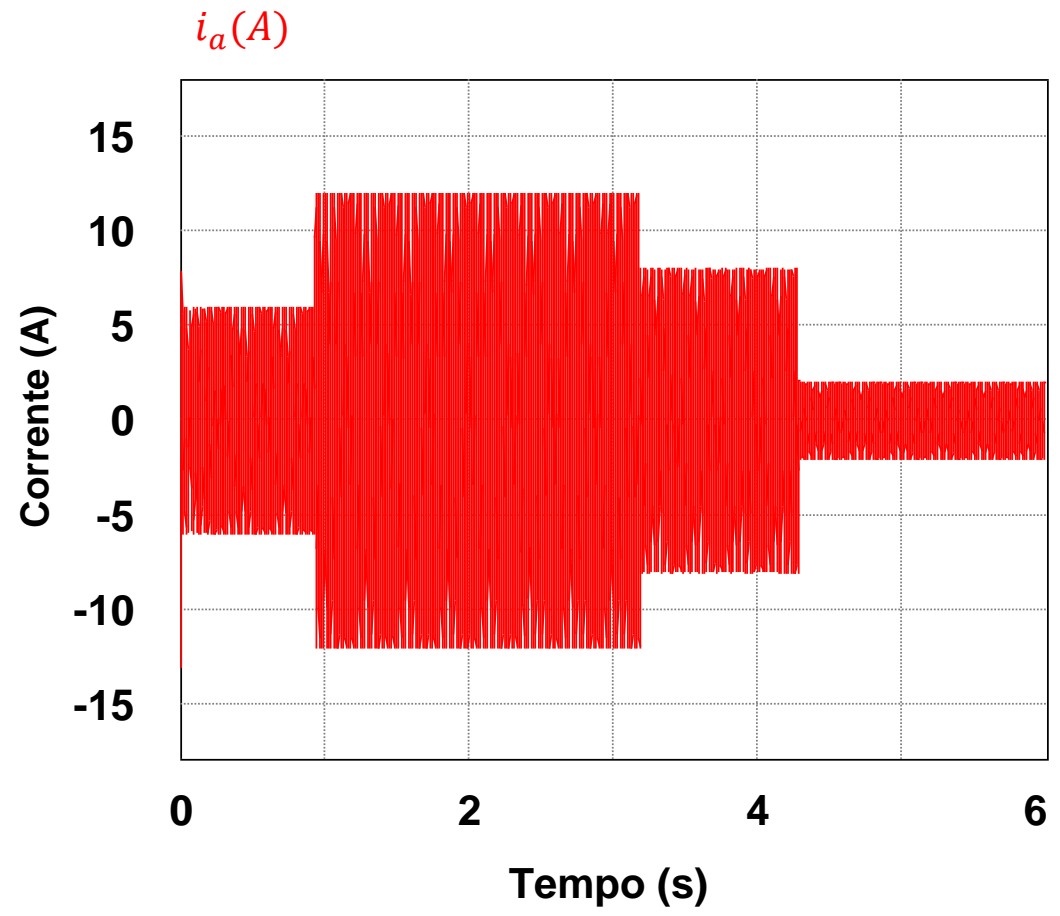

Figura 5.5 - Corrente na fase “A” do inversor durante os transitórios. 


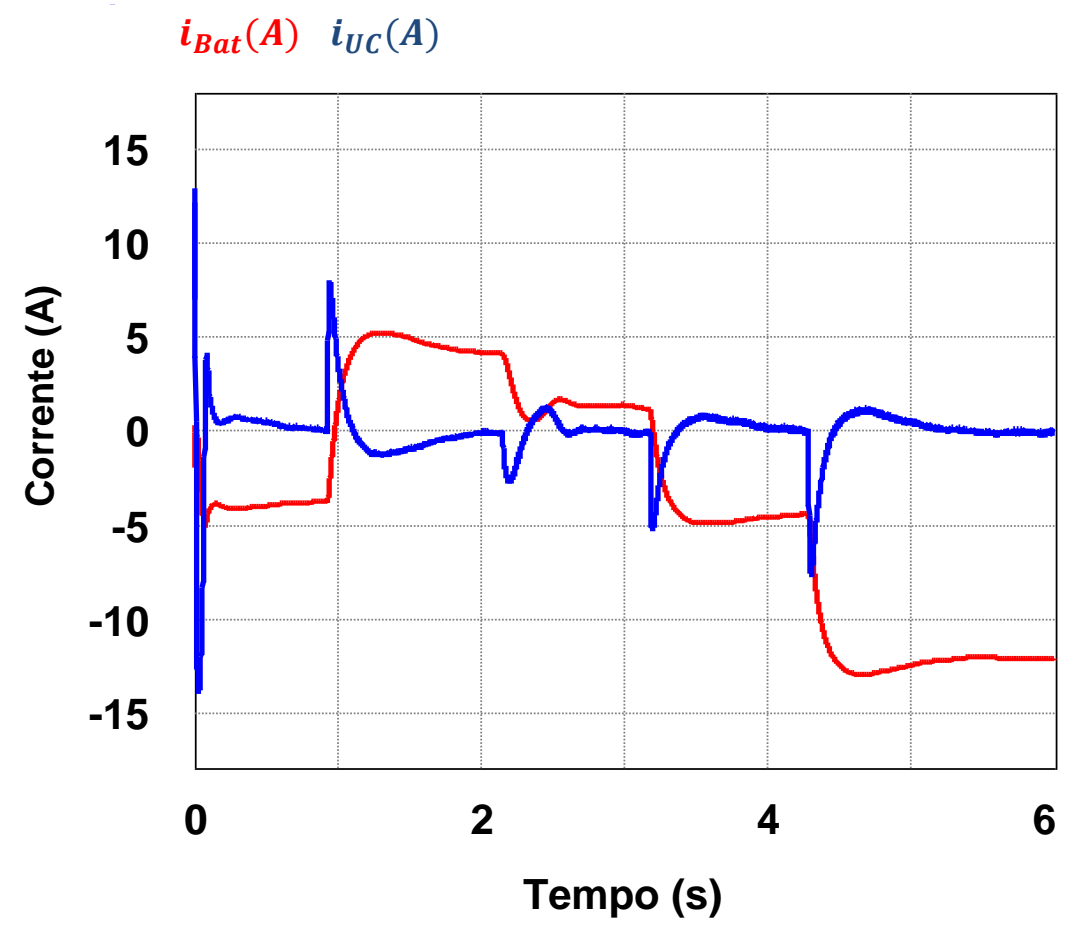

Figura 5.6 - Corrente da bateria e do UC.

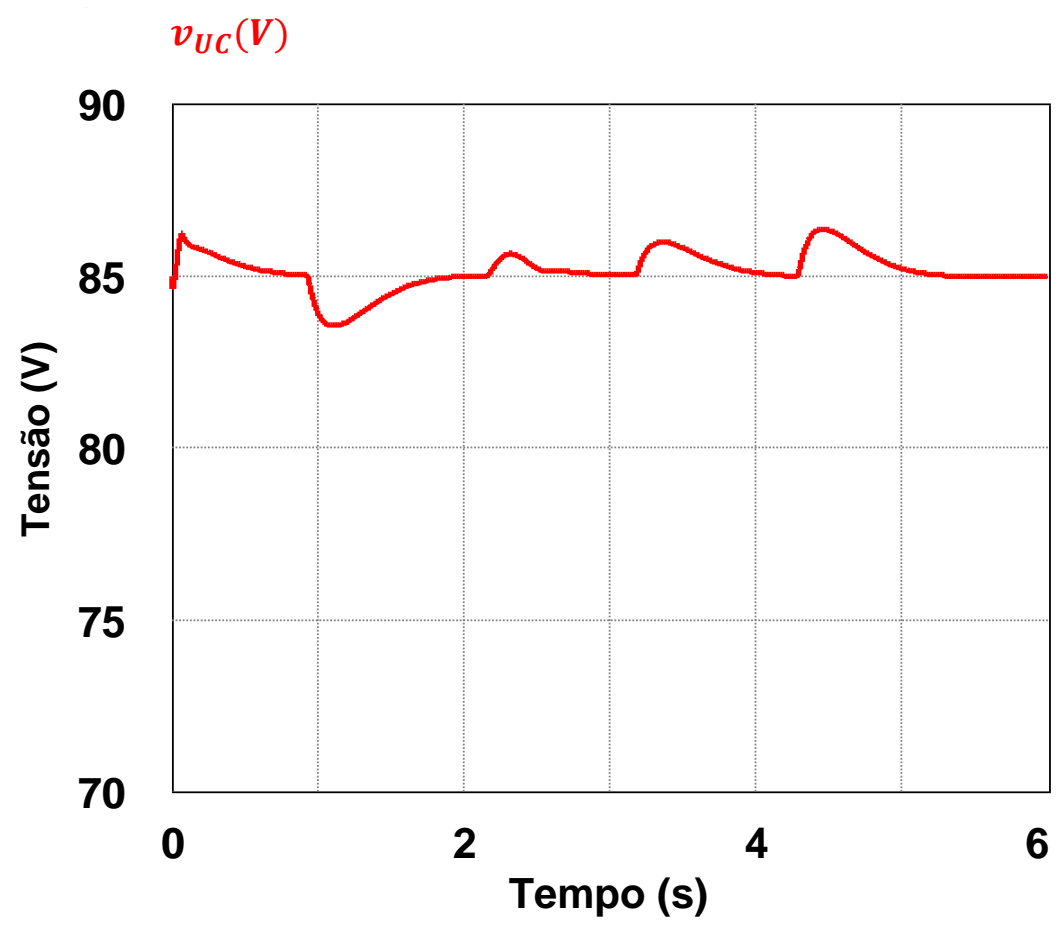

Figura 5.7 - Tensão terminal do UC sendo restaurada pela estratégia proposta. 


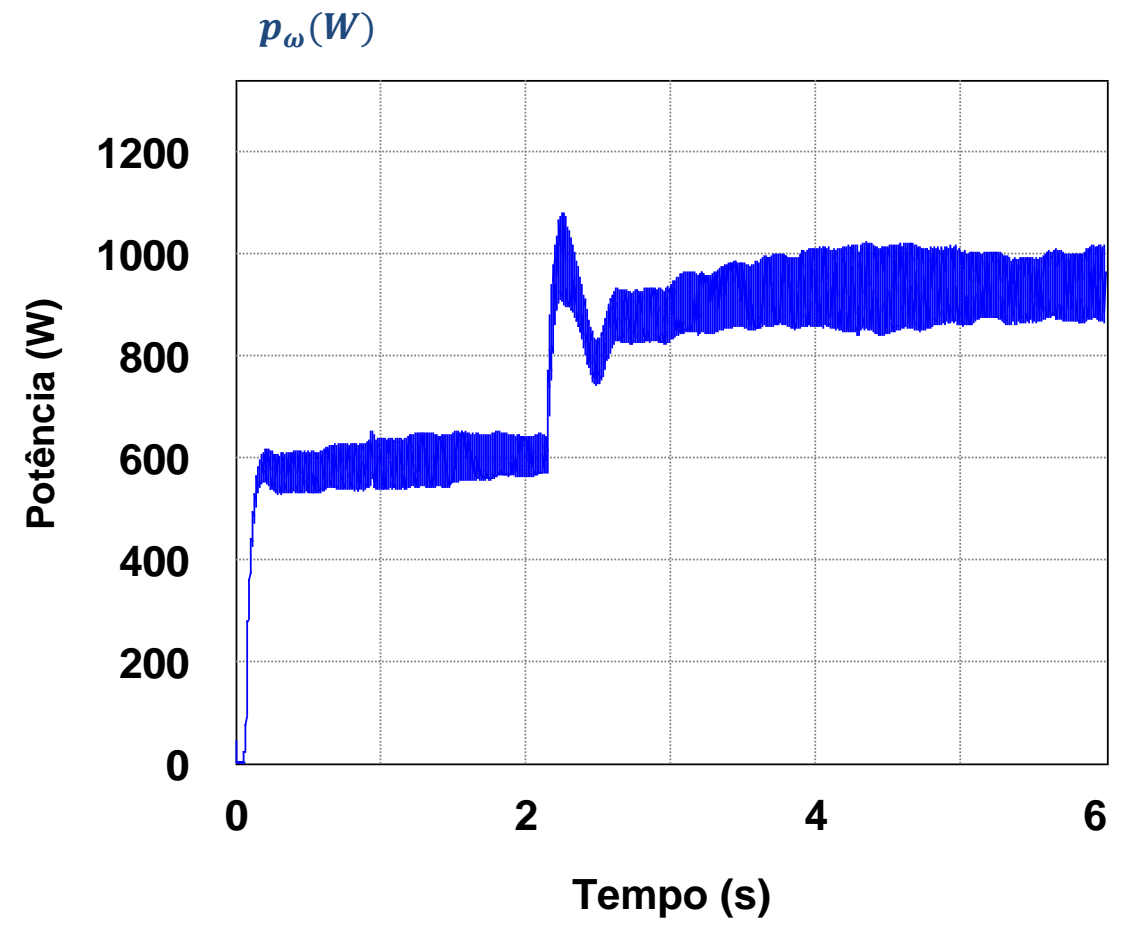

Figura 5.8 - Potência de saída do aerogerador.

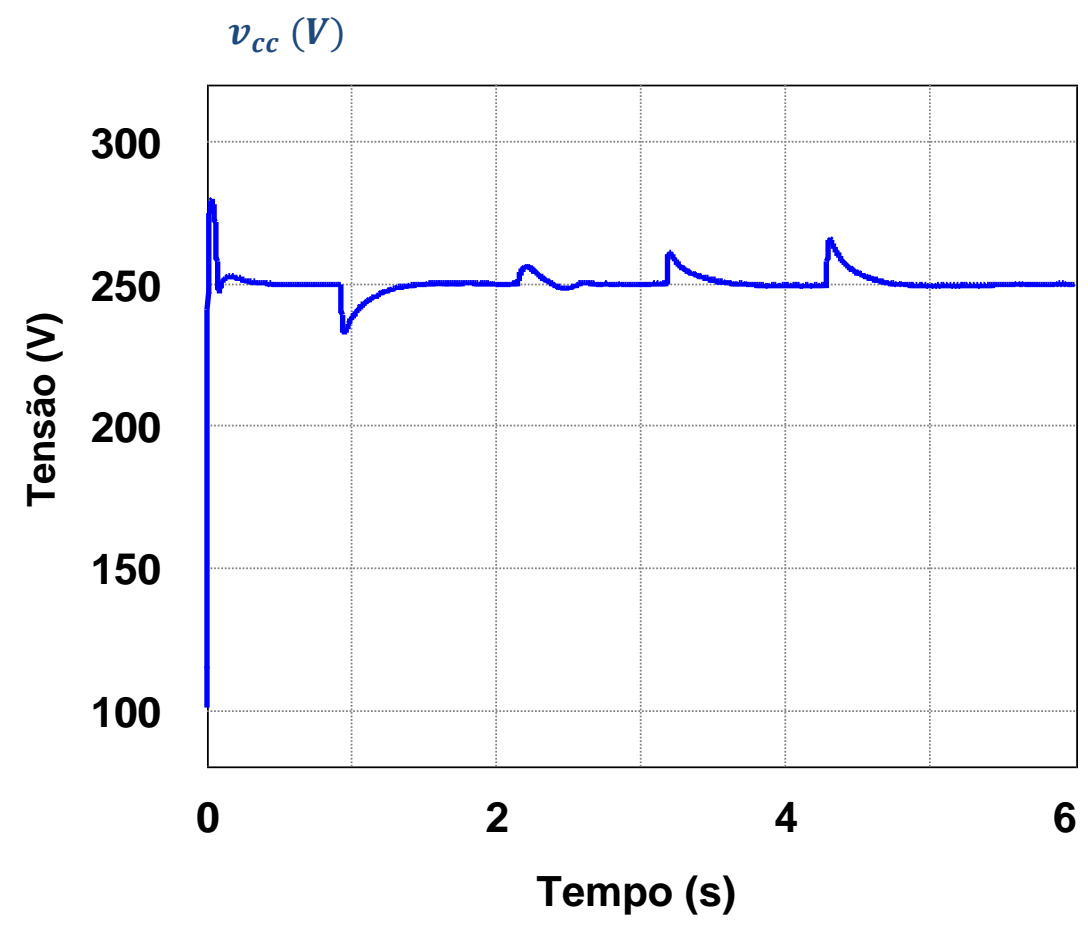

Figura 5.9 - Tensão do barramento CC durante os eventos.

As Figuras 5.10 e 5.11 mostram a potência produzida pelos painéis fotovoltaicos e tensão em seus terminais, respectivamente. Nessas figuras, pode-se observar o algoritmo buscando ponto de máxima potência $\left(V_{m p}=76 \mathrm{~V}\right.$ e $\left.P_{m p}=600 \mathrm{~W}\right)$. 


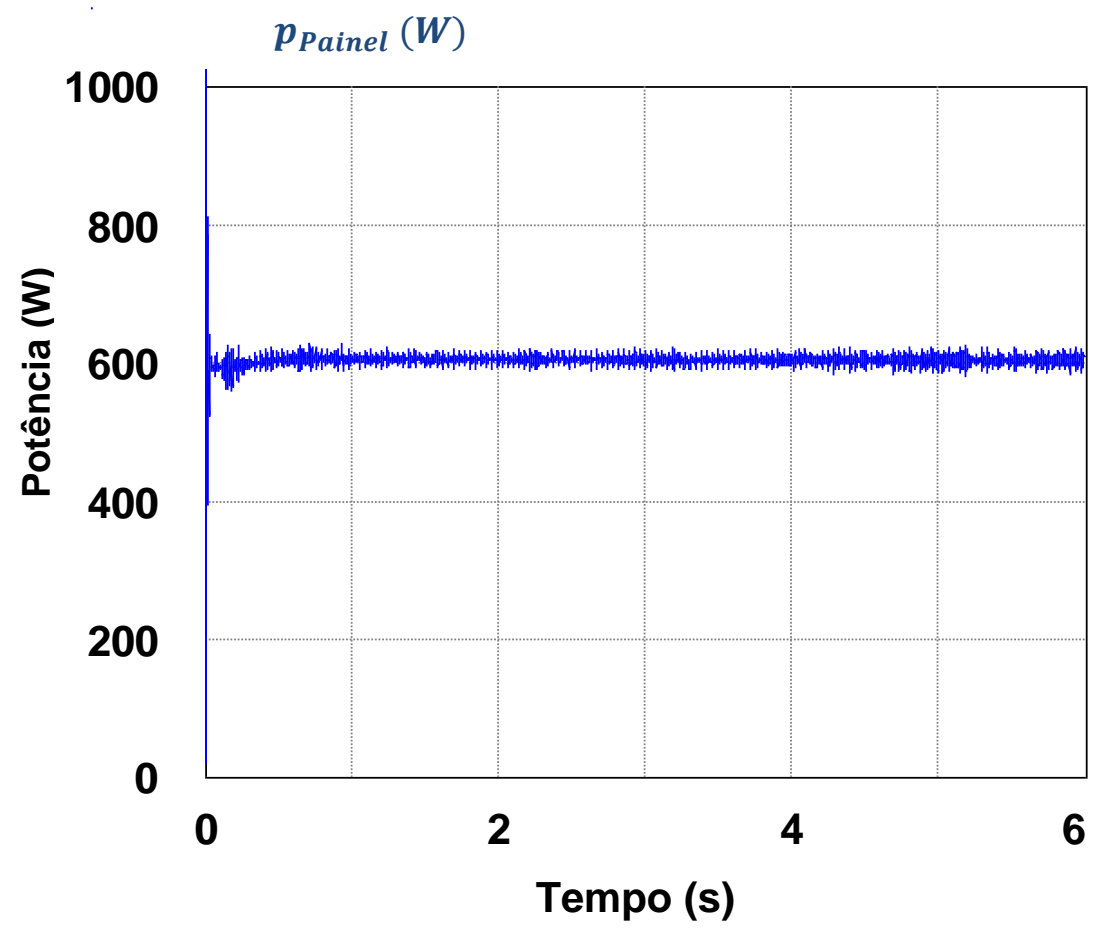

Figura 5.10 - Potência de Saída do conjunto PV sob irradiação solar constante.

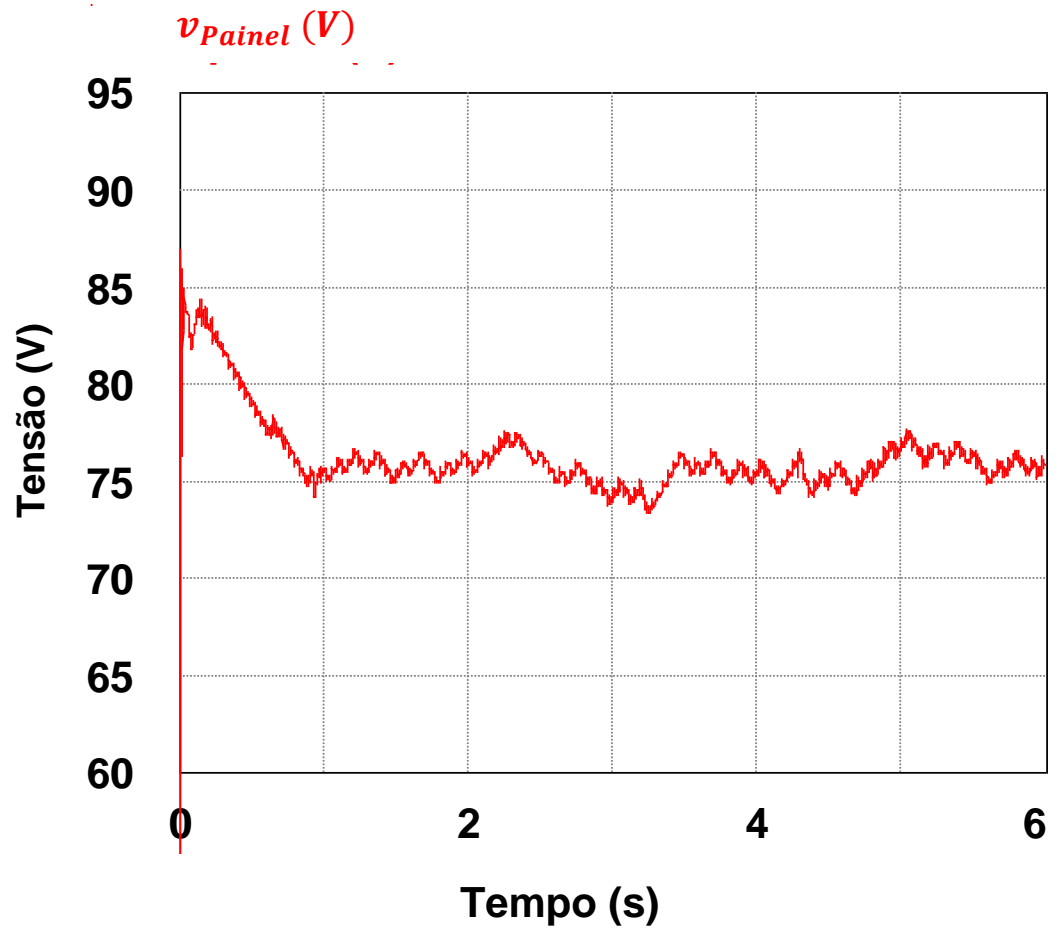

Figura 5.11 - Tensão de saída do conjunto PV sendo controlado pelo algoritmo de busca MPPT P\&O. Irradiação solar ajustada constante em $1000 \mathrm{~W} / \mathrm{m}^{2}$ e $V_{m p}=76 \mathrm{~V}$. 


\subsection{Considerações Finais do Capítulo 5}

Nesta seção foi mostrado o funcionamento e a dinâmica da microrrede com a integração de fontes alternativas, provando que esta topologia é estável e possível de ser controlada, mesmo durante eventos críticos nas fontes alternativas e na rede. Foram testadas variações na produção de energia e corrente entregue à rede e mesmo assim a microrrede se manteve estável, além de manter as fontes alternativas operando junto ao ponto de máxima potência. As oscilações do barramento CC, mesmo em situação crítica (dobrando a corrente entregue à rede de distribuição), se mantiveram com um sobressinal inferior a $10 \%$. A técnica de restauração contínua do UC se mostrou efetiva, evitando que a tensão terminal se desviasse do seu valor de referência, mantendo dessa forma, a energia média nos UC constante. 


\section{Capítulo 6}

\section{Sistema Híbrido Descentralizado com Divisão de Carga entre UC e Bateria}

\subsection{Descrição e Motivação}

No capítulo anterior foi discutida e apresentada uma nova técnica de divisão de carga entre UC e bateria, Fig. 5.2. Contudo, assim como outras técnicas de divisão de carga, os dispositivos armazenadores se comunicam entre si e as ações tomadas por cada um são decididas por uma única central processadora, que conhece os estados e variáveis de todos os componentes da microrrede em análise formando assim, um sistema de gerenciamento centralizado.

Entretanto, este modelo apresenta limitações à medida que as microrredes $\mathrm{CC}$ tendem a se expandir, uma vez que todos os dispositivos deverão se comunicar em altíssima velocidade. Logo, surge a necessidade de fazer com que os dispositivos armazenadores façam esta divisão de carga de forma a exigir o mínimo de comunicação possível. Assim, neste capítulo serão apresentadas duas novas estratégias descentralizadas de divisão de carga que têm como objetivo dividir a carga entre ultracapacitores e baterias sem a presença de uma rede de comunicação de alta velocidade.

No caso de várias baterias e UCs conectados ao barramento, busca-se a equalização energética das baterias e restauração da tensão terminal dos UCs. A primeira técnica apresentada utiliza o desvio de tensão do barramento como sinal de divisão de carga entre os armazenadores enquanto, na segunda técnica proposta, a tensão do barramento é sempre restaurada ao valor predefinido.

\subsection{Estado da Arte}

Várias pesquisas foram feitas nos últimos anos a respeito do gerenciamento de microrredes, especialmente em sistemas híbridos, ou seja, contendo UC e baterias, sem que haja comunicação de alta velocidade entre eles. Entretanto, nenhuma destas pesquisas realiza a divisão de carga (UC responsável pelos transitórios e regime permanente a cargo das baterias), 
equalização de várias baterias, restauração da tensão terminal dos UCs e restauração do barramento $\mathrm{CC}$ ao mesmo tempo.

Em [68] os autores apresentam uma estrutura de controle droop para gerenciar a divisão de carga entre baterias, equalizar as mesmas e impor a restauração do barramento CC. No entanto, ela não trata de nenhum sistema híbrido, no qual há a presença de UCs e baterias. Desta forma, todos os picos de potência são fornecidos pelas baterias, o que impacta na vida útil das mesmas.

Em [69, 70] os autores propõem uma estrutura de controle para o gerenciamento descentralizado, utilizando o desvio da tensão do barramento como sinal de divisão de carga e sacrificando a restauração da tensão. Entretanto, assim como em [68], os autores não consideram uma microrrede híbrida, com a presença de UCs e baterias, requisitando da bateria todo o esforço nos transitórios.

Já em [67, 71, 72] é analisada uma microrrede híbrida contendo UCs e baterias, além da restauração do barramento CC. Contudo, eles fazem uso de uma estratégia centralizada de gerenciamento, utilizando comunicação de alta velocidade entre os armazenadores. Além disso, a restauração dos UCs é feita através de um sistema on-off, como em [67], que aciona um algoritmo de restauração apenas quando um limiar de tensão é atingido. Este método de restauração cria vulnerabilidade à estabilidade da microrrede, uma vez que a restauração inibe as demais funções exercidas pelo UC e faz com que seja necessário o uso de capacitores de elevada capacidade para evitar as paradas de restauração em um pequeno intervalo de tempo.

Baseado nos argumentos citados acima, nota-se que uma estratégia híbrida com UCs e baterias que realize a divisão de carga (transitórios de carga suprido pelo UC e o regime permanente fornecido pela bateria), equalização das baterias, restauração dos UCs e restauração do barramento seria de grande valia e um importante passo para o desenvolvimento das microrredes CC.

\subsection{Modelo Matemático do Sistema Eletrônico}

Nas seções 5.1, a microrrede em estudo foi simulada utilizando o modelo eletrônico chaveado, isto foi feito pois tinha-se a necessidade de avaliar o desempenho e estabilidade dos circuitos conversores e controladores projetados. Assim, para o presente capítulo, optou-se por uma modelagem média dos conversores, sem a necessidade de alto poder de processamento, o que reduz a complexidade das simulações em comparação àquelas realizadas via modelos chaveados. Outro motivo para o uso de modelos médios é a possibilidade de verificação de 
quão precisos são estes modelos em relação aos resultados experimentais, que serão apresentados nos próximos capítulos.

A Fig. 6.1 mostra o circuito eletrônico considerado na execução do modelo médio de uma microrrede híbrida com dois UCs, duas baterias e um conjunto de fontes alternativas representadas por uma fonte de corrente $\left(i_{f a}\right)$. Tal simplificação somente é possível devido ao fato das fontes alternativas utilizadas (na microrrede) serem gerenciadas pelo algoritmo de busca de ponto de máxima potência e pela estrutura de controle que regula a tensão terminal no caso dos painéis fotovoltaicos ou a velocidade no caso do gerador eólico, ou seja, essa dupla malha de gerenciamento e controle faz com que elas adquiram a característica de fonte de corrente, tornando $i_{f a}$ diretamente proporcional à potência produzida por elas.

Já a Fig. 6.2 mostra os circuitos eletrônicos dos conversores bidirecionais dos UCs e baterias utilizados no modelo médio para se obter as equações (6.1) a (6.4). Colocando-as na forma de (6.5) e rescrevendo na forma matricial (6.6), obtém-se o modelo em espaço de estados conforme visto na Fig. 6.1. Este modelo, em espaços de estado, será utilizado nas próximas seções para simular o comportamento deste circuito quando comando pelas técnicas propostas que serão apresentadas em seguida.

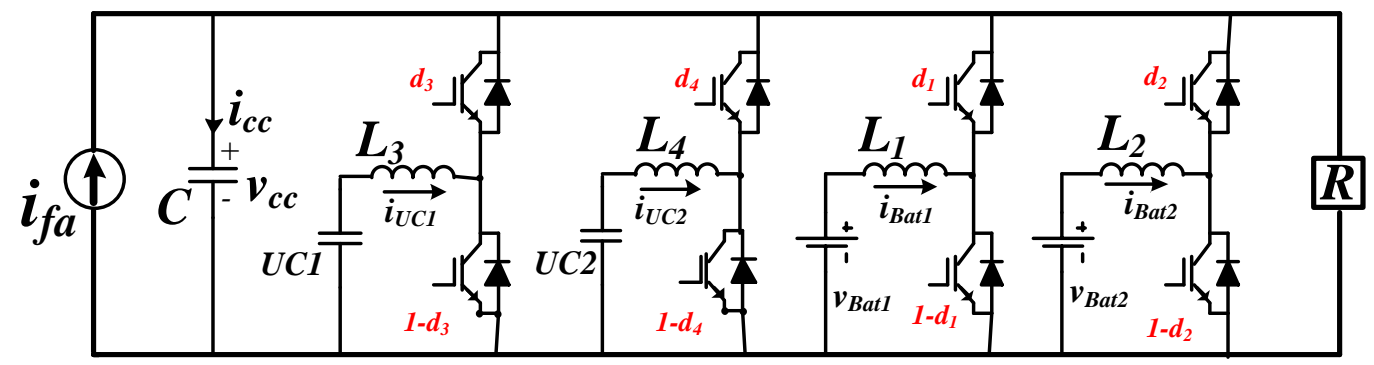

Figura 6.1 - Circuito eletrônico considerado no modelo da microrrede com UC e bateria.

$$
\begin{gathered}
\left\{\begin{array}{c}
\frac{d i_{U C 1}}{d t}=\frac{v_{U C 1}}{L_{3}}-\frac{R_{L 3}}{L_{3}} i_{U C 1}-\frac{v_{C C}}{L_{3}} d_{3} \\
\frac{d i_{U C 2}}{d t}=\frac{v_{U C 2}}{L_{4}}-\frac{R_{L 4}}{L_{4}} i_{U C 2}-\frac{v_{C C}}{L_{4}} d_{4}
\end{array}\right. \\
\left\{\begin{array}{l}
\frac{d i_{B a t 1}}{d t}=\frac{v_{B a t 1}}{L_{1}}-\frac{R_{L 1}}{L_{1}} i_{B a t 1}-\frac{v_{c c}}{L_{1}} d_{1} \\
\frac{d i_{B a t 2}}{d t}=\frac{v_{B a t 2}}{L_{2}}-\frac{R_{L 2}}{L_{2}} i_{B a t 2}-\frac{v_{C c}}{L_{2}} d_{2}
\end{array}\right. \\
\left\{\begin{array}{l}
\frac{d v_{U C 1}}{d t}=-\frac{i_{U C 1}}{U C_{1}} \\
\frac{d v_{U C 2}}{d t}=-\frac{i_{U C 2}}{U C_{2}}
\end{array}\right.
\end{gathered}
$$




$$
\begin{gathered}
\frac{d_{v_{c c}}}{d t}=-\frac{v_{c c}}{R C}+\frac{i_{f a}}{C}+\frac{i_{B a t 1}}{C} d_{1}+\frac{i_{B a t 2}}{C} d_{2}+\frac{i_{U C 1}}{C} d_{3}+\frac{i_{U C 2}}{C} d_{4} \\
\dot{\boldsymbol{x}}=\boldsymbol{A} \boldsymbol{x}+\boldsymbol{B u}
\end{gathered}
$$
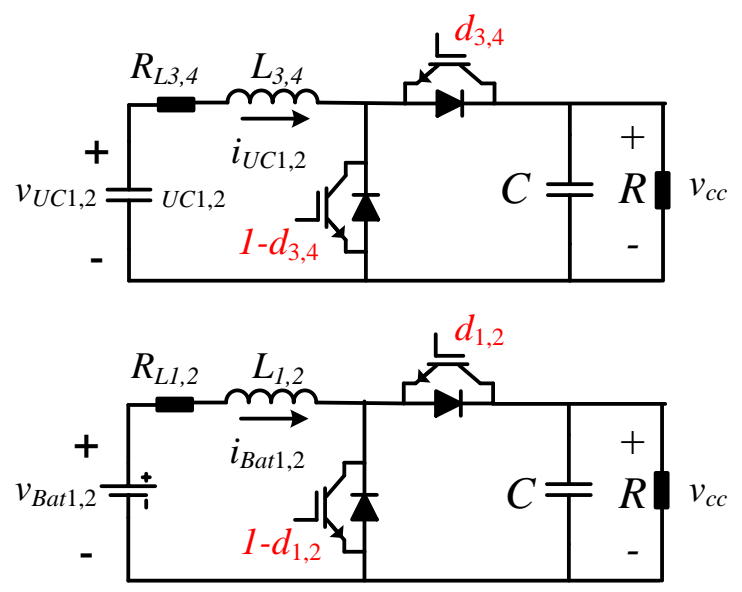

Figura 6.2 - Circuito eletrônico dos conversores bidirecionais dos UCs e baterias, respectivamente.

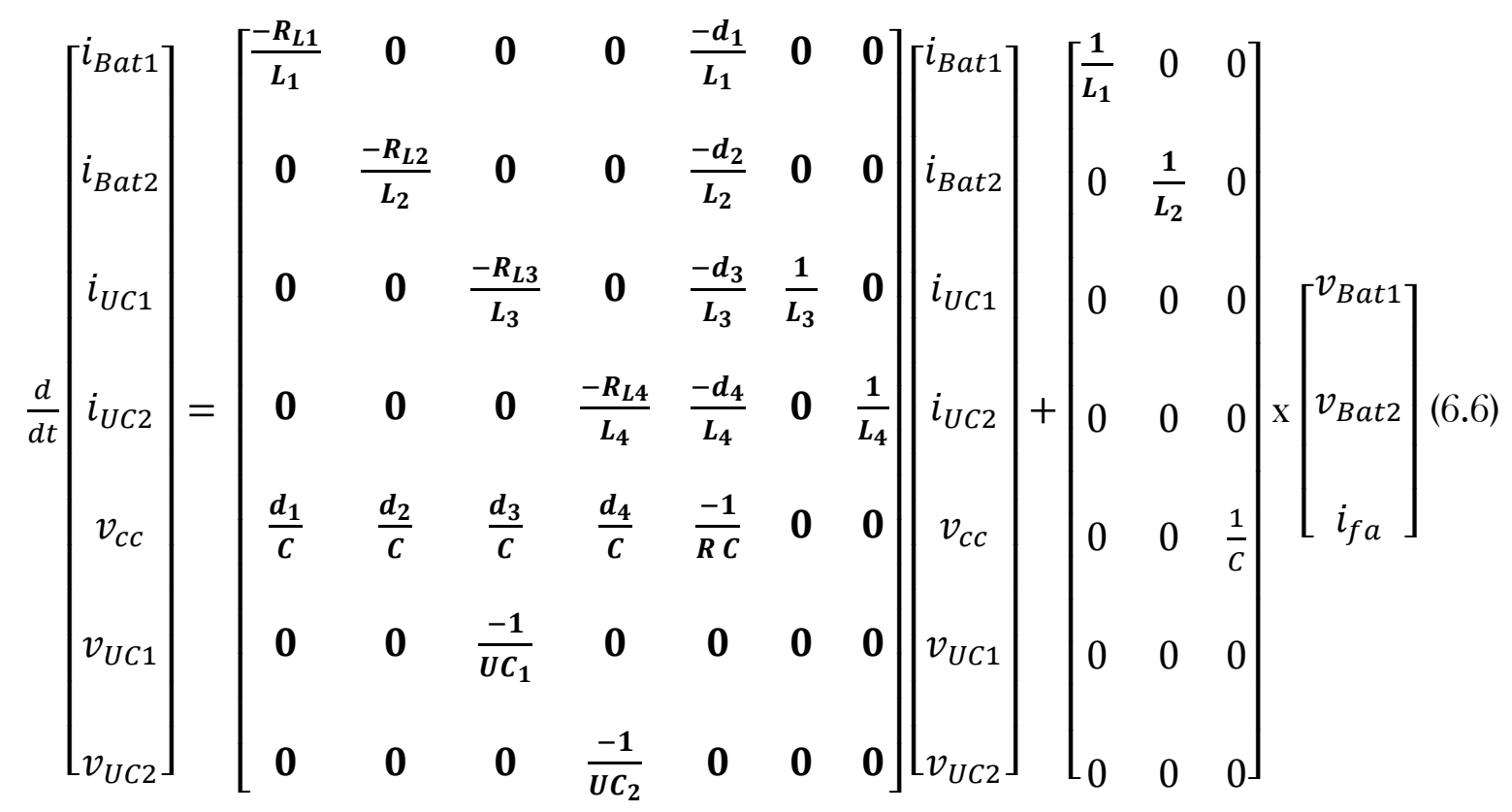

\subsection{Controle Descentralizado para Microrrede}

\section{Híbrida - sem Restauração do Barramento CC}

A primeira técnica proposta para divisão de carga a ser implementada em uma microrrede híbrida e com controle descentralizado tem como objetivo fazer com que os 
transitórios de alta velocidade sejam absorvidos/supridos pelos UCs e o regime permanente pelas baterias.

Além da divisão de carga, será realizada restauração da tensão terminal dos UCs e a equalização de carga das baterias da microrrede, sem a necessidade de comunicação de alta velocidade entre armazenadores, Fig. 6.3, ou seja, assim como discutido em [69, 70], o meio de comunicação entre os armazenadores é o desvio de tensão no barramento CC. Logo, quanto maior for a quantidade de potência exigida pelas cargas, maior será o desvio de tensão no barramento CC, porém conforme visto na seção 6.2, os autores de [70, 69] não apresentam nenhum tipo de solução para uma microrrede híbrida que combine UCs e baterias.

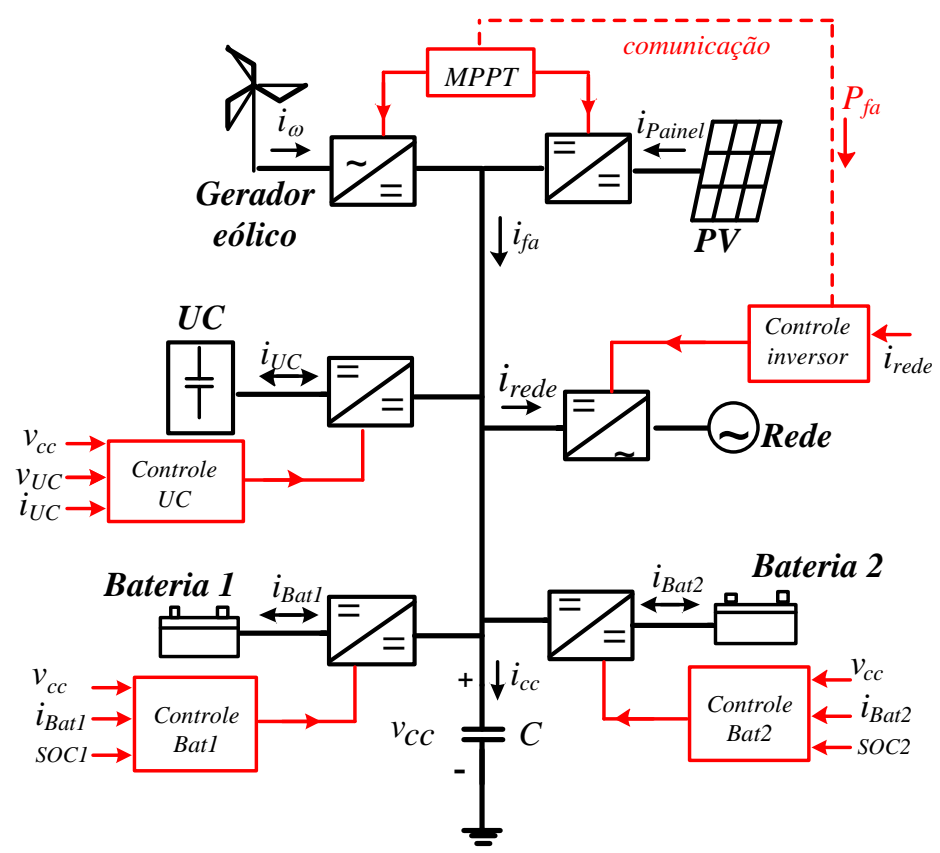

Figura 6.3 - Microrrede com sistema descentralizado de controle onde os armazenadores não se comunicam.

As Fig. 6.4 e 6.5 apresentam as malhas de controle dos UCs e baterias, respectivamente. Nota-se que ambos são dependentes do erro proporcional da tensão do barramento CC, sendo que para a malha de controle dos UCs o erro é processado através de um filtro passa-alta (FPA) e nas baterias por um passa-baixa $(F P B)$. Graças à presença dos filtros e às características dinâmicas e de regime permanente de cada um deles, os transitórios podem ser compensados pelos UCs enquanto que, o regime permanente é suprido pelas baterias, uma vez que o $F P A$ dos UCs só permite a compensação do erro transitório do barramento, enquanto que o $F P B$, no controlador da bateria, o erro de regime permanente. 


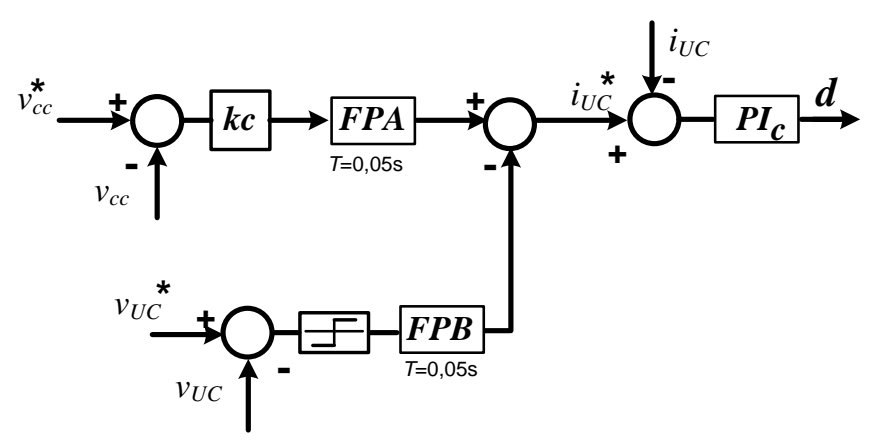

Figura 6.4 - Técnica de controle dos UCs.

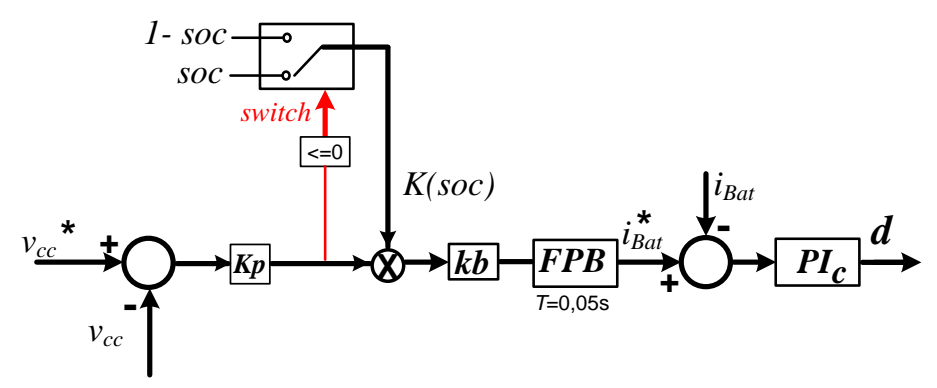

Figura 6.5 - Técnica de controle das baterias.

Para a restauração da tensão dos UCs, assim como apresentado no Capítulo 5, a referência de corrente dos UCs é reajustada filtrando o erro de tensão através de um FPB, Fig. 6.4. A filtragem atrasa a restauração e faz com que este processo seja suave e lento, apenas agindo ao final dos picos de corrente supridos ou absorvidos pelo UC.

O ganho $k c$, mostrado na técnica, faz o escalonamento das correntes em uma microrrede com um número de UC superior a um. Logo, o UC com maior capacitância apresenta um $k c$ maior, fazendo com que este entregue uma maior quantidade de corrente do que aqueles que possuem menor capacitância.

De forma resumida, quando um transitório ocorre no barramento CC, o FPA gera uma referência em forma de pico transitório, que é imposto aos UCs por $P I_{C}$. Assim que o transitório é finalizado e a saída do $F P A$ se aproxima de zero, o $F P B$ do restaurador de tensão inverte a da corrente de referência produzida antes do evento, o que recupera a tensão terminal do UC lentamente, até que esta corrente retorne a zero e o capacitor esteja pronto para um novo transitório.

Similarmente a [68] e [73], a equalização das baterias é feita pela inclusão de um ganho proporcional ao estado de carga de cada uma delas, contudo, nas referências citadas acima a equalização é feita de forma centralizada, ou seja, cada bateria sabe o estado das demais. Assim, 
a bateria com maior quantidade de energia armazenada, supre uma corrente maior do que as demais quando em descarga e menor corrente, quando em carga.

Na técnica proposta, este comportamento é alcançado de forma descentralizada, ou seja, multiplicando o ganho proporcional $K p$ pelo estado de carga normalizado $(S O C)$ quando em descarga, e por (1-SOC) quando em carga, Fig. 6.5. Desta forma, independentemente de uma bateria saber ou não o estado de carga das demais, a bateria que possui uma maior quantidade de energia armazenada fornecerá maior nível de corrente uma vez que, o seu ganho $K($ soc) é maior.

A Fig. 6.6 apresenta a influência do estado de carga na divisão de carga entre baterias com diferentes $S O C$. Suponha que existam apenas duas baterias na microrrede, Bat1 e Bat2, tendo a primeira um $S O C 1=0,6$ e a segunda $S O C 2=0,3$. Caso a microrrede esteja em modo descarga das baterias $\left(v_{c c 2}<v_{c c}{ }^{*}\right)$, o controlador da Bat1 terá uma ação proporcional de valor 0,6 Kp enquanto que Bat2 uma ação 0,3Kp. Logo, a Bat1 entregará uma corrente (duas vezes) superior do que Bat2 irá fornecer.

Entretanto, caso a microrrede esteja em uma situação de carga $\left(v_{c c 1}>v_{c c}{ }^{*}\right)$ Bat1 terá uma ação -0,3Kp enquanto Bat2 uma ação $-0,6 K p$, fazendo com que Bat2 absorva uma maior quantidade de energia. Com esta dinâmica, os estados de carga de todas as baterias tendem a convergir para o mesmo ponto, além de que uma bateria específica em operação na microrrede não necessita conhecer o $S O C$ das demais.

Já o ganho $k b$ tem como função escalonar os ganhos dos diferentes controladores caso as baterias tenham capacidade diferentes. Logo, se uma bateria possui o dobro da capacidade das demais, faz-se $k b=2$ para a maior bateria e $K b=1$ para as demais, assim mesmo que elas tenham estados de carga iguais a bateria com maior capacidade entregaria uma corrente duas vezes superior ao que seria entregue pelas outras baterias, de forma a mantê-las equalizadas.

Em suma, a referência de corrente para as baterias é obtida por um controlador proporcional com ganho escalonado pelo $S O C$, sendo então processada por um $F P B$, que retarda o crescimento da corrente de referência de forma a proteger a bateria contra surtos de corrente, que são produzidos pelos UCs. É somente então, que a referência de corrente pode ser comparada com a corrente medida e processada pelo $P I_{c}$ que foi projetado e apresentada no Capítulo 4 e testado no Capítulo 5.

Entretanto esta técnica apresenta deficiências caso o $S O C$ de todas as baterias seja muito elevado/reduzido, o que resulta em um $K(s o c)$ reduzido. No caso de todas as baterias apresentarem um $S O C$ muito baixo, durante as descargas o ganho proporcional $K p$ é 
multiplicado por um $K(s o c)$ reduzido, fazendo com que o desvio de tensão no barramento seja grande em relação à referência.

Caso todas as baterias tenham $S O C$ elevado, o aumento no desvio se dará em modo de carga, uma vez que o ganho proporcional é multiplicado por 1-SOC. Desta forma, para evitar altos desvios de tensão nos extremos do $S O C$, o ganho $K(S O C)$ pode ser limitado para que não produza valores muito reduzidos. Contudo, a limitação deste ganho irá interferir na equalização das baterias quando na região de limitação.

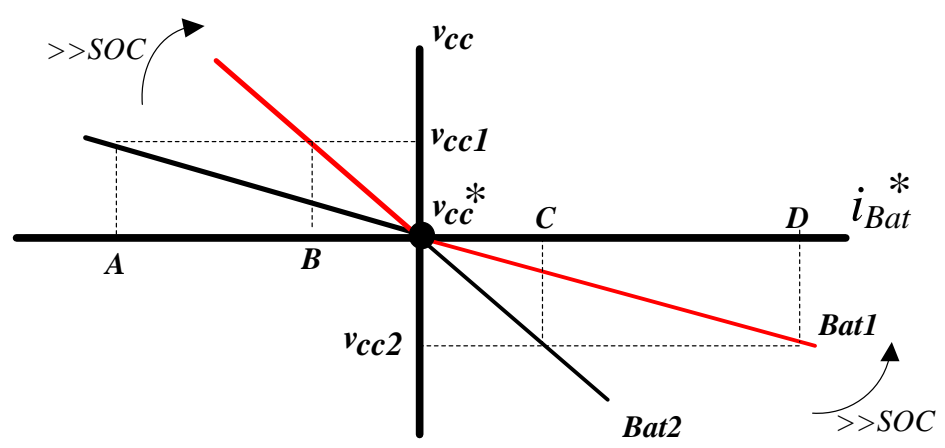

Figura 6.6 - Representação gráfica da influencia do SOC na divisão de carga.

\subsubsection{Resultados Simulados}

De forma a comprovar o desempenho da metodologia proposta, o modelo médio (6.6) é acionado pelas técnicas de controle propostas das Fig. 6.4 e 6.5 e os resultados simulados apresentados nas Fig. 6.7 a 6.11 . A Tabela 6.1 mostra os valores usados na parametrização do modelo médio e dos controladores.

A Fig. 6.7 mostra o padrão de corrente gerado pelas fontes alternativas $\left(i_{f a}\right)$ e a resposta de produzida pelos armazenadores $\left(i_{B a t}+i_{U C}\right)$ devido ao desequilíbrio instantâneo de corrente ou potência criado pelas fontes alternativas. Nota-se que o degrau de corrente criado por $i_{f a}$ é compensado pelos armazenadores, mantendo o equilíbrio de potência no barramento CC.

Assim como apresentado na descrição dos controladores, de forma a entregar uma maior quantidade de potência, a tensão do barramento deve ser desviada do valor de referência, como pode ser visto na Fig. 6.8. O ganho $K p$ da técnica de controle das baterias pode ser aumentado para reduzir o desvio de tensão, contudo este aumento gera impactos na estabilidade do sistema, como será discutido mais a frente. 
TABELA 6.1

PARÂMETROS DO MODELO SIMULADO

\begin{tabular}{cc}
\hline \hline Símbolo & Valor \\
\hline$L_{3}=L_{4}$ & $2 \mathrm{mH}$ \\
$L_{1}=L_{2}$ & $10 \mathrm{mH}$ \\
$U C 1$ & $0,4 \mathrm{~F}$ \\
$U C 2$ & $0,2 \mathrm{~F}$ \\
$V_{\text {Bat } 1 \text { e } V_{\text {Bat } 2}}$ & $75 \mathrm{~V}$ \\
$V_{U C}^{*}$ & $85 \mathrm{~V}$ \\
$V_{c c}^{*}$ & $250 \mathrm{~V}$ \\
$R$ & $70 \Omega$ \\
$C$ & $1 \mathrm{mF}$ \\
$R_{L}$ & $0,1 \Omega$ \\
$k b$ & 2 \\
$K p$ & 1 \\
$S O C 1$ & 0,7 \\
$S O C 2$ & 0,4 \\
$k c 1$ & 2 \\
$k c 2$ & 1 \\
\hline \hline
\end{tabular}

Já a Fig. 6.9 mostra a resposta do UCs e baterias frente à entrada $i_{f a}$, onde a soma das correntes dos UCs mais baterias resulta em uma corrente com o mesmo perfil da entrada $i_{f a}$, Fig. 6.7. Nota-se pela Fig. 6.9 o comportamento esperado para a técnica desenvolvida, no qual os UCs produzem os picos de corrente e as baterias convergem para o valor de regime, evitando desgastes com picos transitórios. Entretanto, quando o transitório é finalizado, a tensão dos UCs é resturada para o seu valor de referência.

Na Fig. 6.9 um dos UCs apresenta o dobro da capacitância do outro, como pode ser visto na Tabela 6.1, ou seja $k c 1=2 k c 2$, assim, na divisão de carga $U C 1$ entrega o dobro da corrente fornecida por $U C 2$. Devido à inclusão da técnica de restauração da tensão terminal dos UCs, uma rápida recuperação desta tensão é alcançada, graças à inversão da corrente do UC após o pico de corrente. Esta inversão é suave (graças a presença do $F P B$ do controle do UC) e tem como objetivo recuperar a energia gasta para produzir os picos de corrente, sendo esta energia advinda das baterias. Em suma, o capacitor empresta uma porção de energia ao sistema durante o transitório, e logo em seguida requisita esta energia de volta, ou seja, na média a energia dos UCs é sempre constante.

Nesta simulação (Fig. 6.9) as baterias foram consideradas com a mesma capacidade, porém com estados de carga diferentes, $S O C 1=0,7$ e $S O C 2=0,3$, fazendo com que na descarga Bat1 entregue uma quantidade de corrente superior àquela entregue pela Bat2, entretanto, 
durante a carga será Bat2 que absorverá o maior nível de corrente. Nota-se que de 0 a $5 \mathrm{~s}$ apenas uma bateria está conectada à microrrede CC (Bat2 não fornece corrente), sendo que a partir de 5 s é inserida a segunda bateria. No momento em que Bat2 é conectada, as baterias iniciam o compartilhamento de carga de acordo com o estado de carga, fazendo com que Bat1 entregue um maior nível de corrente na descarga (5 a 8 s e 12 a 15 s) e Bat2 absorva uma quantidade de corrente maior durante o processo de carga (8 a 12 s).

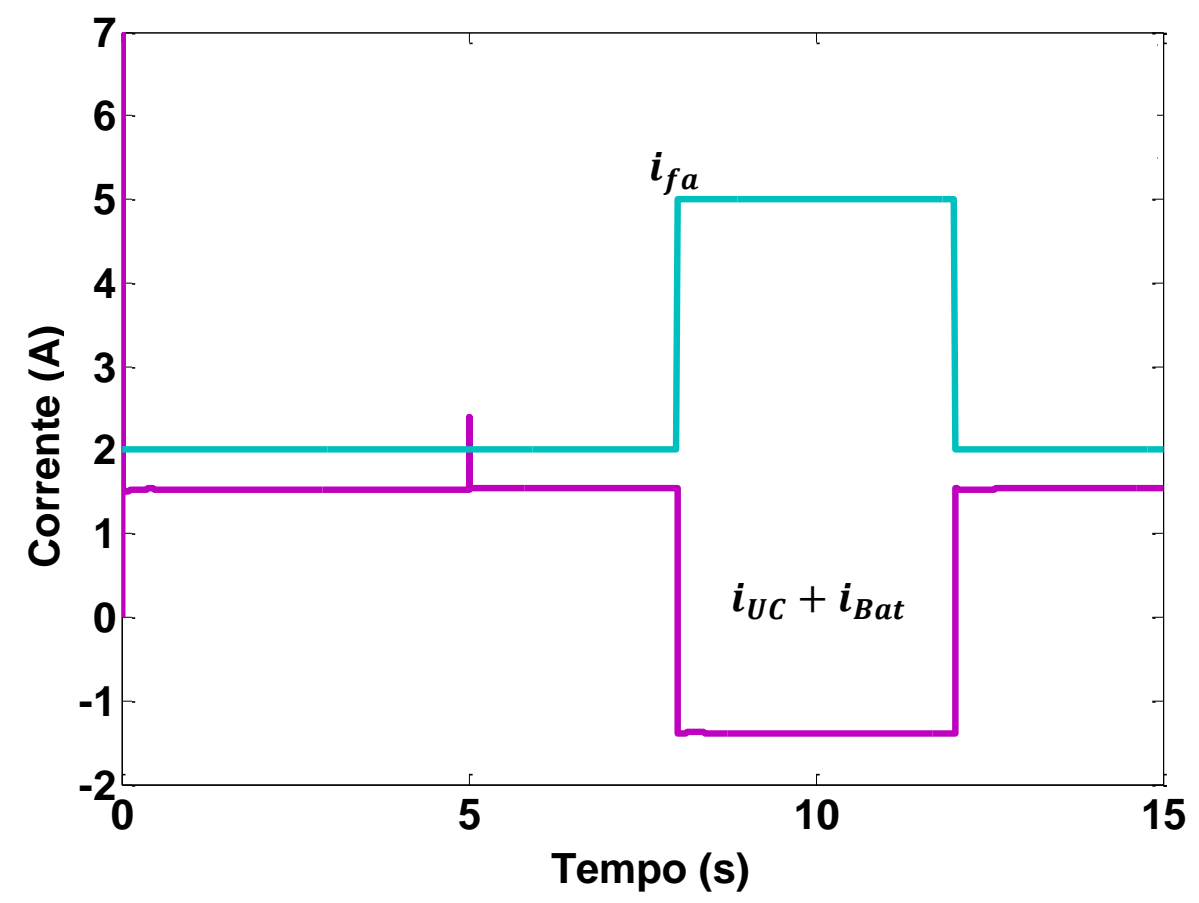

Figura 6.7 - Corrente imposta pelas fontes alternativas $i_{f a}$ ao barramento CC e a resposta dos armazenadores $\left(i_{B a t}+i_{U C}\right)$ para manter o equilíbrio. 


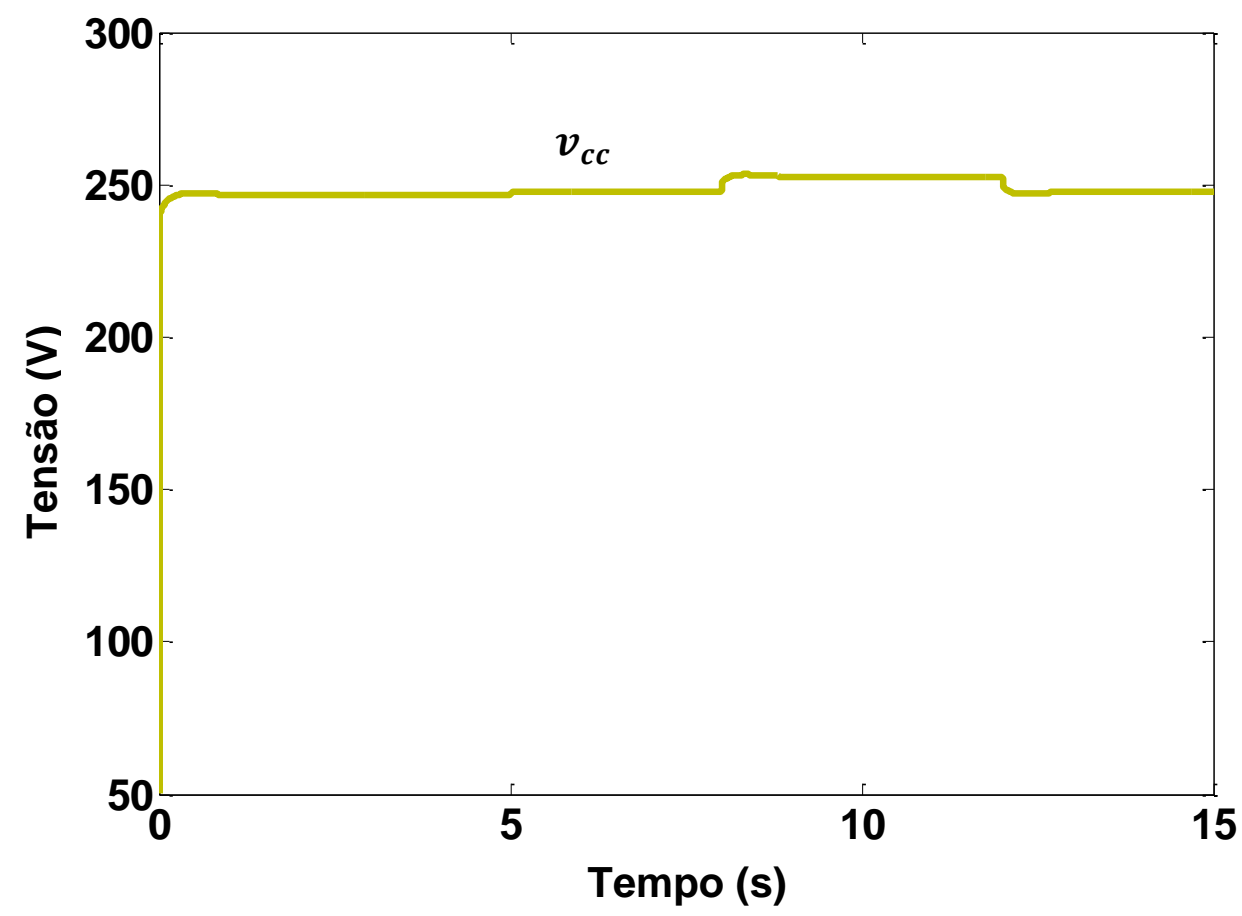

Figura 6.8 - Tensão do barramento CC.
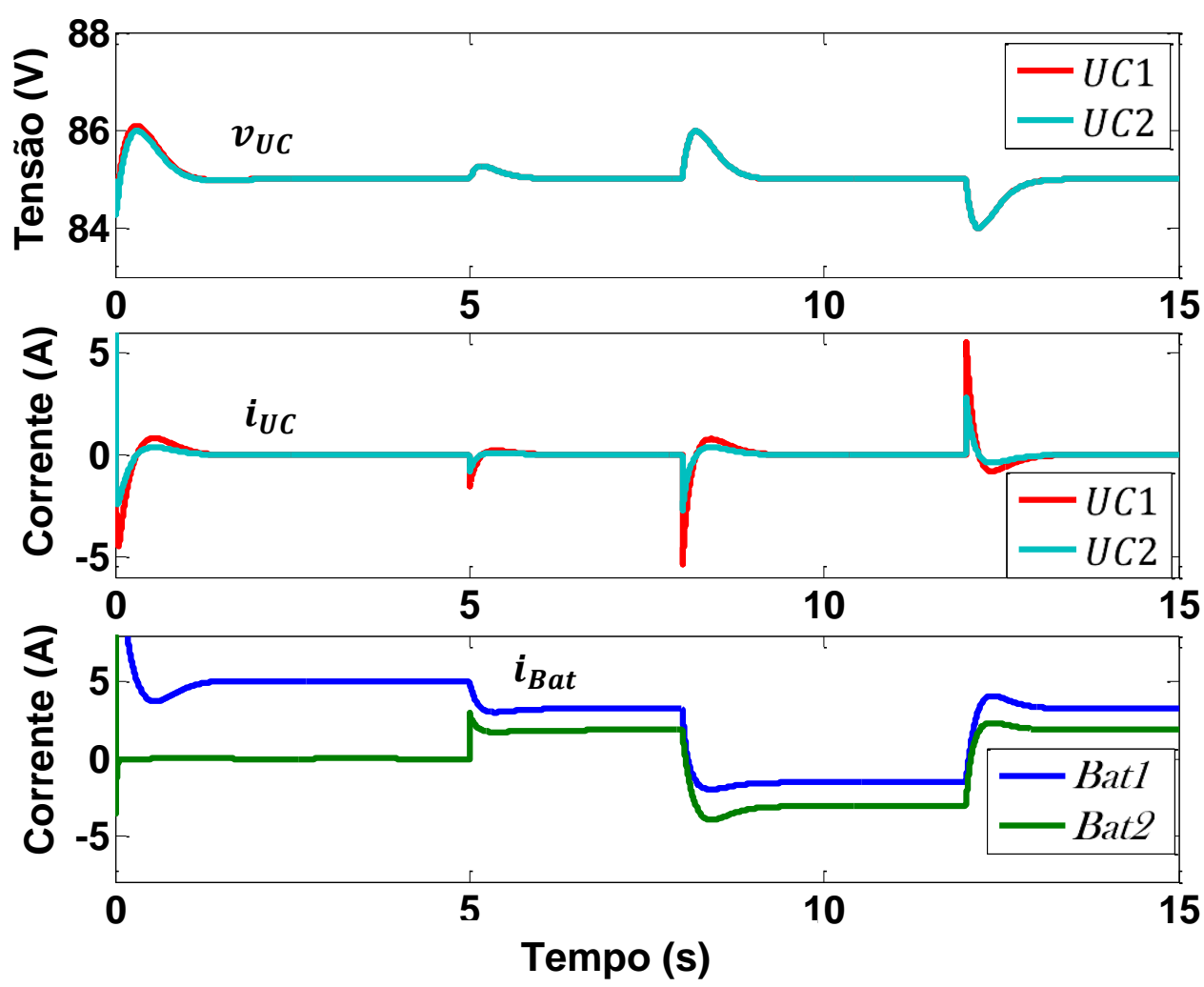

Figura 6.9 - Resposta dos UCs e baterias frente à entrada $i_{f a}$ apresentada na Fig. 6.6 quando a constante de tempo dos filtros FPA e FPB é $T=0,05 \mathrm{~s}$.

A Fig. 6.10 apresenta os mesmos modelos e dados de entrada da Fig. 6.9, contudo foram alteradas as constantes de tempo dos filtros $F P B$ e $F P A$ dos controladores das baterias e 
UCs de $T=0,05$ s para $T=0,15 \mathrm{~s}$. Desta forma, a resposta dinâmica das baterias, durante os transitórios, torna-se mais lenta, protegendo-as de qualquer distúrbio impostos a microrrede.

Outra alteração de comportamento que se pode notar é o desvio de tensão nos terminais dos UCs, que se torna maior, à medida que os transitórios são mais longos, o que requisita uma maior quantidade de energia dos UC. Apesar da modificação na velocidade na qual as baterias podem ser carregadas/descarregadas, os UCs acompanham esta dinâmica, devido ao casamento das constantes de tempo dos filtros e mantendo dessa forma, a estabilidade e a disponibilidade de energia no barramento CC.
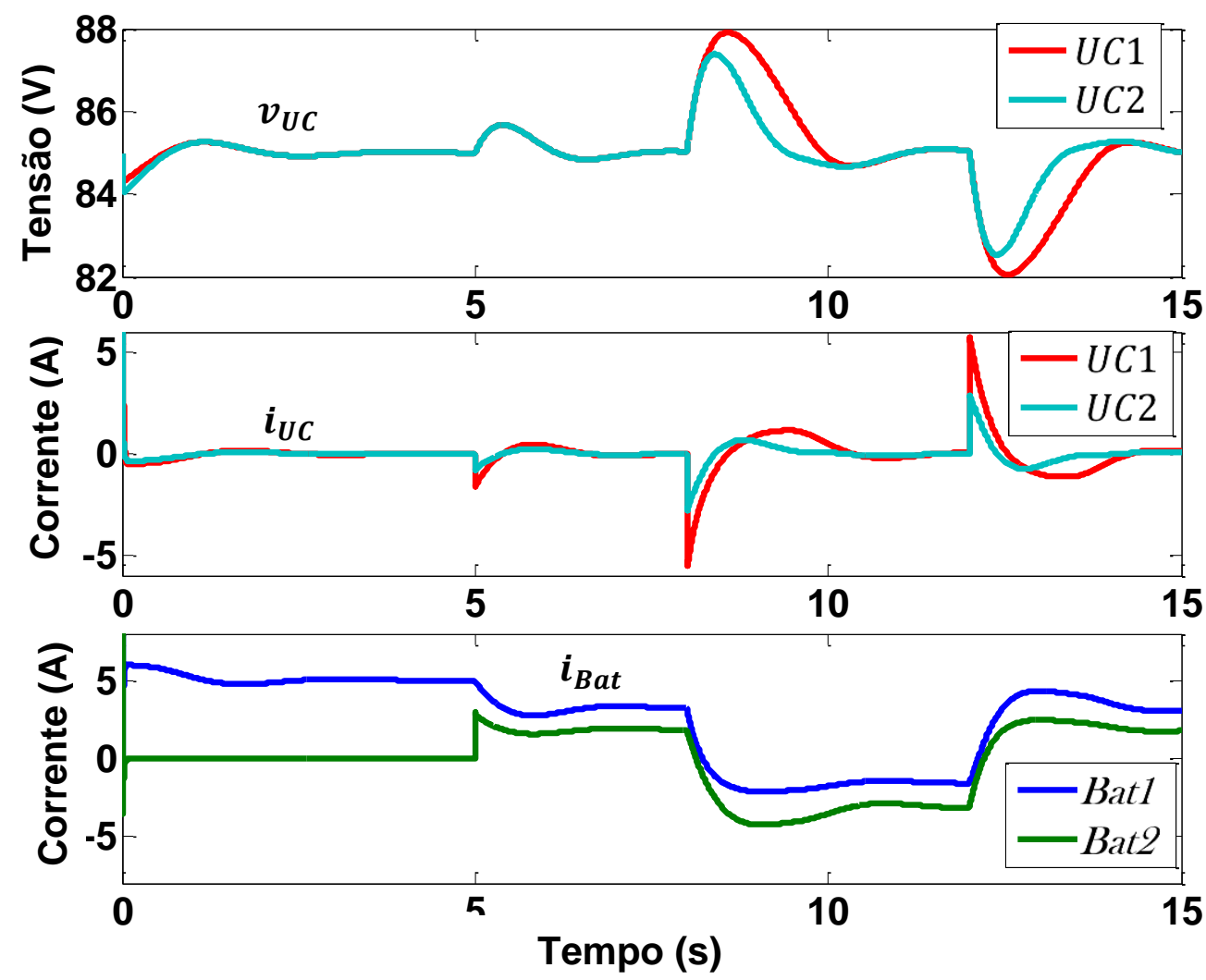

Figura 6.10 - Resposta dos UCs e baterias frente à entrada $i_{f a}$ apresentada na Fig. 6.7 quando a constante de tempo dos filtros FPA e FPB é alterada para $T=0,15$ s.

Nos resultados simulados (Fig. 6.9 e 6.10) o estado de carga das baterias foi considerado fixo em $S O C 1=0,7$ e $S O C 2=0,3$, de forma a ilustrar a divisão de carga proporcional ao $S O C$. Entretanto, esta consideração omite o comportamento dinâmico do SOC, assim, para a simulação seguinte o estado de carga das baterias é modelado pela equação (6.7), de forma a mostrar o comportamento dinâmico e a equalização da carga nas baterias. 
Já a Fig. 6.11 apresenta o comportamento dinâmico da Bat1 e Bat2 considerando o comportamento dinâmico do $S O C$ modelado por (6.7), dada uma entrada com sucessivos degraus na corrente das fontes alternativas. Nota-se que devido ao uso da técnica de divisão de carga proporcional ao $S O C$ as baterias tendem a se equalizar, convergindo para um mesmo estado de carga. É visível que à medida que os SOCs se aproximam, a corrente entregue pelas baterias tende a se tornar igual.

$$
\operatorname{SOC}(p u)=\operatorname{SOC}_{0}+\left(\frac{\int i_{B a t} d t}{\text { Capacidade da bateria }}\right)
$$
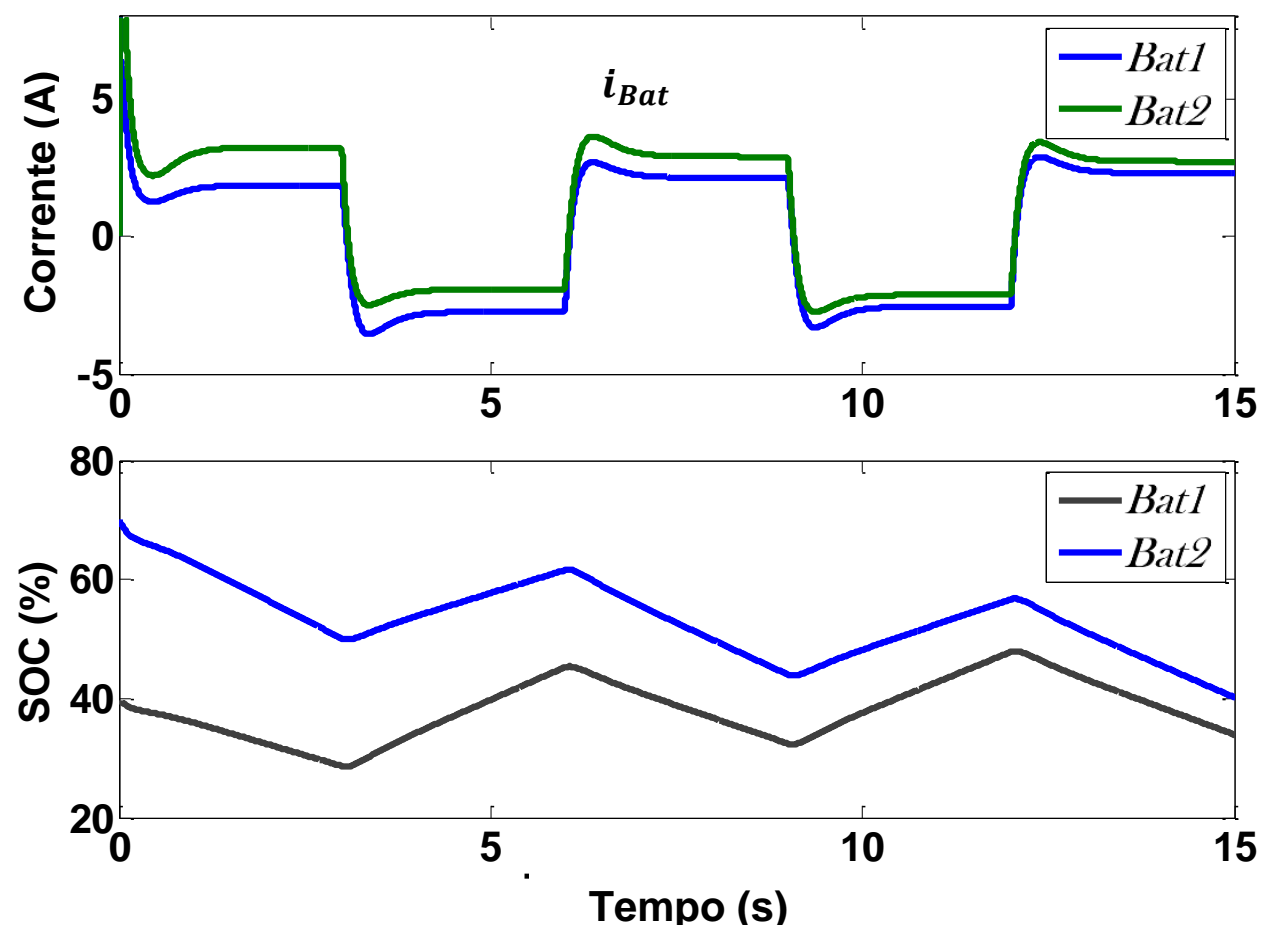

Figura 6.11 - Comportamento dinâmico do $S O C$ durante equalização da Bat1 e Bat2.

De forma a analisar a estabilidade da microrrede utilizando a técnica proposta, o circuito da Fig. 6.1 é modelado (em diagrama de blocos) incluindo os controladores da Fig. 6.4 e 6.5. Nessa análise, os conversores CC-CC operam em modo de controle de corrente e foram modelados utilizando a técnica de pequenos sinais apresentada no Capítulo $4, G_{c}(s)$.

A Fig. 6.12 mostra o modelo da microrrede considerando um conjunto UC e um banco de baterias conectados ao barramento CC e uma carga resistiva, enquanto que a Fig. 6.13 ilustra o mesmo modelo, porém de uma forma simplificada. Utilizando este modelo para uma entrada com sucessivos degraus de corrente, impostos por $i_{f a}$, e os parâmetros da Tabela 6.2, obtém-se a Fig. 6.14. Assim, é possível verificar que o modelo simplificado apresenta um comportamento 
condizente com os resultados do modelo médio, Fig. 6.8 e 6.9. Este fato comprova a precisão do modelo simplificado em representar a microrrede no domínio do tempo, logo, é esperada a mesma precisão no domínio da frequência, no qual a estabilidade será analisada.

TABELA 6.2

\begin{tabular}{cc} 
PARÂMETROS DO MODELO SIMPLIFICADO \\
\hline \hline Símbolo & Valor \\
\hline$R$ & $70 \Omega$ \\
$C$ & $1000 \mathrm{uF}$ \\
$k b$ & 2 \\
$K p$ & 1 \\
$T$ & $0,05 \mathrm{~s}$ \\
$k c$ & 2 \\
$K(\mathrm{soc})$ & 1 \\
\hline \hline
\end{tabular}

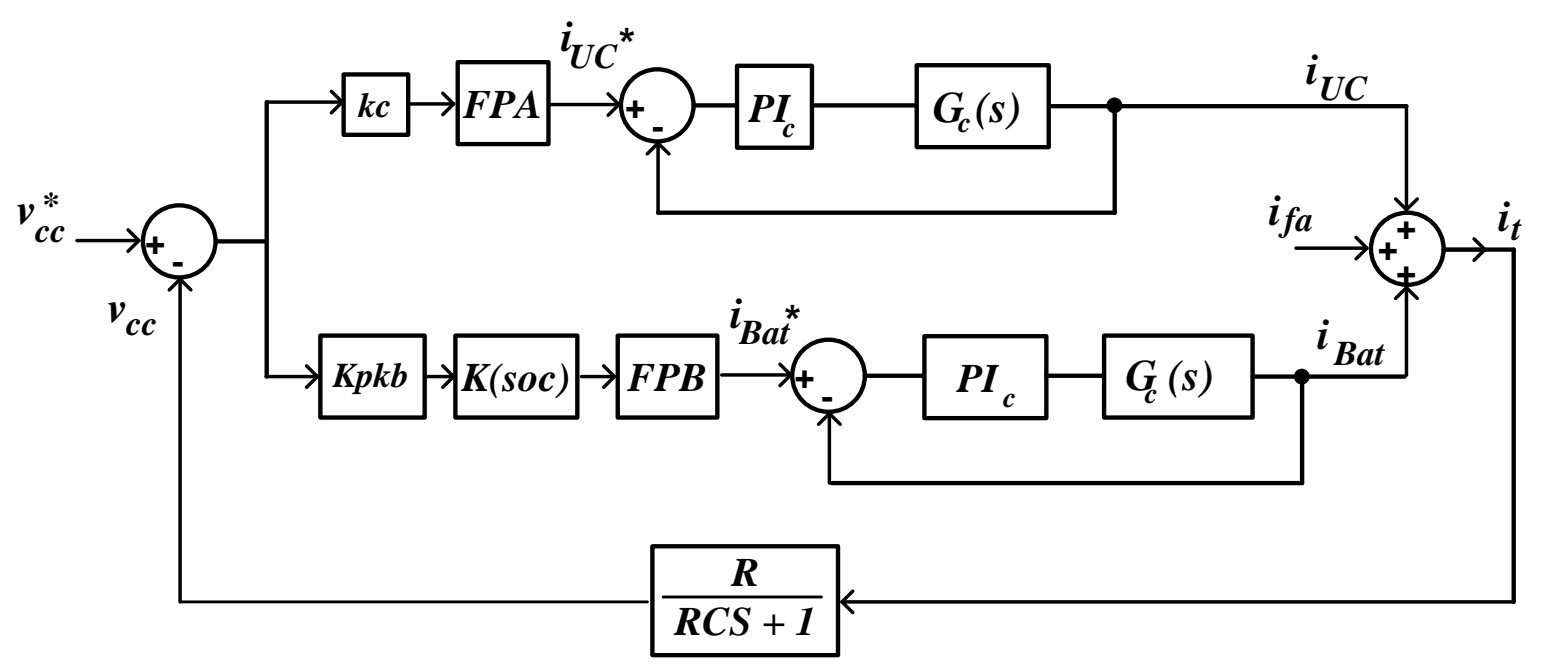

Figura 6.12 - Modelo do sistema completo em diagrama de blocos.

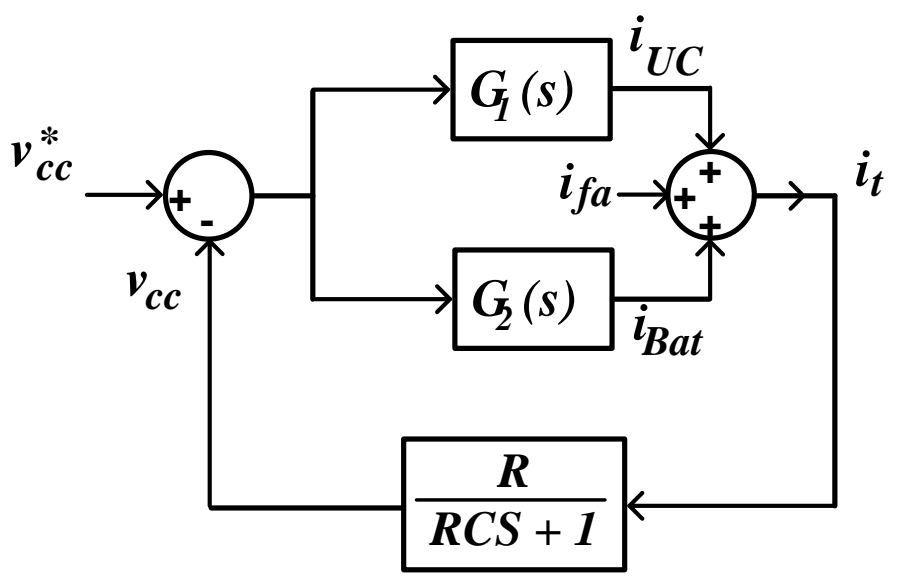

Figura 6.13 - Modelo simplificado em diagrama de blocos. 


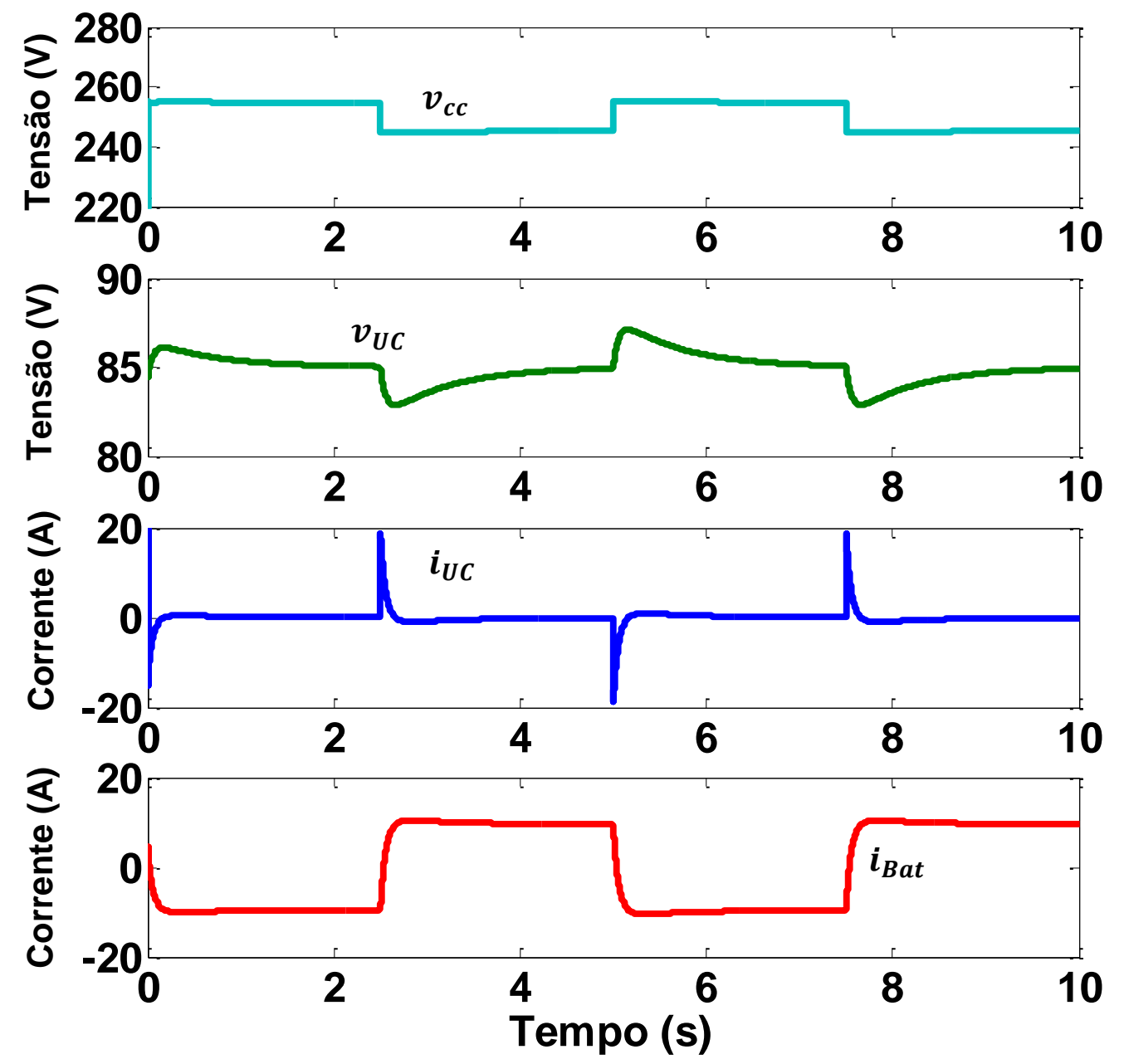

Figura 6.14 - Resposta do modelo em diagrama de blocos para uma entrada com sucessivos degraus de $i_{f a}$.

Utilizando os dados da Tabela 6.2, a função de transferência $G_{c}(s)$ e o controlador $P I_{c}$ calculado no Capítulo 4, obtém-se a análise no domínio da frequência da microrrede em malha fechada da Fig. 6.13. A Fig. 6.15 descreve esta resposta em frequência analisando, individualmente, a resposta do UC e considerando nula a ação da bateria $\left(G_{2}(s)=0\right)$ e a resposta da bateria quando a ação do UC é nula $\left(G_{1}(s)=0\right)$.

Os UCs apresentam uma forte atenuação tanto nas baixas quanto nas altas frequências, mostrando uma característica passa-faixa. Isto ocorre devido ao fato do controle dos UCs não contribuir com o regime permanente (frequências próximas de zero), uma vez que a estratégia foi desenvolvida para compensar apenas transitórios. Já os transitórios muito rápidos não são compensados pelo controle, uma vez que o conversor CC de corrente $\left(G_{c}(s)\right)$ apresenta uma limitação de velocidade (característica passa-baixa do conversor de corrente, Capítulo 4), devido aos elementos passivos do circuito (indutância), o que limita a resposta nas altas frequências. 
Já a resposta da bateria apresenta uma característica passa-baixa, devido à característica do $F P B$ da técnica aliada a característica da planta $G_{c}(s)$, compensando o regime permanente de forma lenta e suave, sem se comprometer com os transitórios.

A Fig. 6.15 também mostra a resposta em frequência do diagrama de controle da Fig. 6.13 considerando a ação combinada de ambos, UCs e baterias. Devido à característica de cada um dos dispositivos, nas baixas frequências a planta completa (UC+bateria) segue o comportamento do controle da bateria e nas altas frequências segue o comportamento do controle do UC, ou seja, combinando a ação individual de cada um deles para se obter a compensação desejada.

Observa-se ainda, que nas frequências próximas a zero o ganho da estrutura de controle UC+bateria é inferior a $0 \mathrm{~dB}(-0,6 \mathrm{~dB})$, ou seja, não anula o erro de regime permanente, apresentando desvios de tensão assim como esperado para a técnica.

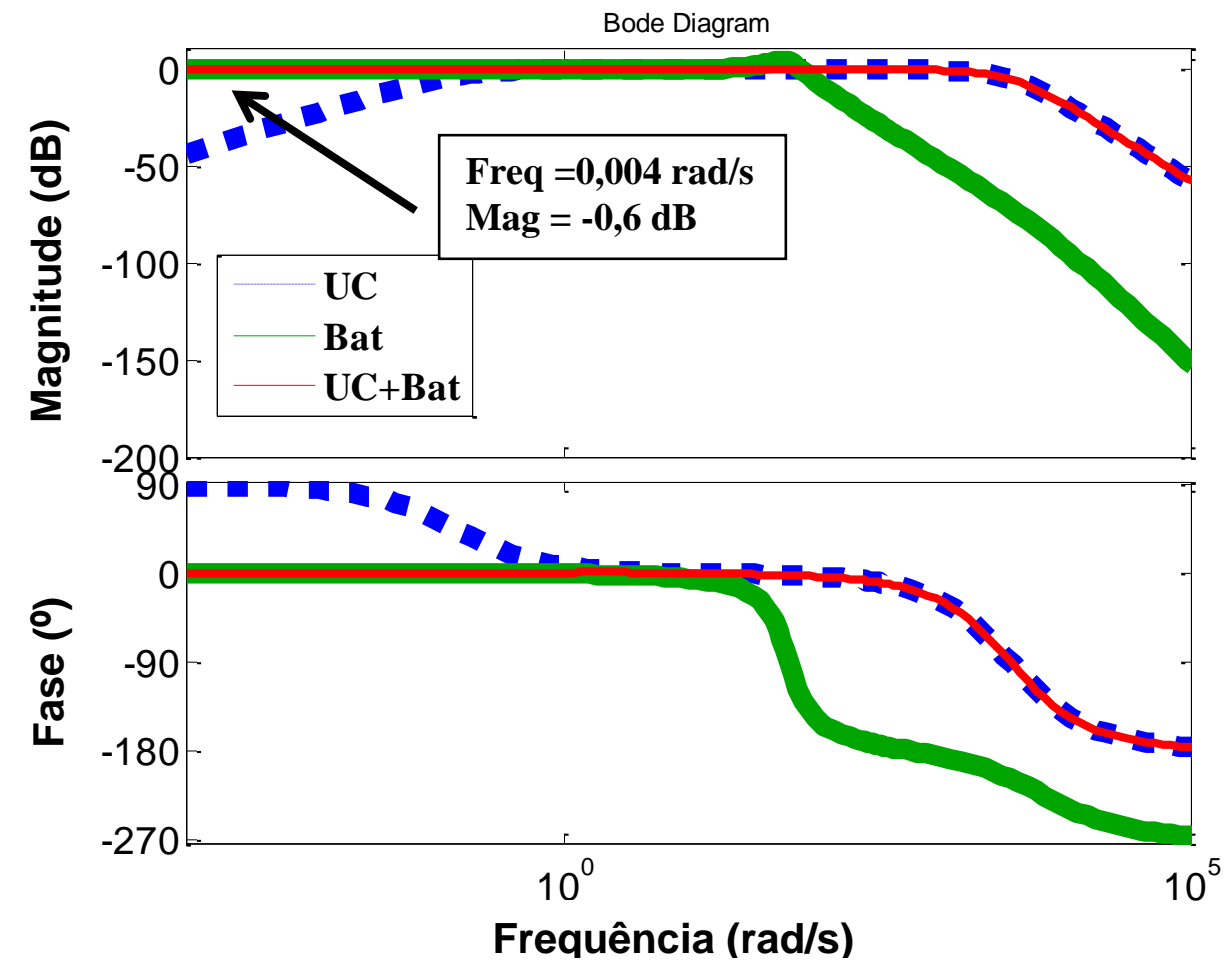

Figura 6.15 - Diagrama de bode do sistema da Fig. $6.13 \mathrm{em}$ malha fechada para $G_{2}(s)=0$ (apenas $\mathrm{UC}$ ), $G_{1}(s)=0$ (apenas bateria) e malha combinada $\mathrm{UC}$ e bateria.

Assim como discutido no início da Seção 6.3, valores reduzidos de $K(s o c)$ tendem a gerar grandes desvios na tensão do barramento CC, logo espera-se uma redução da margem de estabilidade quando esta constante se aproximar de zero. Para comprovar este comportamento, é utilizado o diagrama de blocos da Fig. 6.12 quando o parâmetro $K(s o c)$ é alterado de 1 a 0 e é analisado o lugar das raízes, Fig. 6.16 a 6.18. Nota-se que à medida que o $K$ (soc) é reduzido, o 
polo mais próximo da origem se aproxima da região de instabilidade, comprometendo a estabilidade da microrrede, conforme esperado.

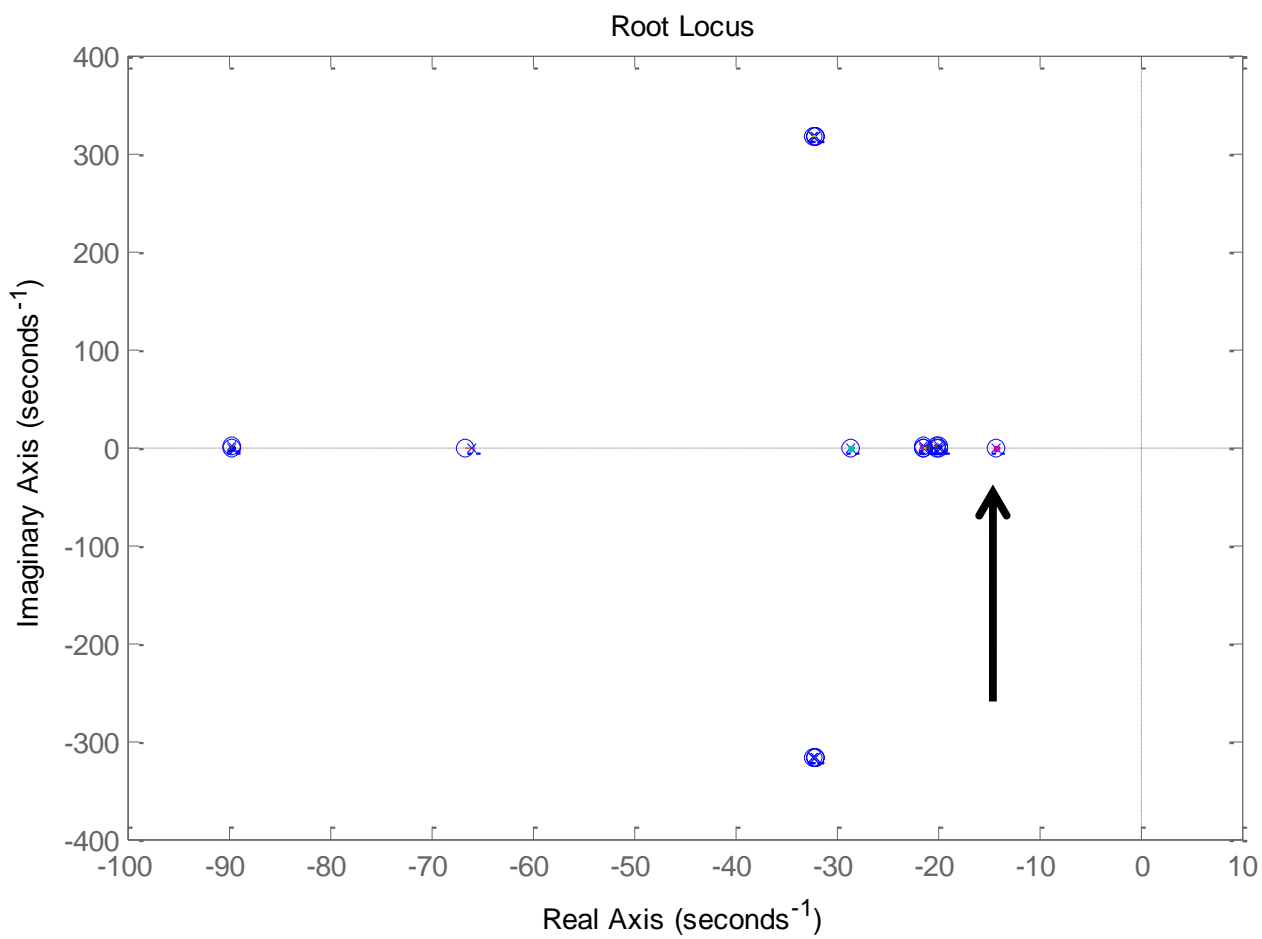

Figura 6.16 - Lugar das raízes para $K(s o c)=1$ mostrando o polo mais crítico do sistema se movimentando para direita (região de instabilidade) à medida que $K($ soc) se reduz.

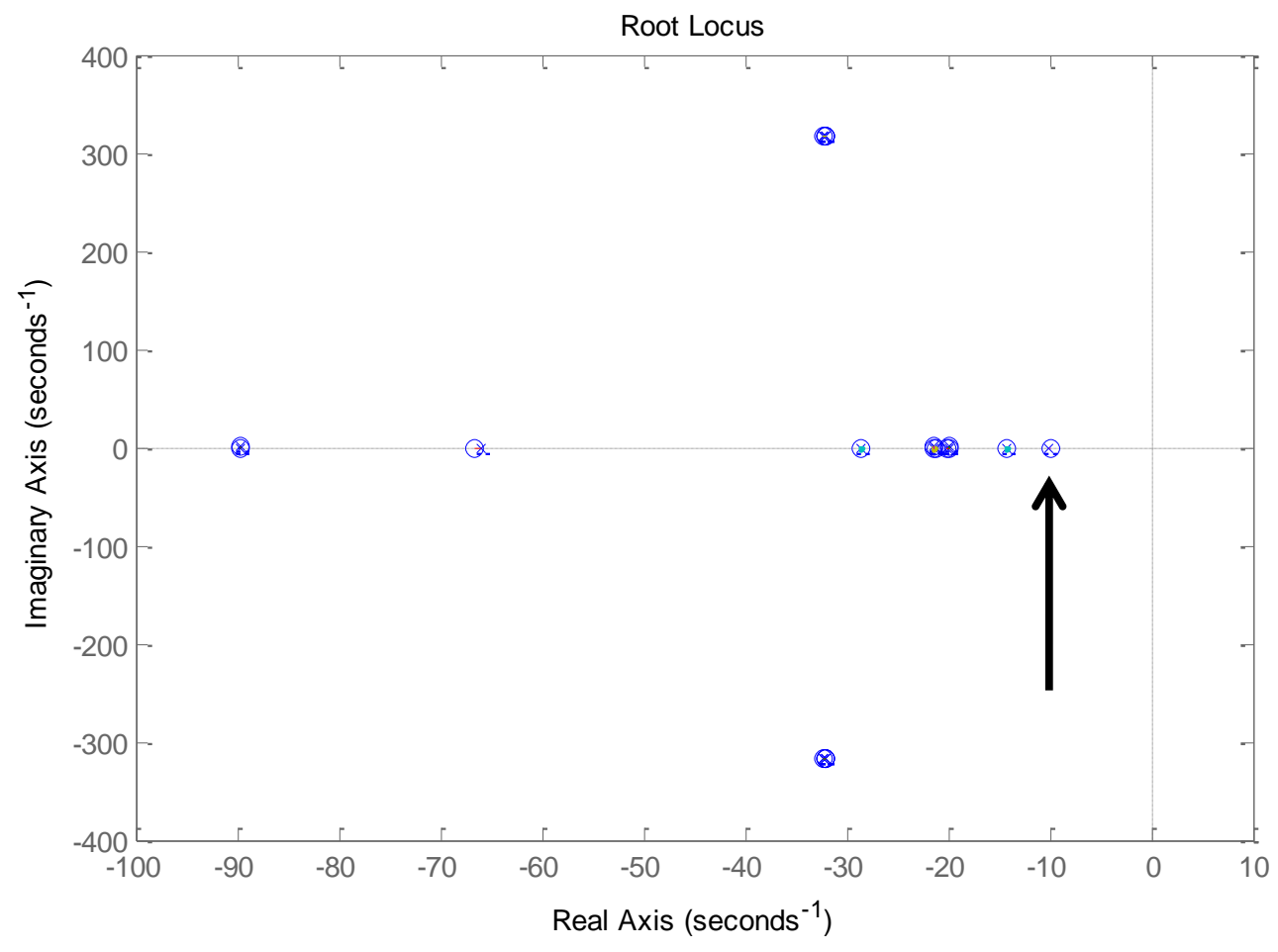

Figura 6.17 - Lugar das raízes para $K(s o c)=0,5$ mostrando o polo mais crítico do sistema se movimentando para a direita (região de instabilidade) à medida que $K(s o c)$ se reduz. 


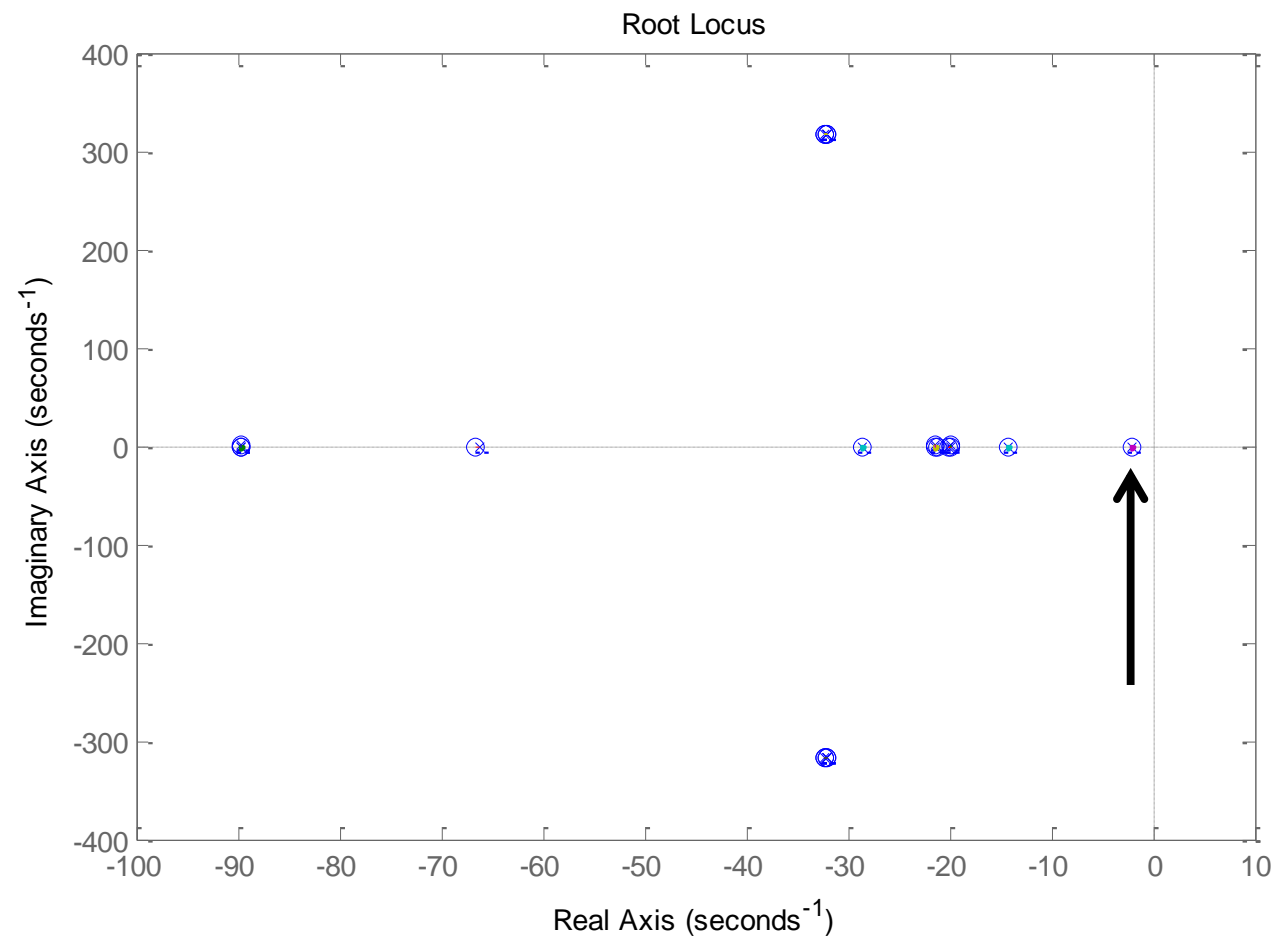

Figura 6.18 - Lugar das raízes para $K(s o c)=0,1$ mostrando o polo mais crítico do sistema se movimentando para a direita à medida que $K(s O c)$ se reduz.

\subsection{Controle Descentralizado para Microrrede Híbrida - com Restauração do Barramento CC}

Nesta seção é descrita a estratégia proposta para a integração de UC e baterias na microrrede de forma descentralizada, ou seja, sem comunicação entre os armazenadores. Como novidade em relação à proposta descrita na seção anterior, o barramento CC é restaurado para o valor de referência após qualquer tipo de distúrbio causado por manobras de carga ou variações nas condições atmosféricas, que fazem com que a produção de energia se altere. Assim como citado na descrição do estado da arte, [71, 67, 72] realizam a divisão de carga de uma microrrede CC híbrida com restauração de barramento, contudo fazem uso de uma estrutura de gerenciamento centralizada e realizam a restauração dos UCs através de um controle on-off conforme pode ser visto em [67], entretanto, a restauração só é ativada após a tensão ultrapassar um limiar mínimo.

A estratégia proposta restaura o barramento de forma descentralizada, ou seja, cada dispositivo armazenador usa apenas a tensão do barramento $v_{c c}$ como medida externa, Fig. 6.3. Outra diferença entre a estratégia proposta neste capítulo e as referências encontradas na literatura [67], é que a técnica de restauração, vista na Fig. 6.4, se mantém ativa durante todo o 
processo, garantindo uma restauração após cada transitório e permitindo assim, o uso de UCs com baixa capacitância comparada as técnicas usadas na literatura.

Como a técnica de controle dos UCs é utilizada apenas durante os transitórios, ela não afeta o comportamento e/ou funcionamento no regime permanente, ou seja, não contribui para a restauração do barramento. Logo, o controle dos UCs permanece inalterado em relação à técnica da seção 6.3. Já o controle da bateria sofre uma leve alteração, sendo adicionado um controlador $P I_{v}$ de tensão à malha mais externa, Fig. 6.19. Entretanto, este controlador apresenta uma entrada de Reset, de forma que seja possível sincronizar vários controladores em paralelo.

Para que se possa compreender a necessidade do Reset, suponha que exista apenas uma bateria na microrrede funcionando em regime permanente e restaurando a tensão do barramento CC. Logo, o erro de tensão é zero e o integrador está carregado com o valor de regime permanente.

Caso uma segunda bateria seja adicionada à microrrede, o controlador desta bateria enxergará erro zero de tensão e, portanto, não irá contribuir para a entrega de potência à microrrede. Apenas quando ocorrer um transitório e, consequentemente, existir um erro de tensão no barramento $\mathrm{CC}$ é que a segunda bateria terá alguma contribuição. Neste momento, diferentes baterias presentes na microrrede dividirão a carga de acordo com o valor inicial do integrador da primeira bateria, ou seja, esse valor de compartilhamento é definido pelo valor inicial do integrador da primeira bateria, que é aleatório logo, elas não irão dividir a carga por meio de uma lógica pré-definida e, consequentemente, não se equalizarão.

Assim, foi adicionado um Reset aos integradores dos controladores de tensão, logo, a cada instante que a microrrede for submetida a um transitório de tensão, os integradores serão sincronizados com o mesmo valor (zero), fazendo com que a divisão de carga seja influenciada apenas por $K i, K p$ e $k b$, como na técnica anterior sem restauração.

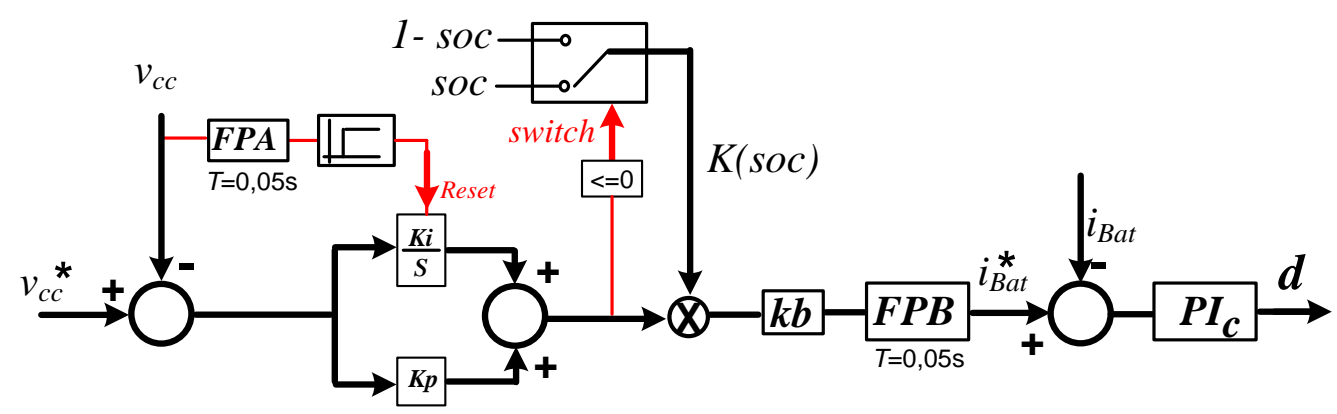

Figura 6.19 - Técnica de controle proposta para as baterias no sistema descentralizado com restauração do barramento CC. 
De forma a comprovar a eficácia desta técnica, o controlador apresentado na Fig. 6.19 é utilizado junto ao modelo médio da equação (6.6) com os parâmetros da Tabela 6.1, os resultados são apresentados nas Fig. 6.20 a Fig, 6.23.

A Fig. 6.20 mostra o perfil de entrada de corrente gerada pelas fontes alternativas assim como a tensão do barramento CC sendo restaurada para $250 \mathrm{~V}$. De acordo com o que foi como descrito, na apresentação da técnica, foi visto que diferentes baterias precisam sincronizar os integradores para realizarem a divisão de carga de forma correta, uma vez que não há comunicação entre elas. Como a técnica reinicia os integradores a cada transitório no barramento $\mathrm{CC}$, propõe-se que cada nova bateria adicionada a microrrede $\mathrm{CC}$ crie um distúrbio proposital, de forma a gerar a reinicialização e o sincronismo entre os dispositivos.

A Fig. 6.21 mostra este procedimento, no qual a nova bateria conectada (Bat2) entrega um degrau de corrente proposital durante $1 \mathrm{~s}$ para reiniciar os integradores. No momento em o degrau é eliminado, as baterias estão sincronizadas e entregando a mesma corrente, uma vez que o $S O C$ para as ambas foi definido igual a 0,5 .

Caso as baterias não tenham o mesmo estado de carga, a partir do sincronismo elas entregam correntes diferentes, como na Fig. 6.22. Nessa situação, os estados de carga são definidos fixos, $S O C 1=0,7$ e $S O C 2=0,4$.

De forma a analisar o comportamento dinâmico da técnica em relação ao estado de carga, o $S O C$ é modelado de forma dinâmica pela equação (6.7) como na seção 6.3. A Fig. 6.23 representa este comportamento, mostrando as baterias convergindo para um mesmo estado de carga e, consequentemente, entregando correntes iguais à medida que o SOC é equalizado.

Assim como nas técnicas apresentadas anteriormente, a tensão terminal dos UCs sempre é restaurada para o valor de referência $(85 \mathrm{~V})$, mantendo a energia média nos capacitores constante. Isto faz com que os UCs sempre tenham energia disponível para os transitórios de carga. 

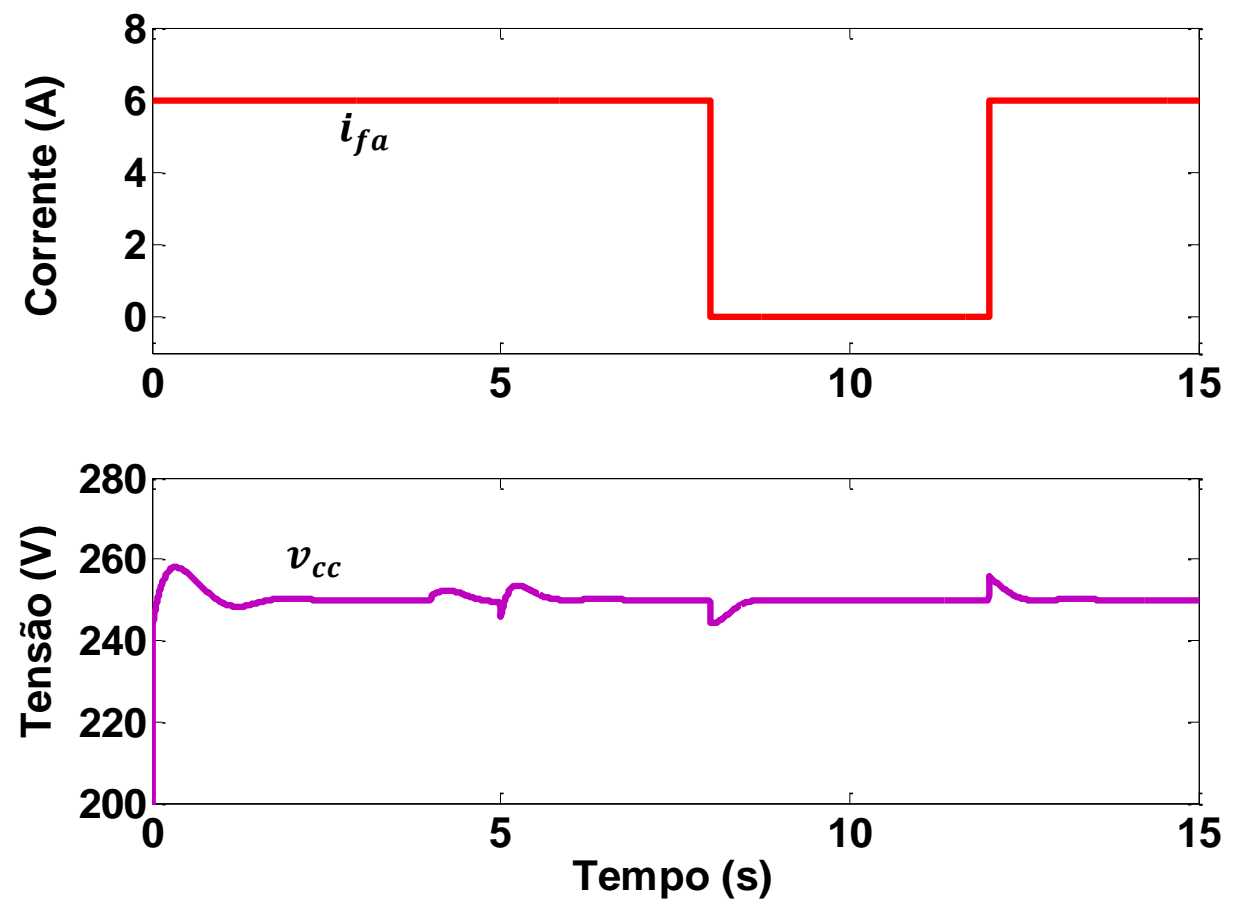

Figura 6.20 - Perfil da corrente gerada $i_{f a}$ e da tensão do barramento CC sendo restaurada para $250 \mathrm{~V}$. 

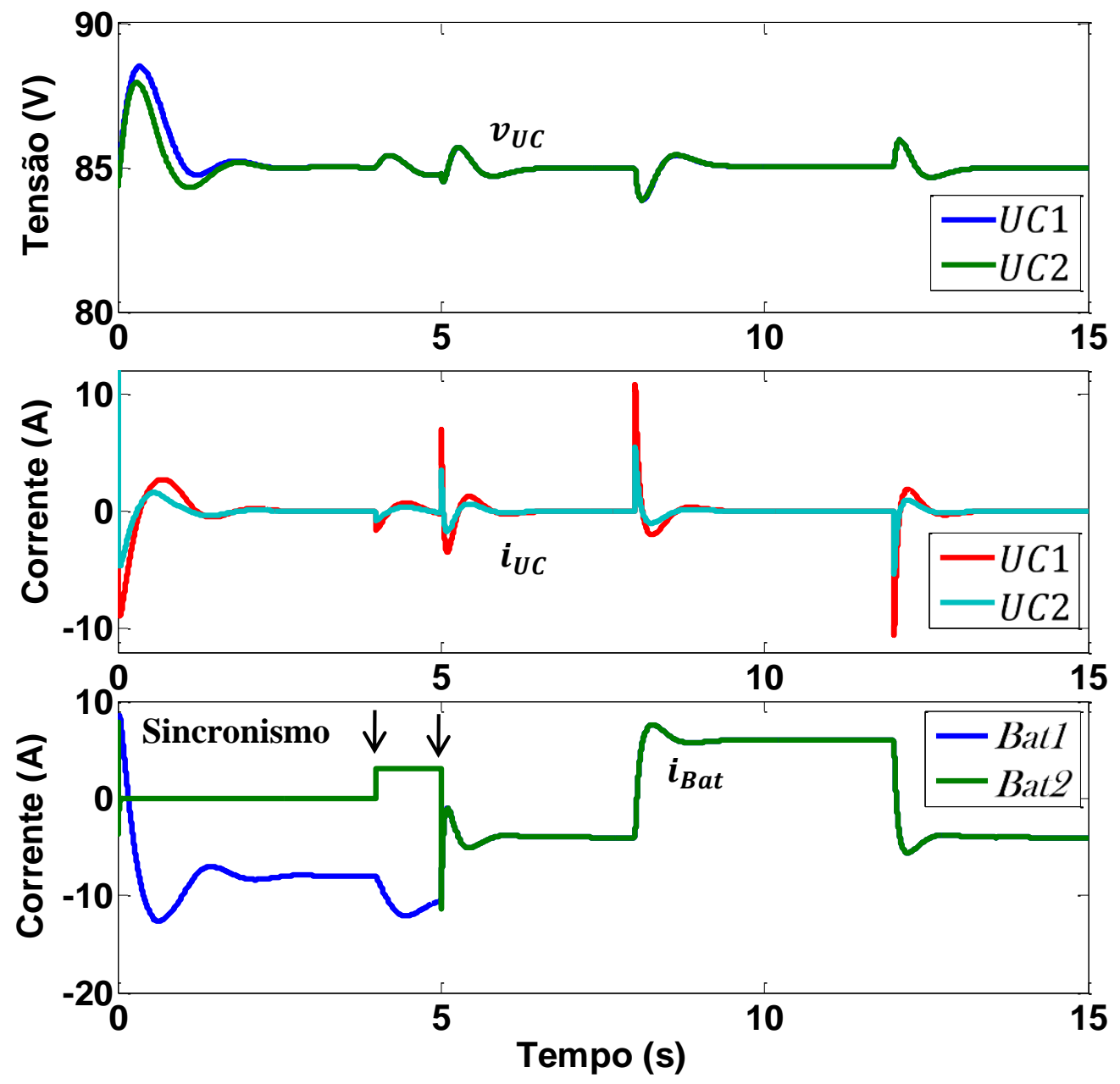

Figura 6.21 - Tensão dos UCs, corrente dos UCs e corrente das baterias para um mesmo estado de carga.

A análise da estabilidade da técnica será feita da mesma forma que foi apresentada na seção anterior, na qual o diagrama de blocos sofreu uma leve modificação pela adição do bloco integrador na técnica aplicada à bateria, Fig. 6.24.

Esta modificação inclui a adição de um controlador do tipo proporcional-integral na malha de tensão do barramento $\mathrm{CC}\left(P I_{v}\right)$ com os seguintes parâmetros, $K p=1$ e $K_{i}=3$. Para comprovar a precisão deste modelo simplificado em diagrama de blocos, a entrada $i_{f a}$ é variada por meio de sucessivos degraus e a resposta é analisada, Fig. 6.25. Nota-se que a resposta do modelo apresenta o mesmo comportamento dos resultados das Fig. 6.21, 6.22 e 6.23 que é representado pelo modelo médio da equação (6.6). Logo, espera-se uma resolução satisfatória do modelo no domínio da frequência, uma vez que no domínio do tempo as respostas são precisas. 

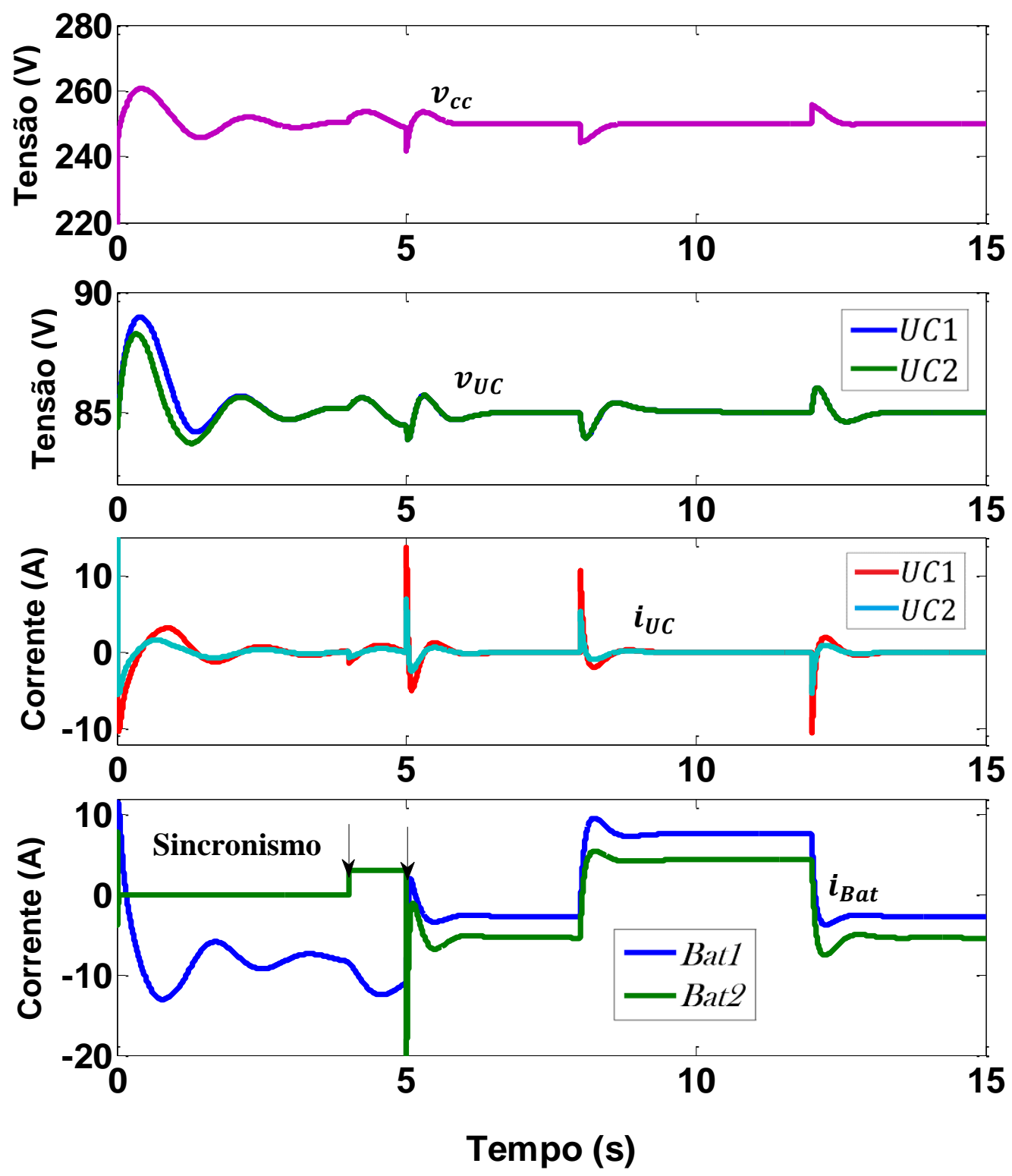

Figura 6.22 - Tensão do barramento CC, tensão dos UCs, corrente dos UCs e corrente das baterias para $S O C 1=0,7, S O C 2=0,4$. 

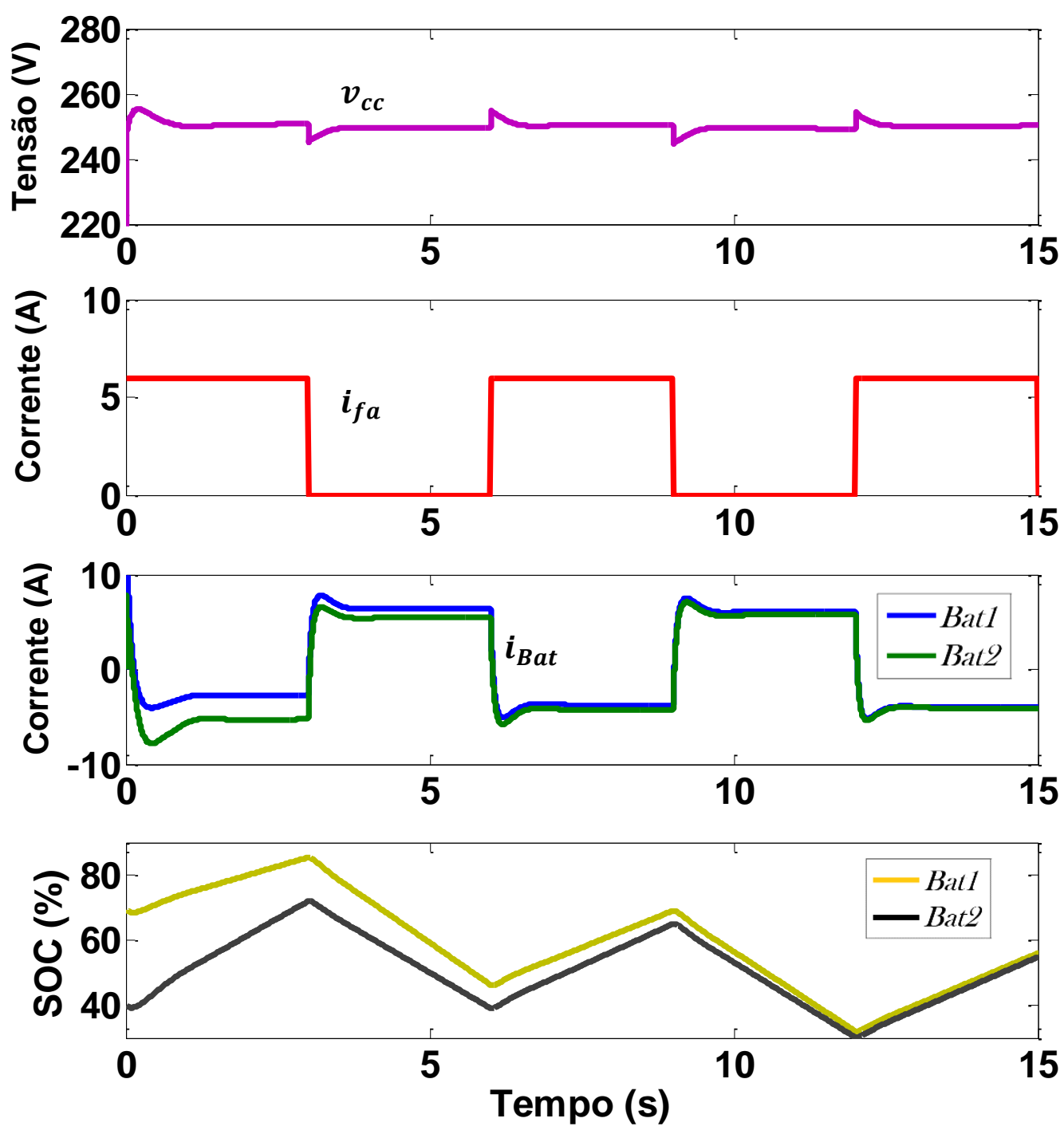

Figura 6.23 - Tensão do barramento CC, corrente $i_{f a}$, corrente das baterias e estado de carga das baterias, utilizando o modelo de $S O C$ dinâmico da equação (6.7).

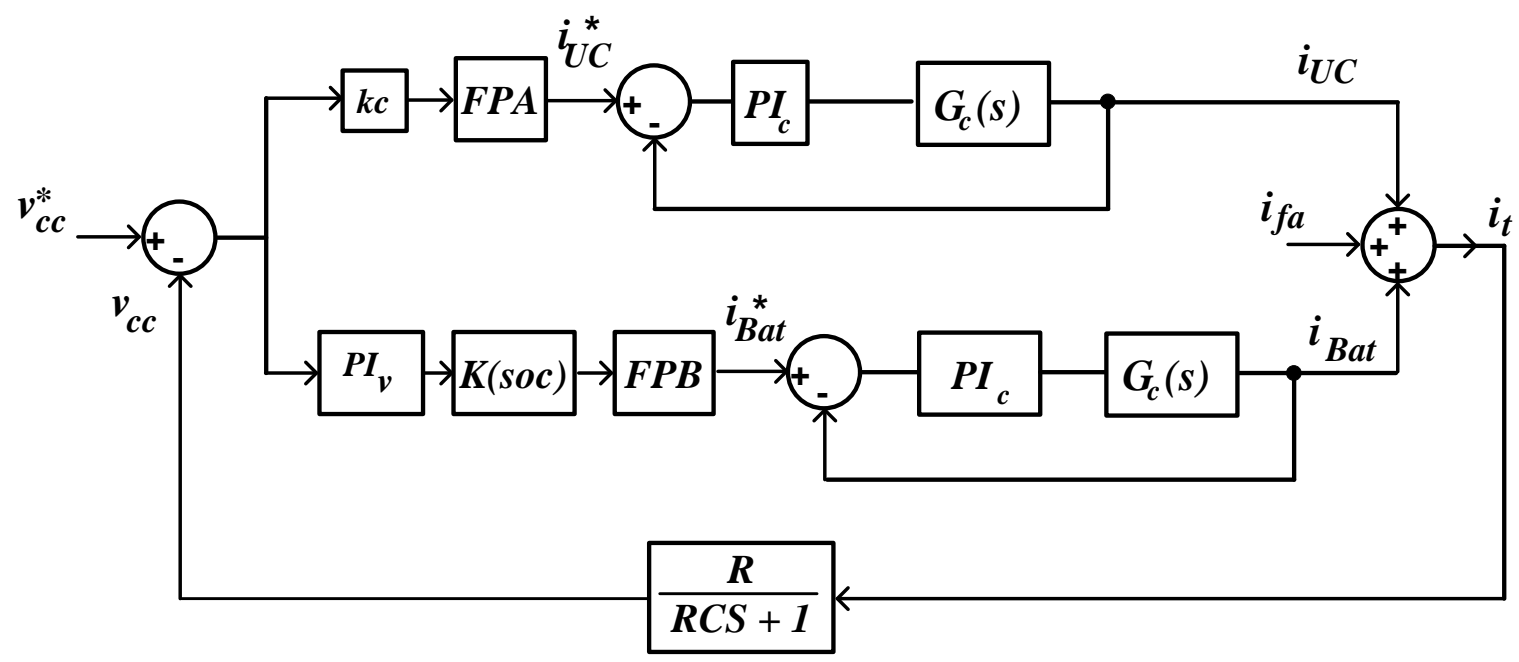

Figura 6.24 - Modelo em diagrama de blocos para uma microrrede híbrida com restauração da tensão do barramento CC. 

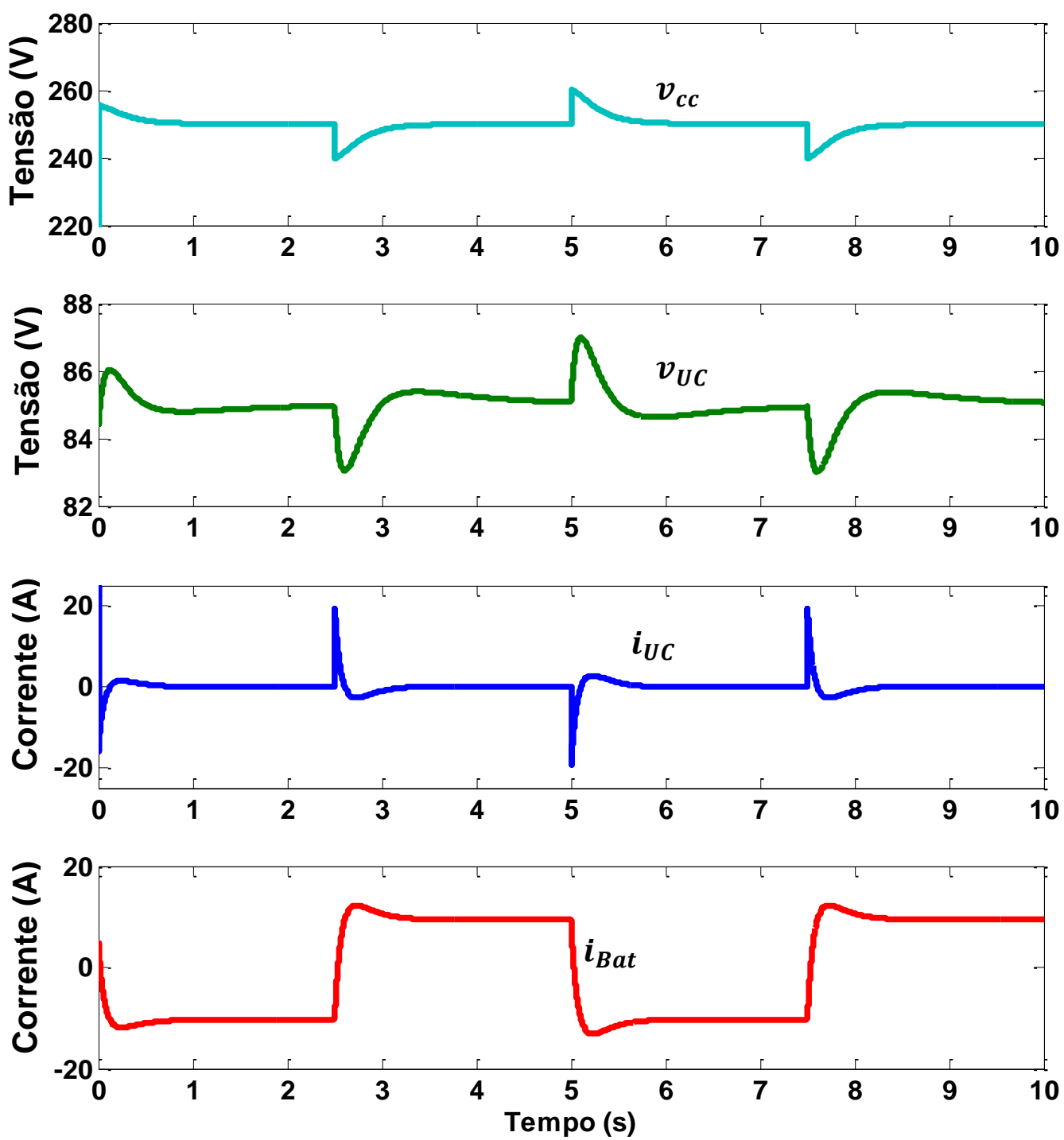

Figura 6.25 - Resposta do modelo em diagrama de blocos para o sistema híbrido com restauração da tensão do barramento CC para sucessivos degraus de $i_{f a}$.

Assim como na seção anterior, a análise no domínio da frequência é feita por partes, ou seja, primeiramente é considerado apenas o controle dos UCs depois, o controle das baterias e por fim, é feita a análise sobre a microrrede incorporando a estrutura de controle completa, Fig. 6.26.

Na Fig. 6.26 nota-se uma resposta semelhante àquela visualizada na Fig. 6.15, cujo controle dos UCs apresentou uma resposta dinâmica equivalente a um filtro passa-faixa enquanto que, a estrutura de controle das baterias comportou-se como um filtro passa-baixa. Por fim, ambas as estruturas de controle são incorporadas e analisadas de forma a verificar o comportamento generalizado, ou seja, ambas as estruturas de controle contribuem com a compensação. 
Como citado na seção anterior, o controle dos UCs não contribui para o regime permanente, o que explica a sua incapacidade de compensação em baixas frequências, já nas altas frequências o ganho é reduzido pela dinâmica do conversor de corrente $\left(G_{c}(s)\right)$, que é limitado em velocidade pelos elementos passivos (indutor). Já o controlador da bateria apresenta uma característica passa-baixa, uma vez que seu objetivo é compensar o regime permanente.

Por fim, a estrutura de controle completa da microrrede requer a combinação das baterias e UCs, com as baterias funcionando nas baixas frequências e os UCs nas altas. Entretanto, diferentemente do que se observou na Fig. 6.15, o ganho do controlador da bateria e do controlador combinado apresentam ganho $0 \mathrm{~dB}$ nas baixas frequência, uma vez que esta técnica restaura a tensão do barramento $\mathrm{CC}$, eliminando o erro de regime permanente, ao contrário do que foi visto na Seção 6.3.

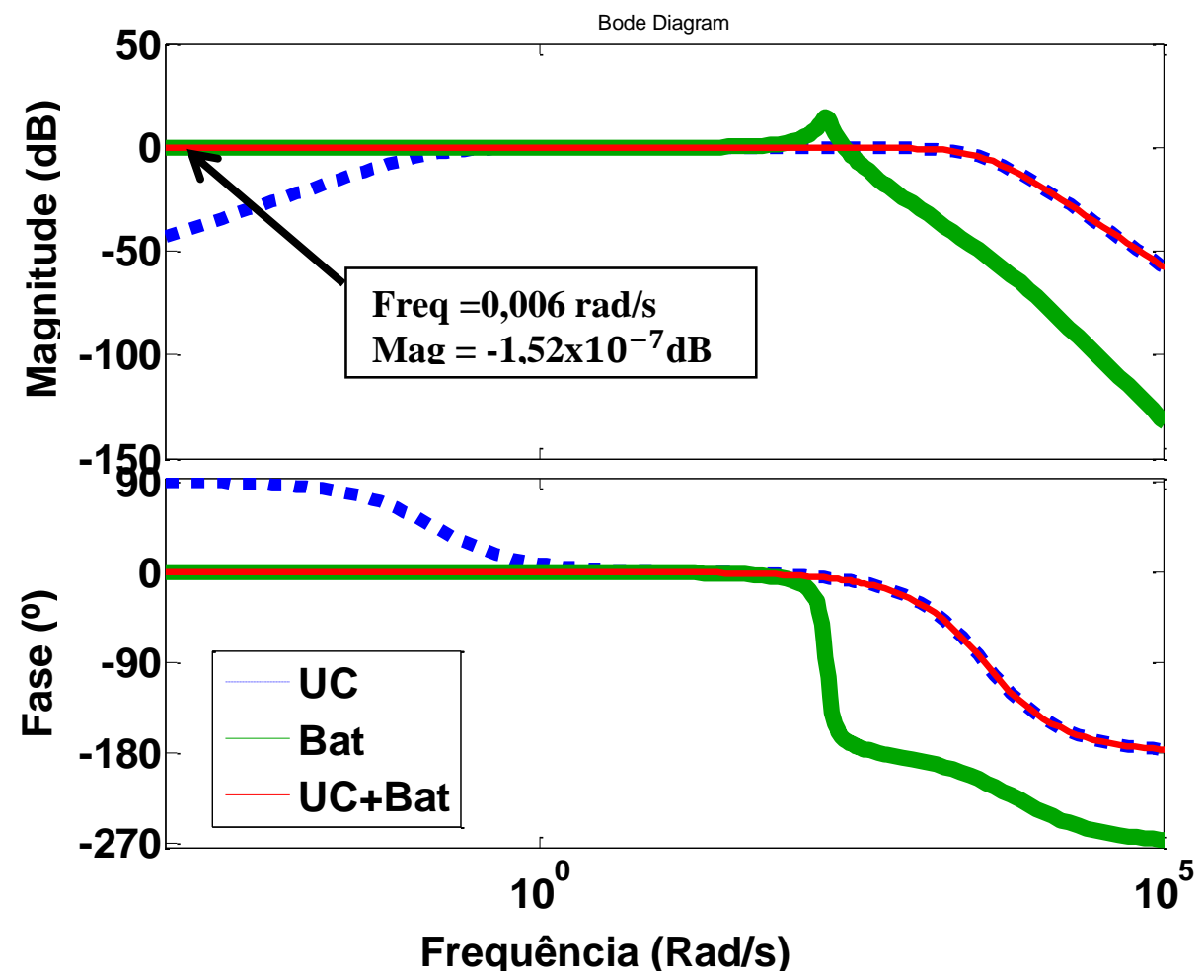

Figura 6.26 - Diagrama de bode do sistema da Fig. $6.24 \mathrm{em}$ malha fechada para $G_{2}(s)=0$ (apenas UC), $G_{1}(s)=0$ (apenas bateria) e malha combinada UC e bateria.

Assim como na técnica apresentada na seção 6.3, a técnica proposta com restauração de barramento CC também possui influência direta do estado de carga na estabilidade, uma vez que a saída do controlador $P I_{v}$ é multiplicada pelo ganho proporcional $K($ soc $)$ logo, se este ganho for muito pequeno, espera-se um comportamento mais instável, uma vez que os ganhos do controlador serão reduzidos. 
As Fig. 6.27 e 6.28 apresentam o lugar das raízes do diagrama de blocos do modelo completo (Fig. 6.24) para $K(s o c)=0,5$ e $K(s o c)=0,1$, respectivamente. Nota-se um claro deslocamento do polo mais crítico em direção à região de instabilidade à medida que o ganho é reduzido, assim como esperado. Dessa forma, como citado anteriormente, o ganho proporcional ao $S O C$ deve ser limitado para não atingir valores muito pequenos, que levariam a microrrede para a instabilidade. Contudo, caso este ganho seja limitado, a equalização entre várias baterias é prejudicada, sendo o preço a se pagar pela estabilidade da microrrede na qual os armazenadores não se comunicam.

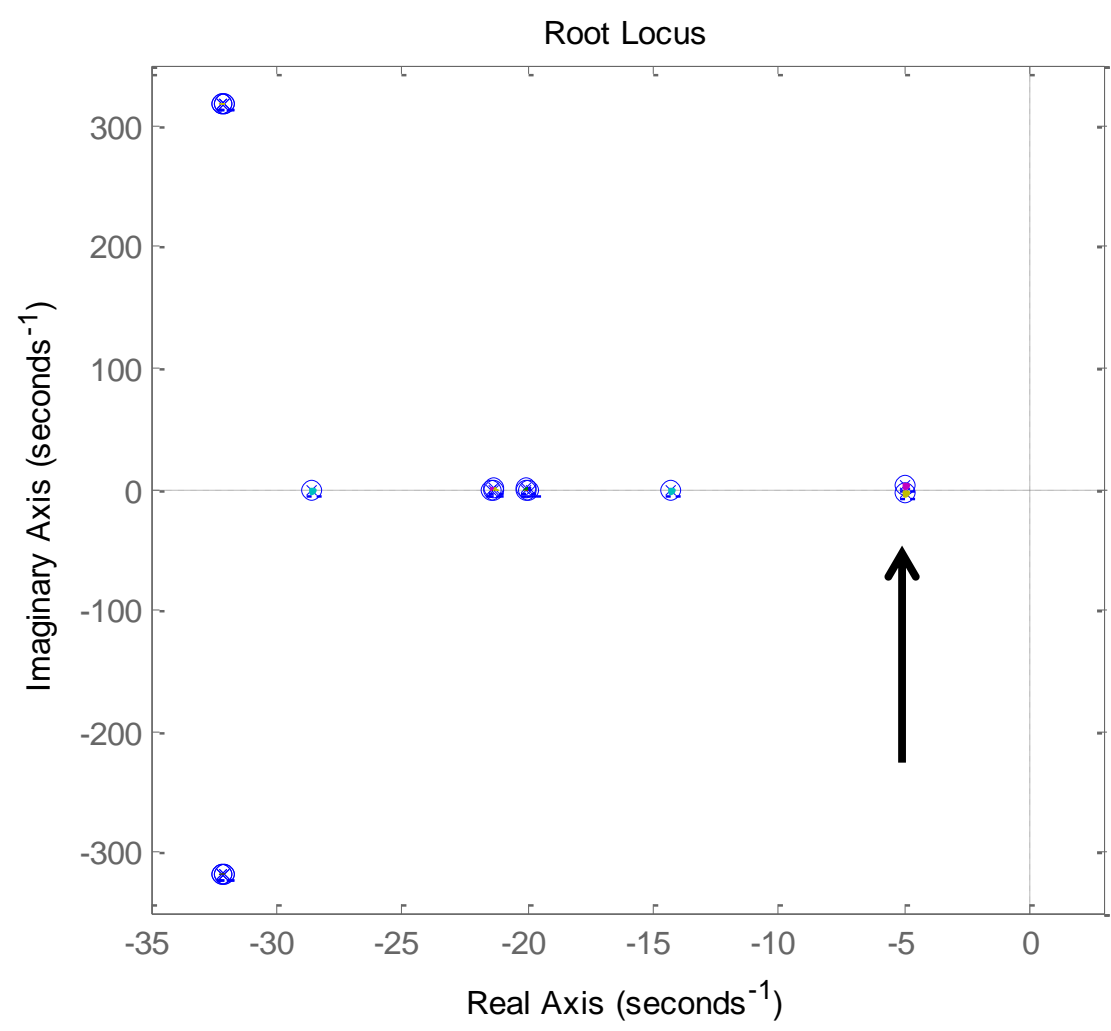

Figura 6.27 - Lugar das raízes para $K(s o c)=0,5$ mostrando o polo mais crítico que se movimenta para a região de instabilidade à medida que esta constante se reduz. 


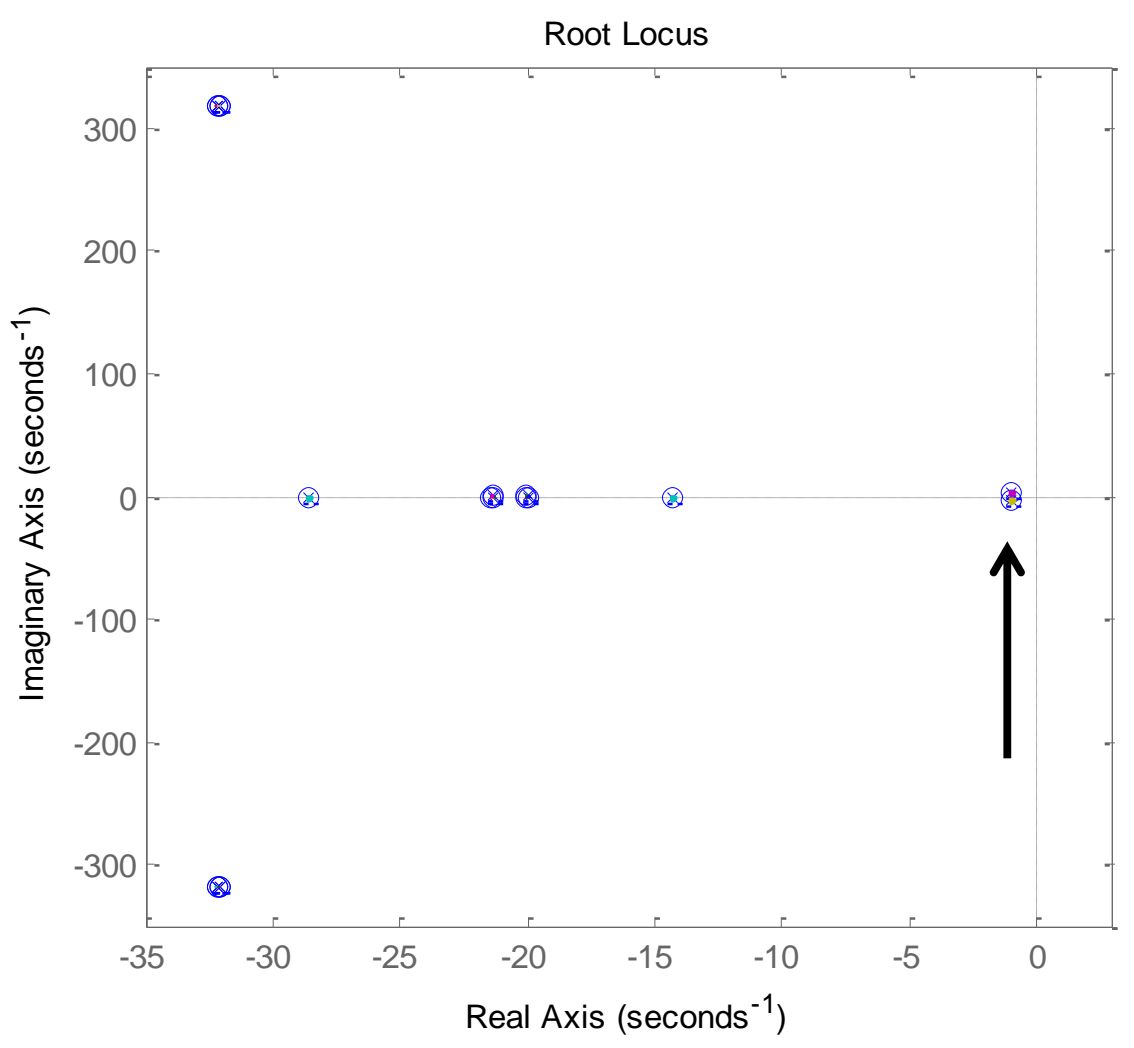

Figura 6.28 - Lugar das raízes para $K(S O c)=0,1$ mostrando o polo mais crítico que se movimenta para a região de instabilidade à medida que esta constante se reduz.

\subsection{Considerações Finais do Capítulo 6}

Neste capítulo foram apresentadas duas novas técnicas descentralizadas de divisão de carga utilizadas em microrredes híbridas. Estas técnicas direcionam os transitórios aos UCs, enquanto o regime permanente é fornecido por baterias, sem que haja qualquer tipo de rede de comunicação de alta velocidade. Na primeira técnica, o barramento $\mathrm{CC}$ não é restaurado, apresentando desvios proporcionais à carga. A segunda técnica possui a mesma funcionalidade da primeira, contudo o barramento CC é restaurado, graças à ação de controladores de tensão sincronizados.

As técnicas propostas foram testadas em um modelo médio e a estabilidade analisada por meio de uma estrutura de blocos, com os conversores modelados em pequenos sinais, de forma que fosse possível mostrar a influência do estado de carga sobre a estabilidade. Outra novidade apresentada foi a técnica de restauração dos UCs, que mantém estes armazenadores com uma quantidade de energia armazenada constante e sempre disponíveis para uso, sem a necessidade de parada para recarga dos mesmos. 


\section{Capítulo 7 \\ Modelo Simplificado e Algoritmos de Gerenciamento de Energia}

Neste capítulo, é descrito e simulado o modelo simplificado baseado no fluxo de potência da microrrede. Este modelo foi desenvolvido com o intuito de fornecer uma abordagem mais focada no gerenciamento e não nos dispositivos eletrônicos e de controle, vistos que estes já foram testados nos capítulos anteriores e se mostraram eficientes.

O enfoque no fluxo de potência sem levar em conta os modelos eletrônicos (considerando que os conversores são apenas ganhos de tensão ou corrente), faz com que o modelo exija pouco poder computacional e memória, permitindo simulações com intervalos de tempo da ordem de dias, logo, é possível analisar o impacto das estratégias de gerenciamento da microrrede de forma abrangente.

Assim, neste capítulo é considerado que, dada uma referência de corrente ou tensão a qualquer conversor, este é capaz de segui-la sem atraso, uma vez que os intervalos de tempo envolvidos são da ordem de horas e dias. A Fig. 7.1 apresenta o diagrama referente ao modelo simplificado da microrrede. Para que este modelo apresente um comportamento próximo ao real, foram utilizados dados reais de irradiação solar e velocidade do vento, Fig. 7.2 e 7.3, respectivamente [74].

De posse destes dados, duas funções que relacionam a potência máxima extraída da irradiação solar $\left(F_{1}(G)\right)$ e a potência máxima da velocidade do vento $\left(F_{2}\left(v_{\omega}\right)\right)$ são definidas, (7.1) e (7.2). Estas funções são definidas de acordo com os modelos matemáticos do PV e do aerogerador no Capítulo 3, que estabeleceu para o PV uma relação linear entre a irradiação incidente e a potência máxima extraída e uma relação cúbica entre a potência de saída de uma turbina eólica e a velocidade do vento incidente. Ambas as funções consideram a temperatura e ângulo das pás da turbina constantes.

Em outras palavras, as funções $F_{1}(G)$ e $F_{2}\left(v_{\omega}\right)$ representam o algoritmo MPPT extraindo a máxima potência da respectiva fonte alternativa, ou seja, dada uma irradiação solar ou velocidade do vento de entrada, a função extrai da sua fonte a máxima potência possível. 


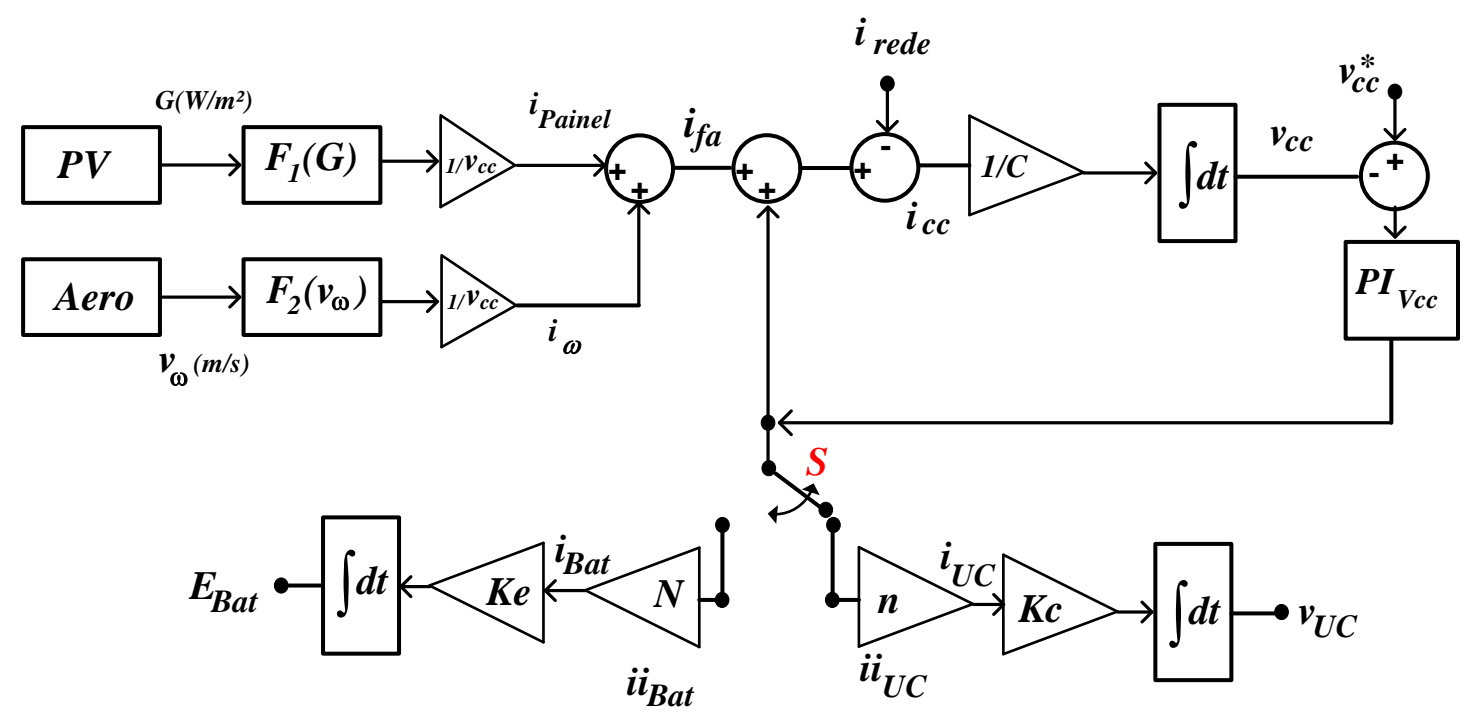

Fig. 7.1 - Modelo simplificado analisando valores médios.

$$
\begin{array}{r}
P_{\text {Painel }}(G)=F_{1}(G)=k 1 G \\
P_{\text {aero }}\left(v_{\omega}\right)=F_{2}\left(v_{\omega}\right)=k 2 v_{\omega}{ }^{3}
\end{array}
$$

As constantes $k 1$ e $k 2$ ajustam a potência da fonte de acordo com o desejado no modelo, ou seja, para um conjunto PV que produza $500 \mathrm{~W}$ no ponto de máximo, $k 1=0,5$ (unidade $\mathrm{em} \mathrm{m}^{2}$ ) uma vez que a irradiação máxima é de $1000 \mathrm{~W} / \mathrm{m}^{2}$. Para $k 2$ é usada uma turbina que produza um máximo de $500 \mathrm{~W}$ a $14 \mathrm{~m} / \mathrm{s} \operatorname{logo}, k 2=0,1822$ (unidade em Ws/m).

O modelo do barramento CC é definido pela equação do capacitor do barramento $v_{c c}=i_{c c} /_{s C}$, onde $i_{c c}=i_{f a}+i i_{u c}+i i_{B a t}-i_{r e d e}$. De forma a emular o controlador de tensão do barramento CC, o mesmo foi definido no Capítulo 4 e é utilizado no modelo simplificado, podendo atuar tanto na corrente da bateria quanto na corrente do UC (alterando a posição da chave " $S$ '), de acordo com as metodologias de gerenciamento que serão propostas neste capítulo. A inserção do controlador de tensão garante que o balanço de potência da equação (3.7) não seja quebrado, Fig. 7.1 e que a tensão do barramento CC se mantenha constante.

Tanto os modelos da bateria quanto do UC são considerados integradores de corrente, sendo que para a bateria possui a constante "Ke" que é relacionada à conversão da unidade da integral, de As para Ah e a constante " $N$ " que está relacionada ao ganho de corrente do conversor CC-CC (para a bateria foi considerado um ganho de corrente fixo no conversor, uma vez que tanto a tensão da bateria quanto do barramento CC são constantes). Para o UC deve-se 
considerar um ganho de corrente variável, uma vez que a tensão terminal do UC se altera de acordo com a carga armazenada, logo " $n$ " é definida como $n={ }^{v_{c c}} / v_{U C}$ e $K c=1 / U C$, representando a capacitância do banco UC.

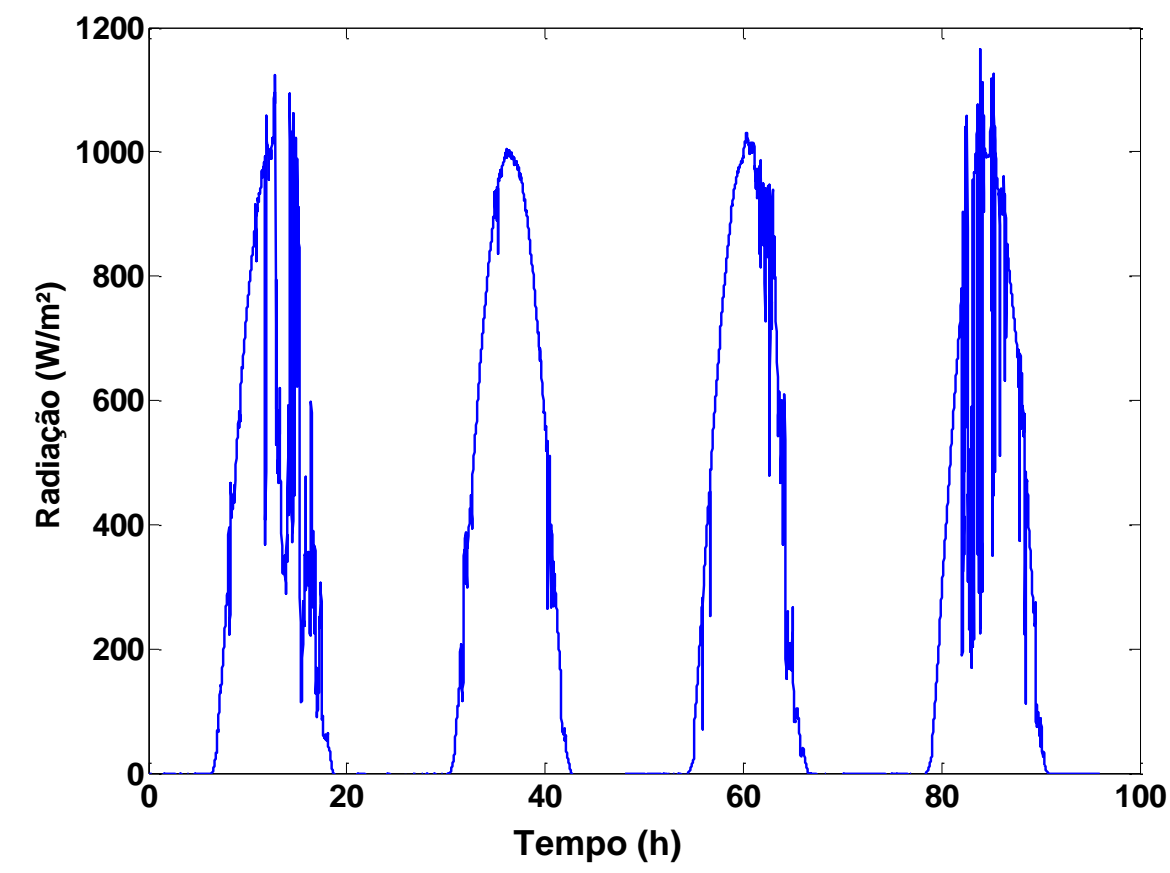

Figura 7.2 - Irradiação solar média global durante 96 h seguidas [74].

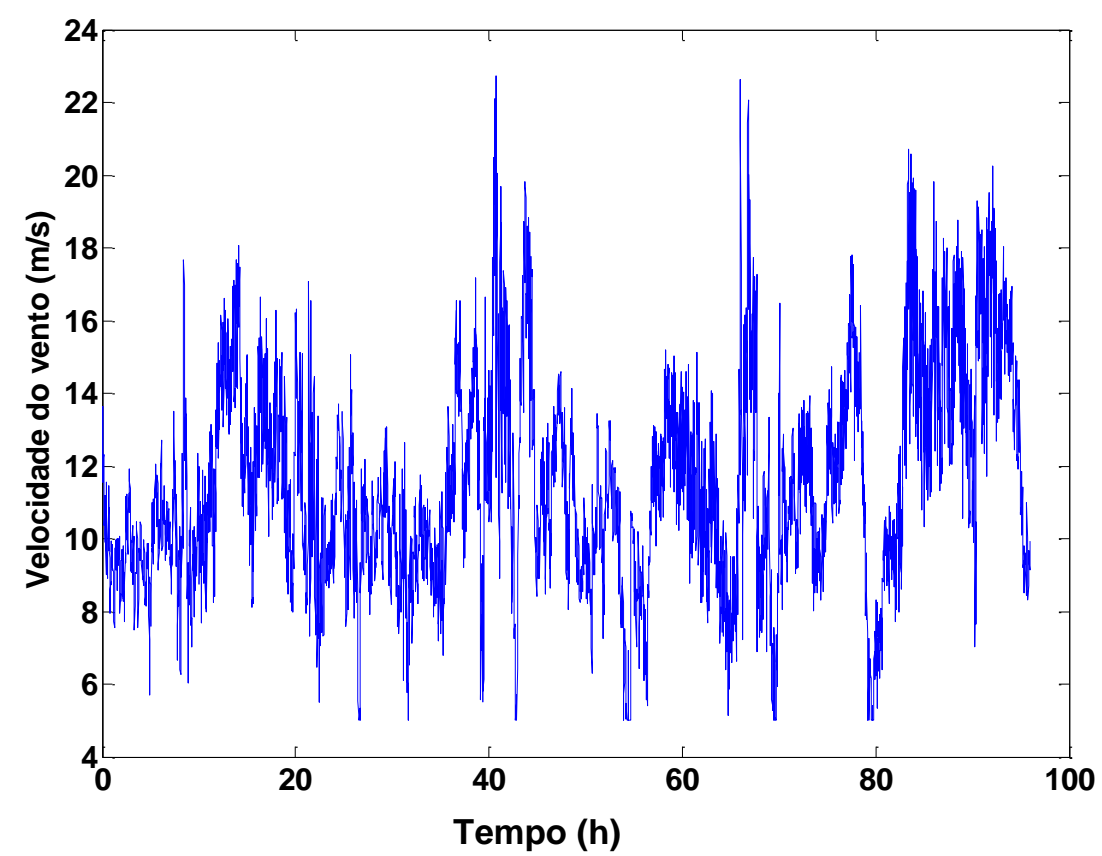

Figura 7.3 - Velocidade do vento durante 96 h seguidas [74].

A Fig. 7.4 mostra as potências geradas pelo conjunto fotovoltaico e aerogerador, sendo que $F_{1}(G)$ e $F_{2}\left(v_{\omega}\right)$ são modeladas de forma que $k 1=1$ e $k 2=0,094$ extraiam, no máximo, 
$1000 \mathrm{~W}$ de cada fonte, totalizando uma potência de pico máxima de $2000 \mathrm{~W}$, o que faz com que a corrente $i_{f a}$ máxima seja de $8 \mathrm{~A}$, uma vez que o barramento CC é de $250 \mathrm{~V}$.
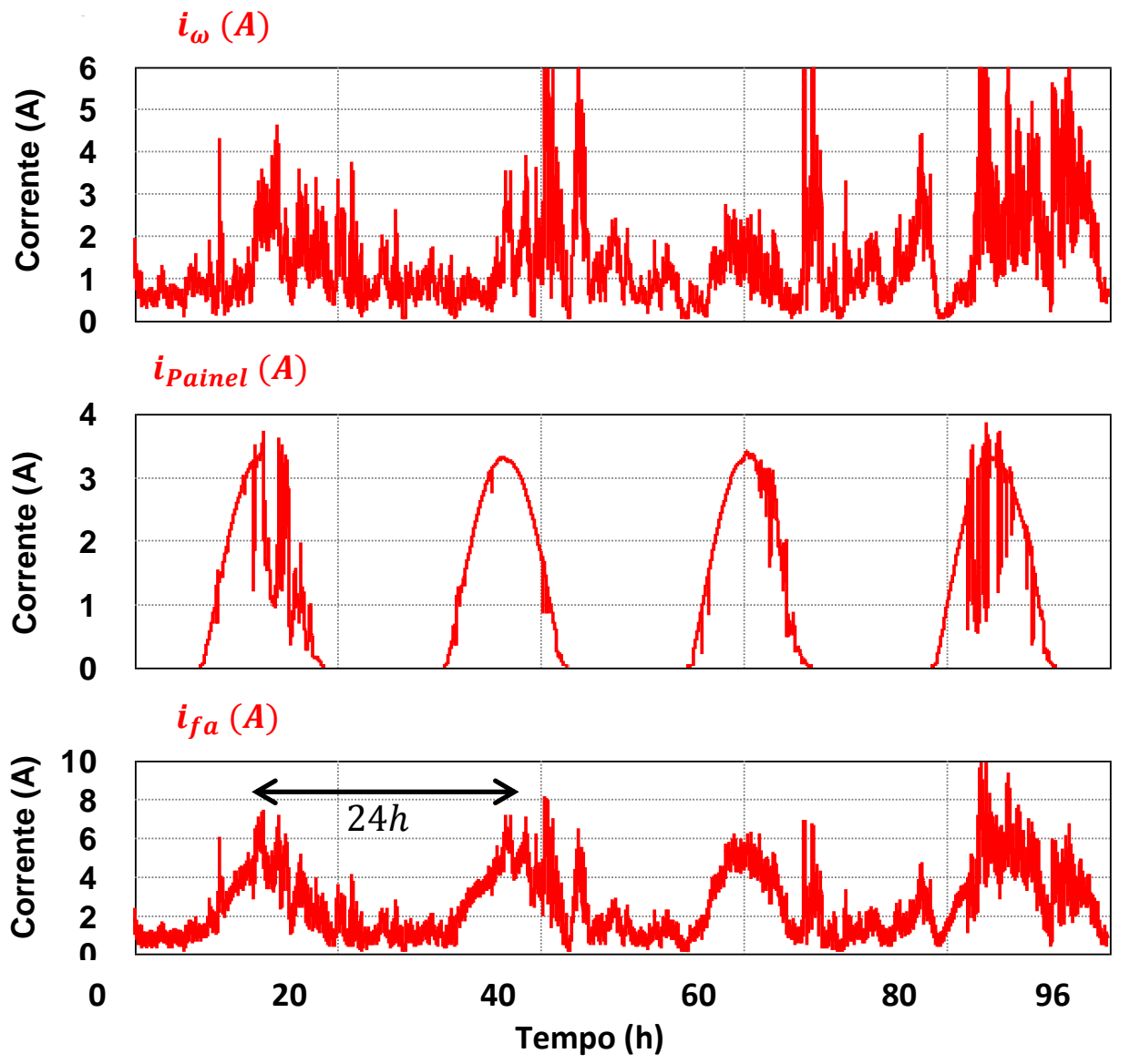

Figura 7.4 - Corrente média entregue ao barramento pelo aerogerador, painel fotovolotaico e a soma de ambas, respectivamente.

\subsection{Estratégia de Gerenciamento Baseado em UC de Alta Capacidade}

Assim como discutido no Capítulo 3, os UC apresentam uma vida útil muito superior a de outros tipos de armazenadores de energia baseados em princípios químicos, como por exemplo, as baterias. Além disso, eles possuem uma densidade de potência muito mais elevada [49], fazendo com que os algoritmos que gerenciem a energia em uma microrrede que empregue UC possam ter um desempenho muito mais elevado e um custo, a longo prazo, menor do que uma microrrede que empregue somente baterias por exemplo.

A Fig. 7.5 descreve o método de decisão proposto utilizado no algoritmo de gerenciamento baseado em UC, ou seja, o UC é responsável por controlar a tensão do barramento CC (chave $S$ do modelo da Fig. 7.1 está na posição do UC), enquanto a bateria se 
mantém inerte. Este algoritmo utiliza como variável de decisão a tensão terminal do UC, uma vez que a tensão de um capacitor está, diretamente, associada à energia armazenada, descrita pela equação $E\left(v_{U C}\right)=0,5 U C v_{U C}^{2}$, sendo $U C$ a capacitância do UC e $v_{U C}$ é a tensão terminal.

Como pode ser visto na Fig. 7.5, o algoritmo se comporta como um controlador a histerese, injetando uma corrente fixa na rede caso a tensão terminal do UC ultrapasse o limite superior $\left(V_{\lim _{s}}\right)$ ou transferindo potência nula para a rede de distribuição, caso a tensão do UC atinja o limite inferior $\left(V_{\lim _{i}}\right)$. O limite de tensão superior do algoritmo é selecionado de acordo com a limitação física do UC e o limite inferior de acordo com o ganho máximo de tensão do conversor CC-CC utilizado (no caso deste trabalho, o ganho máximo de 5 vezes com o conversor Boost) logo, para uma tensão CC de $250 \mathrm{~V}$ o limiar inferior será definido em $50 \mathrm{~V}$.

No momento em que a tensão terminal do UC atinge o limite superior, a corrente injetada na rede de distribuição é definida pela função $i_{\text {rede }}=$ Ceil $\left(i_{f a}\right)+$ constante, sendo que a função Ceil retorna o maior inteiro menor que o argumento da função, ou seja, a função arredonda o valor da corrente gerada pelas fontes alternativas $\left(i_{f a}\right)$ e adiciona um valor constante, pré-estabelecido.

Como consequência do uso desse tipo de função, a corrente injetada na rede é constante e superior à corrente gerada pelas fontes alternativas, produzindo um déficit energético na microrrede. Assim, o UC será responsável em suprir déficit, logo, ele se descarrega enquanto controla a tensão do barramento CC.

No momento no qual a tensão atinge o limite inferior, a corrente injetada na rede de distribuição é zerada, ou seja, existe um superávit de energia que é absorvida pelo UC, fazendo com que a tensão aumente. O resultado deste algoritmo é a produção de uma corrente injetada na rede de distribuição que alterna entre um valor constante inteiro maior que a corrente gerada e zero. Tal situação faz com que o intervalo de tempo no qual a corrente se mantém constante dependerá do déficit/superávit energético gerado pela técnica, da capacidade do UC e dos limites de tensão do método.

Como definido acima, o modo de ação do UC dependerá da sua tensão terminal, que é proporcional à energia armazenada do mesmo, logo, capacitores com maiores capacitâncias armazenam uma quantidade maior de energia, tendo a capacidade de fornecer energia, em regime permanente, por um tempo maior antes de mudar de estado. Assim, este método de gerenciamento apresenta melhor desempenho quanto maior for o UC, mantendo a corrente na rede de distribuição fixa por um tempo maior, independente de oscilações na geração. 
A Fig. 7.6 representa um intervalo de $15 \mathrm{~h}$ de simulação do modelo simplificado utilizando o algoritmo em questão. Neste teste é utilizado um UC de 200 F com os limiares de tensão do algoritmo em $80 \mathrm{~V}$ e $50 \mathrm{~V}$ e uma função $i_{\text {rede }}=$ Ceil $\left(i_{f a}\right)+2$. Nesta figura são apresentadas a tensão do barramento CC regulada em $250 \mathrm{~V}$, a corrente gerada pelas fontes alternativas $\left(i_{f a}\right)$, a corrente entregue à rede $\left(i_{\text {rede }}\right)$, tensão terminal do $\mathrm{UC}\left(v_{U C}\right)$ e a corrente que flui através do $\mathrm{UC}\left(i_{U C}\right)$ de forma a manter a estabilidade de $v_{c c}$.

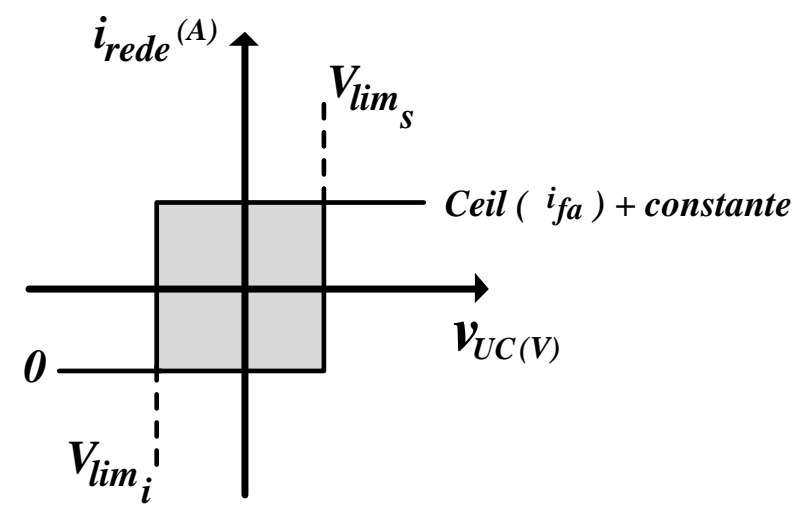

Figura 7.5- Algoritmo de decisão para o algoritmo de gerenciamento baseado no UC. 

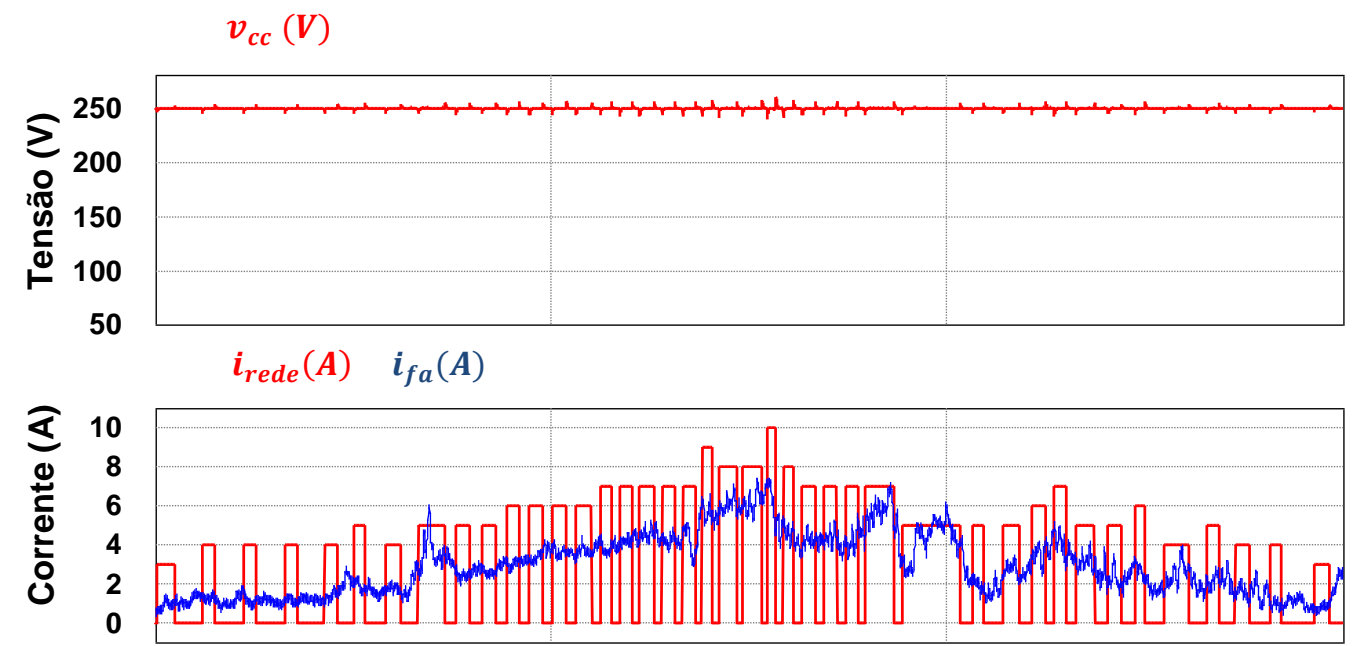

$v_{U C}(V)$
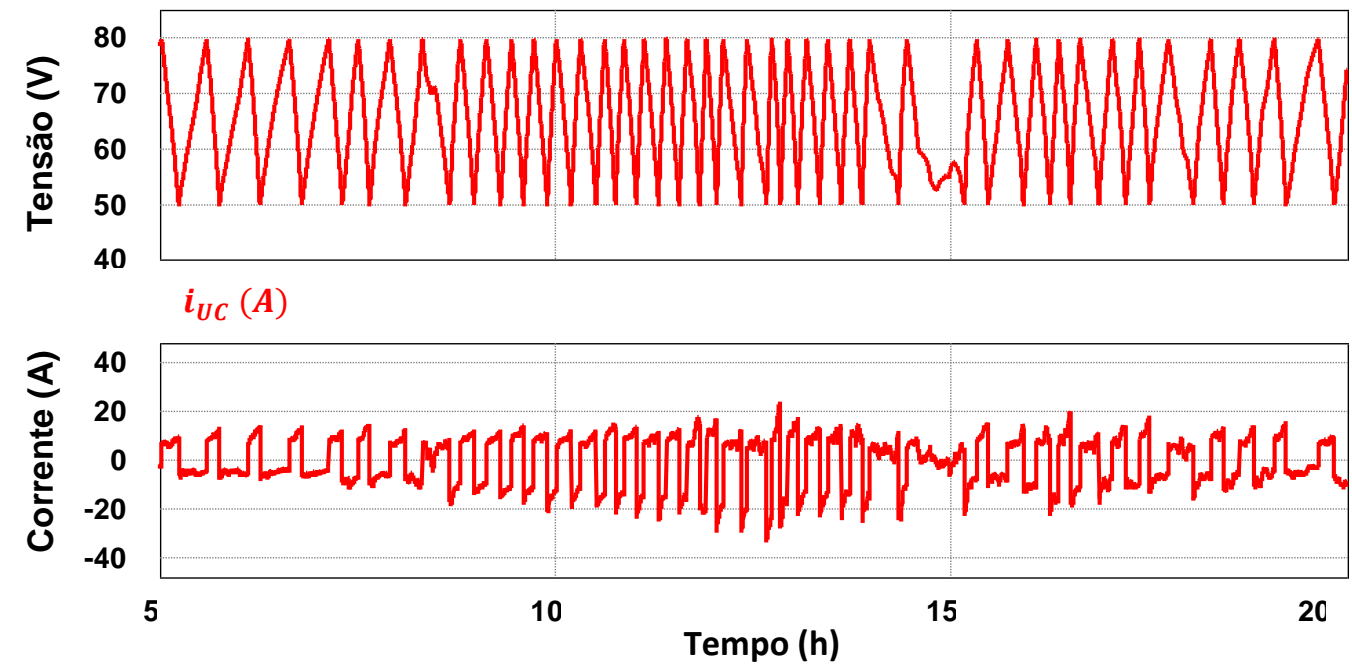

Figura 7.6 - Algoritmo de gerenciamento baseado no UC, quando há a injeção de potência na rede ocorre de forma de constante por intervalos.

A Fig. 7.7 mostra um zoom da Fig. 7.6 em um intervalo de 2 h. Nota-se que a corrente média injetada na rede apresenta um perfil chaveado, com intervalos constantes da ordem de minutos enquanto que, a tensão terminal do UC apresenta o perfil de uma histerese com $30 \mathrm{~V}$ de banda (variando de $80 \mathrm{~V}$ a $50 \mathrm{~V}$ como previsto). É possível expandir os intervalos de injeção constante pelo aumento da capacidade do UC, reduzindo a quantidade de steps aplicados na corrente que circula pela rede de distribuição, tornando a operação menos oscilatória.

De forma a evitar que a corrente injetada na rede de distribuição se reduza a zero ao atingir o limiar inferior, uma alteração no algoritmo pode ser implementada de forma que os steps de corrente alternem entre valores diferentes de zero. A Fig. 7.8 apresenta a modificação na estratégia de gerenciamento, ou seja, no instante em que a tensão do UC atinge o limite inferior a corrente da rede é ajustada em $i_{\text {rede }}=\operatorname{Ceil}\left(i_{f a}\right)-2$. A Fig. 7.9 apresenta o resultado da simulação do algoritmo de gerenciamento modificada, porém, agora a corrente injetada alterna-se entre valores em torno da corrente gerada. 


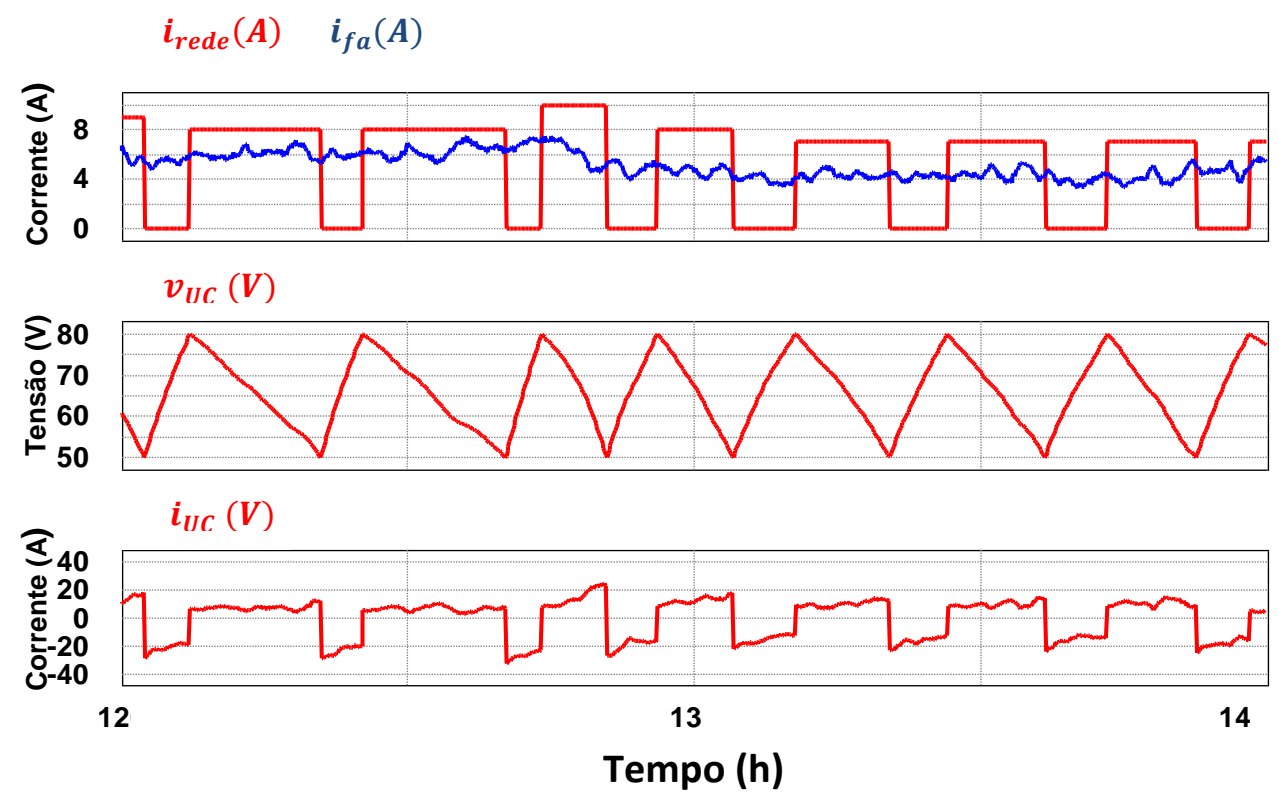

Figura 7.7 - Zoom sobre a Fig. 7.6.

Vale ressaltar que estes algoritmos baseados nos UCs eliminaram as oscilações aleatórias de alta frequência geradas pelas fontes alternativas, entretanto criaram oscilações em baixa frequência (com o período na ordem de alguns minutos), sendo que a frequência de oscilação gerada pode ser alterada de acordo com o tamanho do UC (reduzindo pela metade a capacidade do UC dobra-se a frequência de oscilação) Fig. 7.10.

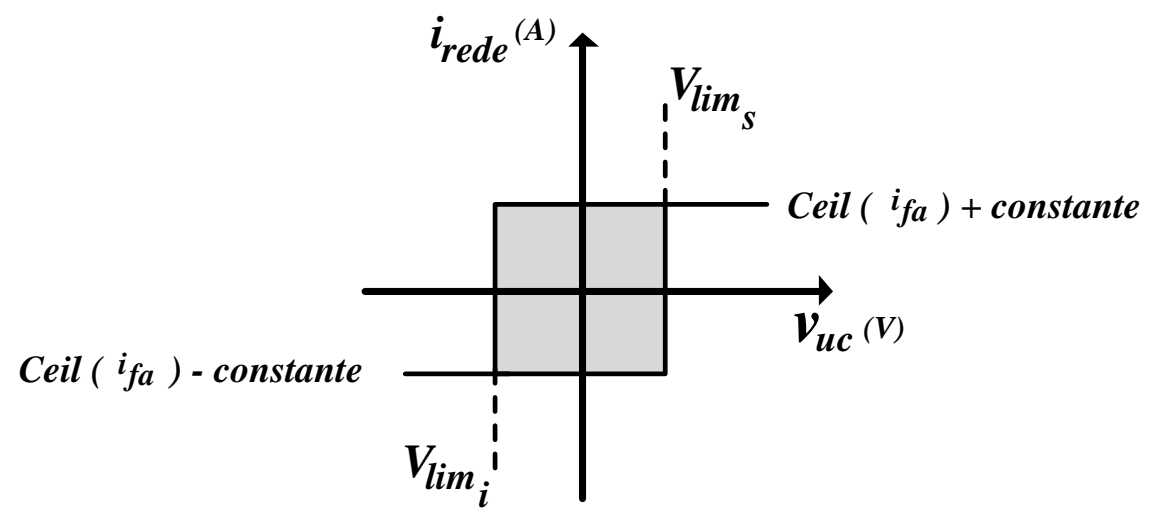

Figura 7.8 - Algoritmo de decisão modificado para o gerenciamento baseado no UC. 


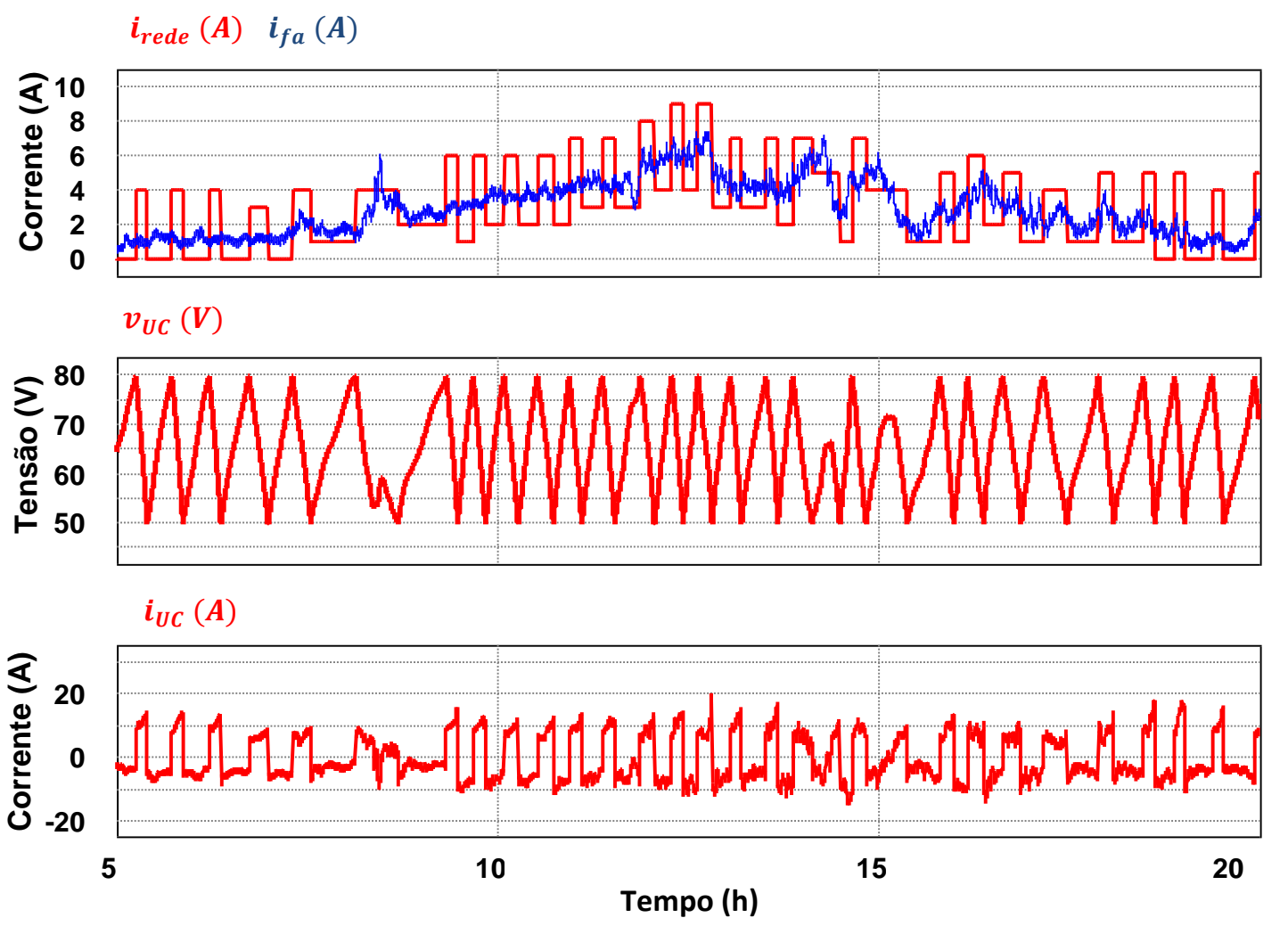

Figura 7.9 - Algoritmo de gerenciamento modificado baseado no UC, com a injeção de potência na rede constante por intervalos.

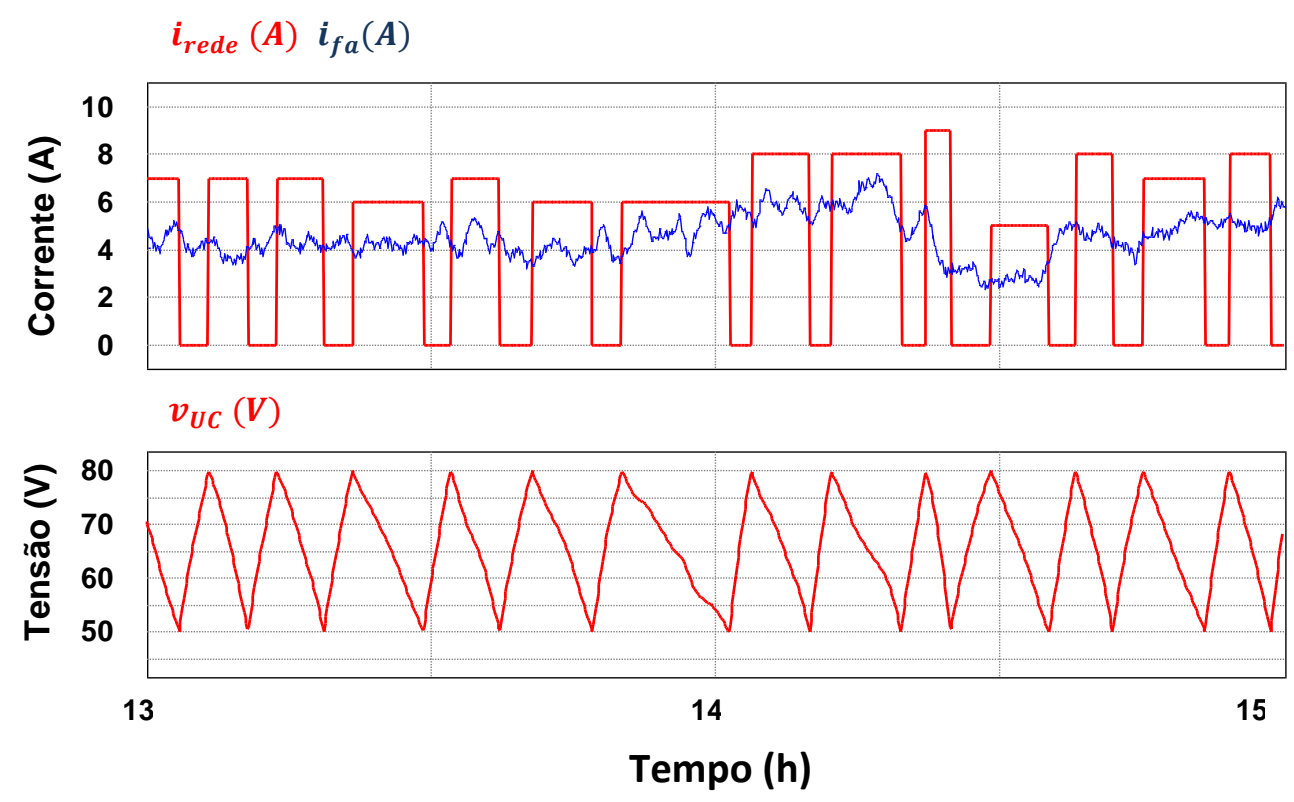

Figura 7.10 - Aumento da frequência de oscilação da corrente na rede pela redução do UC, $200 \mathrm{~F}$ para $100 \mathrm{~F}$ (Fig. 5.18). 


\subsection{Estratégia de Gerenciamento Baseado na Potência Média Gerada}

Nesta seção são apresentadas duas estratégias de gerenciamento da microrrede baseadas no banco de baterias, a primeira utiliza como referência para a corrente da rede a potência média gerada pelas fontes alternativas e a segunda é semelhante à estratégia aplicada nos UC, ou seja, espera-se uma injeção constante de potência na rede de distribuição pelo maior tempo possível. Uma vez que a bateria possui densidade energética superior àquela apresentada pelos UCs, permitindo diferentes manobras e em intervalos de tempo maior [67].

Assim como nas estratégias baseadas nos UCs, as estratégias desse capítulo apresentam como objetivo a redução ou eliminação de oscilações de potência de alta frequência na corrente/potência injetada na rede, com o intuito de melhorar a qualidade da energia produzida.

A Fig. 7.11 apresenta a estratégia de controle dos armazenadores e a forma como a referência de corrente injetada na rede de distribuição é gerada, sendo ela definida pelo valor filtrado da potência gerada pelas fontes alternativas.

Para simular esta estrutura de gerenciamento em intervalos de tempo da ordem de dias, será utilizado o modelo simplificado de energias que foi apresentado na Fig. 7.1 (neste caso a chave " $S$ " está na posição bateria) e utiliza os mesmos parâmetros das Fig. 7.2 e 7.3. Além disso, não será considerado, na simulação simplificada, o uso do UC suprindo os transitórios de energia, como definido pela técnica da Fig. 7.11, uma vez que como visto na seção 5.1 a variação da energia média no UC é zero, devido à restauração da tensão terminal, logo, toda energia em regime permanente é fornecida pela bateria quando utilizado esta técnica. Assim, a execução é simplificada, sem perder o foco no fluxo de energia do sistema, que é o ponto em questão. Nesta seção também será definida a influência da ordem e constante de tempo do filtro de potência $\left(F_{n}(s)\right)$ na energia demandada do conjunto de baterias.

A Fig. 7.12 apresenta o resultado da simulação do modelo simplificado utilizando a estratégia proposta (Fig. 7.11) para uma constante de tempo no FPB $F_{n}(s)$ de 0,5 h. Nota-se que a corrente entregue à rede de distribuição $\left(i_{\text {rede }}\right)$ apresenta o mesmo perfil da corrente gerada pelas fontes alternativas $\left(i_{f a}\right)$, entretanto as oscilações de alta frequência foram transferidas para corrente da bateria $\left(i_{B a t}\right)$.

Dessa forma, utilizando uma constante de tempo igual a $0,5 \mathrm{~h}$ para microrrede que gere $2 \mathrm{~kW}$ de pico, é necessária uma bateria com uma capacidade de aproximadamente $14 \mathrm{Ah}$, uma 
vez que a energia acumulada na bateria $\left(E_{B a t}\right)$ alcança valores próximos de 13 Ah no horário de pico de geração. Caso uma bateria de menor capacidade fosse utilizada, no momento em que a carga máxima da bateria fosse alcançada, a microrrede seria obrigada a entregar para a rede uma maior quantidade de energia do que está sendo gerado, de forma a não sobrecarregar a bateria, perdendo a característica da filtragem de potência. Além disso, o sistema corre o risco de entrar em colapso por falta de energia, uma vez que a microrrede deixou de armazenar o que deveria, de acordo com o filtro $F_{n}(s)$. Logo, a operação de filtragem não pode ser garantida durante toda a operação caso a bateria seja sub dimensionada.
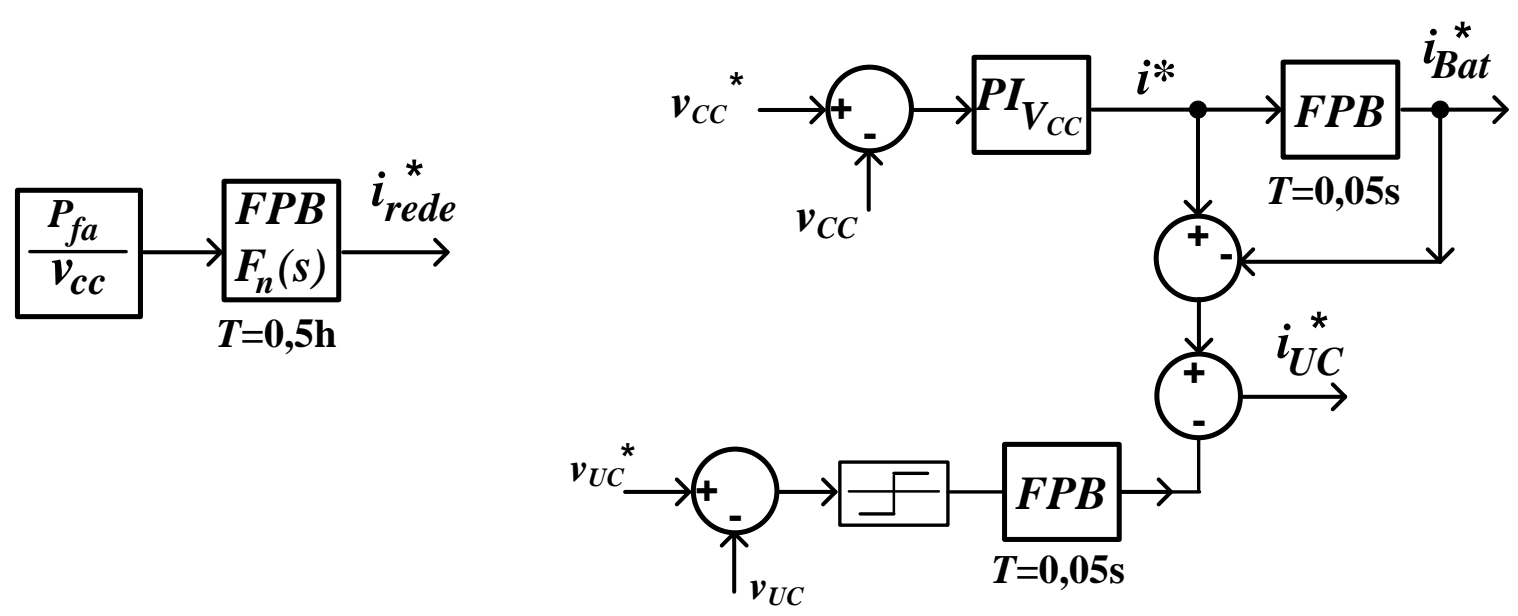

Figura 7.11- Estratégia de controle da bateria combinada com UC e referência do inversor conectado. 

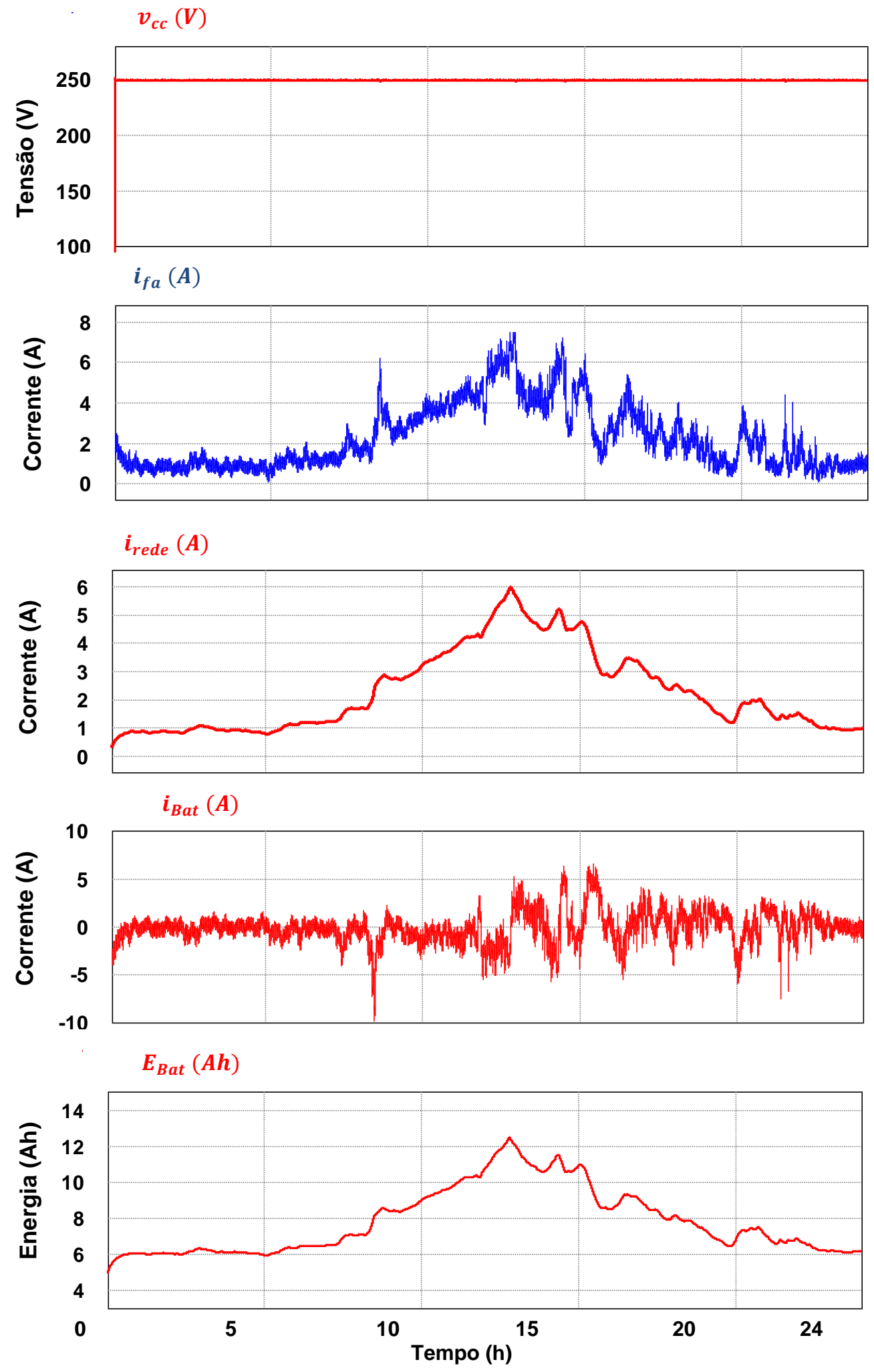

Figura 7.12- Algoritmo de gerenciamento baseado na média da potência gerada e a constante de tempo do filtro é ajustada em $0,5 \mathrm{~h}$.

Caso seja requerido um menor nível de oscilação de potência a ser transferido para a rede de distribuição, a constante de tempo do filtro pode ser ajustada de forma a reduzir essa 
variação. Como consequência disso, a capacidade da bateria deve ser aumentada, uma vez que a energia média necessária ao funcionamento aumenta na mesma proporção.

Suponha que a corrente gerada pelas fontes alternativas é representada por $i_{f a}=I_{f a}+$ $\widehat{l_{f a}}$ cujo primeiro termo dessa igualdade representa os valores médios e o segundo termo as variações em torno do ponto médio. Aplicando um $F P B$ com uma constante de tempo $T$ (na corrente) $I_{f a}$, tem-se (7.3). Uma vez que o $P I_{V_{c c}}$ garante o equilíbrio das correntes no barramento CC, pode-se afirmar (7.4). Substituindo (7.3) em (7.4) e integrando, pode-se obter a energia média entregue à bateria do sistema (7.8), que representa a relação entre a energia média armazenada nas baterias, a corrente média gerada pelas fontes e a constante de tempo do filtro.

$$
\begin{gathered}
I_{\text {rede }}(s)=I_{f a}(s) \frac{1 / T}{s+1 / T} \\
I_{B a t}(s)=I_{f a}(s)-I_{\text {rede }}(s) \\
I_{B a t}(s)=I_{f a}(s)-I_{f a}(s) \frac{1 / T}{s+1 / T} \\
I_{B a t}(s)=I_{f a}(s) \frac{s}{s+1 / T}
\end{gathered}
$$

Integrando (7.6) para se obter a energia acumulada na bateria tem-se:

$$
H(s)=\frac{E_{B a t}(s)}{I_{f a}(s)}=\frac{k}{s+1 / T}
$$

Logo, aplicando o teorema do valor médio, em regime permanente ou $\lim _{s \rightarrow 0} H(s)$.

$$
E_{m}=k I_{f a} T
$$

Assim, de (7.8) conclui-se que a energia média na bateria $\left(E_{m}\right)$ é, diretamente dependente da constante de tempo do filtro. Em outras palavras, com o aumento da constante de tempo, obtém-se uma maior filtragem da potência gerada, fazendo com que a potência injetada na rede de distribuição possua um perfil suave, em contrapartida, a energia média necessária nas baterias para a operação da microrrede aumenta proporcionalmente a $T$.

Considerando que o componente fundamental da oscilação de $\widehat{\iota_{f a}}$ (com frequência $W_{f a}$ ) possui um período de $24 \mathrm{~h}$ (pico de potência ao meio dia Fig. 7.4), logo o módulo da função $H(s)(7.7)$, na frequência fundamental de $\widehat{l_{f a}}(1 / 24 \mathrm{~h})$, indica a influência da constante 
de tempo na amplitude da oscilação de energia da bateria (7.9), uma vez que a frequência da oscilação fundamental é fixa, Fig. 7.13. Note ainda, que (7.8) pode ser obtida a partir de (7.9) quando $W_{f a}=0$, o que quer dizer que $\widehat{l_{f a}}$ possui frequência de oscilação igual a zero, ou seja, $I_{f a}=\widehat{l_{f a}}$, levando (7.9) a se tornar (7.8).

$$
E_{S}=|H(j w)| \widehat{l_{f a}}=\frac{k}{\sqrt{W_{f a}{ }^{2}+1 / T^{2}}} \widehat{l_{f a}}
$$

Plotando a equação (7.9) em um gráfico, obtém-se a Fig. 7.14, nota-se que a amplitude da oscilação $\left(E_{s}\right)$ cresce até certo momento e somente então, ela se torna constante. O ponto no qual a oscilação se torna constante se dá quando a constante de tempo é tão grande que a potência entregue à rede de distribuição se torna constante e igual à média da potência gerada. Assim a oscilação de energia na bateria é igual à oscilação de energia gerada.

Logo, a capacidade mínima do banco de baterias deve ser projetada de acordo com a constante de tempo do filtro de potência, ou seja, a capacidade mínima deve ser maior ou igual à energia média $\left(E_{m}\right)$ acrescida da metade da oscilação de energia $\left(E_{s}\right)$, como pode ser visto na Fig. 7.13.

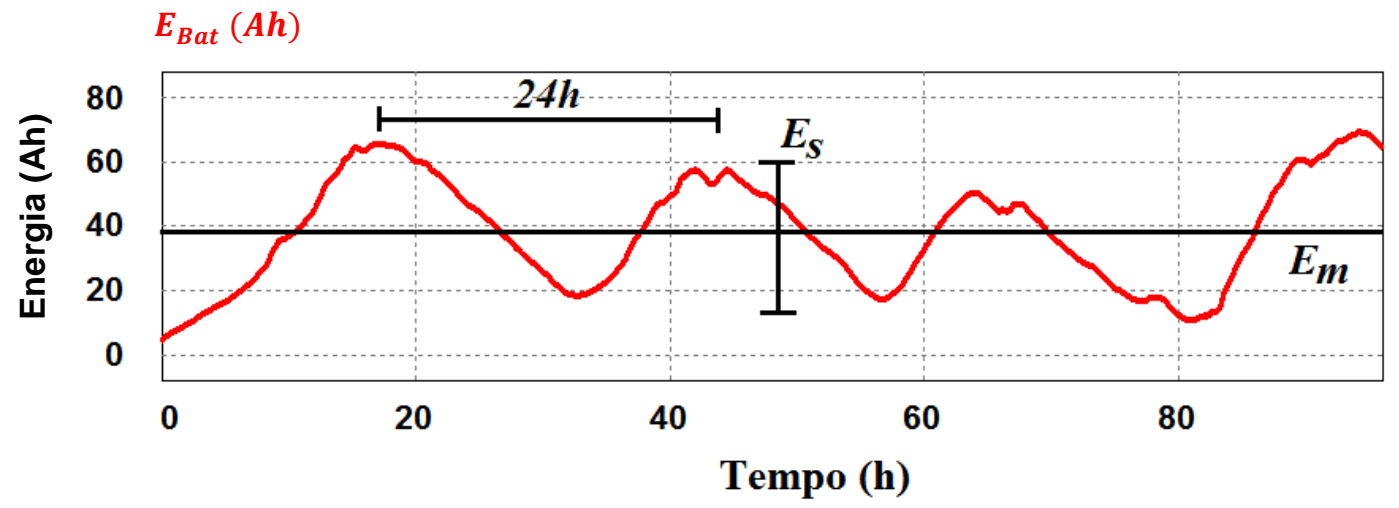

Figura 7.13- Energia média na bateria $\left(E_{m}\right)$ oscilação de energia $\left(E_{s}\right)$ e frequência da oscilação. 


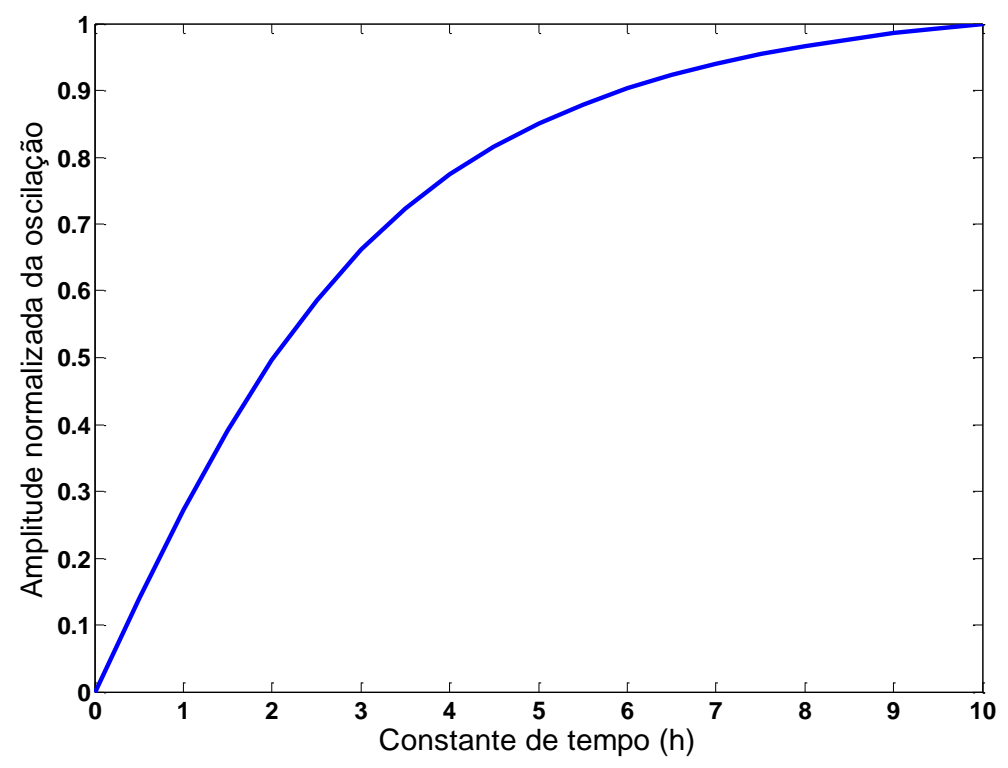

Figura 7.14 - Variação da oscilação de energia $E_{s}$ no banco de baterias com o aumento da constante de tempo.

Fazendo a mesma análise para um filtro $F_{n}(S)$ genérico passa-baixa de ordem ' $n$ ' é possível definir as equações (7.10) a (7.19):

$$
\begin{gathered}
I_{\text {rede }}(s)=I_{f a}(s) \overbrace{\left(\frac{1}{T_{F} s+1}\right)^{n}}^{F_{n}(S)} \\
I_{\text {Bat }}(s)=I_{f a}(s)-I_{\text {rede }}(s) \\
E_{\text {Bat }}(s)=I_{f a}(s)\left(1-\left(\frac{1}{T_{F} s+1}\right)^{n}\right) \frac{1}{s}
\end{gathered}
$$

Utilizando o binômio Newton (7.14) para expandir a equação (7.15), encontra-se a equação (7.16) que pode ser reescrita como (7.17), cujos coeficientes $K_{0} \ldots K_{n}$ são os coeficientes do filtro. Assim, a partir de (7.14) conclui-se que $K_{n}=K_{0}=1$ e $K_{n-1}=K_{1}=n$ logo, (7.16) pode ser simplificada conforme é visto em (7.18).

$$
\begin{gathered}
(X+1)^{n}=\sum_{m=0}^{n}\left(\begin{array}{c}
n \\
m
\end{array}\right) X^{n-m} \\
H_{n}(s)=\frac{E_{B a t}(s)}{I_{f a}(s)}=\left(\frac{\left(T_{F} s+1\right)^{n}-1}{\left(T_{F} s+1\right)^{n}}\right) \frac{1}{s} \\
H_{n}(s)=\left(\frac{K_{0}\left(T_{F} S\right)^{n}+K_{1}\left(T_{F} s\right)^{n-1} \ldots+K_{n-1}\left(T_{F} s\right)^{1}+K_{n}\left(T_{F} s\right)^{0}-1}{\left(T_{F} s+1\right)^{n}}\right) \frac{1}{s}
\end{gathered}
$$




$$
H_{n}(s)=\left(\frac{K_{0} T_{F}^{n} s^{n-1}+K_{1} T_{F}{ }^{n-1} s^{n-2}+\cdots+K_{n-2} T_{F}^{2} s^{1}+n T_{F}}{\left(T_{F} s+1\right)^{n}}\right)
$$

Utilizando o teorema do valor final em resposta ao degrau para encontrar o valor de regime permanente, a equação (7.19) é encontrada.

$$
E_{m}=\lim _{s \rightarrow 0} H_{n}(s) I_{f a}(s)=\lim _{s \rightarrow 0}\left(\frac{K_{0} T_{F}{ }^{n} s^{n-1}+K_{1} T_{F}{ }^{n-1} s^{n-2} \ldots K_{n-2} T_{F}^{2} s^{1}+n T_{F}}{\left(T_{F} s+1\right)^{n}}\right) I_{f a}(s)
$$

Logo:

$$
E_{m_{n}}=k I_{f a} n T_{F}
$$

Assim, conclui-se que ao empregar esta técnica, a energia média nas baterias sempre será proporcional à constante de tempo e à ordem do filtro. Para ilustrar a dependência da energia em relação à ordem do filtro, foram projetados quatro diferentes filtros (ordens 1, 2 e 3 e um filtro butterworth de segunda ordem) todos com a mesma frequência de corte $W_{c}=1$ rad/s (7.20). A Fig. 7.15 mostra a resposta em frequência dos filtros e as respostas de energia $\left|F_{n}(s)\right|$ e $\left|H_{n}(s)\right|$ para todos os quatro filtros.

$$
T_{F}=\frac{1}{W_{c}} \sqrt{\sqrt[n]{2}-1}
$$

Ao analisar a Fig. 7.15 é possível inferir que os filtros $F_{n}(s)$ apresentaram a mesma frequência de corte e mesmo ganho nas baixas frequências. No entanto quando a análise é realizada sobre $H_{n}(s)$, o filtro de terceira ordem apresenta a maior energia necessária para realizar a filtragem de corrente/potência (maior ganho em baixa frequência), como definido pela equação (7.19).

Assim, ao utilizar os filtros $F_{n}(s)$ na estratégia e no modelo simplificado da Fig. 7.1, é possível observar que a corrente média entregue à rede distribuição difere, ligeiramente, para cada ordem, Fig. 7.16, porém a energia demandada das baterias cresce com a ordem de $H_{n}(s)$, Fig. 7.17. Isto ocorre, pois os filtros de diferentes ordens, apesar de apresentarem o mesmo ganho em regime (frequência zero) e mesma frequência de corte, se comportam de maneira diferente ao longo do espectro, fazendo o filtro com maior ordem requisitar maior capacidade de armazenamento de energia da bateria, como previsto por (7.19). 

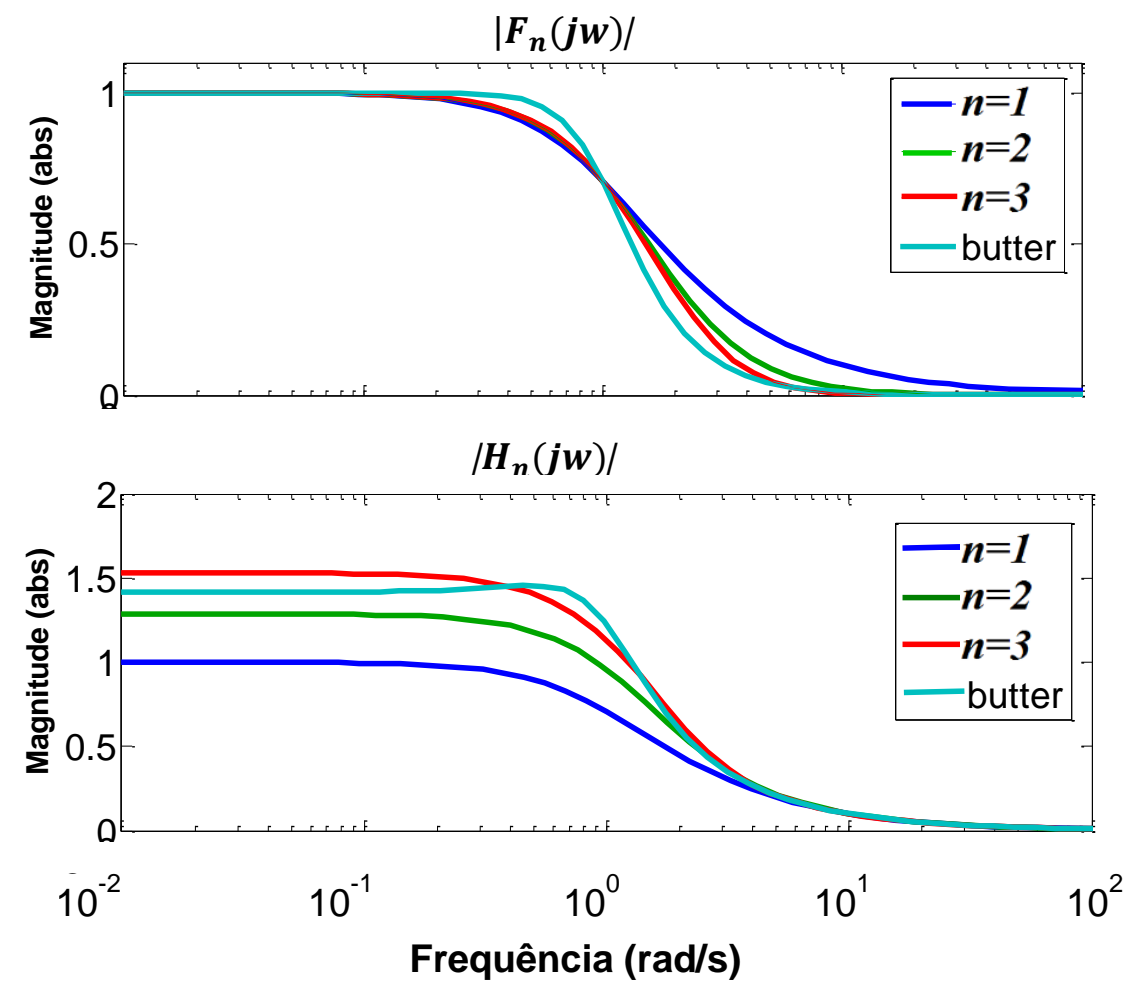

Figura 7.15 - Resposta de $F_{n}(s)$ e $H_{n}(s)$ para a mesma frequência de corte $1 \mathrm{rad} / \mathrm{s}$.

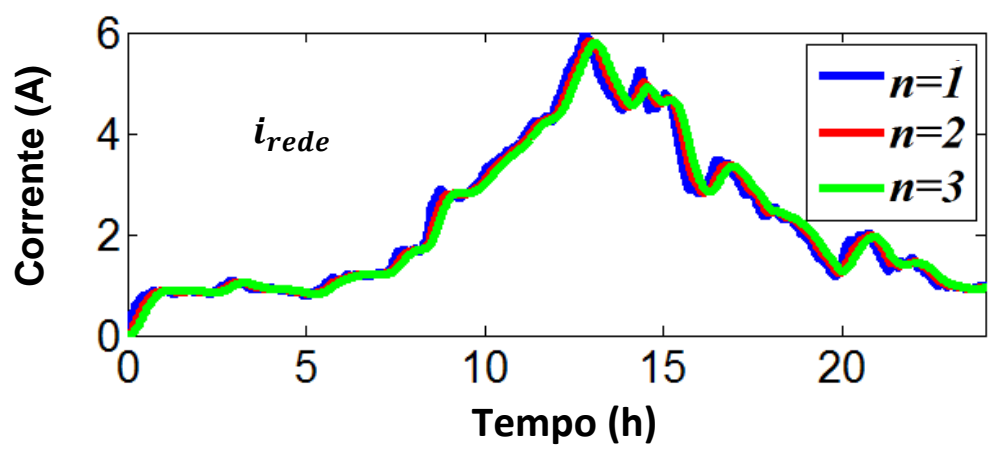

Figura 7.16 - Corrente média entregue a rede usando filtros de ordem 1, 2 e 3 e frequência de corte $1 \mathrm{rad} / \mathrm{s}$.

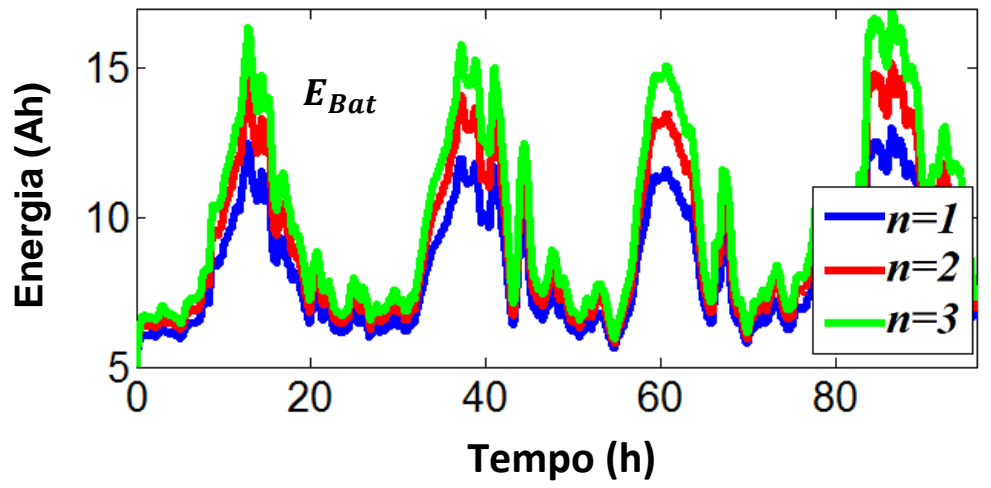

Figura 7.17- Energia da bateria usando filtros de ordem 1, 2 e 3 e frequência de corte $1 \mathrm{rad} / \mathrm{s}$. 
As Fig. 7.18 e 7.19 mostram a resposta da estrutura de controle da microrrede para três filtros de primeira ordem com constantes de tempo distintas $T=0,5 \mathrm{~h}, T=3 \mathrm{~h}$ e $T=8 \mathrm{~h}$, respectivamente, ou seja, ao aumentar a constante de tempo há uma redução na distorção da corrente média entregue à rede de distribuição bem como, um aumento tanto na energia média quanto na amplitude da oscilação de energia nas baterias conforme é descrito pelas equações (7.8) e (7.9).

Analisando os dados simulados dos resultados das figuras 7.18 e 7.19 para $T=3$ h e $T=$ $8 \mathrm{~h}$, pode-se calcular um aumento na média da energia da bateria $\left(E_{B a t}\right)$ de 2,29 vezes e de 45\% na amplitude das oscilações de energia. Este resultado é condizente com as equações (7.8) e (7.9), uma vez que um aumento da constante de tempo de $T=3 \mathrm{~h}$ para $T=8 \mathrm{~h}$, teoricamente, produziria um incremento de 2,66 vezes na energia média e de $46 \%$ de aumento nas oscilações.

Outra característica deste método de gerenciamento pode ser visto na Fig. 7.20, que mostra a corrente gerada pelas fontes alternativas e a corrente injetada na rede de distribuição para uma constante de tempo de $T=3 \mathrm{~h}$. Nesse caso, é possível verificar um atraso na corrente injetada em relação à corrente gerada que é decorrente da característica do filtro, que desloca a curva de potência, movendo o pico de geração para um horário proporcional a $T$, logo, em uma situação de operação do sistema elétrico, pode-se alterar a constante de tempo $T$ de forma a atrasar o pico de geração ao ponto desejado.

Uma solução para se obter potência constante através da rede de distribuição seria aumentar a constante de tempo do filtro para valores elevados, contudo, foi mostrado pela equação (7.8) que para esta abordagem, uma bateria de capacidade infinita seria necessária.

Assim, uma alteração na abordagem inicial é apresentada para a eliminação das oscilações na rede de distribuição e produzir baterias com capacidades factíveis (possíveis de serem encontradas no mercado). Tal metodologia faz uso de uma abordagem semelhante àquela usada nos UCs, porém, diferentemente do que acontecia com os UCs, a bateria possui uma densidade de energia muito superior, permitindo intervalos de injeção de potência constante por horas. 


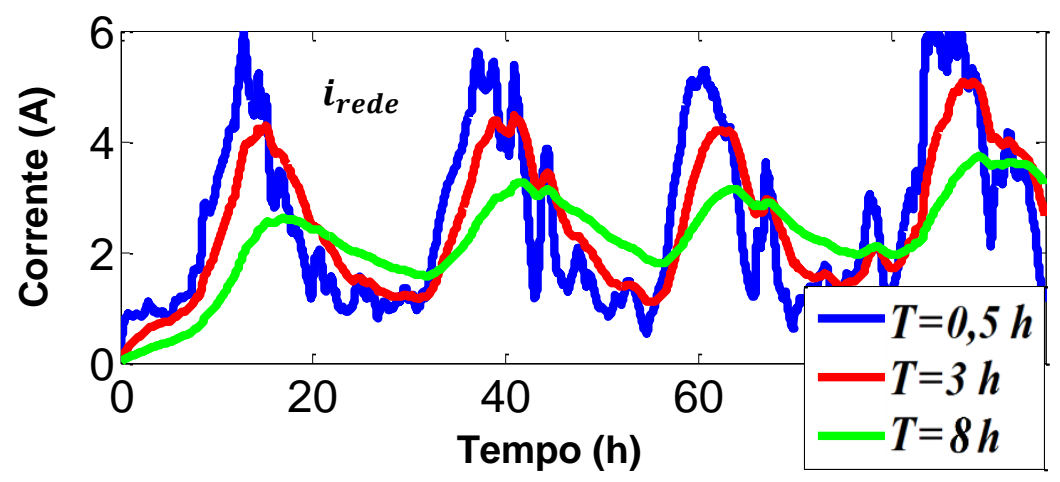

Figura 7.18 - Filtragem da potência entregue a rede de distribuição ou sub transmissão para constantes de tempo $T=0,5 \mathrm{~h}, T=3 \mathrm{~h}$ e $T=8 \mathrm{~h}$.

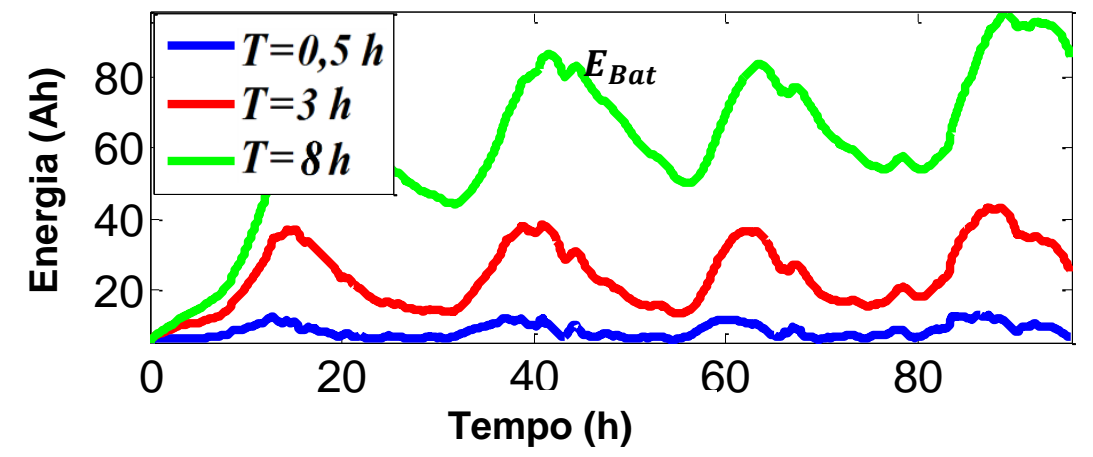

Figura 7.19 - Energia total requerida da bateria para constantes de tempo $T=0,5 \mathrm{~h}, T=3 \mathrm{~h}$ e $T=8 \mathrm{~h}$.

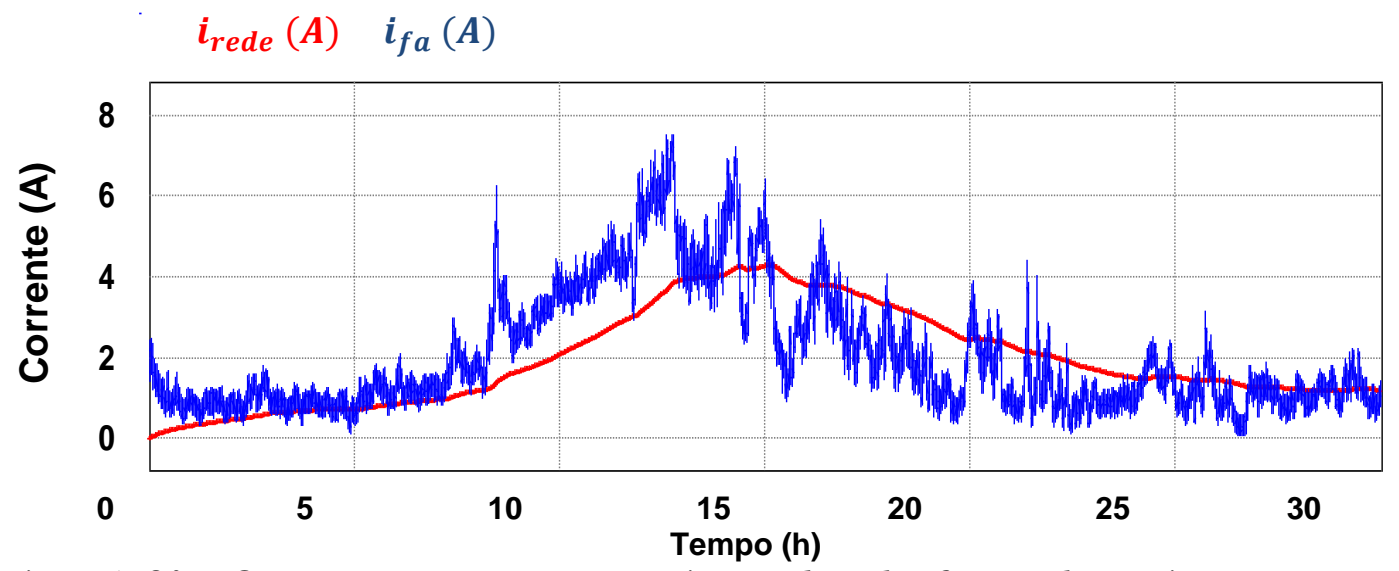

Figura 7.20 - Comparação entre a potência gerada pelas fontes alternativas com a potência injetada na rede para uma constante de tempo $T=3 \mathrm{~h}$.

A Fig. 7.21 apresenta a metodologia de decisão utilizada para esta estratégia de gerenciamento, cuja corrente injetada na rede $\left(i_{\text {rede }}\right)$ é definida constante $\left(i_{g}\right)$ a partir do momento em que a energia total acumulada nas baterias é maior que um valor específico $\left(E_{g}\right)$, ou seja, a corrente fornecida à rede de distribuição só retorna ao estado zero no momento em que a bateria atinge o limiar inferior de energia (neste caso definido como $5 \mathrm{Ah}$ ). 


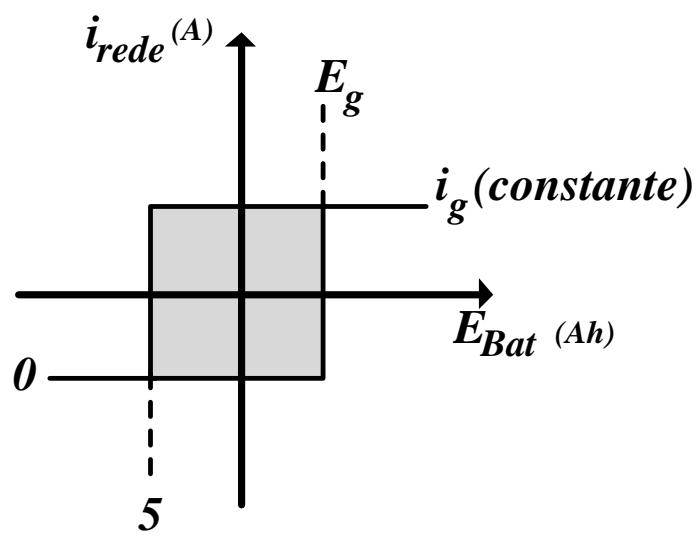

Figura 7.21 - Algoritmo de decisão empregado no gerenciamento baseado na bateria.

Considerando os resultados apresentados nas simulações das Figs. 7.2 e 7.3 para uma microrrede que possui um conjunto de painéis fotovoltaicos que produzem $1 \mathrm{~kW}$ e um aerogerador de similar capacidade $(1 \mathrm{~kW})$, o total máximo produzido durante as melhores condições atmosféricas é uma potência de pico de $2 \mathrm{~kW}$ e média de $650 \mathrm{~W}$. Entretanto, devido às características da estratégia proposta (Fig. 7.21), se uma potência média transferida para a rede de distribuição for inferior aos $650 \mathrm{~W}$, a capacidade da bateria precisaria ser infinita para manter a estabilidade da microrrede, uma vez que sempre haveria superávit de energia, dado que o sistema produz $650 \mathrm{~W}$ de média, porém o seu consumo é menor do que é gerado.

Caso um valor de potência superior a $650 \mathrm{~W}$ sejam entregues à rede de distribuição, a bateria tenderá a se descarregar por completo, devido ao déficit energético. Logo, nesta metodologia é necessário que o valor de potência constante entregue à rede de distribuição permaneça em torno da média gerada, que é conhecida pelo projetista da microrrede, uma vez que as condições climáticas locais são estudadas antes da implantação das fontes alternativas. Este valor pode ser corrigido por um filtro de média, de forma que a microrrede entregue uma potência constante em torno da média gerada.

De forma a estimar a capacidade mínima da bateria e o valor de $E_{g}$ do algoritmo para garantir um funcionamento estável, é preciso conhecer a potência máxima e média produzida pela microrrede em estudo. Logo, considera-se que a potência entregue à rede de distribuição é igual à média gerada de acordo com os dados de entrada $\left(i_{g}=2,6 \mathrm{~A}\right.$ ou $\left.650 \mathrm{~W}\right)$, de forma a não produzir déficits ou superávits energéticos na bateria.

A Fig. 7.22 mostra a resposta da estrutura de controle e gerenciamento da microrrede para um $i_{g}=2,6 \mathrm{~A}$ e $E_{g}=36 \mathrm{Ah}$, ou seja, a microrrede entrega para a rede de distribuição uma corrente constante e igual à média da potência gerada $(2,6 \mathrm{~A}$ ou $650 \mathrm{~W})$ iniciando a entrega de energia para a rede assim que a energia total armazenada na bateria alcança $36 \mathrm{Ah}$. Baseando-se 
nessa premissa, a microrrede somente deve iniciar a entrega de potência após a energia total armazenada na bateria alcançar $36 \mathrm{Ah}$, de forma que na pior situação, a energia da bateria oscile em torno da média $E_{m}$, que é próxima ao valor de $E_{g}$ e evita que a microrrede entre em colapso por falta de energia, ou seja, é imprescindível que a condição $E_{g}>E_{S} / 2$ seja respeitada.

Na Fig. 7.22 fica evidente que o superávit de energia (energia extra, indicada em azul) é responsável pela inclinação positiva da energia da bateria, enquanto o déficit de energia (região indicada em verde) é responsável pela inclinação negativa da energia da bateria. Na média, a área azul é equivalente à verde e ambas, iguais a $E_{S}$, assim, ao estimar qualquer uma destas áreas, consegue-se estimar o valor de $E_{s}$ e, consequentemente, projetar $E_{g}$.

A equação (7.21) estima o valor de $E_{s}$ considerando que uma parcela $\boldsymbol{\sigma}$ (região em azul da Fig. 7.22) de toda energia gerada pelas fontes alternativas seja enviada para as baterias. Nessa mesma equação “ $N$ ” representa o ganho de corrente do conversor da bateria e $P_{f a}$ a energia média gerada pelas fontes alternativas instaladas na microrrede quando é considerado um período de $24 \mathrm{~h}$.

$$
2 E_{g} \geq E_{S}=\frac{N P_{f a} 24 \mathrm{~h}}{V_{c c}} \sigma
$$

Nessas simulações, foi considerado que $i_{g}=2,6$ A (que representa a média de $P_{f a}=650$ W), $N=2,5$ e $V_{c c}=250 \mathrm{~V}$, o que resulta em $E_{s}=62,4$ Ah e $E_{g} \geq 31,2$ Ah quando $\sigma=40 \%$. Isso significa que é preciso entregar à rede distribuição um valor de potência $650 \mathrm{~W}$ definindo um $E_{g}=31,2$ Ah para manter a estabilidade da microrrede. 


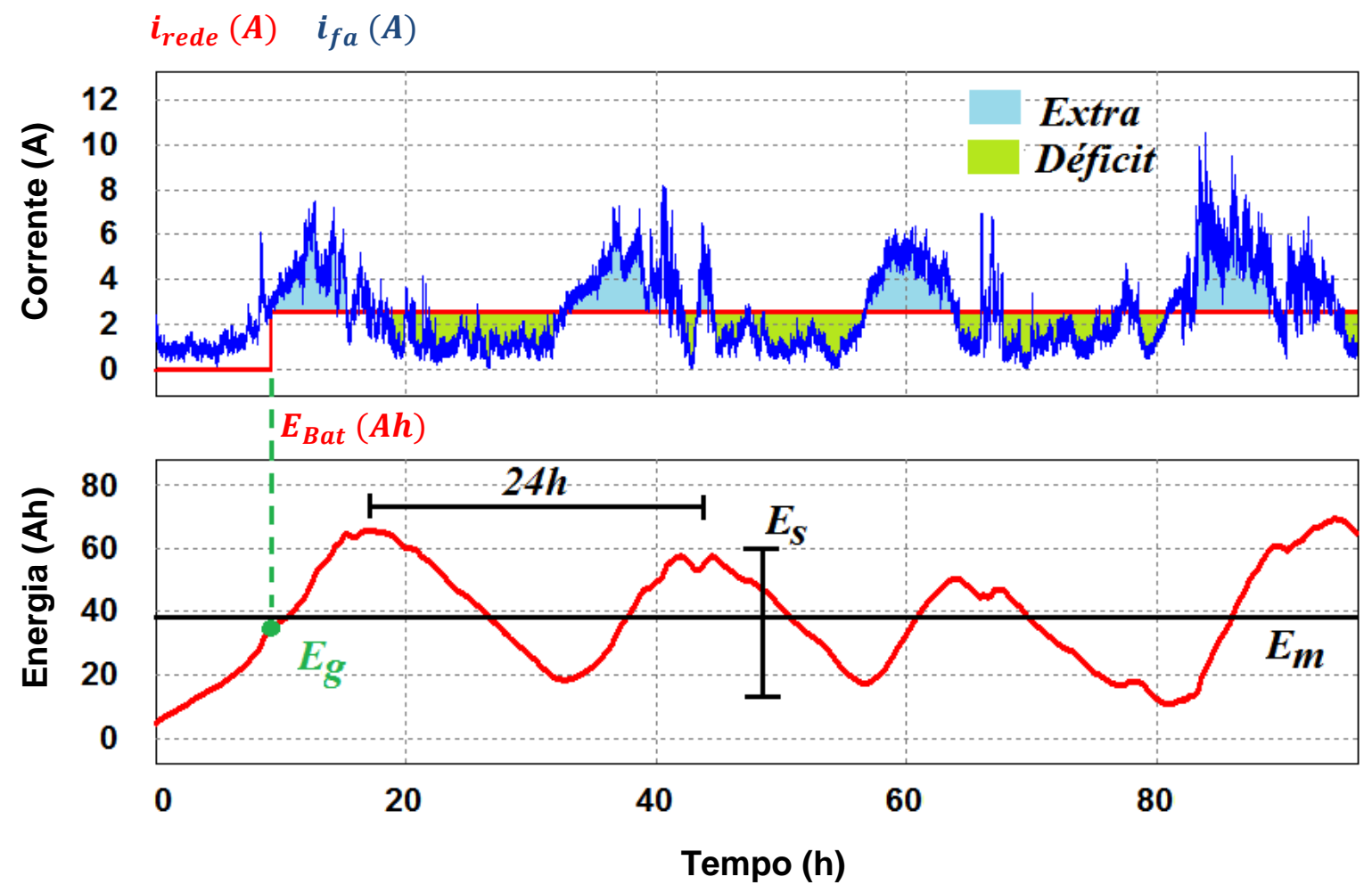

Figura 7.22 - Resposta do sistema para $i_{g}=2,6 \mathrm{~A}$ e $E_{g}=36 \mathrm{Ah}$. Destacando a energia média na bateria $E_{m}=38$ Ah e a oscilação de energia na bateria $E_{s}=40 \mathrm{Ah}$.

A consideração de $\sigma=40 \%$ é uma clara extrapolação de forma a sobre dimensionar a bateria, garantindo um funcionamento estável, uma vez que, de maneira geral, não se sabe com exatidão qual o percentual de energia gerado será de excedente. Entretanto, quanto mais próximas são a média gerada e a potência gerada máxima, menor deve ser o fator $\sigma$, uma vez que o superávit será menor.

As Figuras 7.23 e 7.24 mostram a resposta da estrutura de controle e gerenciamento da microrrede quando aplicado o algoritmo de gerenciamento em questão para $i_{g}$ constante definido em 2,6 A $(650 \mathrm{~W})$ e alterando-se o ponto de início do algoritmo em $E_{g}=22 \mathrm{Ah}, E_{g}=$ $30 \mathrm{Ah}$ e $E_{g}=50 \mathrm{Ah}$. Nota-se que a microrrede CC enfrenta um desligamento quando o valor inicial é definido $E_{g}=22 \mathrm{Ah}$, pois não havia energia inicial suficiente para suportar o regime de oscilação de energia, alcançando o limiar inferior. Já para 30 Ah ou qualquer outro valor superior a esse, a microrrede não se desliga, mesmo o valor de $E_{g}$ sendo, levemente, inferior ao valor calculado pela equação (7.21), isto ocorre porque a equação leva em conta um fator de segurança devido às considerações feitas anteriormente.

Assim, ao analisar a Fig. 7.24 é possível concluir que quanto maior for o fator de segurança, aumentando $E_{g}$, maior o pico de energia na bateria, que pode ser estimado por 
(7.22). Logo, para $E_{g}=50 \mathrm{Ah}$ a energia máxima na bateria atinge aproximadamente $80 \mathrm{Ah}$, uma vez que foi estimado $E_{S}=62,4$ Ah.

$$
E_{\text {Bat_Max }} \approx E_{g}+E_{S} / 2
$$

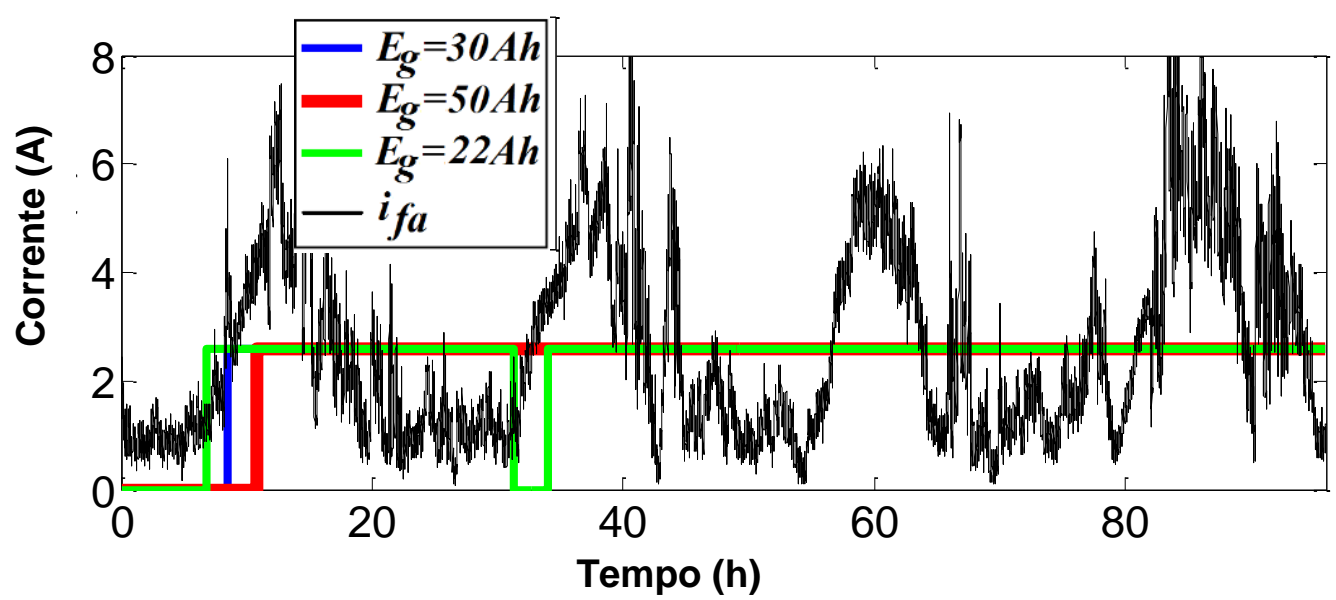

Figura 7.23 - Resposta do algoritmo de gerenciamento baseado na bateria para $i_{g}$ definido em $2.6 \mathrm{~A}$ (650 W de injeção constante) considerando $E_{g}=22 \mathrm{Ah}, E_{g}=30 \mathrm{Ah}$ e $E_{g}=50 \mathrm{Ah}$.

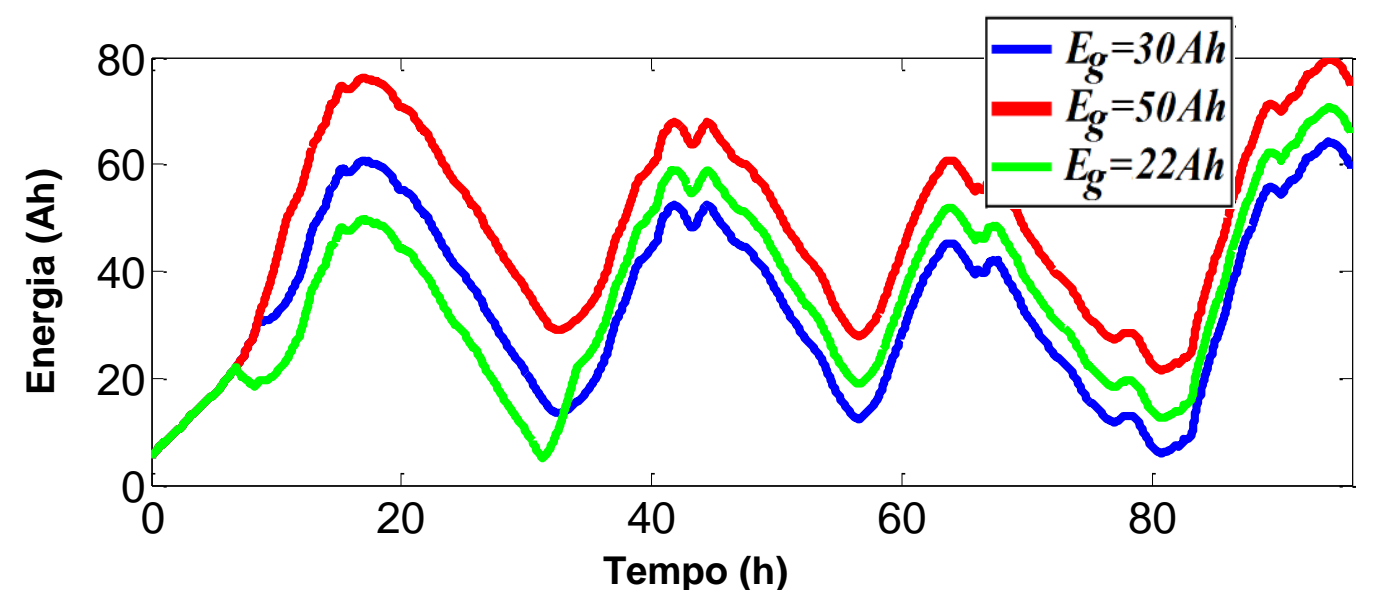

Figura 7.24 - Resposta do algoritmo de gerenciamento para $i_{g}$ definido em 2,6 A $(650 \mathrm{~W}$ de injeção constante) considerando $E_{g}=22 \mathrm{Ah}, E_{g}=30 \mathrm{Ah}$ e $E_{g}=50 \mathrm{Ah}$.

Como foi citado anteriormente, caso a potência entregue à rede de distribuição seja maior que a média gerada, independente do valor de $E_{g}$, a microrrede operará com um déficit energético e entrará em colapso. As Fig. 7.25 e 7.26 ilustram esta situação, fazendo $i_{g}=2,6 \mathrm{~A}$ e $i_{g}=3,5 \mathrm{~A}$. No segundo caso $\left(i_{g}=3,5 \mathrm{~A}\right)$, a potência média entregue supera o valor de potência produzido pelas fontes alternativas, ocasionando sucessivos desligamentos sendo que o religamento da microrrede pode ser feito, somente, se existir energia suficiente armazenada nelas $\left(E_{\text {Bat }}>E_{g}=36 \mathrm{Ah}\right)$. 


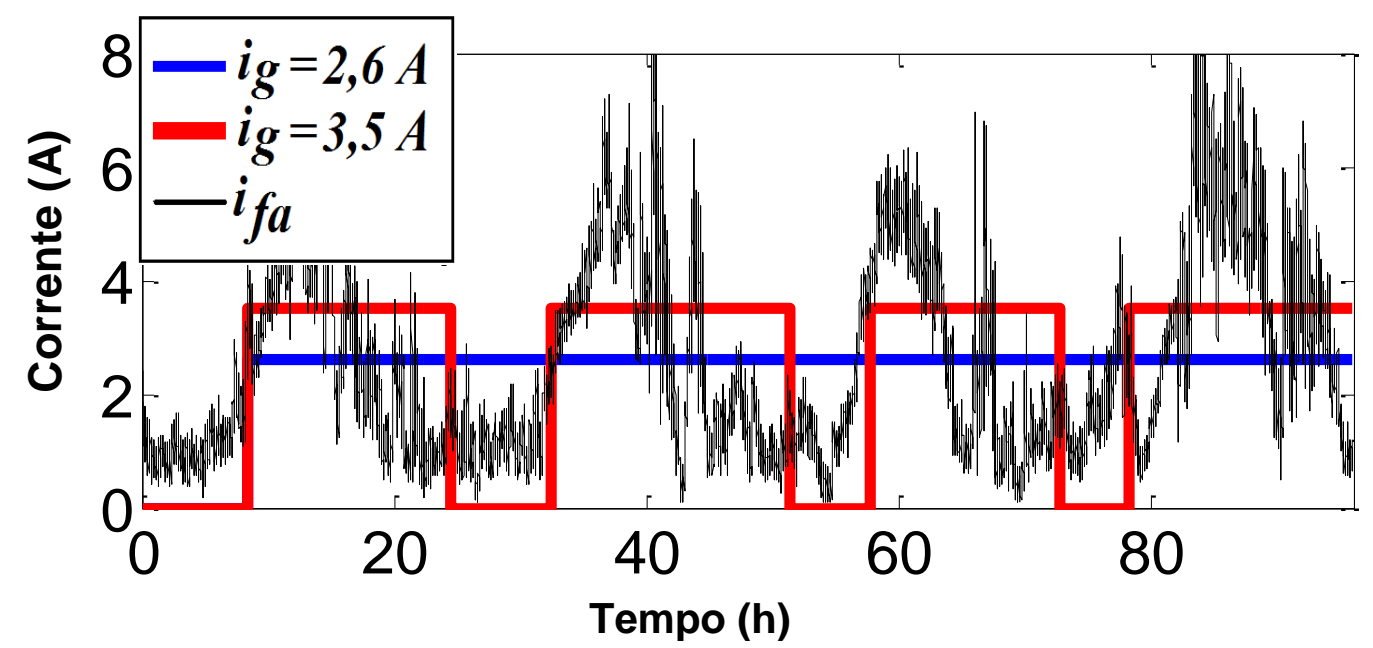

Figura 7.25 - Resposta do algoritmo de gerenciamento para $i_{g}=2,6 \mathrm{~A}$ e $i_{g}=3,5$ A quando $E_{g}=$ $36 \mathrm{Ah}$.

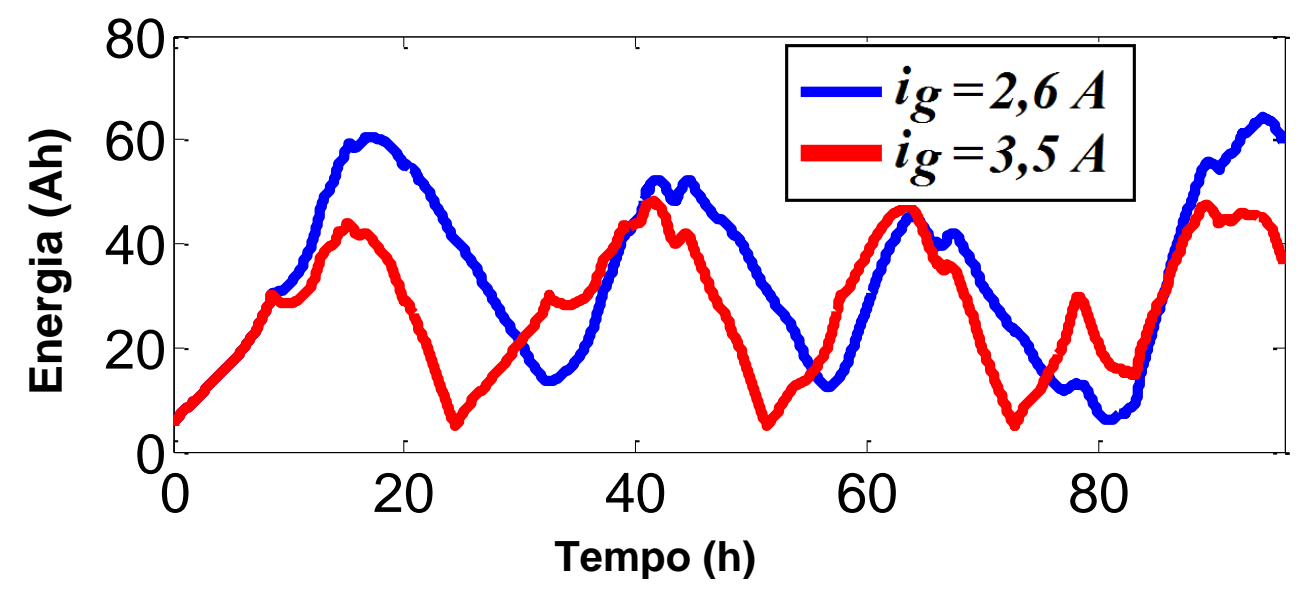

Figura 7.26 - Resposta do algoritmo de gerenciamento para $i_{g}=2,6 \mathrm{~A}$ e $i_{g}=3,5 \mathrm{~A}$ quando $E_{g}=$ 36 Ah.

\subsection{Considerações Finais do Capítulo 7}

Neste capítulo foram descritos os algoritmos de gerenciamento baseado em UCs de alta capacidade, algoritmo de gerenciamento baseado na média gerada pelas fontes alternativas e por último, um algoritmo para entrega de potência constante para a rede.

Foi mostrado, que o tempo de entrega de energia constante à rede depende da capacitância do UC, além dos limites de tensão do método. No caso da potência filtrada, foi avaliada a dependência da capacidade da bateria em relação à ordem e a constante de tempo do filtro, ou seja, quanto maior for a ordem e a constante $T$, implica em uma bateria de maior capacidade para o método ser efetivo. Para o caso de injeção constante com a bateria, foi estimada a capacidade mínima da bateria de forma a suprir o regime de carga. 


\section{Capítulo 8}

\section{Resultados Experimentais}

\subsection{Descrição da Bancada Experimental}

Neste capítulo são apresentadas as características do set-up experimental, assim como vários resultados práticos que comprovam a capacidade da microrrede em operar de forma estável, além de mostrar a performance das estratégias de controle e gerenciamento propostas, corroborando os resultados obtidos nas simulações dos capítulos anteriores.

A Fig. 8.1 mostra o esquemático da estrutura de processamento e de atuação do protótipo construído, destacando as variáveis monitoradas para fins de controle. A unidade de processamento utilizada é um microcontrolador TMS320F28335 da Texas Instruments, que possui 16 conversores A/D de 12 bits, 12 PWMs de saída, além de uma unidade de processamento em ponto flutuante de $150 \mathrm{MHz}$. As unidades inversoras utilizadas são módulos comerciais Semikron (Modelo SKS 21F B6U+E1CIF + B6CI 12V12), no qual cada módulo apresenta três braços com dois módulos IGBT em cada braço, formando uma ponte trifásica completa por módulo, para mais detalhes consultar o Apêndice.

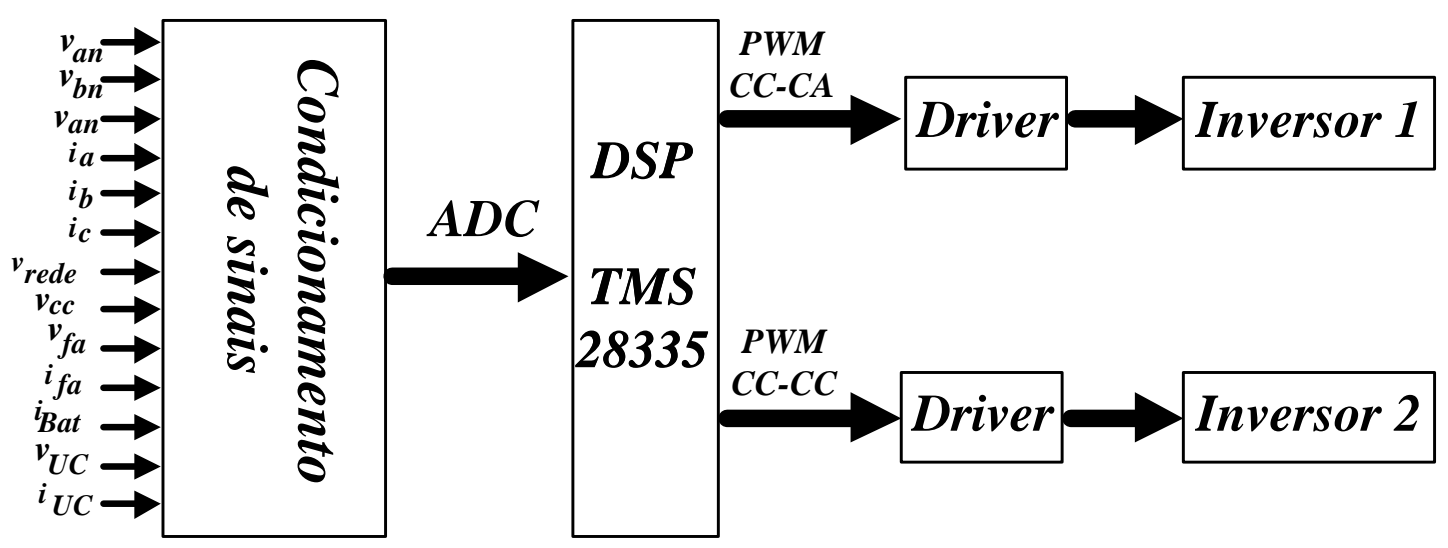

Figura 8.1 - Esquemático do sistema de processamento e atuação do protótipo.

Na Fig. 8.2 é apresentado, em detalhes, o sistema de condicionamento de sinal construído, onde podem ser vistas as placas de medição de tensão e corrente. Já na Fig. 8.3 é ilustrado o banco de UC da Maxwell BCAP3000-P270-K04 conectados em série. Cada unidade apresenta $3000 \mathrm{~F}$ e tensão máxima de $2,7 \mathrm{~V}$, formando um banco de $100 \mathrm{~F}$ e $81 \mathrm{~V}$. Tal estrutura para armazenamento de energia possui uma capacidade de 328050 Joules ou 
91,12 Wh. Este conjunto é usado na técnica baseada no UC de alta capacidade, na qual uma grande quantidade de energia é requerida, mantendo a injeção de potência constante na rede de distribuição pelo maior tempo possível. Nessa mesma figura, é mostrado o conjunto de 100 capacitores eletrolíticos (1000 uF cada) conectados em paralelo, formando 0,1 F e $100 \mathrm{~V}$ que é usado nas técnicas híbridas de controle apresentadas no Capítulo 6.

A Fig. 8.4 ilustra o conjunto de baterias do fabricante Moura 12MF36 de 12 V e 36 Ah utilizadas na montagem do banco de baterias, que possui nove unidades conectadas em série, resultando em $108 \mathrm{~V}$ e $36 \mathrm{Ah}$ ou $3888 \mathrm{Wh}$. Nos testes utilizando as baterias, foram empregados apenas seis conjuntos em série (72 V e 36 Ah). Já a Fig. 8 descreve a imagem do protótipo construído, além de um diagrama esquemático indicando cada componente utilizado na montagem enquanto que, a Tabela 8.1 sumariza o valor dos elementos passivos e ativos utilizados na construção do protótipo.

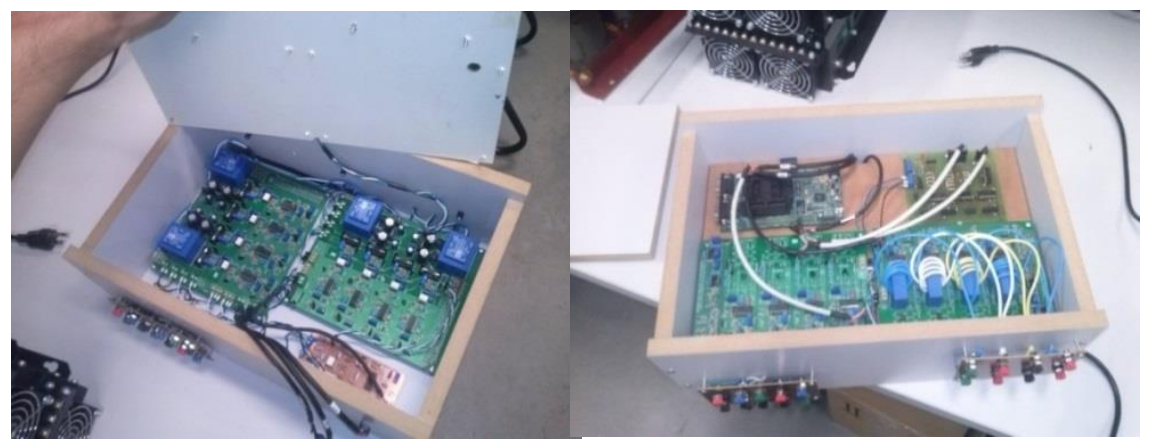

Figura 8.2 - Placas de condicionamento de sinais de tensão e corrente, respectivamente.

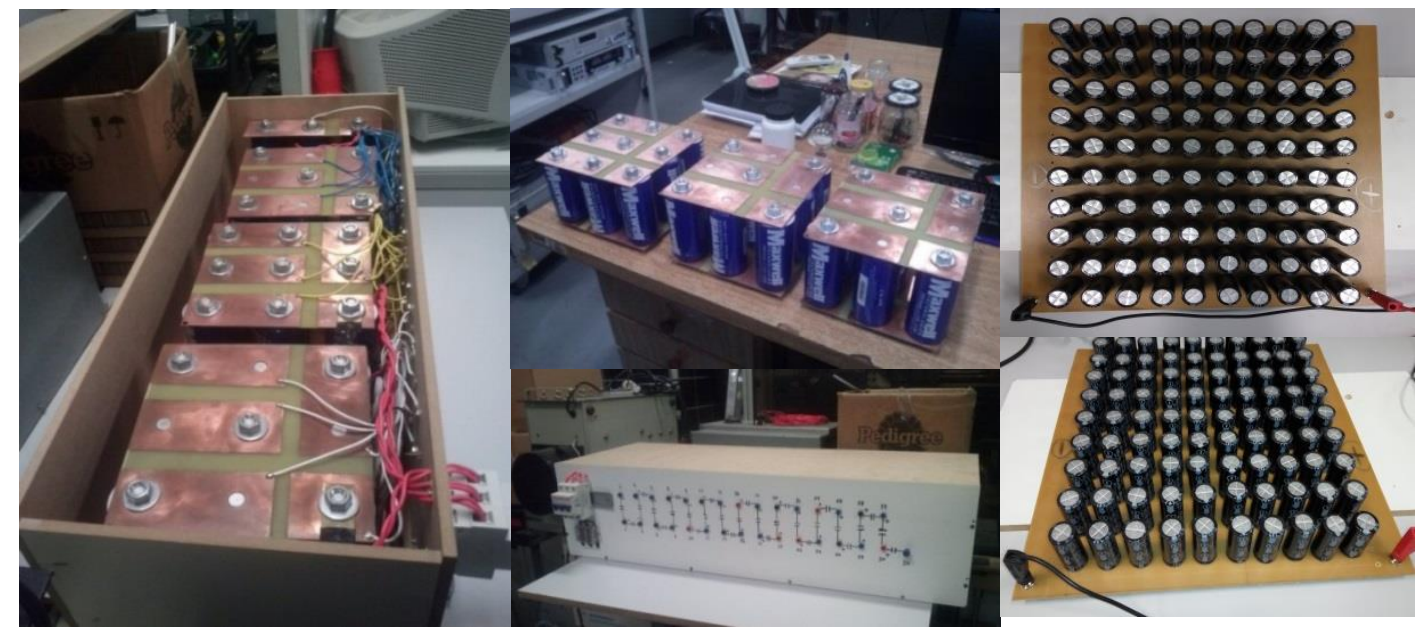

Fig. 8.3 - Banco de 30 UC Maxwell conectados em série e banco de 100 capacitores eletrolíticos (1000 uF cada) em paralelo. 


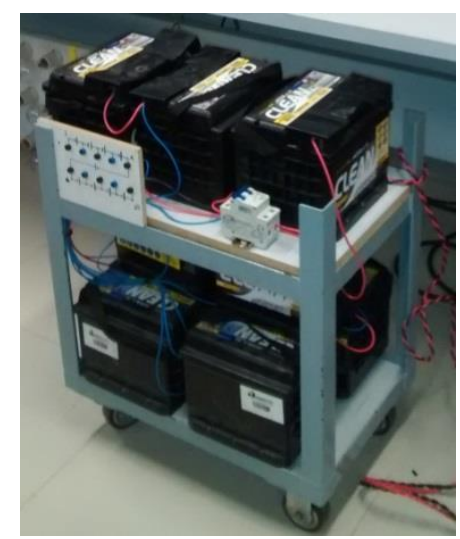

Figura 8.4 - Banco de nove baterias Moura Clean 12MF36 de 12 V e 36 Ah conectadas em série.

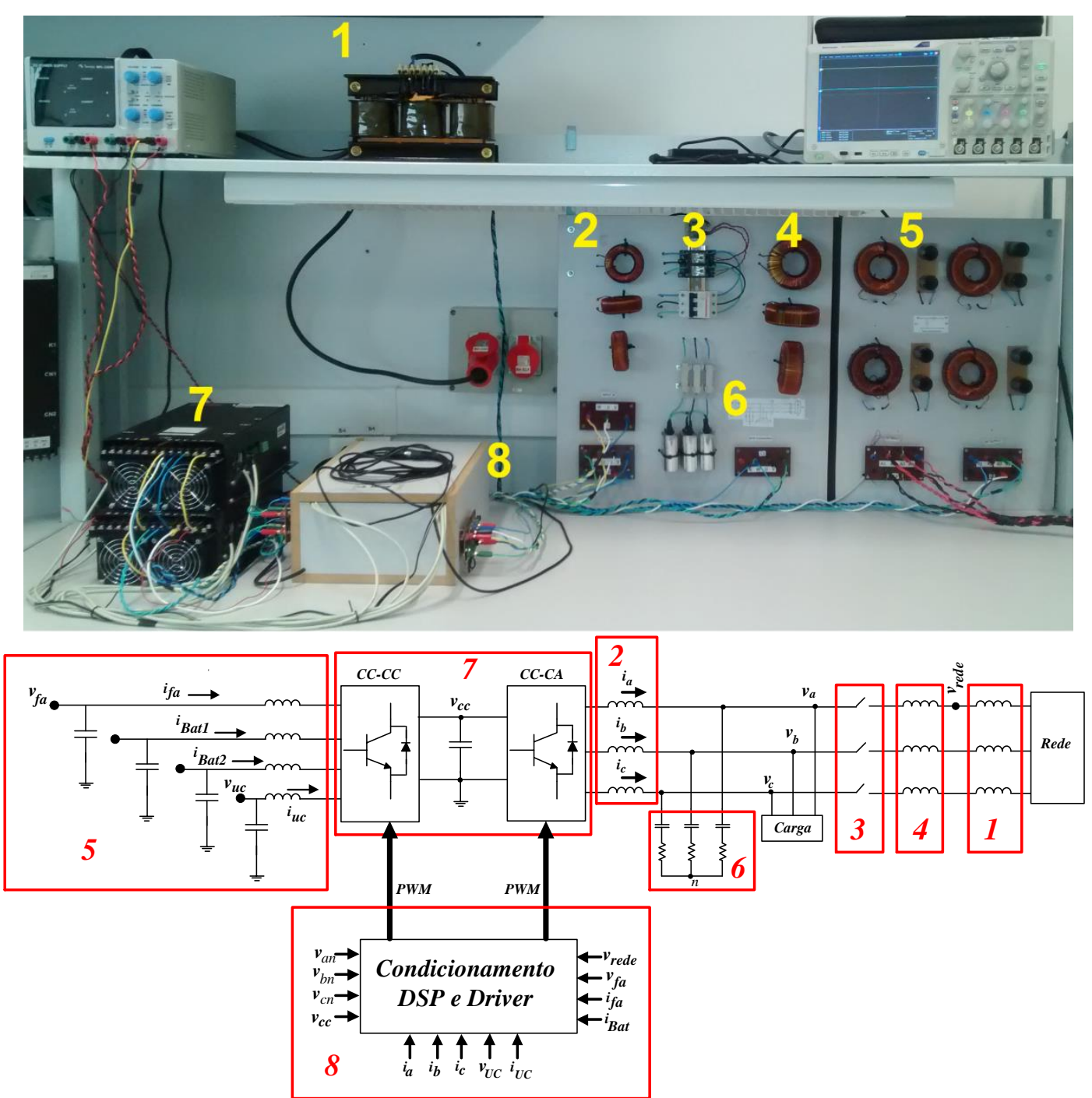

Figura 8.5 - Foto do protótipo construído com esquemático descritivo indicando cada componente. 
TABELA 8.1

COMPONENTES DO SISTEMA EXPERIMENTAL

\begin{tabular}{cc}
\hline \hline Descrição & Valor \\
\hline Filtro LC dos conversores CC-CC & $L_{c c}=10 \mathrm{mH}$ e $C_{i n}=940 \mathrm{uF}$ \\
Capacitor do barramento CC & $C=1880 \mathrm{uF}$ \\
Filtro RLC na saída VSC & $L_{c a}=2 \mathrm{mH}, C_{c a}=30 \mathrm{uF} \mathrm{e} R_{c a}=10 \Omega$ \\
L de acoplamento com a rede & $L_{o}=5 \mathrm{mH}$ \\
Referência $V_{c c}^{*}$ & $250 \mathrm{~V}$ \\
Transformador de acoplamento & $110 \mathrm{Y}-220 \Delta$ \\
Ultracapacitor eletrolítico & $U C=0,1 \mathrm{~F} \mathrm{e} V_{U C_{-} \text {max }}=100 \mathrm{~V}$ \\
Ultracapacitor Maxwell & $U C=100 \mathrm{~F} \mathrm{e} V_{U C_{-} \text {max }}=81 \mathrm{~V}$ \\
Bateria Moura & $V_{\text {Bat }}=108 \mathrm{~V} \mathrm{e} E_{\text {Bat }}=36 \mathrm{Ah}$ \\
\hline \hline
\end{tabular}

Para a realização dos testes e avaliação dos resultados experimentais, foi utilizada uma fonte linear emuladora de painéis fotovoltaicos da Agilent Technologies, com $600 \mathrm{~W}$ de potência máxima ( $5 \mathrm{~A}$ e $120 \mathrm{~V}$ de pico) a qual permite que os testes sejam controlados, ou seja, é possível obter a configuração exata do ponto de operação do módulo PV, além de variações bruscas de geração, colocando à prova as estratégias propostas de eliminação de oscilações de potência.

\subsection{Testes e Ensaios}

Nesta seção são apresentados os resultados experimentais obtidos para as estratégias de gerenciamento propostas nos Capítulos 5, 6 e 7. Inicialmente, são ilustrados os resultados para o gerenciamento baseado no UC de alta capacidade seguido do resultado de gerenciamento baseado na energia média. Na segunda parte, serão apresentados os resultados do gerenciamento descentralizado, com e sem restauração de barramento CC.

A Fig. 8.6 apresenta o funcionamento do algoritmo de sincronismo PLL ajustando a fase da corrente gerada com a tensão de referência sintetizada pela rede elétrica em apenas 5 ciclos. Este sincronismo é de vital importância para que somente potência ativa seja transferida para a rede elétrica, uma vez que não é de interesse, nesse caso, a compensação de reativos e se tenha, apenas, a venda de energia tarifável.

A Fig. 8.7 mostra a microrrede funcionando em regime permanente mantendo sincronizadas tensão e corrente de uma fase específica da rede de distribuição garantindo assim, a injeção de potência ativa. Outro fator importante a ser considerado, na Fig. 8.7, é o funcionamento do controlador de corrente em modo conectado, entregando uma potência 
ativa fixa para uma referência definida $i_{d}^{*}=2 \mathrm{~A}$ (2 A de pico correspondem a 1,41 A rms) e $i_{q}^{*}=0$.

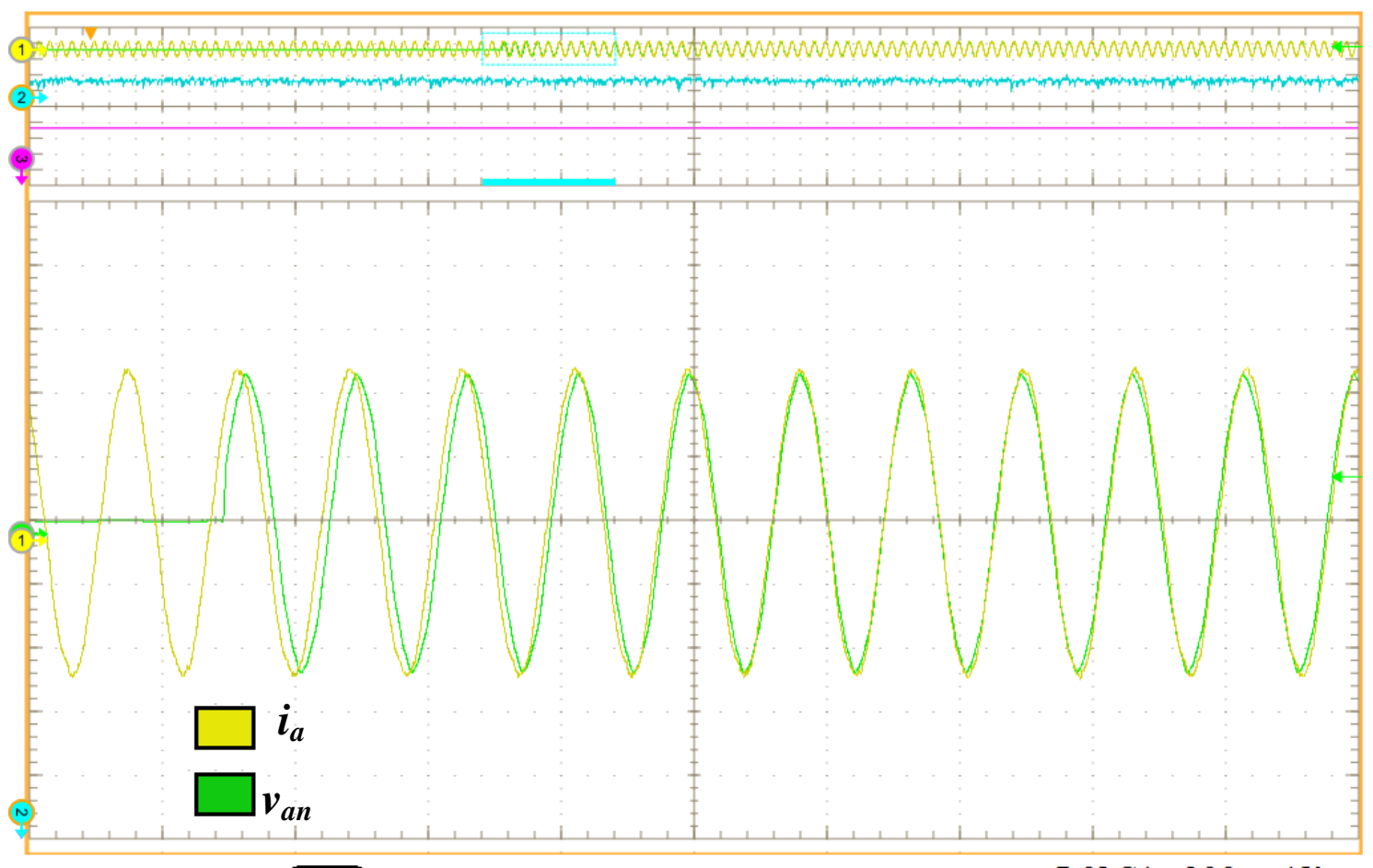

C1 6.0A/div C2

$200 \mathrm{~V} / \mathrm{div}$

$5.0 \mathrm{kS} / \mathrm{s} 200 \mathrm{~ms} / \mathrm{div}$

Figura 8.6 - Funcionamento do algoritmo PLL.

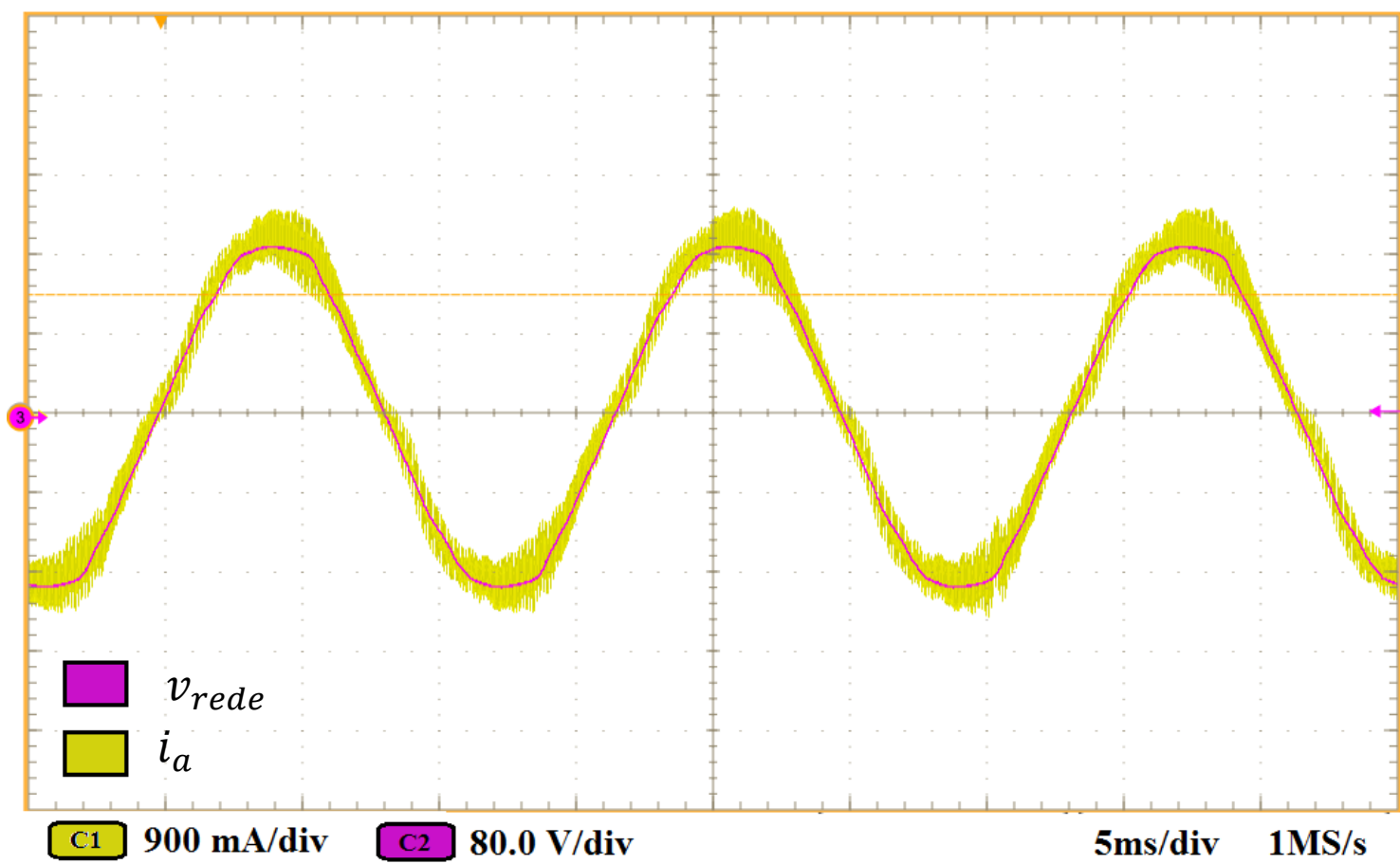

Figura 8.7 - Corrente de 2 A pico (1,41 rms) nos terminais do VSI em fase com a referência. 
Com relação ao controle das fontes alternativas conectadas ao barramento $\mathrm{CC}$, as Figuras 8.8 e 8.9 mostram o algoritmo de busca MPPT atuando sobre o painel fotovoltaico durante variação em degrau da tensão de máxima potência $\left(V_{m p}\right)$. A Fig. 8.8 mostra uma redução de $V_{m p}$, enquanto a Fig. 8.9 apresenta um aumento de $V_{m p}$.

Devido à característica do algoritmo $\mathrm{P} \& \mathrm{O}$, nota-se que a tensão é continuamente perturbada, de forma a buscar o ponto ótimo, gerando uma oscilação de frequência definida pelo passo de tensão entre as perturbações.

A amplitude da perturbação pode ser alterada de forma que a convergência seja obtida mais rapidamente, contudo, o aumento da amplitude das perturbações implica em uma menor estabilidade e maiores perdas, uma vez que as oscilações tendem a desviar a busca do ponto ótimo, mesmo que temporariamente. Na implementação prática, a atualização do passo de tensão foi definida em $0,25 \mathrm{~s}$ e a amplitude da perturbação em $0,5 \mathrm{~V}$.

A Fig. 8.10 mostra uma desconexão e reconexão repentina dos painéis fotovoltaicos na microrrede CC. Devido à descontinuidade na produção de energia, os armazenadores atuam para manter o fornecimento de energia e evitar o colapso da microrrede. Neste teste, foram utilizadas apenas baterias (sem a presença de UCs) que forneceram tanto a energia necessária para suprir o regime permanente quanto compensar os transitórios ocasionados por variações das condições atmosféricas.

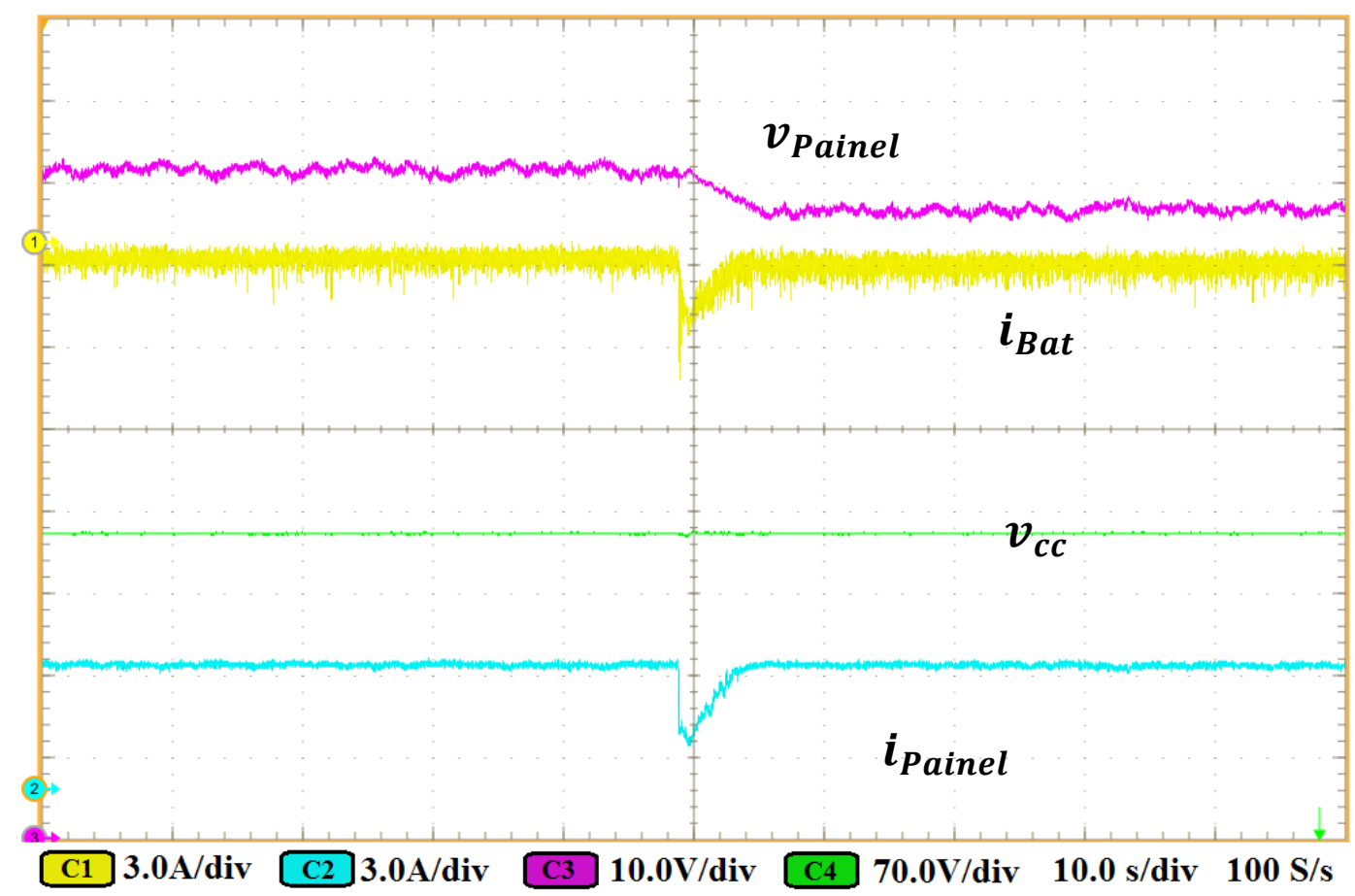

Figura 8.8 - Redução de $V_{m p}$ em degrau. 


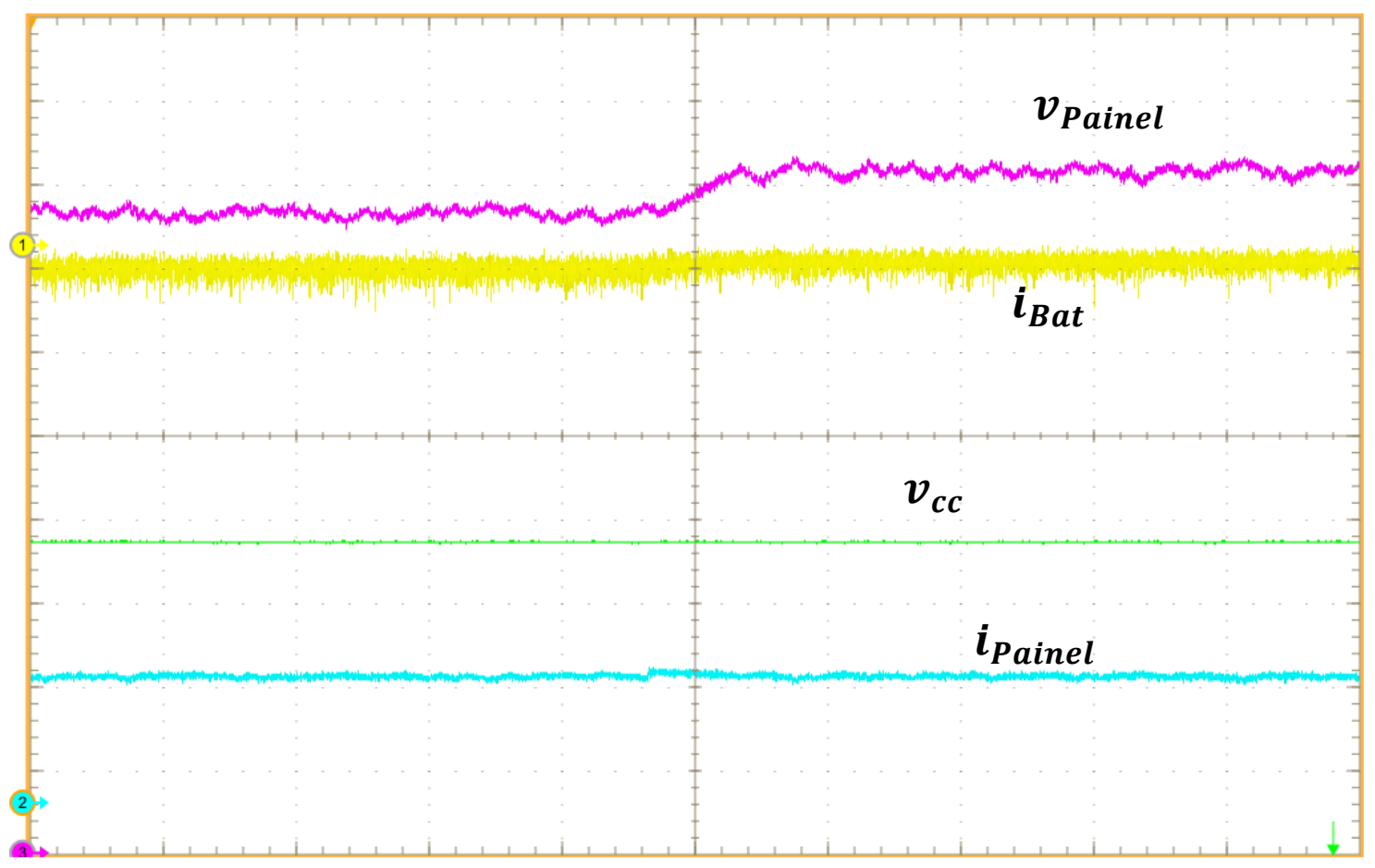

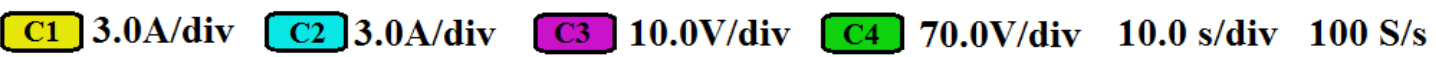

Figura 8.9 - Aumento de $V_{m p}$ em degrau.

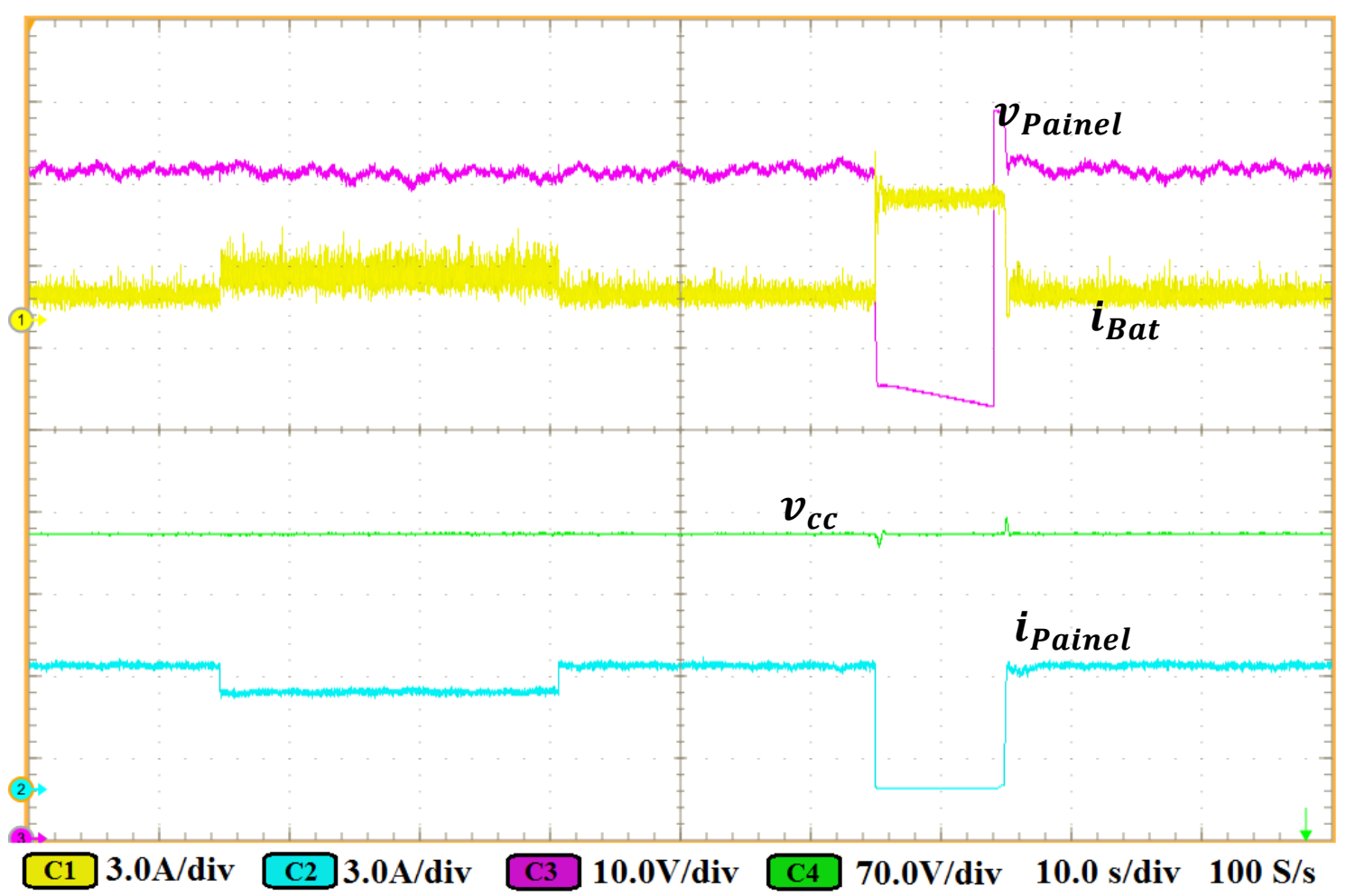

Figura 8.10 - Desconexão e reconexão de painéis fotovoltaicos na microrrede. 


\subsubsection{Gerenciamento Baseado no UC de alta}

\section{capacidade}

A Fig. 8.11 mostra o funcionamento da estratégia de gerenciamento baseada no UC, cujos limites de tensão do algoritmo foram definidos em $75 \mathrm{~V}$ e $55 \mathrm{~V}$. Ao atingir o limite superior $\left(v_{U C}=75 \mathrm{~V}\right)$ a corrente de referência da rede é incrementada de forma a gerar um déficit energético no UC, forçando o descarregamento. Já quando o limite inferior é alcançado $\left(v_{U C}=55 \mathrm{~V}\right)$ a referência é reduzida para gerar um superávit energético, recarregando o UC.

Este ciclo é repetido permanentemente, mantendo a corrente na rede fixa durante pequenos intervalos de tempo (5 min em média), cuja duração da janela fixa depende da capacidade do UC, dos limites de tensão do método e da quantidade de energia fornecida pelas fontes alternativas.

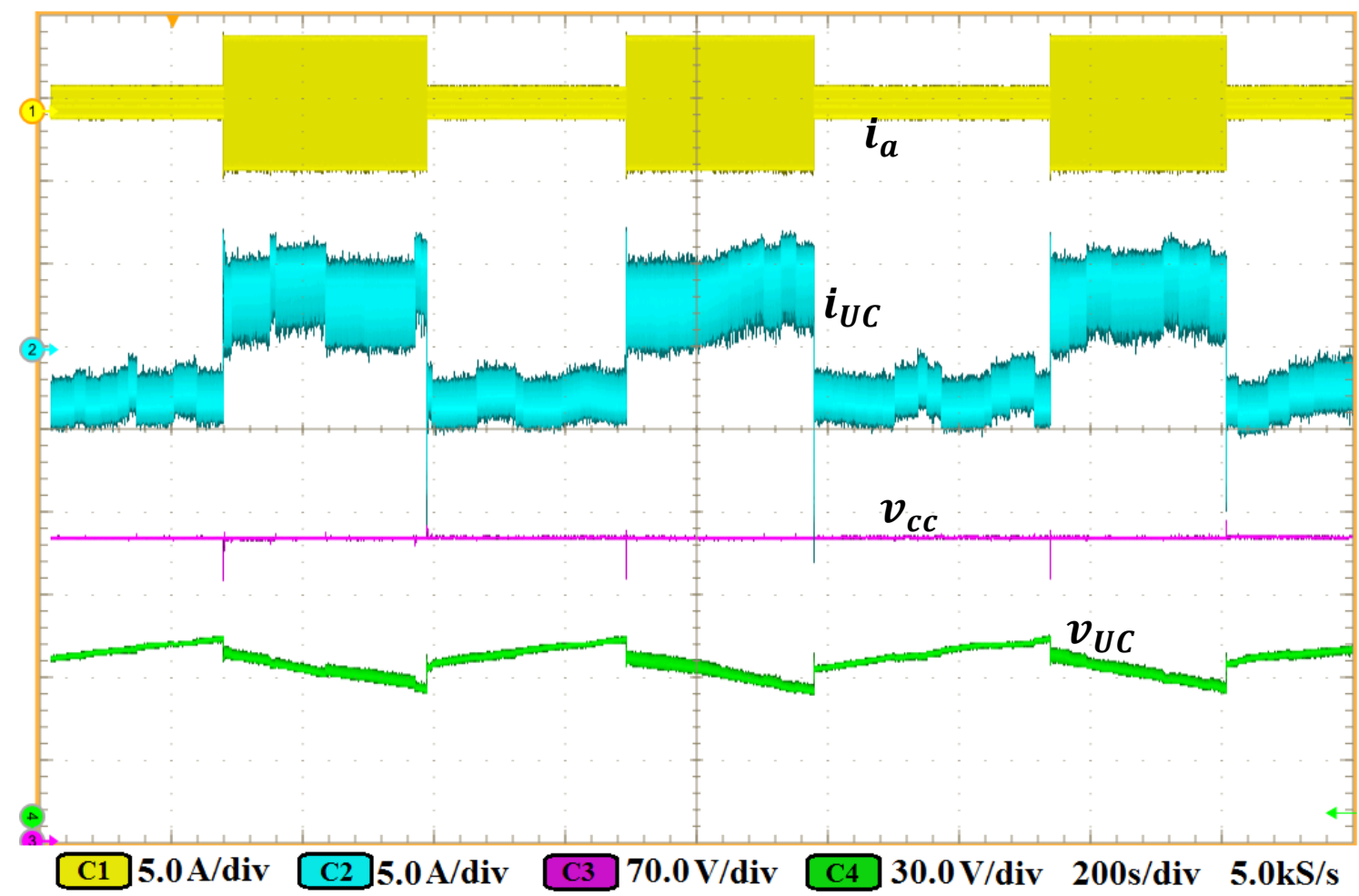

Figura 8.11 - Funcionamento do algoritmo de gerenciamento baseado no UC, alternando entre os limites de tensão (75 V e $55 \mathrm{~V}$ ) e mantendo a corrente fixa por intervalos.

Vale ressaltar as oscilações na corrente do $\mathrm{UC}\left(i_{U C}\right)$ são originados pelas alterações nas condições atmosféricas e, consequentemente, do ponto de operação das fontes alternativas, ou seja, o UC absorve todas as oscilações de potência e entrega para a rede apenas potência 
constante. Logo, consegue-se evitar que tais distúrbios sejam transferidos à rede, caso o método não estivesse ativo.

Este resultado é análogo ao resultado simulado da Fig. 7.10, no qual a estratégia de gerenciamento foi apresentada e simulada pelo modelo simplificado, comprovando assim, a validade da estratégia proposta.

A Fig. 8.12 mostra com detalhes o funcionamento do algoritmo de gerenciamento. Nessa situação, é possível observar as oscilações de corrente no UC $\left(i_{U C}\right)$, que são distúrbios produzidos pelas fontes alternativas e que foram inseridos propositalmente para testar os controles em casos extremos.

Contudo, de forma a manter a tensão do barramento e corrente na rede fixas, as oscilações são absorvidas pelo UC, cuja corrente se ajusta para manter o equilíbrio da equação (3.7). Com relação à tensão do barramento $\mathrm{CC}$, a única perturbação significante só ocorre no momento em que a corrente do UC inverte seu sentido, devido ao chaveamento do modo de controle, uma vez que o UC atinge o limite superior da técnica $(75 \mathrm{~V})$.

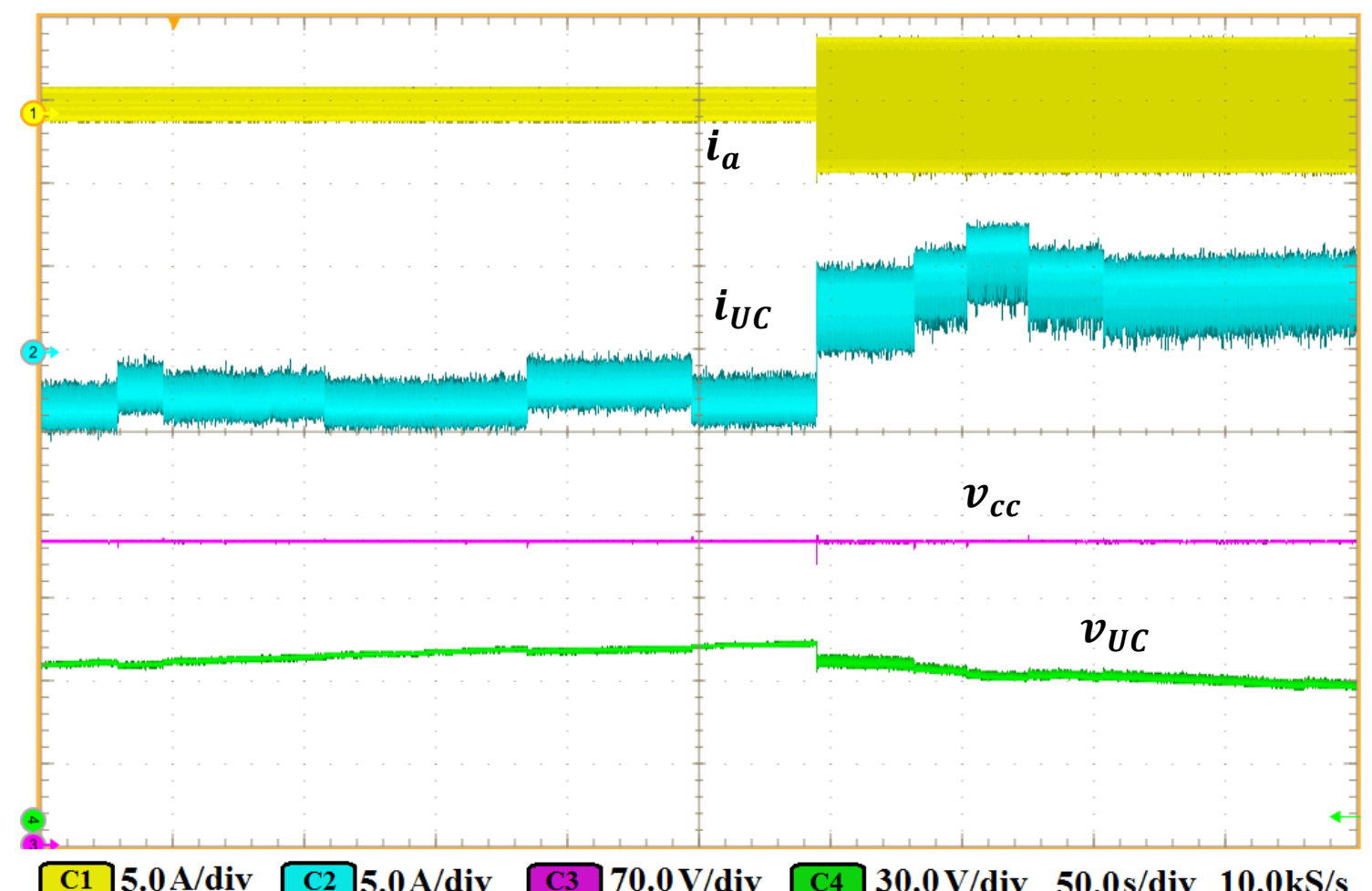

Figura 8.12 - Detalhe durante o funcionamento do algoritmo de gerenciamento baseado no $\mathrm{UC}$. 
Para os resultados das Fig. 8.11 e 8.12 foi utilizado o UC Maxwell de alta capacidade $(100 \mathrm{~F}$ e $81 \mathrm{~V})$, devido à necessidade de uma grande quantidade de energia para se manter o regime de funcionamento. Contudo, as técnicas a seguir permitem o uso de dispositivos de baixa capacitância, devido à estratégia de restauração da tensão terminal do UCs, como foi discutido no Capítulo 6. Uma vez que a potência necessária para manter o funcionamento da microrrede em regime permanente é fornecida pelas baterias e apenas os transitórios são supridos pelos UCs, logo, será utilizado o banco de capacitores eletrolíticos de 0,1 F e $100 \mathrm{~V}$.

\subsubsection{Gerenciamento Baseado na Potência Média Gerada em Sistema Centralizado de Controle}

No Capítulo 7, Fig. 7.11, foi proposta a técnica centralizada que divide o fluxo de potência entre um conjunto híbrido de armazenadores, ou seja, transitórios rápidos são supridos pelos UCs e regime permanente pelas baterias. Nessa metodologia de compartilhamento, considera-se que há comunicação entre os armazenadores, além de que a estrutura de controle e gerenciamento é capaz de restaurar a tensão do barramento CC e a tensão terminal dos UC. Já pelo lado CA, deseja-se injetar na rede de distribuição uma potência média fixa ou um perfil filtrado, de forma a eliminar transitórios rápidos na rede de distribuição e evitar assim, problemas de qualidade de energia.

As Fig. 8.13 e 8.14 mostram o protótipo experimental realizando a divisão de carga, onde os UCs compensam os transitórios de alta velocidade e as baterias suprem o regime permanente quando uma entrada em degrau é produzida pelas fontes alternativas $\left(i_{f a}\right)$. Notase, também, que a tensão do barramento CC é desviada devido ao evento em degrau, sendo prontamente recuperada, Fig. 8.13. Assim como esperado, a tensão terminal do UC também é recuperada para o valor de regime permanente $(85 \mathrm{~V})$, Fig. 8.14.

Aplicando o filtro de potência na energia gerada pelas fontes alternativas, as Fig. 8.15, 8.16 e 8.17 são obtidas, respectivamente. Do lado CA, após detectar a variação em degrau, o filtro de potência suaviza as mudanças abruptas, entregando este "degrau” à rede de forma gradual. Nota-se que após cada degrau em $i_{f a}$ a corrente da bateria tende a zerar, uma vez que a potência média entregue a rede é igual à potência gerada, contudo um novo transitório volta a causar variações na potência gerada. Assim como proposto, a tensão do barramento CC e a tensão terminal dos UCs são restauradas para $250 \mathrm{~V}$ e $85 \mathrm{~V}$, respectivamente. A Fig. 8.17 
mostra no detalhe o resultado da filtragem no lado $\mathrm{CA}$, incrementando a corrente entregue à rede de forma suave.

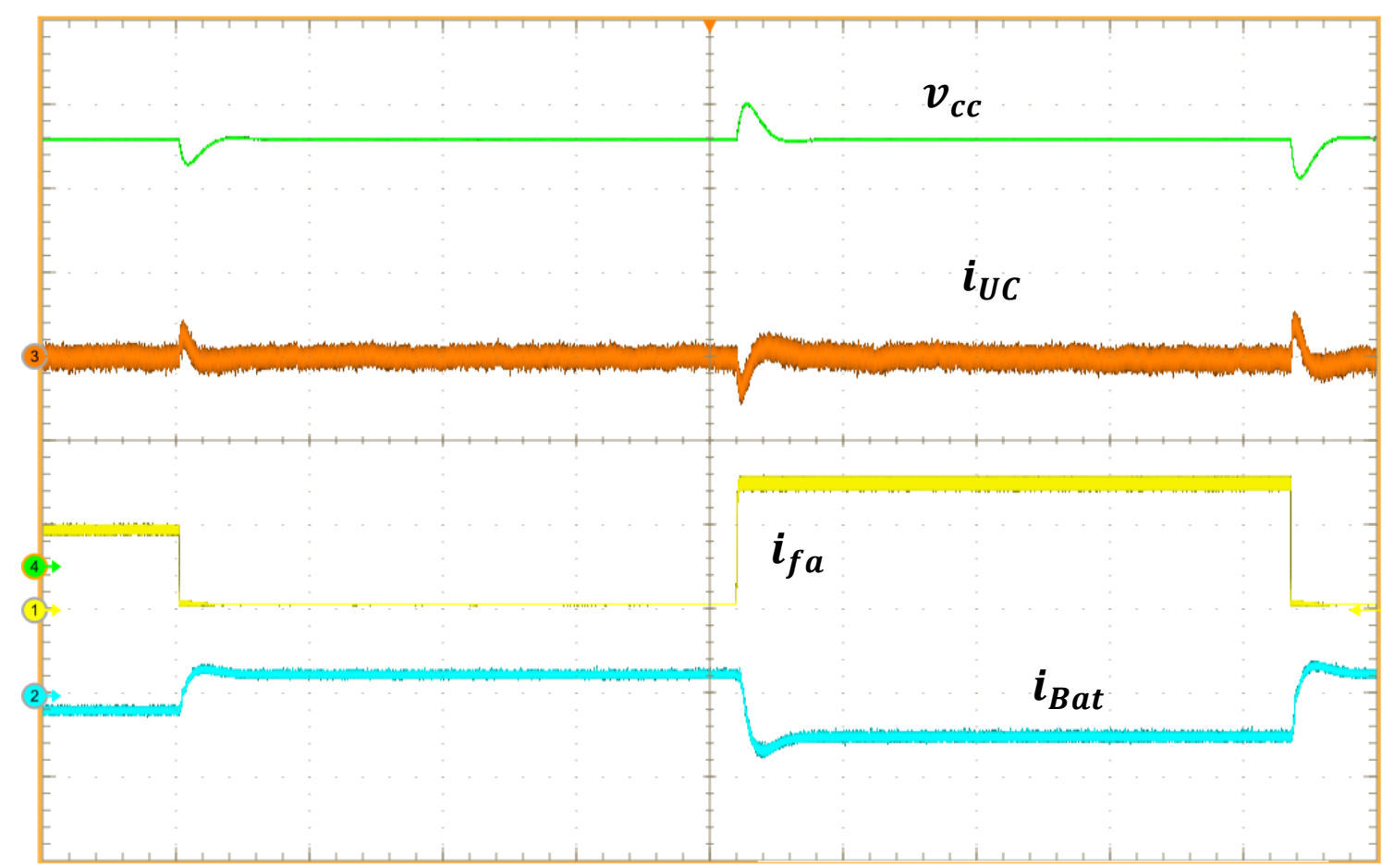

C1 $5.0 \mathrm{~A} / \mathrm{div} \mathrm{C} 25.0 \mathrm{~A} / \mathrm{div} \mathrm{C} 35.0 \mathrm{~A} / \mathrm{div} \mathrm{C} 450.0 \mathrm{~V} / \mathrm{div} 2.0 \mathrm{~s} / \mathrm{div} 100.0 \mathrm{kS} / \mathrm{s}$

Figura 8.13 - Sistema de controle centralizado dividindo a carga em entre um conjunto de armazenadores híbridos dada uma entrada em degrau pelas fontes alternativas $\left(i_{f a}\right)$. Nota-se que a tensão do barramento é sempre restaurada para $250 \mathrm{~V}$ após os transitórios. 


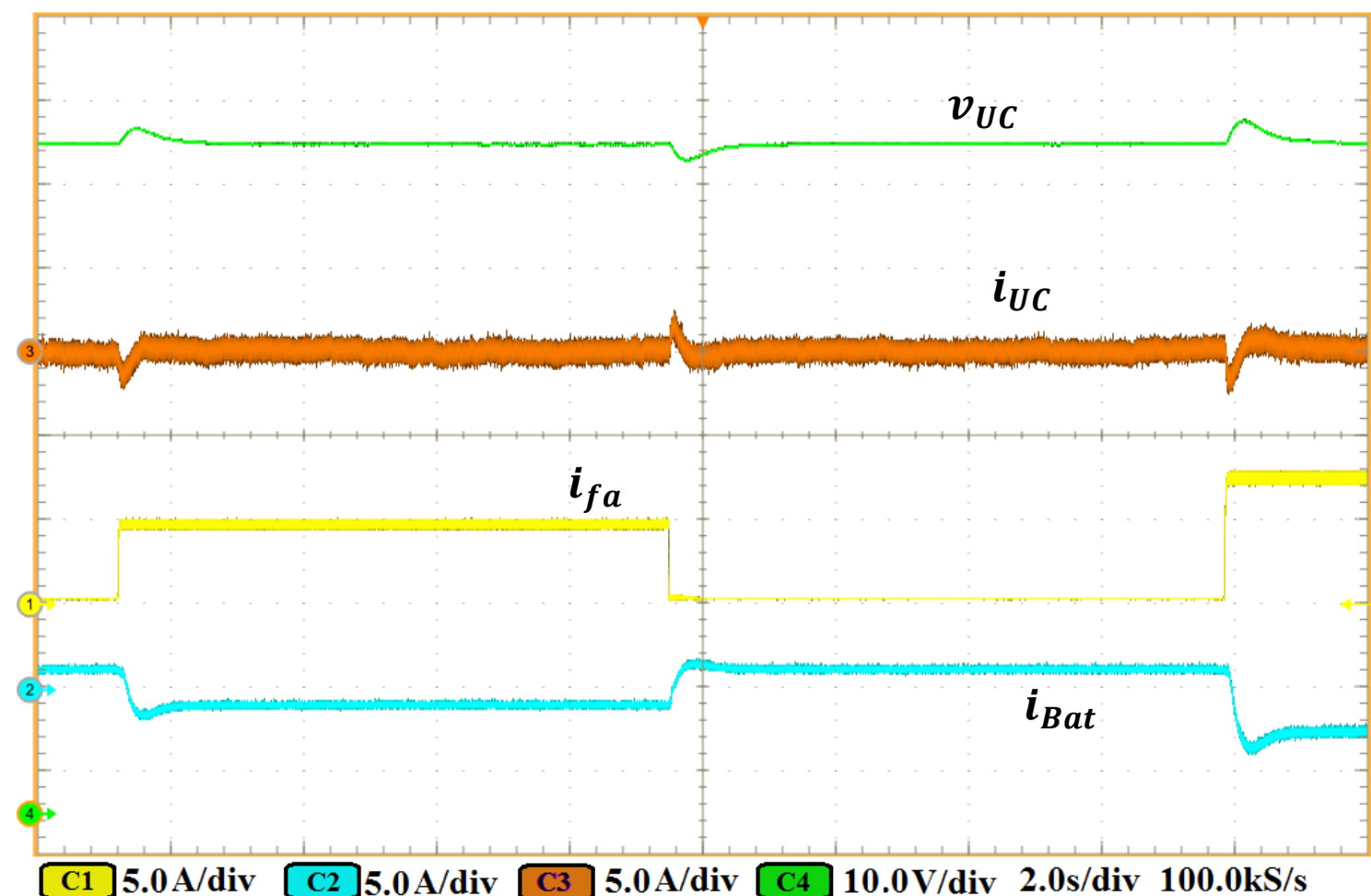

Figura 8.14 - Sistema de controle centralizado dividindo a carga entre um conjunto de armazenadores híbridos para uma entrada em degrau gerada pelas fontes alternativas $\left(i_{f a}\right)$.

Nota-se a restauração da tensão terminal dos UCs após cada transitório, graças a técnica proposta na Fig. 5.2.

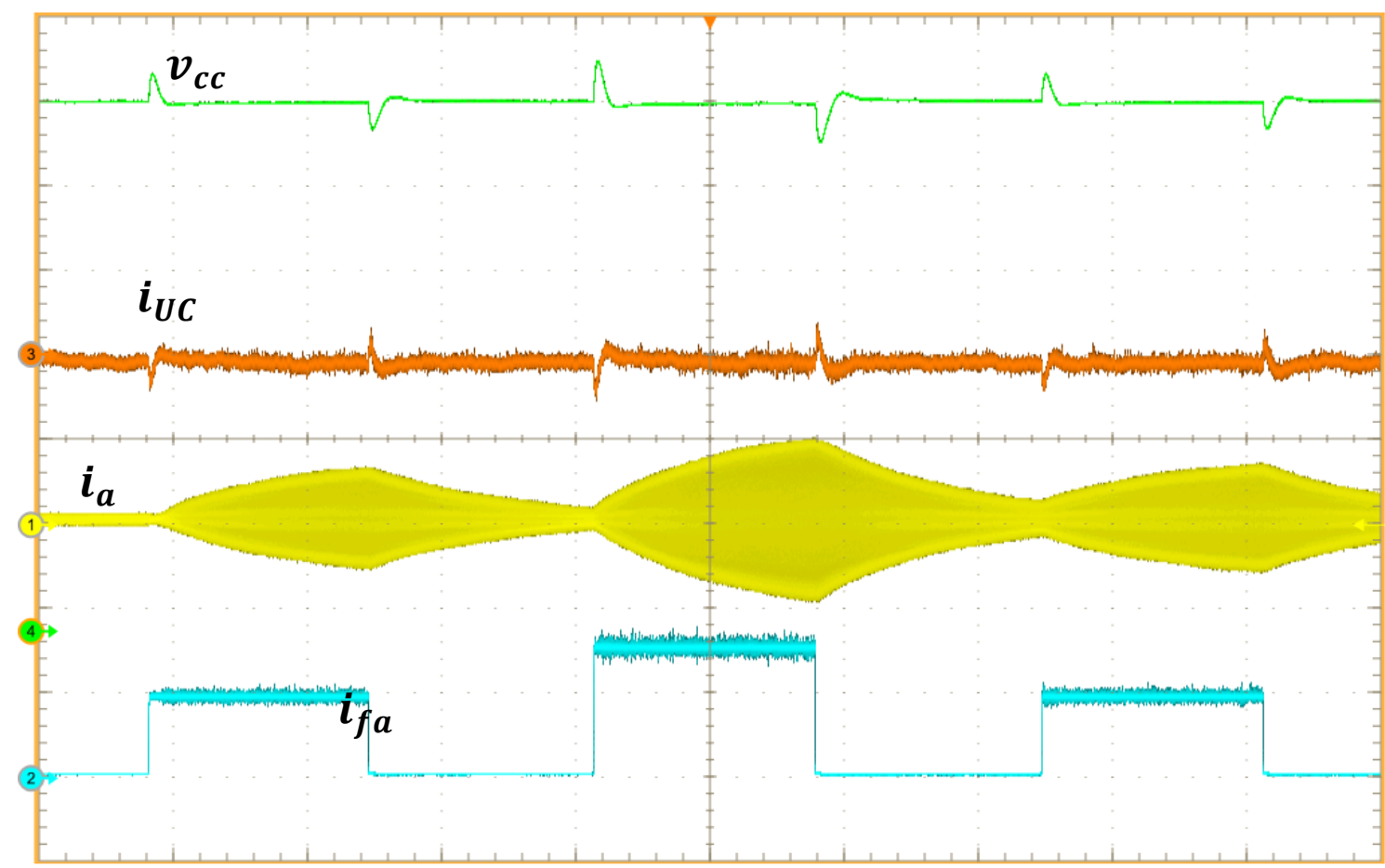

C1 $3.0 \mathrm{~A} / \mathrm{div} \quad \mathrm{C} 25.0 \mathrm{~A} / \mathrm{div} \mathrm{C} 35.0 \mathrm{~A} / \mathrm{div} \mathrm{C} 4 \quad 40.0 \mathrm{~V} / \mathrm{div} 5.0 \mathrm{~s} / \mathrm{div} 20.0 \mathrm{kS} / \mathrm{s}$

Figura 8.15 - Sistema de controle centralizado dividindo a carga entre um conjunto de armazenadores híbridos para uma entrada em degrau gerada pelas fontes alternativas $\left(i_{f a}\right)$. Nota-se a entrega de potência a rede na forma filtrada em relação a $i_{f a}$, reduzindo o impacto destes transitórios na rede de distribuição. 


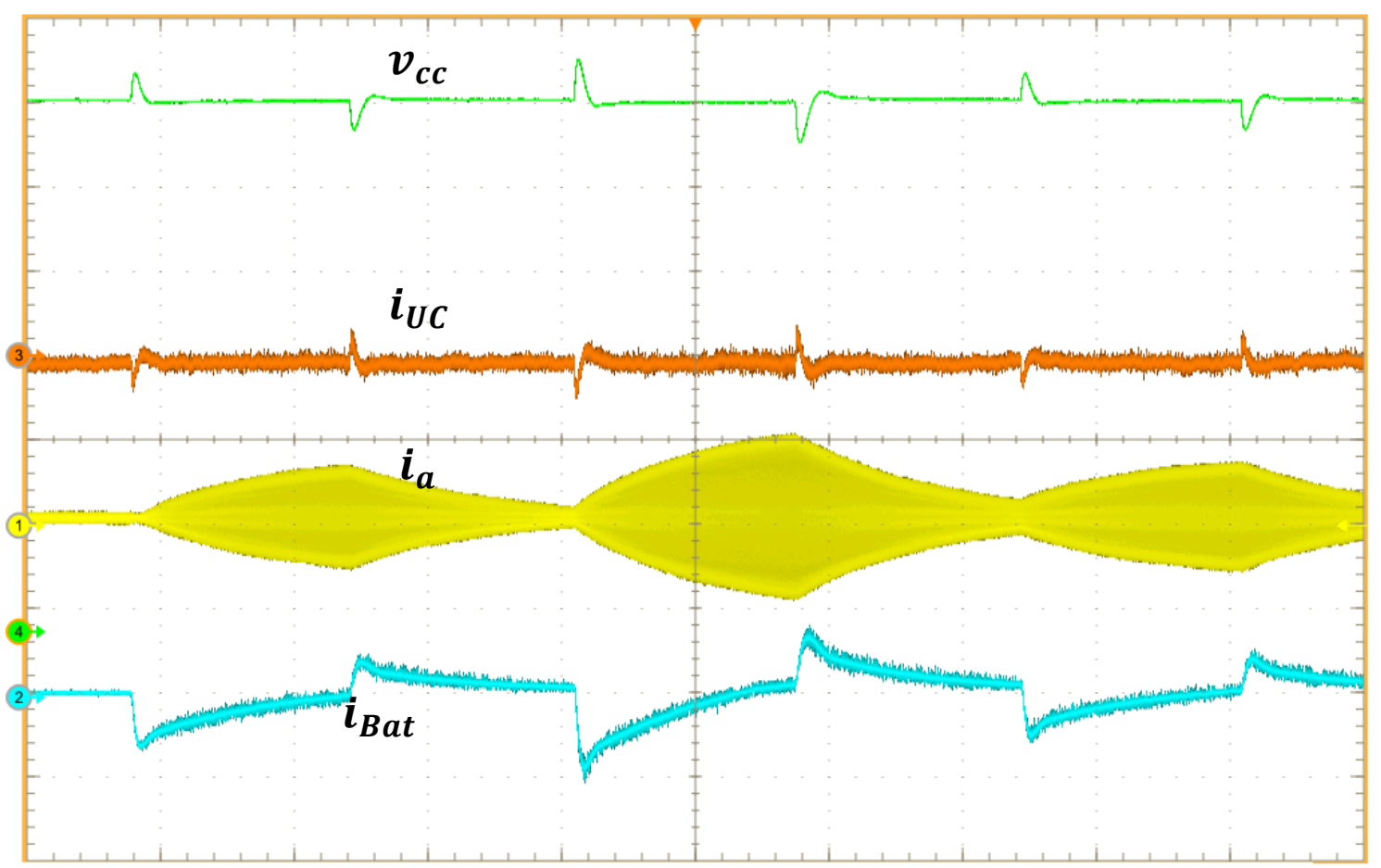

C1 3.0 A/div C2 5.0 A/div C3 5.0 A/div C4 40.0 V/div $5.0 \mathrm{~s} / \mathrm{div} 20.0 \mathrm{kS} / \mathrm{s}$

Figura 8.16 - Sistema de controle centralizado dividindo a carga entre um conjunto de armazenadores híbridos para uma entrada em degrau gerada pelas fontes alternativas $\left(i_{f a}\right)$. Nota-se a corrente da bateria se encarregando do déficit/superávit de energia necessário para manter a estabilidade, enquanto o UC se ocupa dos transitórios rápidos.

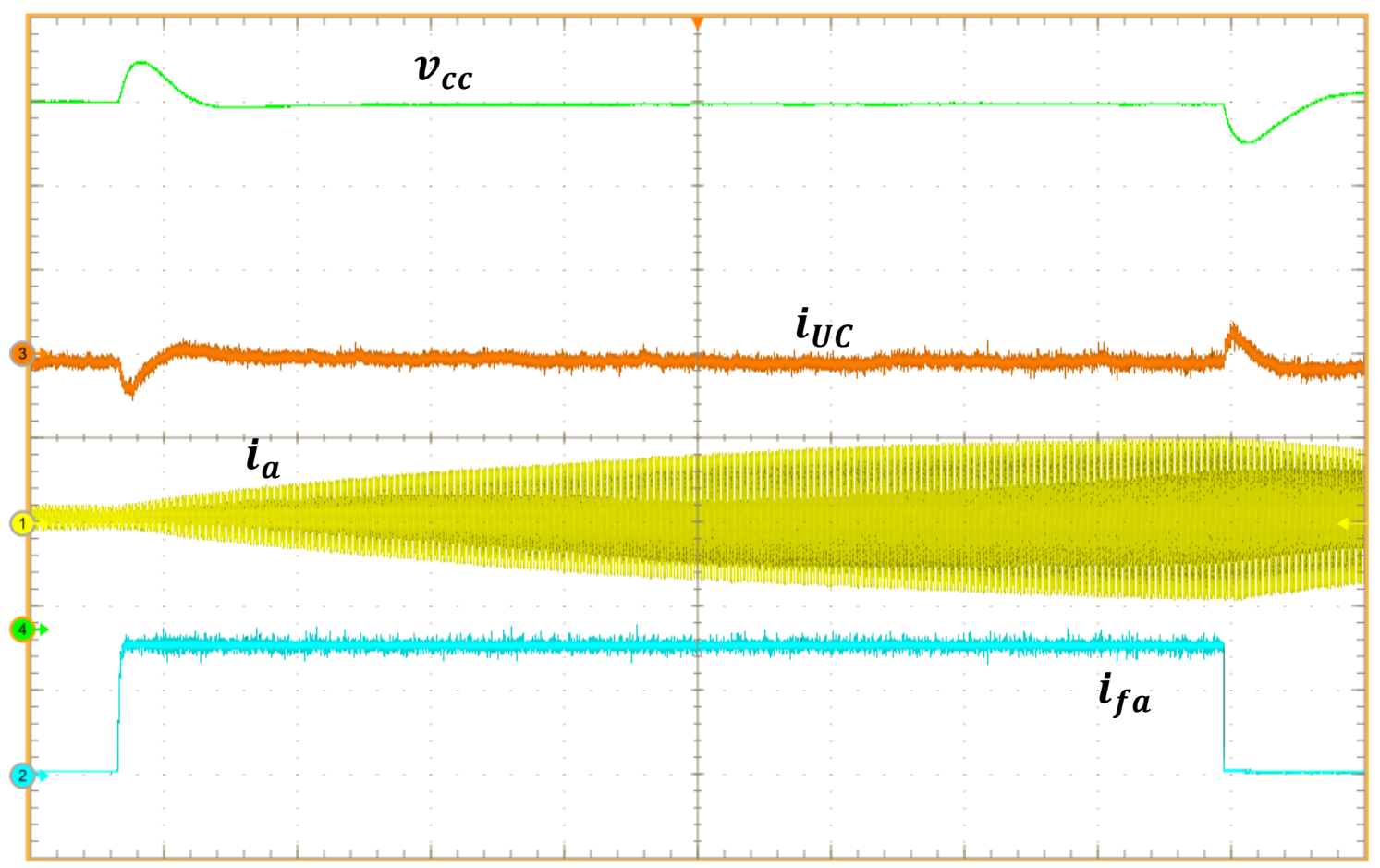

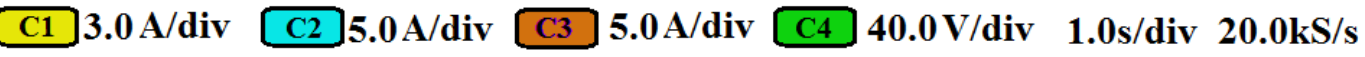

Figura 8.17 - Sistema de controle centralizado dividindo a carga entre um conjunto de armazenadores híbridos para uma entrada em degrau gerada pelas fontes alternativas $\left(i_{f a}\right)$. Nota-se o detalhe da corrente entregue a rede crescendo de forma gradual, devido ao aumento repentino na energia gerada pelas fontes alternativas. 
Caso se queira expandir a microrrede, adicionando outros armazenadores (baterias) incluindo a equalização das mesmas, a estratégia apresentada na Fig. 5.2 pode ser expandida para a forma da Fig. 8.18. Nesse caso, a corrente necessária para estabilizar o barramento CC $\left(i^{* *}\right)$ deve ser dividida entre as " $N$ " baterias do sistema por uma função $F($ soc). Para duas baterias, esta equação $F(s o c)$ pode ser definida por (8.1) e (8.2), fazendo com que a bateria com uma maior quantidade de energia forneça uma corrente maior na descarga e a bateria com uma menor quantidade de energia absorva um nível maior de corrente na carga, levando a microrrede a se equalizar. Para " $N$ ”baterias esta função é definida por (8.3) e (8.4).

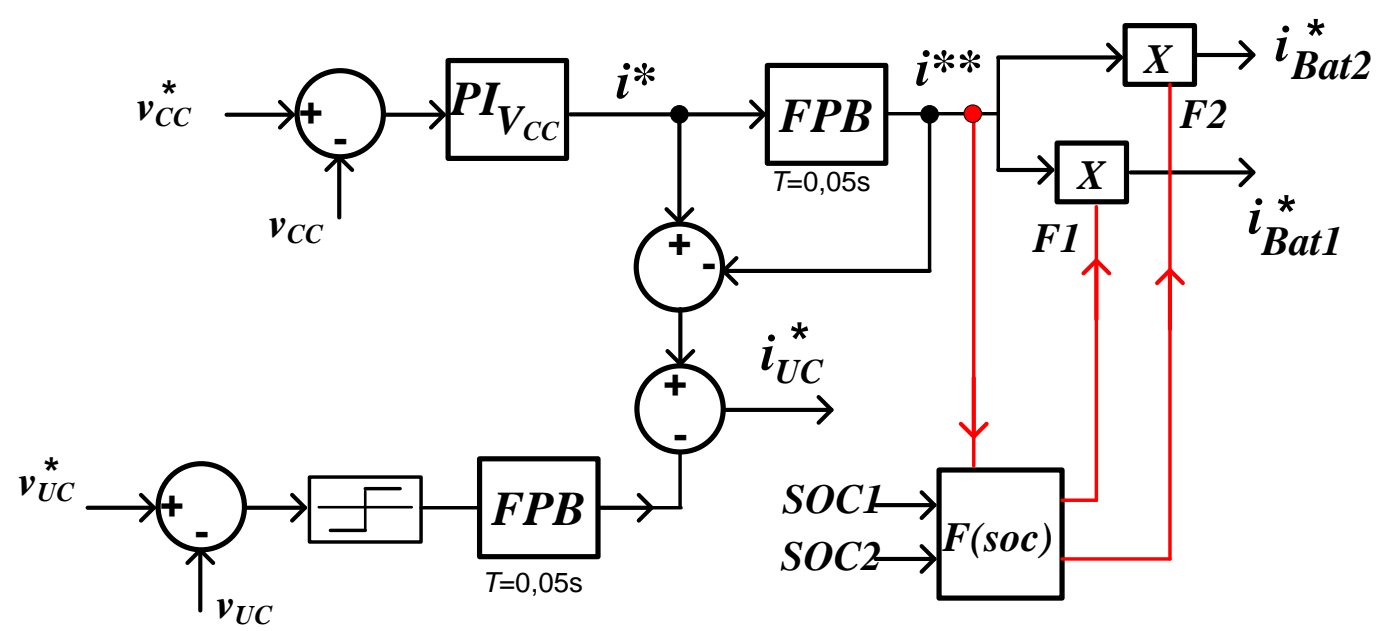

Fig. 8.18 - Expansão da técnica proposta no capítulo 5 quando mais baterias são conectadas ao sistema.

Função $F(s o c)$ para 2 baterias:

$$
\begin{aligned}
& \text { se } i^{* *} \geq 0\left\{F 1=\frac{\operatorname{soc} 1}{\operatorname{soc} 1+\operatorname{soc} 2} \text { e } F 2=\frac{\operatorname{soc} 2}{\operatorname{soc} 1+\operatorname{soc} 2}\right. \\
& \text { se } i^{* *}<0\left\{F 1=\frac{1-\operatorname{soc} 1}{\operatorname{soc} 1+\operatorname{soc} 2} \text { e } F 2=\frac{1-\operatorname{soc} 2}{\operatorname{soc} 1+\operatorname{soc} 2}\right.
\end{aligned}
$$

Função $F(s o c)$ para o caso genérico com “ $N$ ” baterias:

$$
\begin{aligned}
& \text { se } i^{* *} \geq 0\left\{F 1=\frac{\operatorname{soc} 1}{\operatorname{soc} 1+\operatorname{soc} 2+\cdots+\operatorname{soc} N}, F 2=\frac{\operatorname{soc} 2}{\operatorname{soc} 1+\operatorname{soc} 2+\cdots+\operatorname{soc} N} \ldots F N=\frac{\operatorname{soc} N}{\operatorname{soc} 1+\operatorname{soc} 2+\cdots+\operatorname{soc} N}\right. \\
& \text { se } i^{* *}<0\left\{F 1=\frac{1-\operatorname{soc} 1}{\operatorname{soc} 1+\operatorname{soc} 2+\cdots+\operatorname{soc} N}, F 2=\frac{1-\operatorname{soc} 2}{\operatorname{soc} 1+\operatorname{soc} 2+\cdots+\operatorname{soc} N} \ldots F N=\frac{1-\operatorname{soc} N}{\operatorname{soc} 1+\operatorname{soc} 2+\cdots+\operatorname{soc} N}\right.
\end{aligned}
$$

As Fig. 8.19 e 8.20 apresentam os resultados experimentais quando a microrrede CC opera com controle centralizado e utiliza armazenadores híbridos, ou seja, são usadas duas baterias e um UC conforme é visto na Fig. 8.18. Nesse caso, as baterias apresentam estados de cargas diferentes $(S O C 1=0,8$ e $S O C 2=0,4)$ dada uma entrada em degrau de $i_{f a}$. 
Nota-se, claramente, a divisão de carga entre as baterias (proporcionalmente em relação ao $S O C$ ) o que faz com que a Bat1 forneça um nível maior de corrente na descarga e Bat2 absorva, um nível maior, na carga. Assim, como na técnica com apenas uma bateria da Fig. 5.2, a tensão do barramento CC e tensão terminal do UC são restauradas.

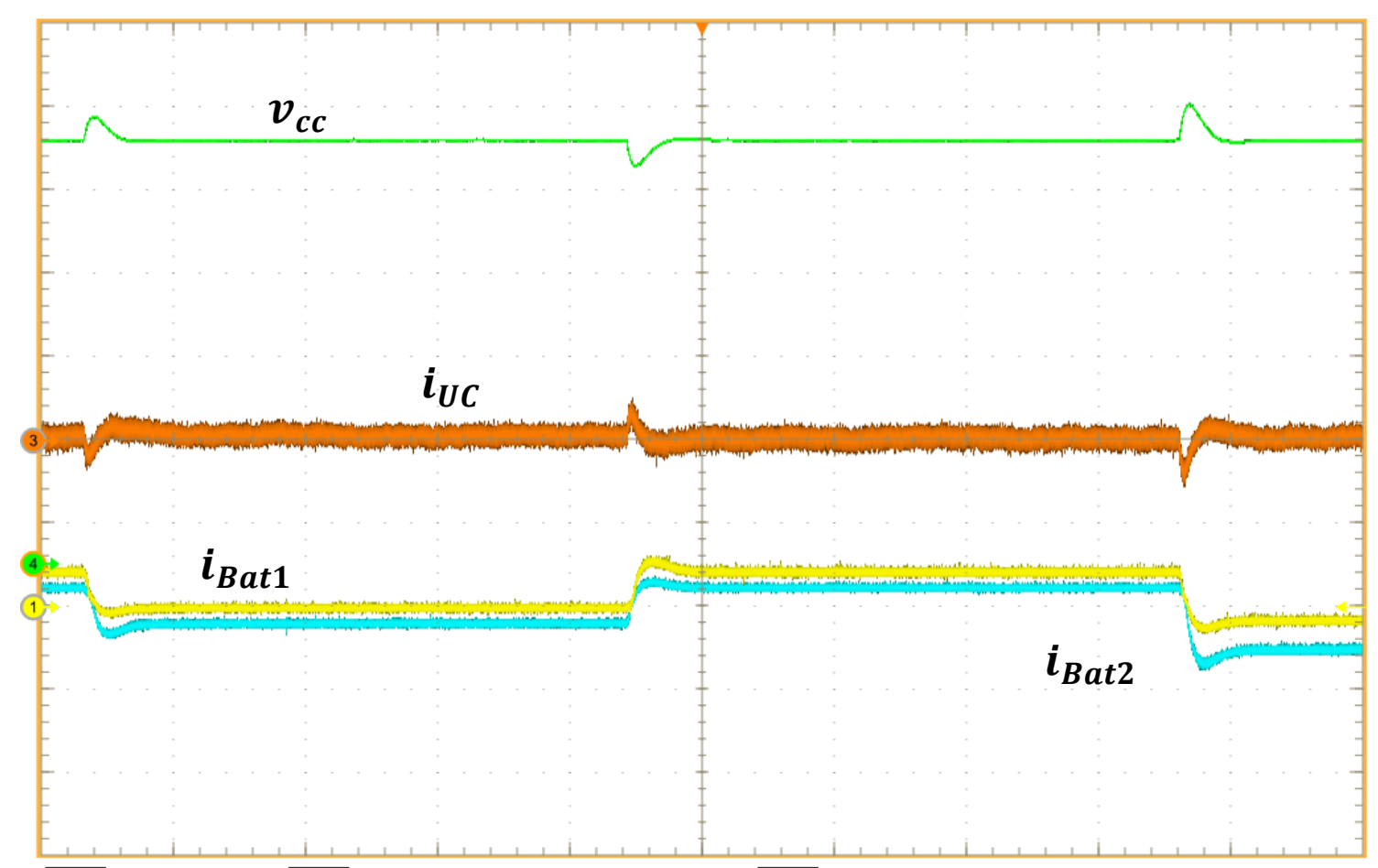

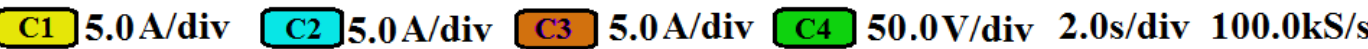

Figura 8.19 - Sistema de controle centralizado dividindo a carga em um sistema híbrido para uma entrada em degrau da corrente $i_{f a}$, onde duas baterias com estados de carga diferentes são conectadas, $S O C 1=0,8$ e $S O C 2=0,4$, dividindo proporcionalmente a carga e restaurando o barramento CC. 


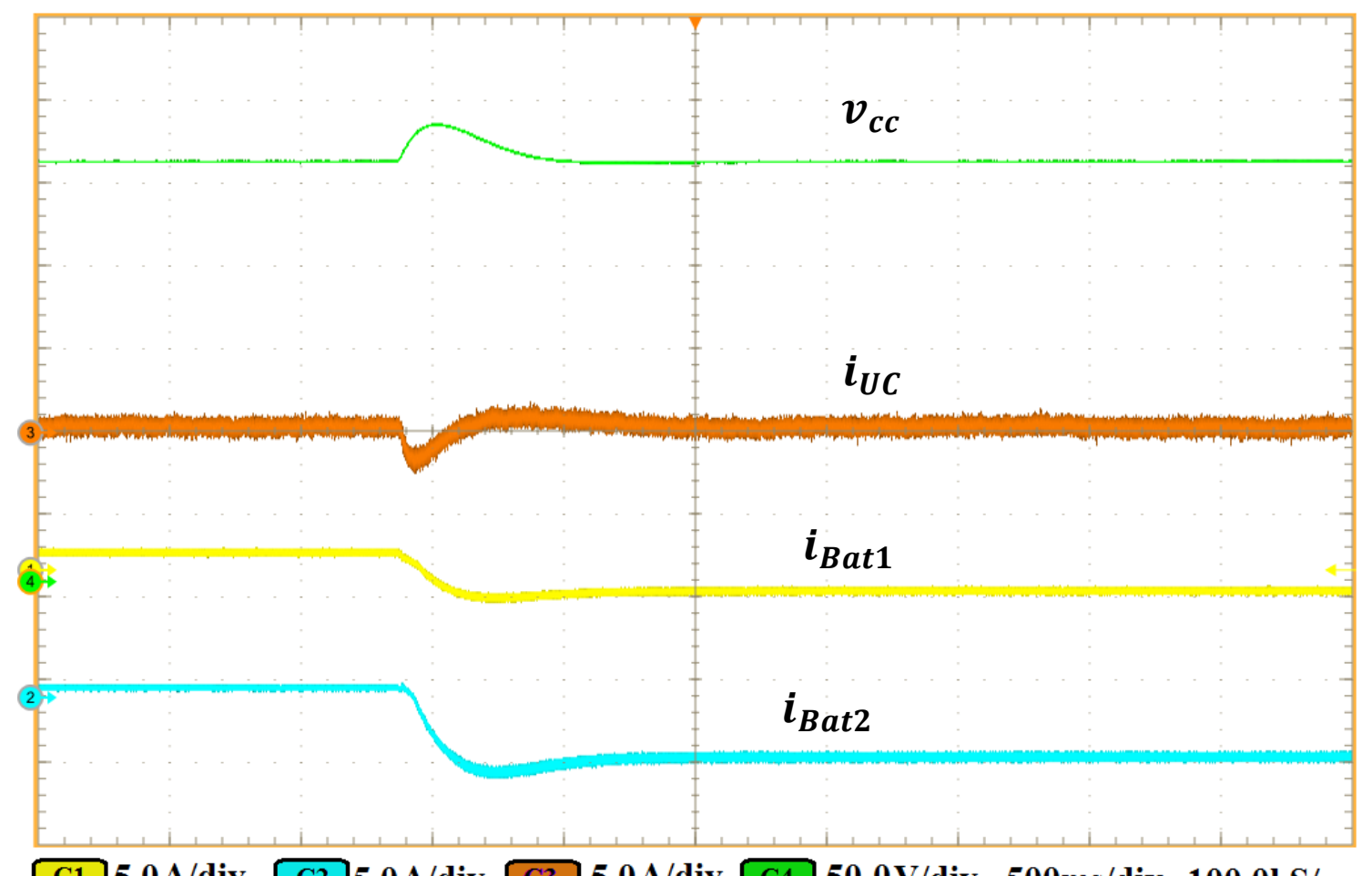

C1 5.0 A/div C2 $5.0 \mathrm{~A} / \mathrm{div}$ C3 5.0 A/div C4 $50.0 \mathrm{~V} / \mathrm{div} 500 \mathrm{~ms} / \mathrm{div} 100.0 \mathrm{kS} / \mathrm{s}$

Figura 8.20 - Sistema de controle centralizado dividindo a carga em um sistema híbrido para uma entrada em degrau da corrente $i_{f a}$, onde duas baterias com estados de carga diferentes são conectadas, $S O C 1=0,8$ e $S O C 2=0,4$, dividindo proporcionalmente a carga e restaurando a tensão terminal dos UCs.

Para fins de testes, nas Fig. 8.21, 8.22 e 8.23 a corrente da rede de distribuição foi alterada em degrau, de forma a analisar o efeito que a mesma causa no lado CC. Nota-se que a variação da demanda energética produzida pelo inversor gera um distúrbio de corrente no barramento, fazendo com que o controle divida esta carga entre o UC e as baterias. Assim como esperado, tanto a tensão do barramento quanto a tensão terminal do UC são restauradas. 


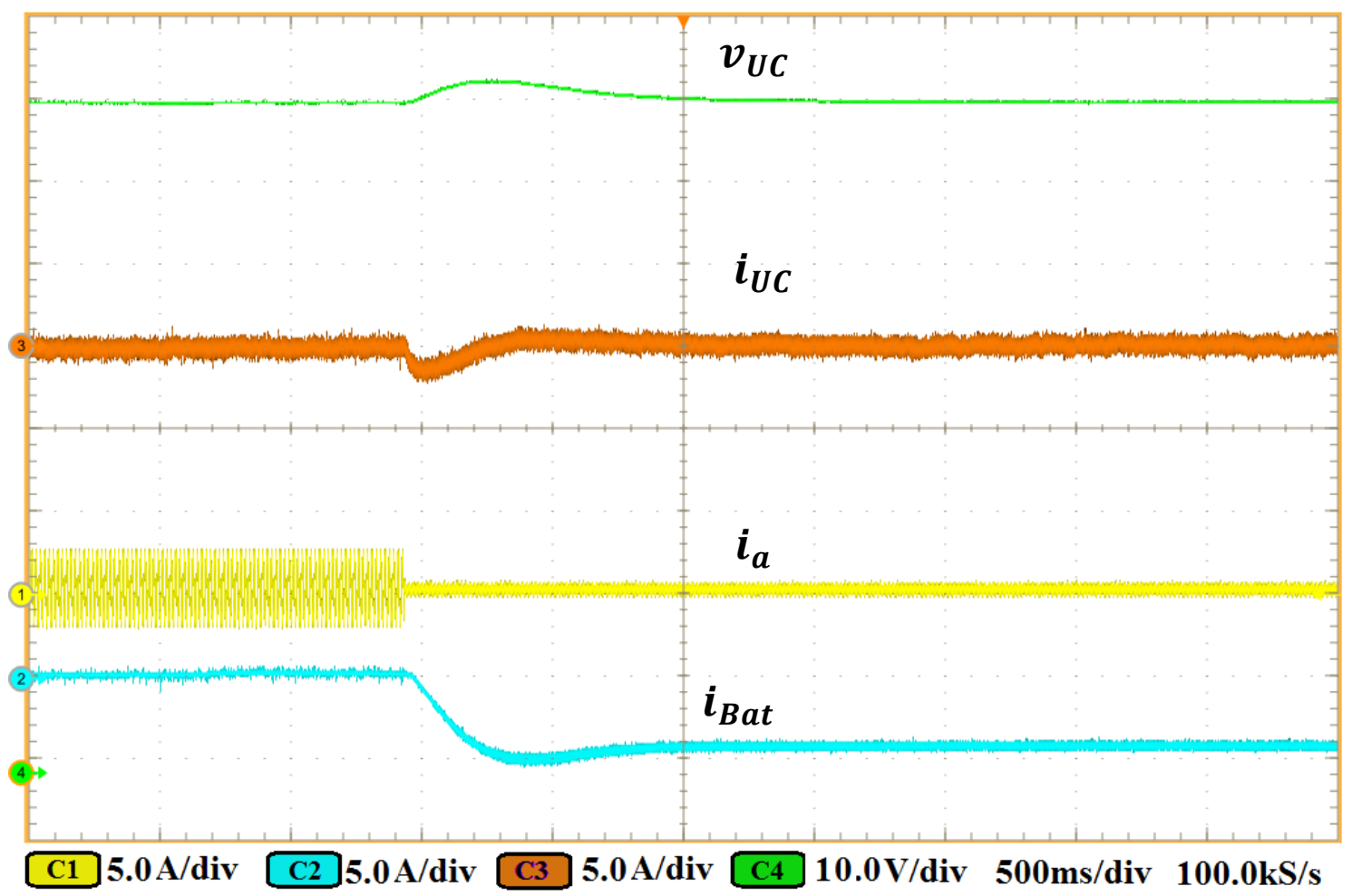

Figura 8.21 - Sistema de controle centralizado dividindo a carga em um sistema híbrido para uma variação em degrau da corrente entregue à rede.

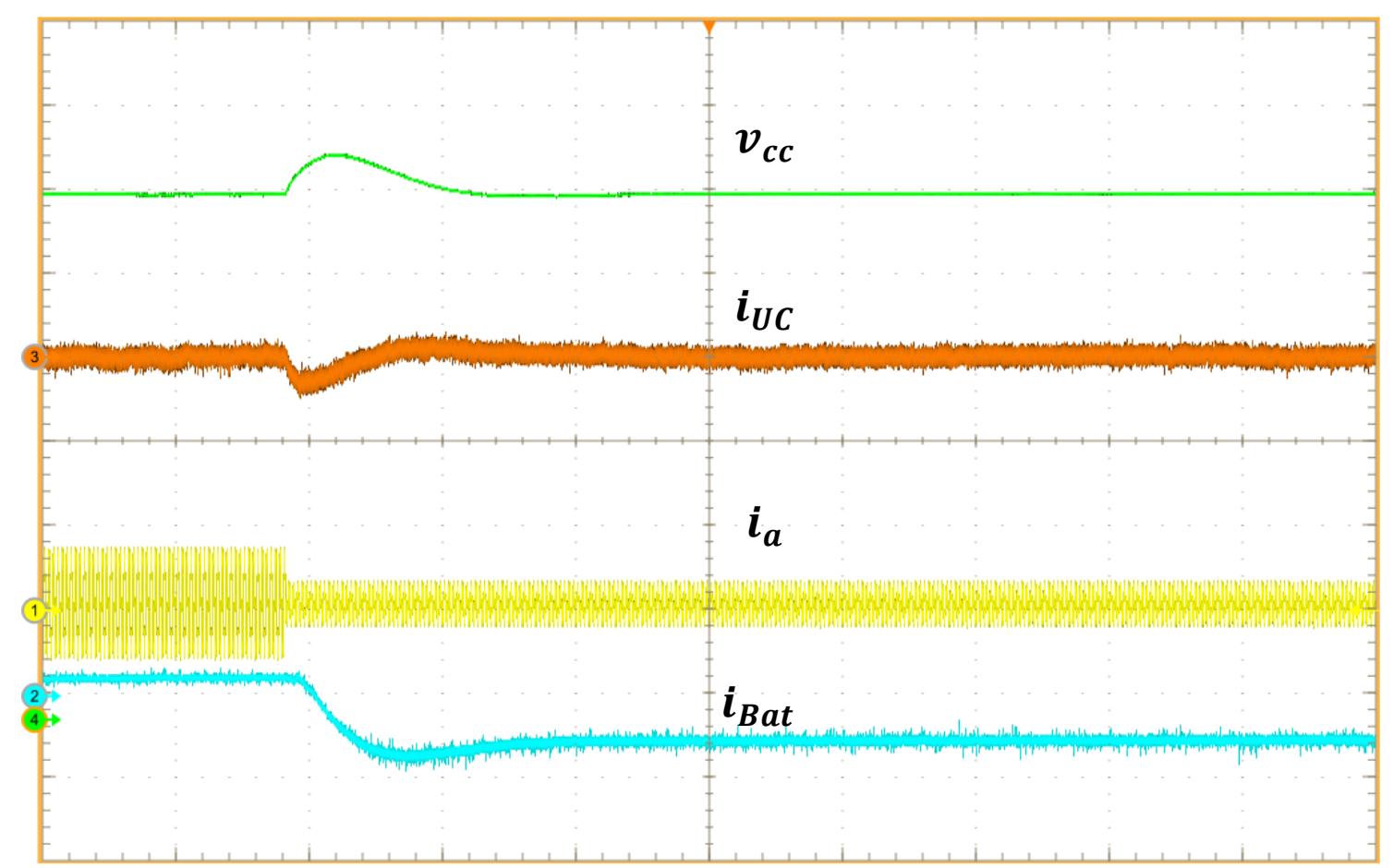

C1 5.0 A/div C2 5.0 A/div C3 5.0 A/div C4 $40.0 \mathrm{~V} / \mathrm{div} 500 \mathrm{~ms} / \mathrm{div} 100.0 \mathrm{kS} / \mathrm{s}$

Figura 8.22 - Sistema de controle centralizado dividindo a carga em um sistema híbrido para uma variação em degrau da corrente entregue à rede. 


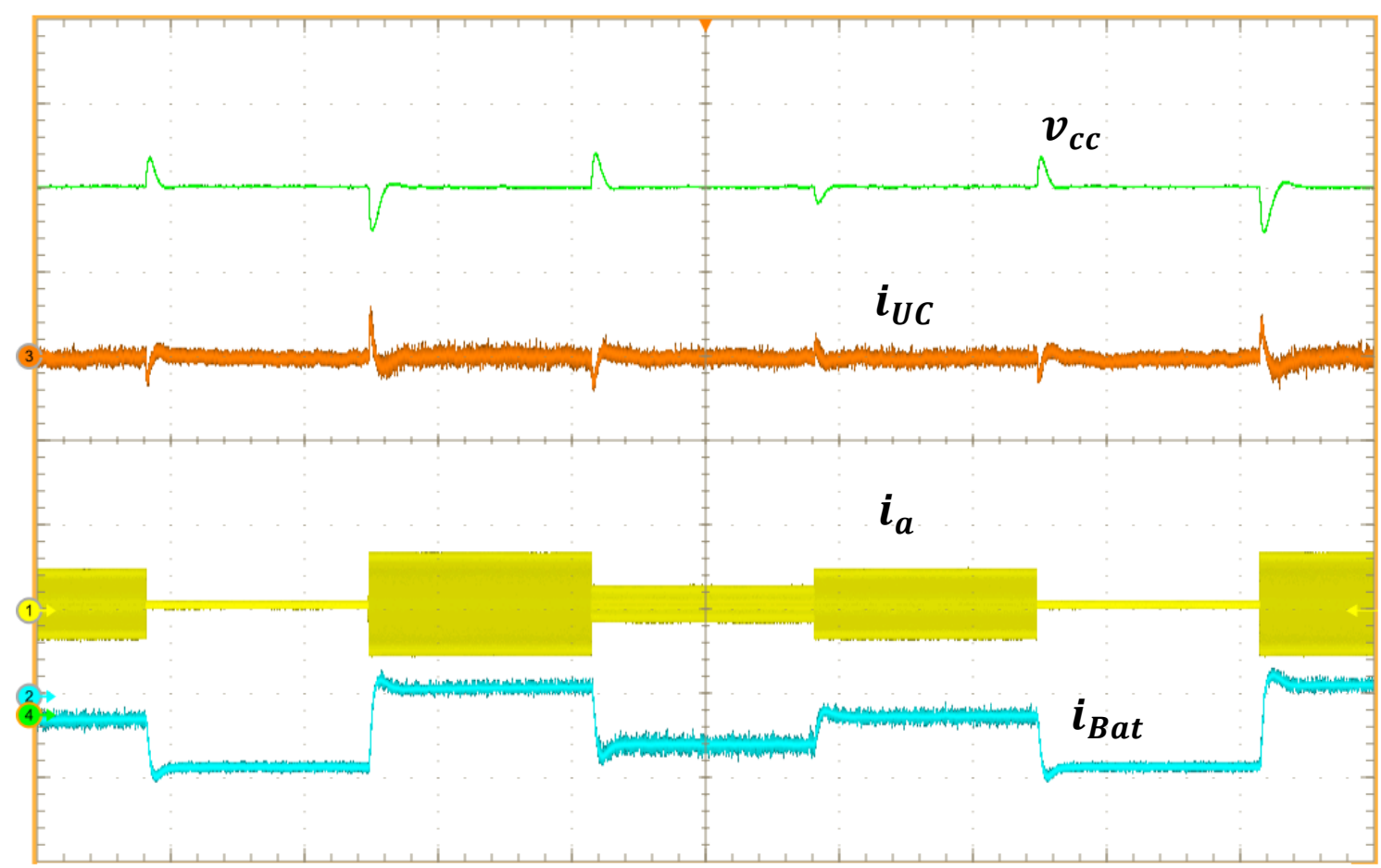

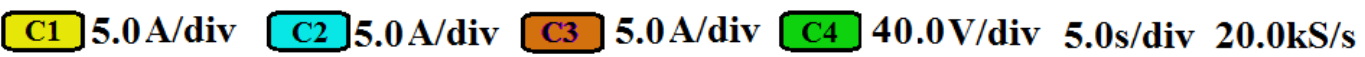

Figura 8.23 - Sistema de controle centralizado dividindo a carga em um sistema híbrido para variações em degrau da corrente entregue à rede.

\subsubsection{Sistema de Armazenamento Híbrido e}

\section{Controle Descentralizado de Divisão de Carga sem}

\section{Restauração do Barramento CC}

No Capítulo 6 foi proposta a técnica de divisão de carga de forma descentralizada, na qual os armazenadores não se comunicam. A primeira das técnicas realiza esta divisão de carga, contudo a tensão do barramento CC não é restaurada e apresenta erro de regime proporcional à potência da carga.

A Fig. 8.24 mostra o funcionamento do circuito de acordo com as simulações do Capítulo 6, dividindo a carga entre o UC e a bateria. Além de restaurar a tensão terminal do UC em $85 \mathrm{~V}$, nota-se a variação da tensão do barramento CC dadas variações sucessivas em degrau na corrente produzida pelas fontes alternativas $\left(i_{f a}\right)$. 


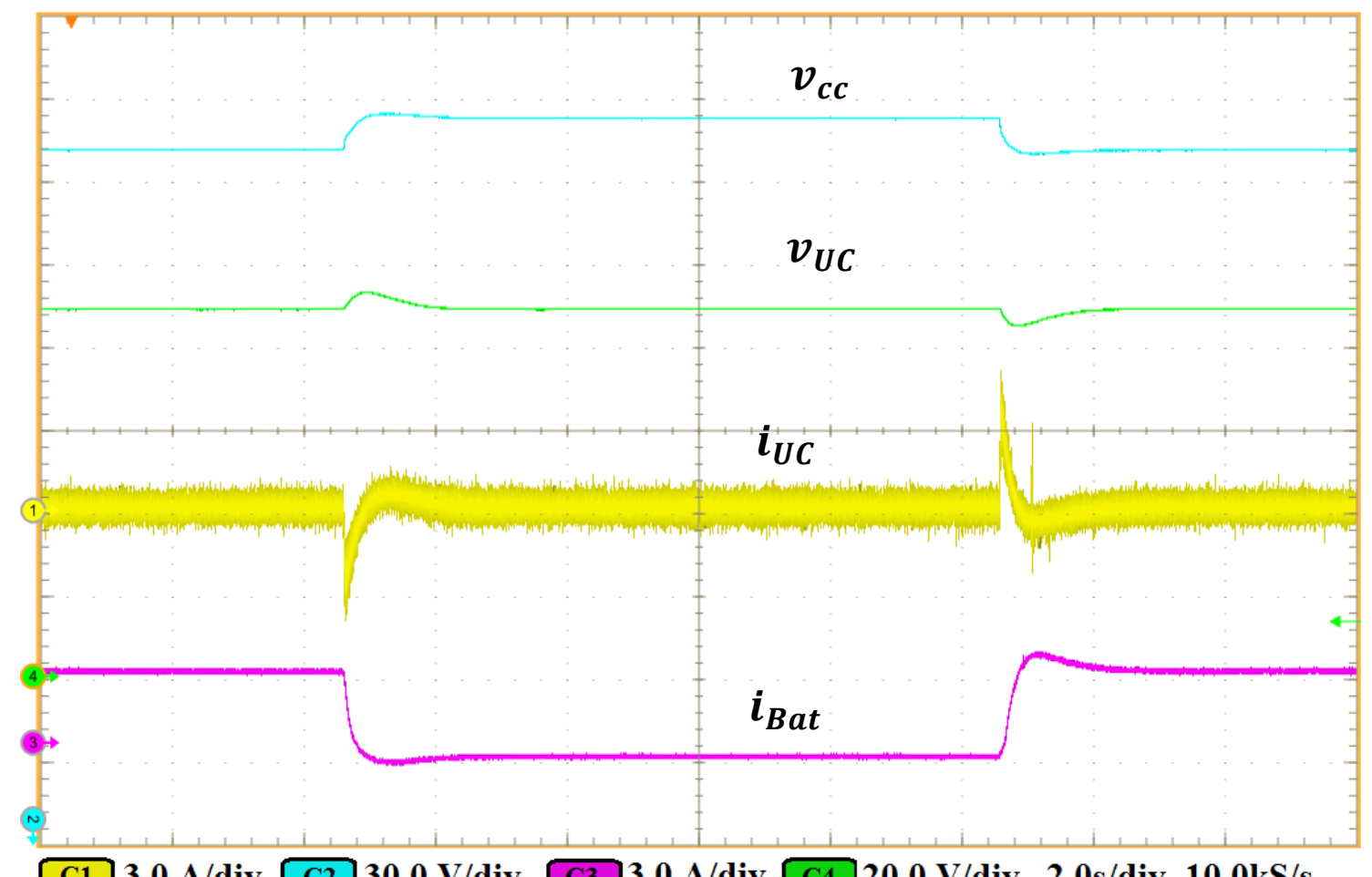

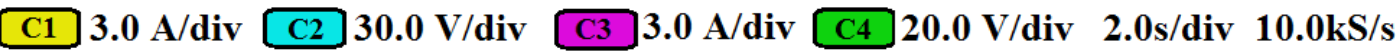

Figura 8.24 - Técnica de controle descentralizado sem restauração do barramento CC dividindo a carga entre o UC e bateria, além de restaurar a tensão do UC.

A Fig. 8.25 mostra a mesma situação da Fig. 8.24, contudo apresenta a soma das correntes geradas pelo UC mais o que é gerado pela bateria, compensando a variação de potência gerada pelas fontes alternativas $\left(i_{f a}\right)$ de forma a manter o balanço de energia no barramento. Nota-se a perfeita concordância com os resultados simulados do Capítulo 6 (Fig. 6.7 a 6.9), que foram obtidos com o modelo médio e comprova dessa forma, a precisão do modelo da microrrede bem como, a eficácia da técnica proposta. 


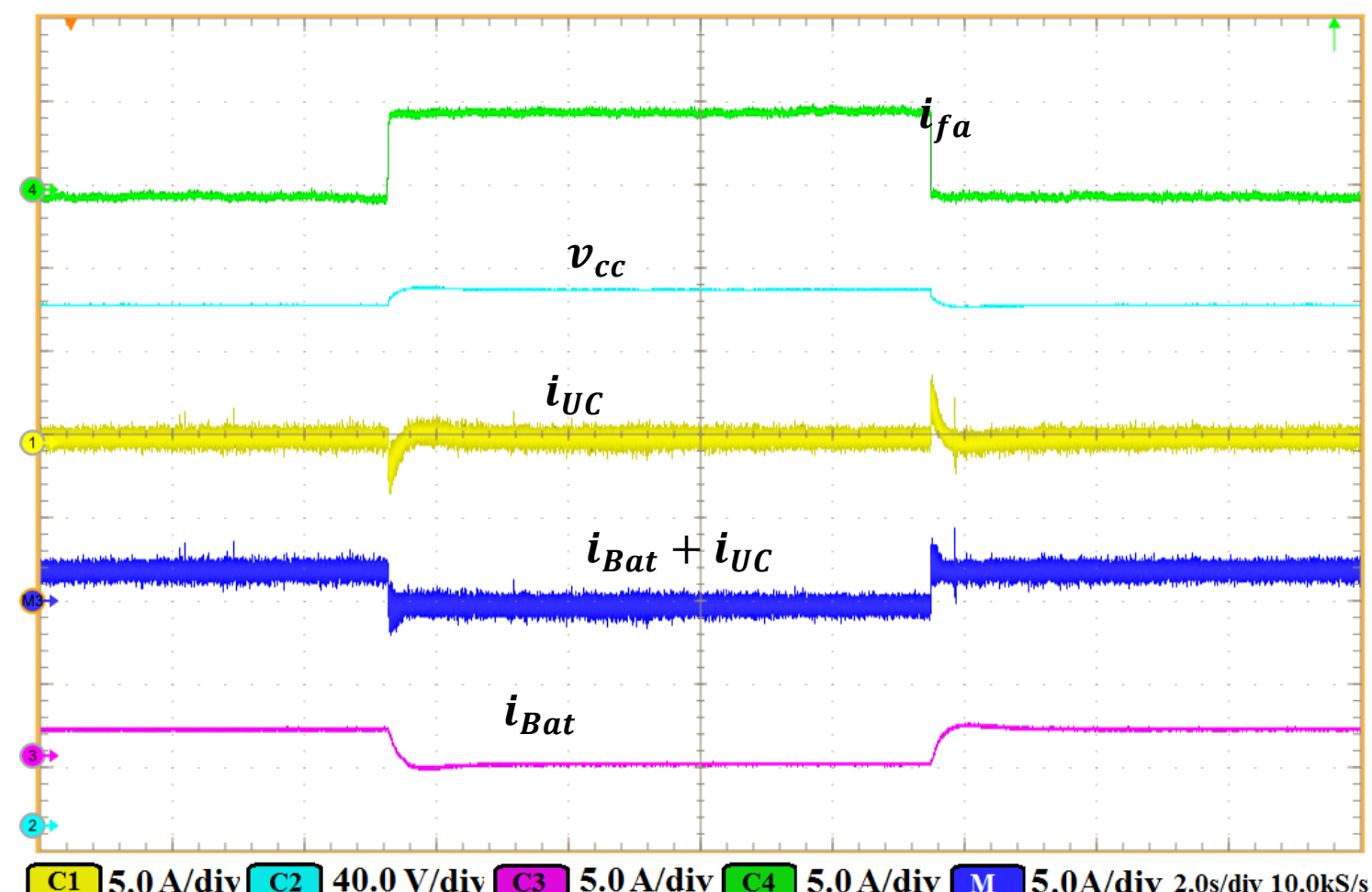

Figura 8.25 - Técnica de controle descentralizado sem restauração do barramento CC dividindo a carga entre o UC e bateria além da corrente total gerada pelos armazenadores.

As Fig. 8.26 e 8.27 ilustram a divisão de carga da microrrede com controle descentralizado, contudo, neste caso as duas baterias dividem o fornecimento de energia em regime permanente proporcionalmente ao estado de carga.

Assim, a bateria com uma maior quantidade de energia armazenada $(S O C 1=0,7 \mathrm{e}$ $S O C 2=0,4)$ fornece um nível maior de potência/corrente na descarga enquanto a bateria com menor nível de energia armazenada absorve uma quantidade de energia maior na carga, levando as baterias da microrrede $\mathrm{CC}$ a se equalizarem.

Por fim, nota-se que a tensão terminal do UC é sempre restaurada para $85 \mathrm{~V}$ após os transitórios, Fig. 8.27. Vale lembrar que os armazenadores não se comunicam, fazendo a equalização e divisão de carga utilizando apenas, o sinal da tensão do barramento CC.

De forma a preservar a integridade das baterias, a constante de tempo dos filtros da técnica de divisão de carga pode ser alterada, levando a bateria a ter dinâmicas lentas, como foi mostrado nas simulações do Capítulo 6 .

As Fig. 8.28 e 8.29 mostram este comportamento, quando a constante é alterada de $T=$ 0,05 s para $T=0,15 \mathrm{~s}$. Assim como nos resultados simulados, os transitórios das baterias e UC se tornaram mais lentos, assim como o desvio de tensão do UC foi maior, Fig. 8.29.

O aumento do desvio da tensão do UC se deve ao transitório mais longo do capacitor, que requer uma quantidade maior de energia para suportar esta dinâmica, sendo recuperada 
pela técnica de restauração proposta, que drena de volta a energia ao inverter o sentido da corrente suavemente após o transitório.

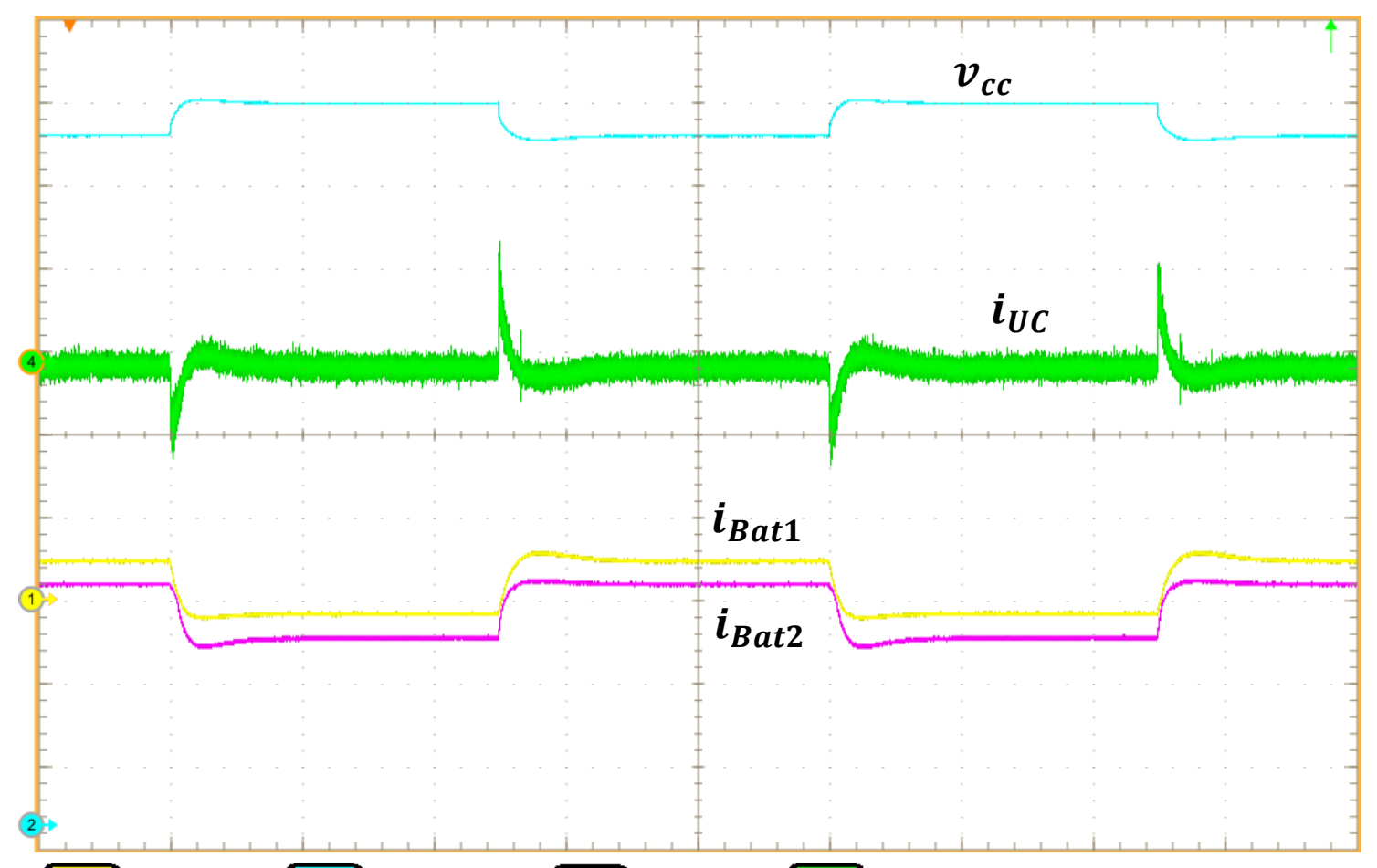

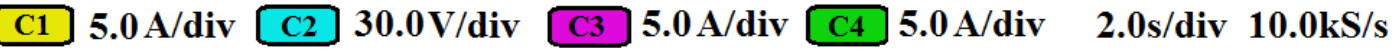

Figura 8.26 - Técnica de controle descentralizado sem restauração do barramento CC dividindo a carga entre o UC e baterias, tendo as baterias diferentes estados de carga, $S O C 1=$ 0,7 e $S O C 2=0,4$.

A Fig. 8.30 mostra uma corrente constante entregue à rede de distribuição durante um transitório na produção de energia (transitório de $i_{f a}$ ). Nesse contexto, mesmo sob uma variação da tensão do barramento $\mathrm{CC}$, a corrente se mantém senoidal e sem oscilações.

Além disso, é possível notar o aumento gradual da corrente da bateria de acordo com a constante de tempo definida pela técnica, assim como o decaimento tanto da tensão do barramento quanto da tensão terminal do UC. 


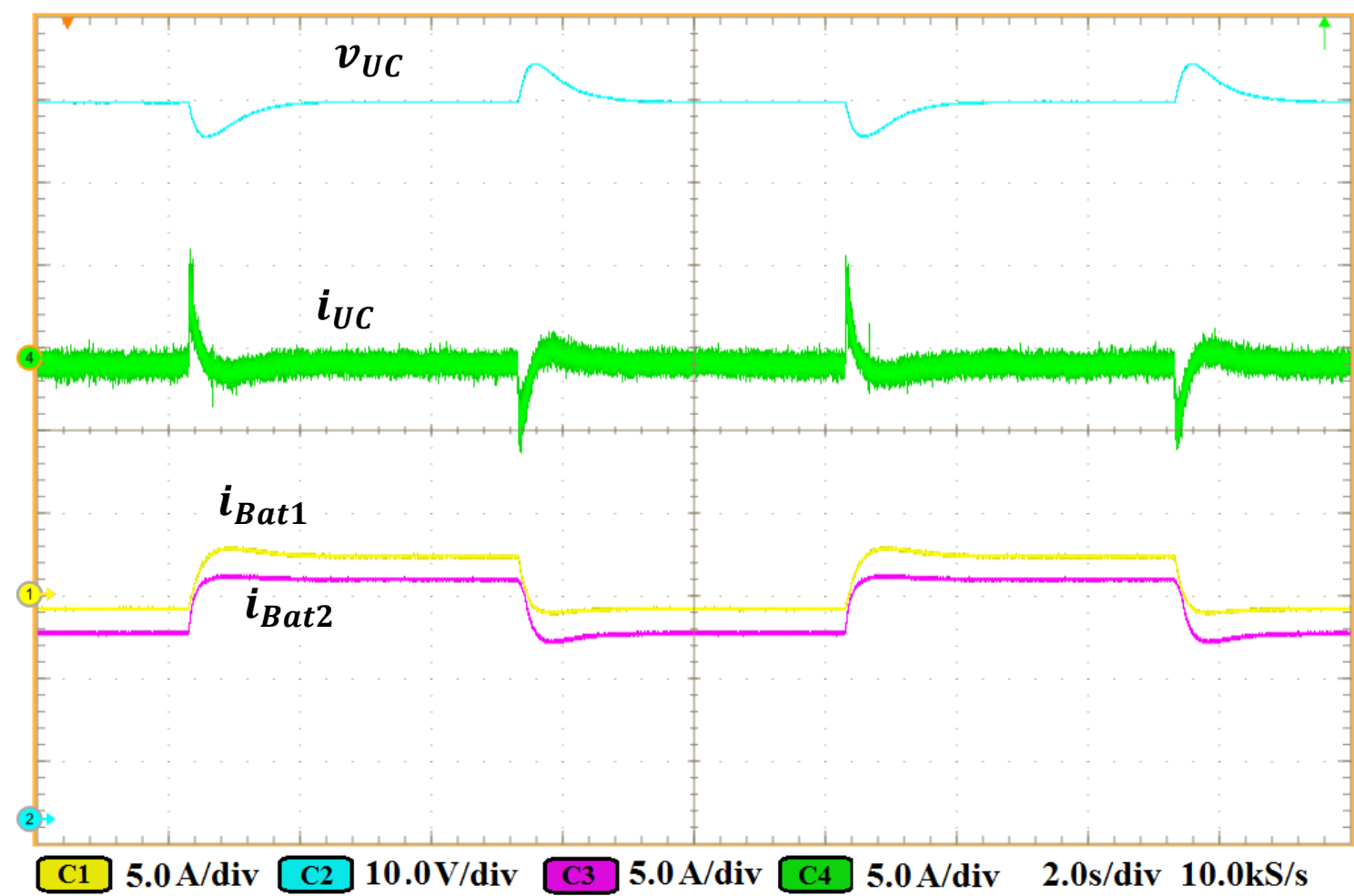

Figura 8.27 - Técnica de controle descentralizado sem restauração do barramento CC dividindo a carga entre o UC e baterias, tendo as baterias diferentes estados de carga, $S O C 1=$ 0,7 e $S O C 2=0,4$.

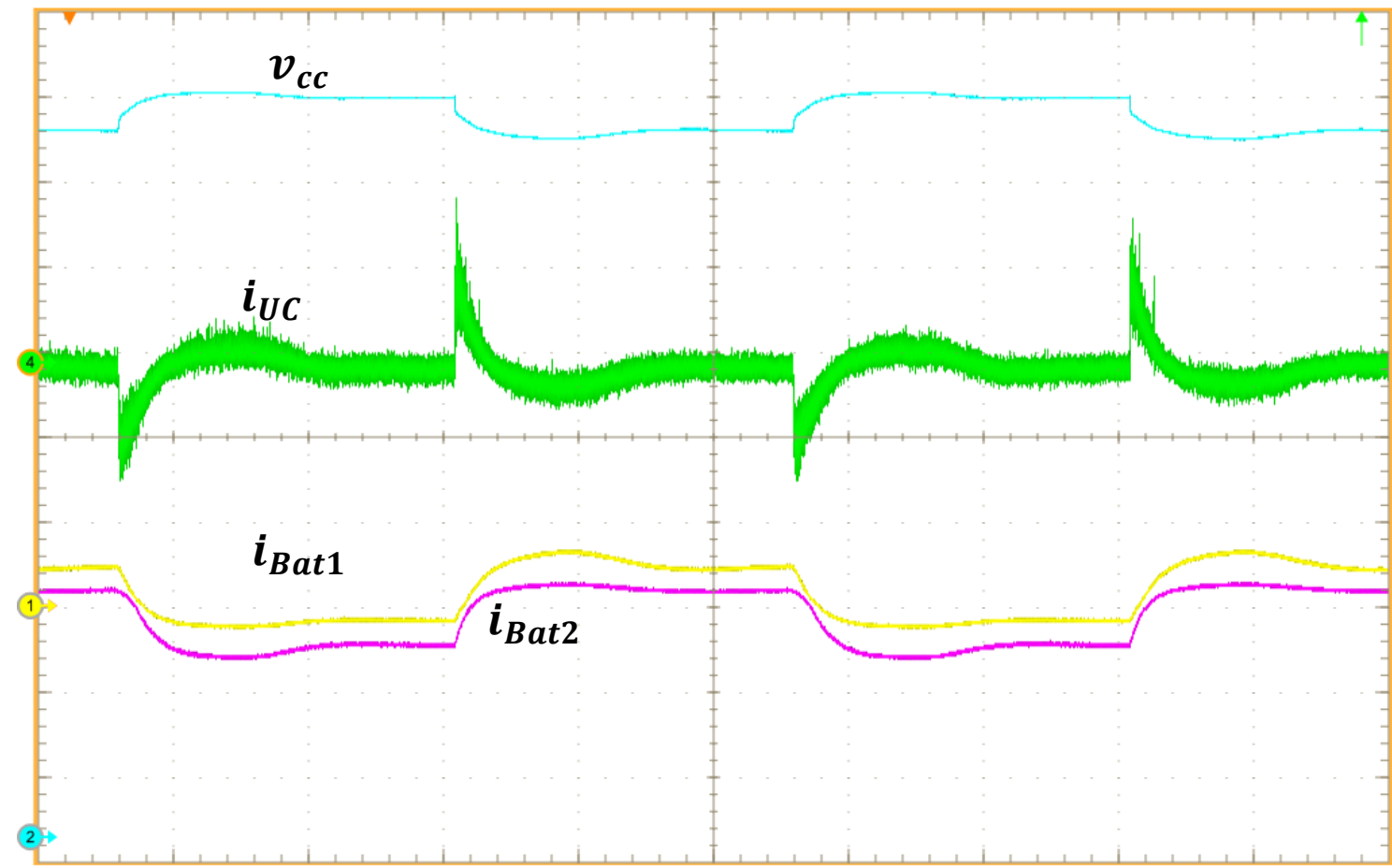

C1 5.0 A/div C2 $30.0 \mathrm{~V} / \mathrm{div} \mathrm{C} 35.0 \mathrm{~A} / \mathrm{div} \mathrm{C} 45.0 \mathrm{~A} / \mathrm{div} 2.0 \mathrm{~s} / \mathrm{div} 10.0 \mathrm{kS} / \mathrm{s}$

Figura 8.28 - Técnica de controle descentralizado sem restauração do barramento CC dividindo a carga entre o UC e baterias, sendo a constante de tempo da técnica alterado de $T=$ $0,05 \mathrm{~s}$ para $T=0,15 \mathrm{~s}$. 


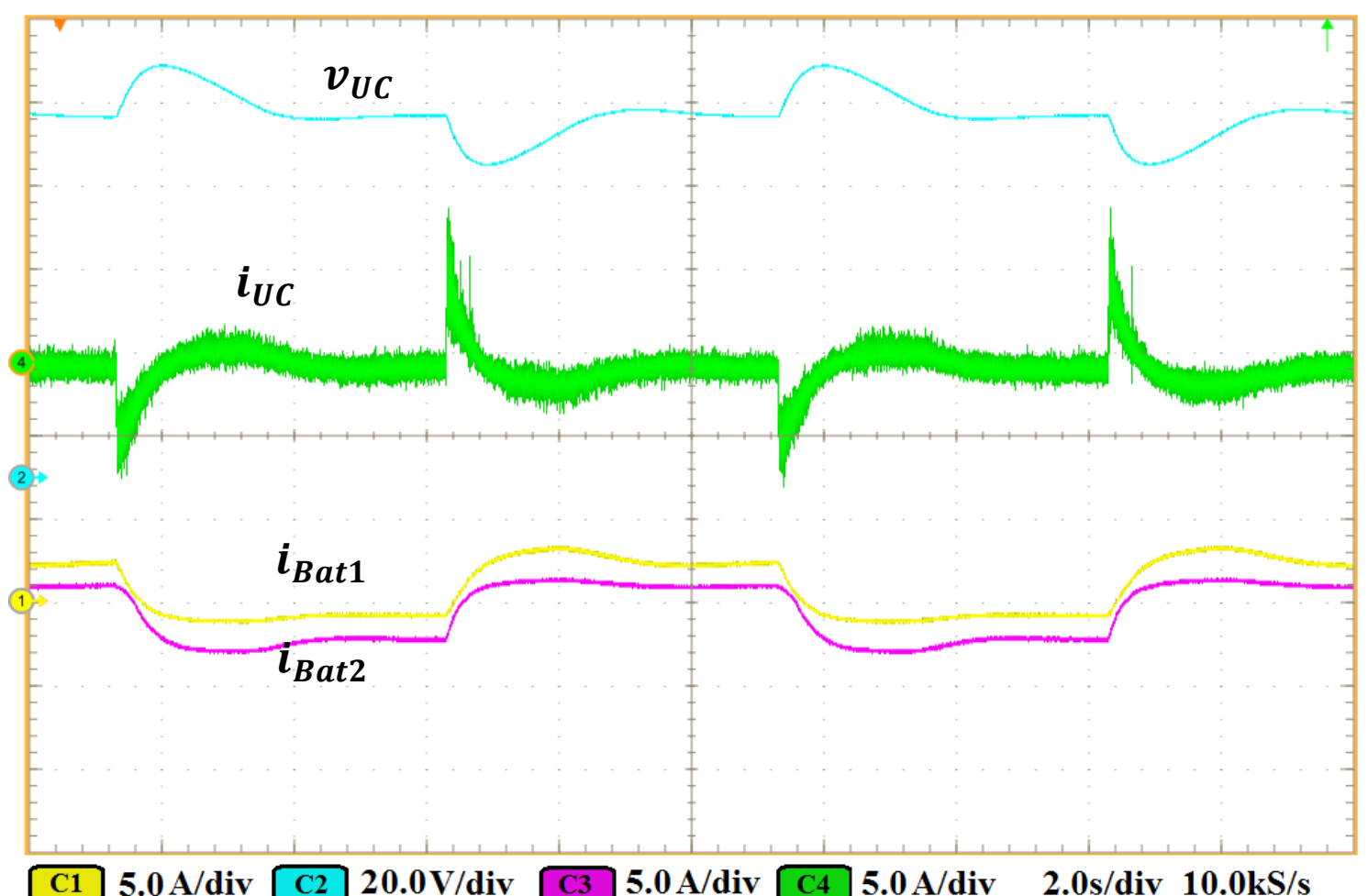

Figura 8.29 - Técnica de controle descentralizado sem restauração do barramento CC dividindo a carga entre o UC e baterias, sendo a constante de tempo da técnica alterado de $T=$ $0,05 \mathrm{~s}$ para $T=0,15 \mathrm{~s}$.

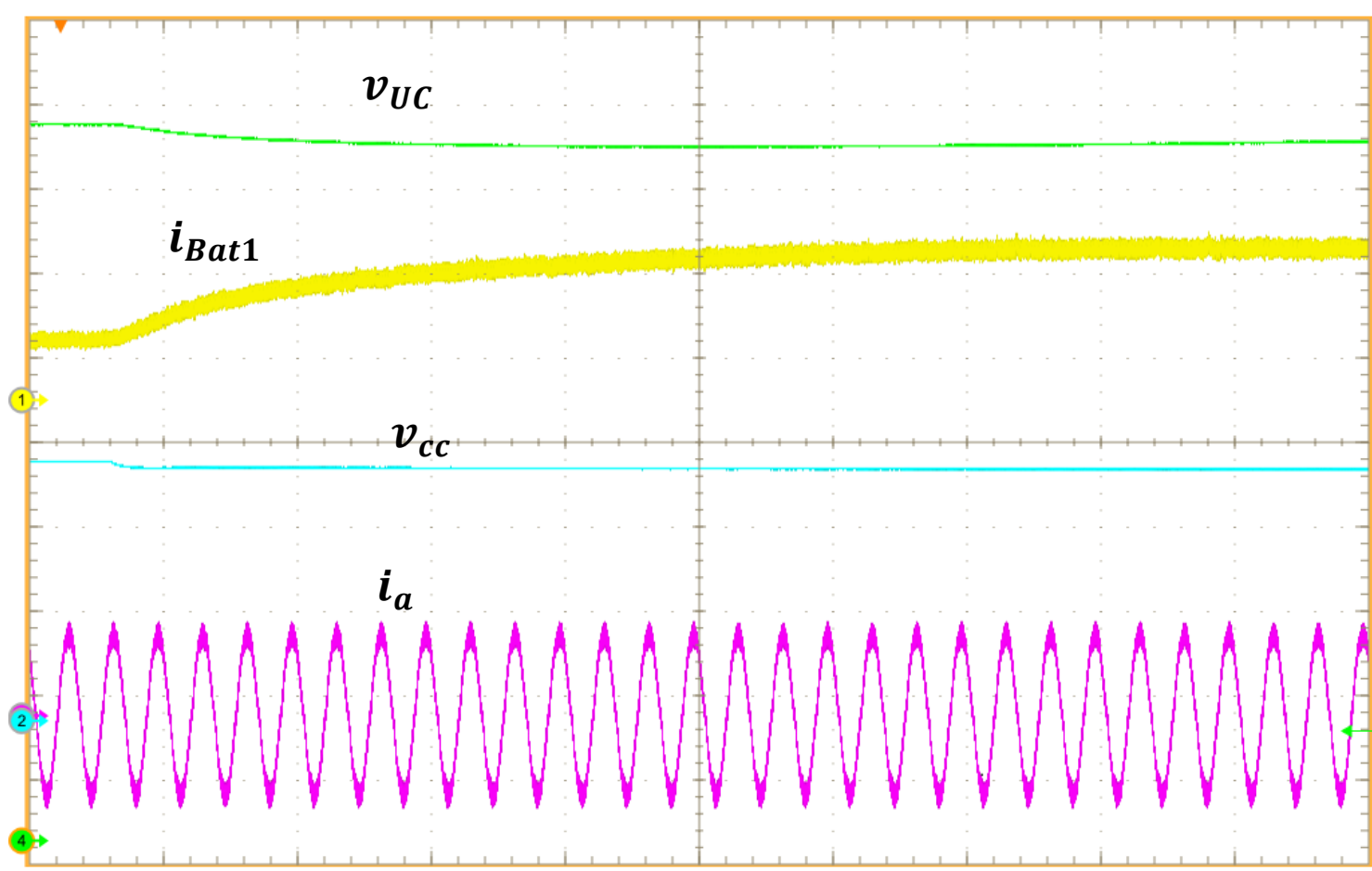

C1 $2.0 \mathrm{~A} / \mathrm{div} \mathrm{C} 280.0 \mathrm{~V} / \mathrm{div} \mathrm{C} 32.0 \mathrm{~A} / \mathrm{div} \mathrm{C} 410.0 \mathrm{~V} / \mathrm{div} 50.0 \mathrm{~ms} / \mathrm{div} 100.0 \mathrm{kS} / \mathrm{s}$

Figura 8.30 - Técnica de controle descentralizado sem restauração do barramento CC dividindo a carga entre o UC e baterias. Zoom durante o transitório mostrando a corrente entregue a rede se mantendo estável mesmo durante o transitório. 
Caso uma célula a combustível $(C a C)$ seja utilizada como fonte primária de geração de energia, as variações na potência gerada não serão decorrentes dos transitórios rápidos como era observado nos painéis fotovoltaicos ou aerogeradores, sendo estes transitórios muito lentos.

As Fig. 8.31 e 8.32 usam o conversor CC-CC das fontes alternativas para emular o comportamento transitório de uma $\mathrm{CaC}$, de forma a analisar a resposta dos armazenadores e do barramento sob essas condições. Nos primeiros instantes das Fig. 8.31 e 8.32 apenas uma bateria está conectada à microrrede e fornecendo potência, porém após $12 \mathrm{~s}$ a segunda bateria é conectada. Uma vez que a técnica de controle utiliza o desvio de tensão do barramento como meio de comunicação a carga é dividida de acordo com o estado de carga das baterias $(S O C 1=$ $0,7$ e $S O C 2=0,4)$.

No entanto, percebe-se que à medida que a potência gerada pela $C a C$ cresce, as baterias deixam de fornecer energia à microrrede $\mathrm{CC}$ e passam a ser carregadas pela $C a C$, devido ao superávit de energia. É perceptível que as baterias, ao cruzarem a corrente zero mudam de comportamento, ou seja, a bateria que fornecia um maior nível de corrente passa a absorver um menor nível e vice-versa.

A Fig. 8.32 mostra a variação da tensão do barramento em função do déficit energético, onde esta tensão atinge $250 \mathrm{~V}$, exatamente, no cruzamento das correntes da bateria por zero. Nota-se que os UCs não são acionados na Fig. 8.32, uma vez que eles só atuam durante transitórios rápidos, logo, como a $C a C$ gera uma variação suave de energia, a corrente dos UCs é mantida em zero a espera de um transitória rápido. 


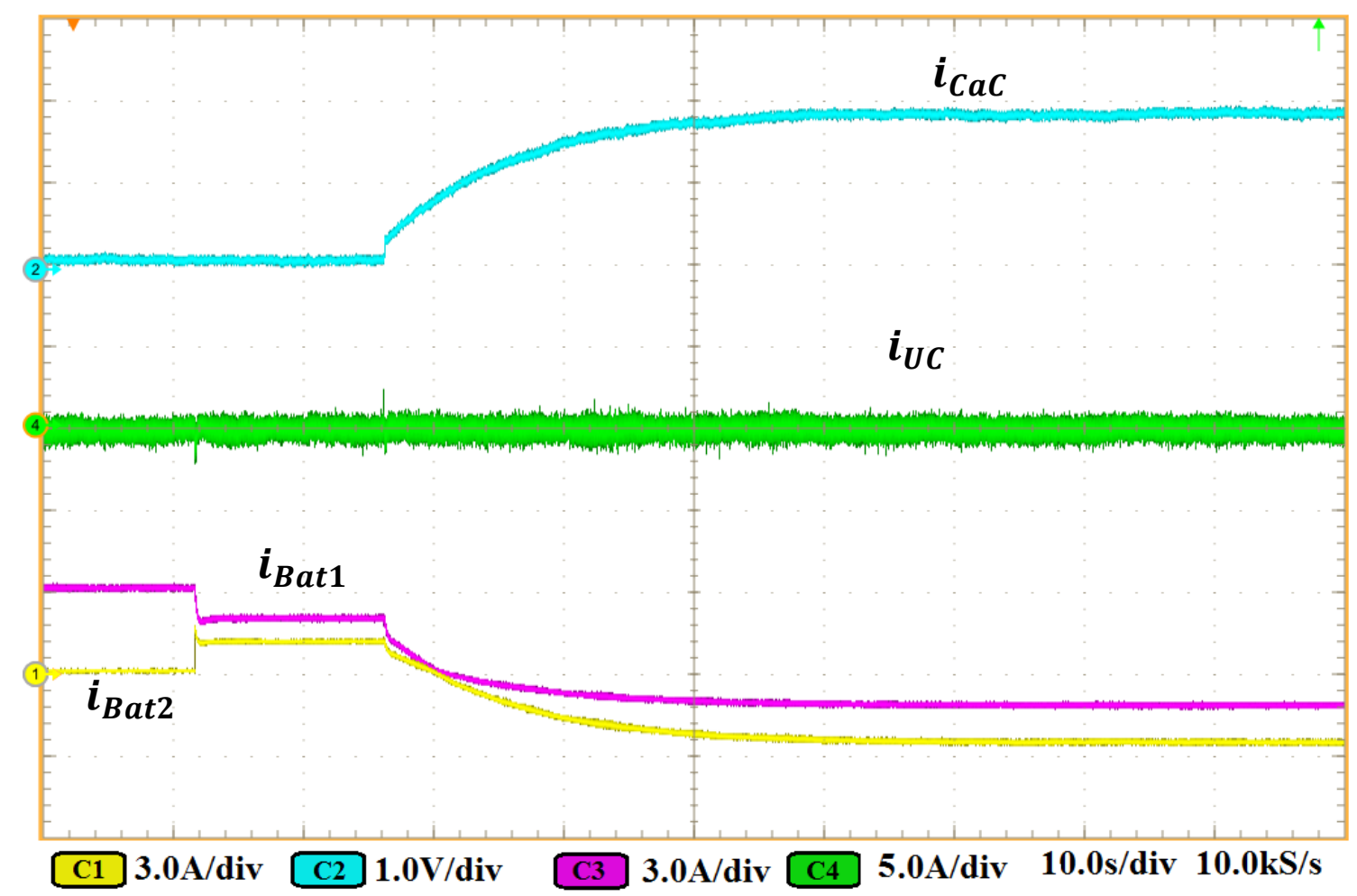

Figura 8.31 - Técnica de controle descentralizado sem restauração do barramento CC dividindo a carga entre o UC e baterias dada uma entrada que emula a geração de energia por uma célula a combustível.

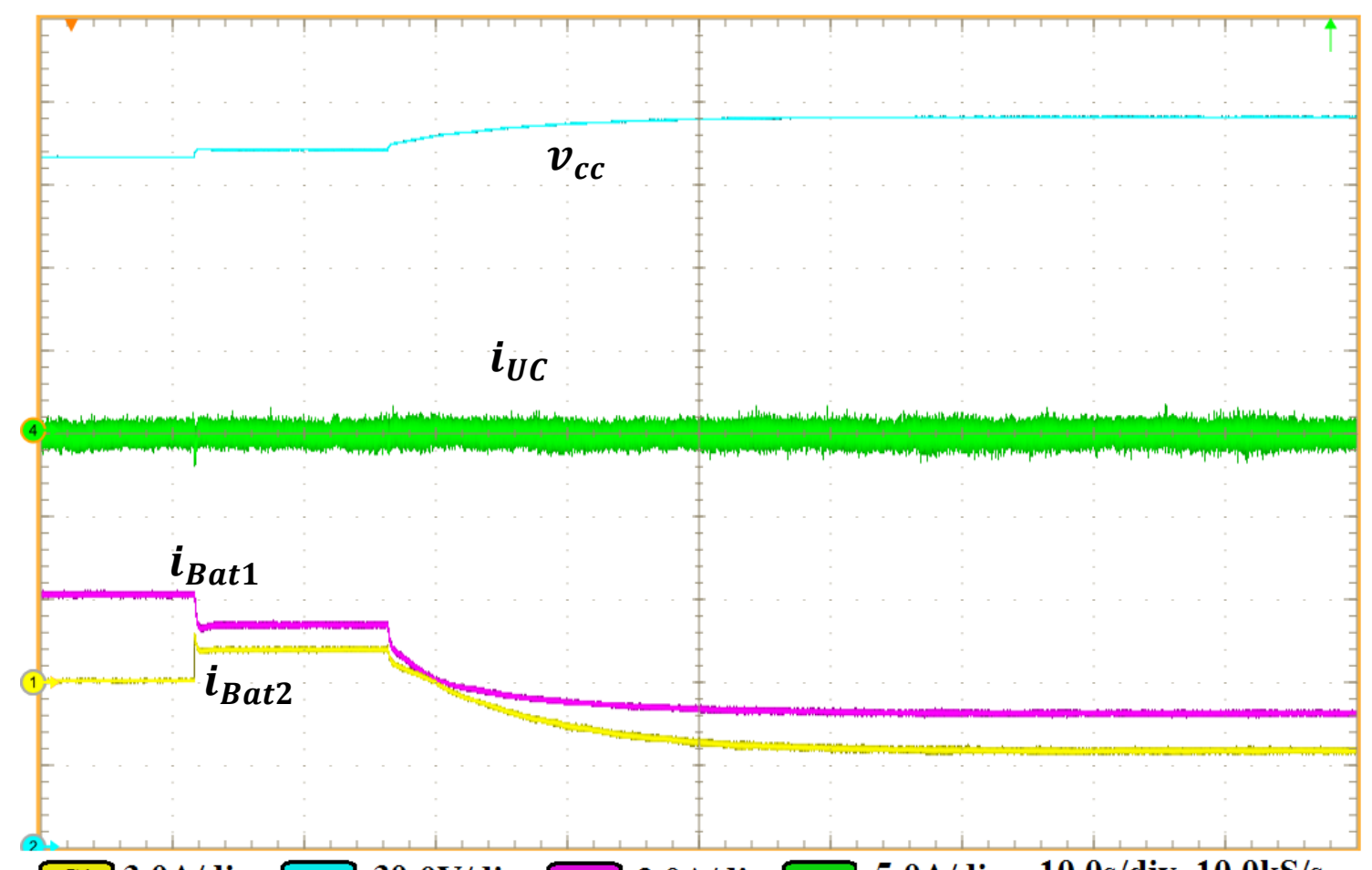

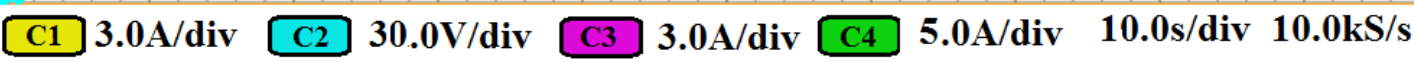

Figura 8.32 - Técnica de controle descentralizado sem restauração do barramento CC dividindo a carga entre o UC e baterias dada uma entrada que emula a geração de energia por uma célula de combustível. 
Assim como nas simulações, os experimentos desta seção foram obtidos considerando o estado de carga das baterias constante, de forma a visualizar a técnica de compartilhamento de carga proporcionalmente ao SOC. Contudo, isso omite o comportamento dinâmico que a técnica possui, equalizando as baterias com o passar do tempo.

Uma vez que as baterias da microrrede apresentam uma capacidade elevada, isso inviabilizaria o uso do estado de carga real das baterias, pelo tempo necessário aos ensaios. Logo, o $S O C$ é emulado da mesma forma como nas simulações, pela equação (6.7), representando uma bateria de capacidade reduzida de forma a acelerar a equalização experimental.

As Fig. 8.33 e 8.34 mostram a equalização de forma que a bateria que possuir o maior valor de $S O C($ Batl) será descarregada com uma corrente com maior valor, enquanto a bateria com menor $S O C$ (Bat2) absorverá um maior nível de corrente nos intervalos de carga. Ao final da equalização, ambas as baterias devem entregar a mesma corrente conforme esperado. Nestes ensaios foram utilizadas como entrada sucessivos degraus na corrente das fontes alternativas $i_{f a}$.

Nota-se que todos os resultados foram condizentes com o esperado e, principalmente, com as simulações executadas pelo modelo médio dos conversores, comprovando a eficácia das técnicas propostas.

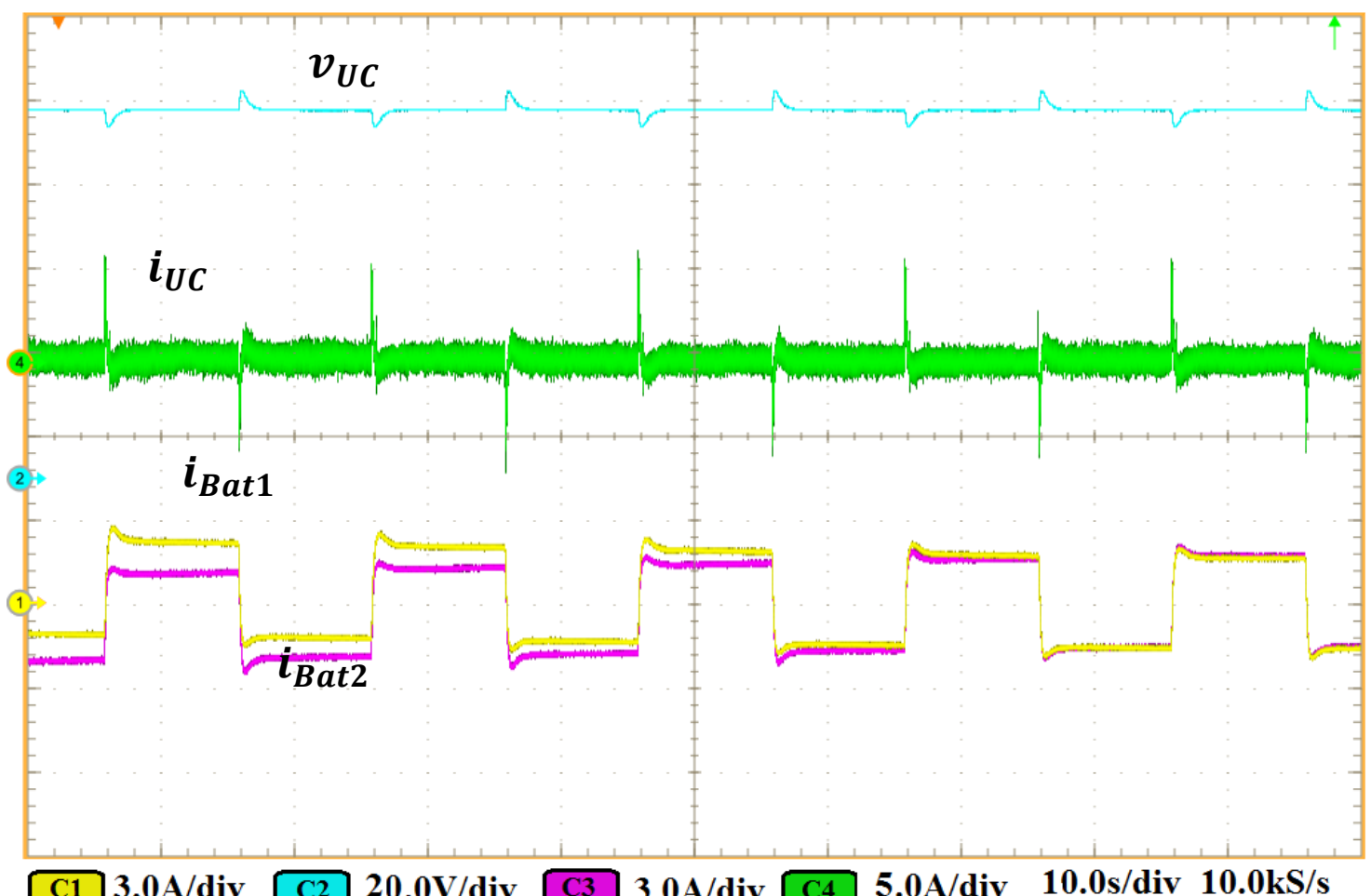

Figura 8.33 - Técnica de controle descentralizado sem restauração do barramento CC dividindo a carga entre o UC e baterias dada entrada em degrau de $i_{f a}$. Neste caso o $S O C$ é emulado pela equação (6.7) de forma a reduzir a capacidade virtual das baterias. 


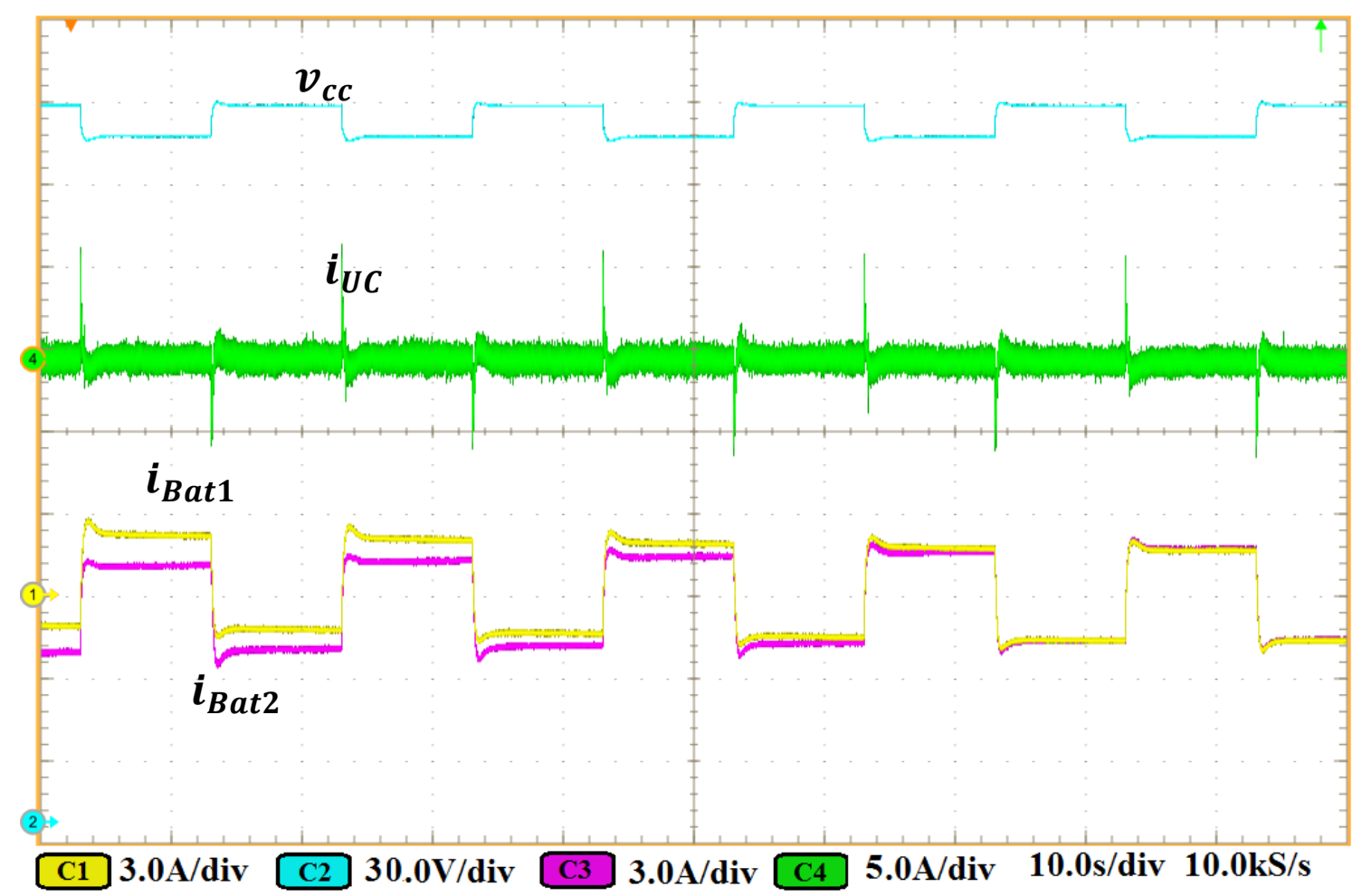

Figura 8.34 - Técnica de controle descentralizado sem restauração do barramento CC dividindo a carga entre o UC e baterias dada entrada em degrau de $i_{f a}$. Neste caso o $S O C$ é emulado pela equação (6.7) de forma a reduzir a capacidade virtual das baterias.

\subsubsection{Sistema de Armazenamento Híbrido e}

\section{Controle Descentralizado de Divisão de Carga com}

\section{Restauração do Barramento CC}

Nesta seção são apresentados os resultados para a microrrede que opera com armazenadores híbridos e controle descentralizado. Entretanto, diferentemente da seção anterior, neste caso o barramento CC é estabilizado graças à adição de um termo integral à técnica, formando um $P I_{v}$.

De acordo com o que foi descrito no Capítulo 6, de forma a trabalhar sem comunicação com os demais armazenadores, os controladores devem ser sincronizados, para que a divisão de carga e a restauração do barramento sejam efetivos. Assim, a Fig. 8.35 e 8.36 mostram a divisão de carga para uma entrada em degrau de geração pelas fontes alternativas $\left(i_{f a}\right)$ após a microrrede ser sincronizada, tendo as baterias o mesmo estado de carga. 


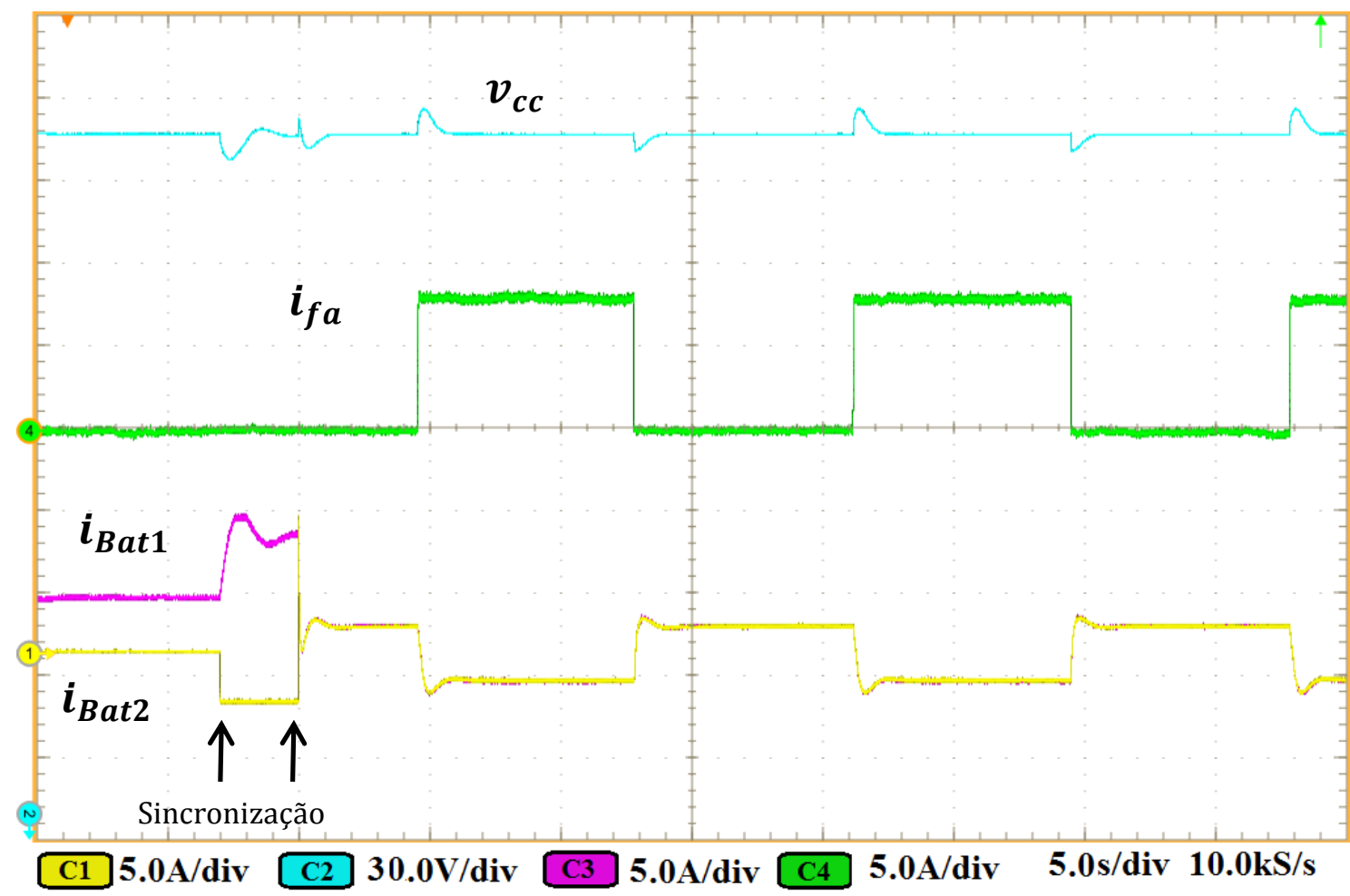

Figura 8.35 - Técnica de controle descentralizado com restauração do barramento CC dividindo a carga entre o UC e baterias para entrada em degrau de $i_{f a}$. Esta figura monstra o momento da sincronização inicial das duas baterias com o mesmo $S O C$.

Neste caso, ambas as baterias possuem o mesmo estado de carga. Entretanto, nos instantes iniciais apenas uma das baterias está fornecendo energia à microrrede (Bat 1 ) enquanto a segunda bateria encontra-se em repouso (Bat2).

No momento em que a segunda bateria é conectada, ela segue o procedimento proposto no Capítulo 6, que consiste em produzir uma corrente constante por um segundo, de forma a criar um transitório no barramento, sincronizando ambos os controladores das baterias.

Após a sincronização, as baterias passam a fornecer a mesma corrente à microrrede, uma vez que o SOC foi definido igual para os armazenadores. Nota-se que a cada transitório de potência, o barramento é perturbado e, sempre, restaurado ao valor de referência $(250 \mathrm{~V})$ com reduzido afundamento ou sobressinal $<10 \%$ (entre 15 a $20 \mathrm{~V}$ ).

A Fig. 8.37 mostra um zoom do evento (transitório). Nessa situação nota-se o funcionamento da técnica de restauração da tensão terminal do UC, invertendo o sentido da corrente do UC após o pico e recuperando a energia concedida à microrrede. 


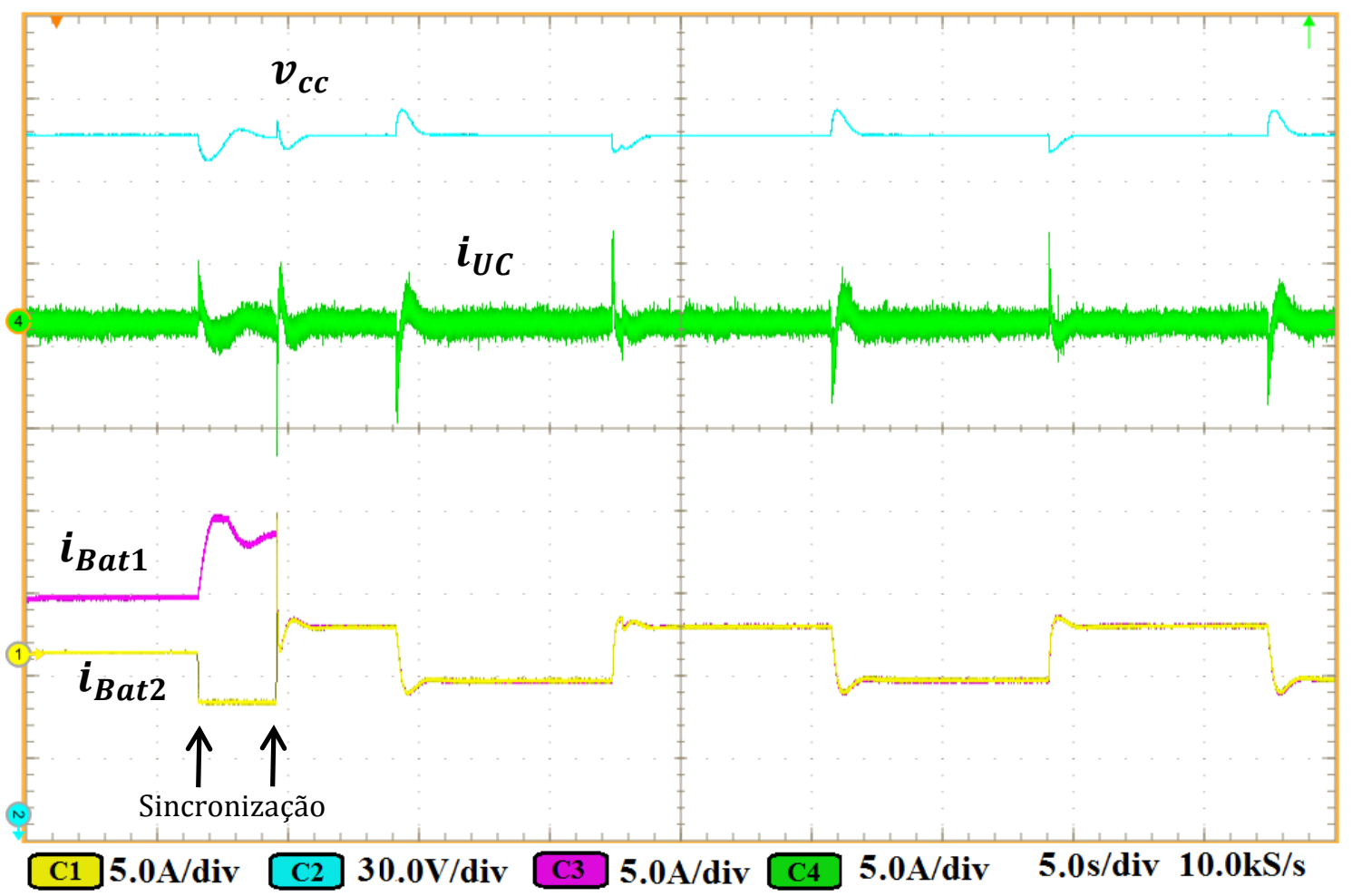

Figura 8.36 - Técnica de controle descentralizado com restauração do barramento CC dividindo a carga entre o UC e baterias para entrada em degrau de $i_{f a}$. Esta figura monstra o momento da sincronização inicial de duas baterias com o mesmo $S O C$, além do comportamento do UC durante os transitórios.

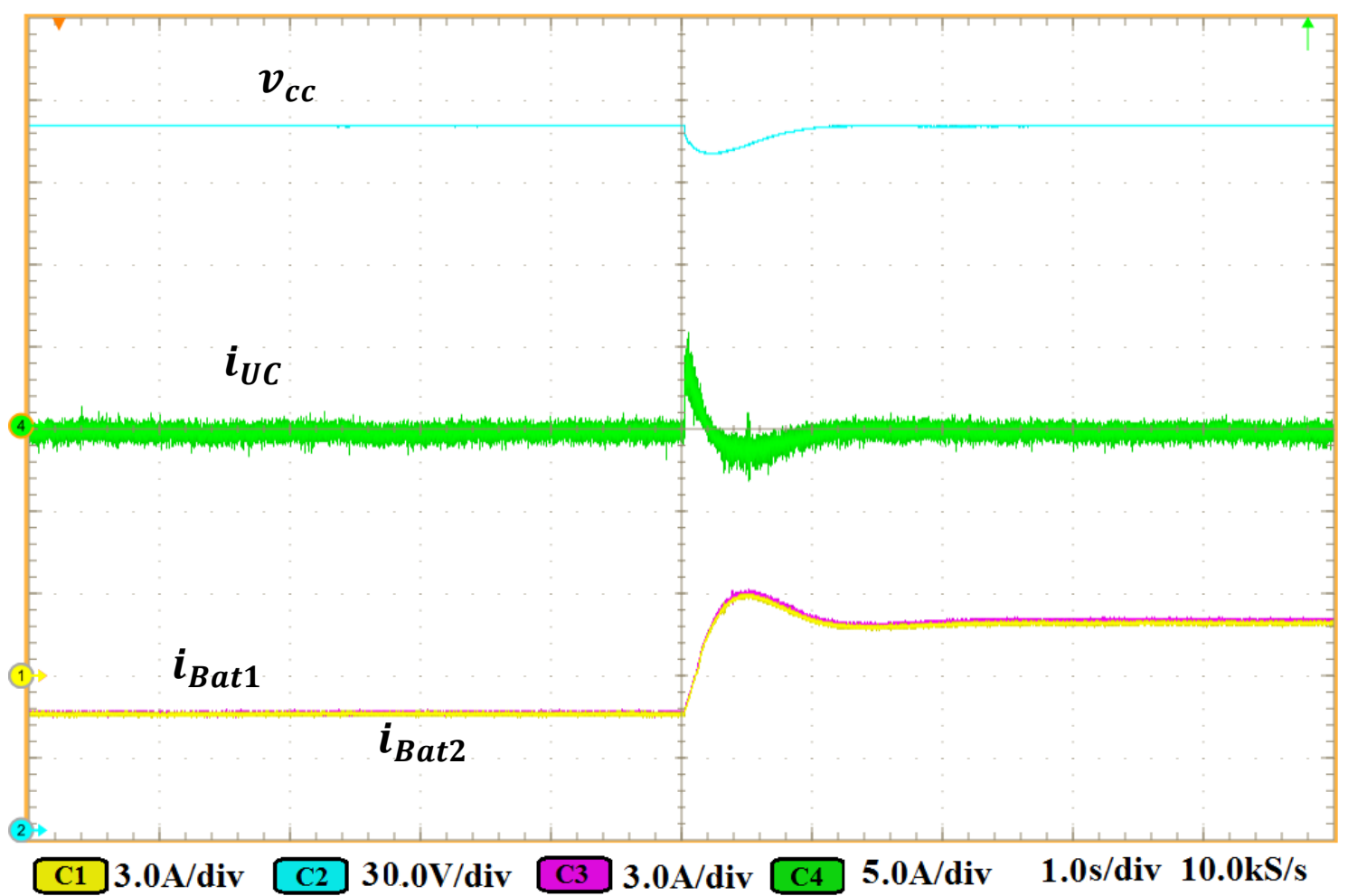

Figura 8.37 - Técnica de controle descentralizado com restauração do barramento CC dividindo a carga entre o UC e baterias para entrada em degrau de $i_{f a}$. Neste caso, ambas as baterias possuem o mesmo $S O C$. 
As Fig. 8.38, 8.39 e 8.40 mostram o funcionamento da microrrede sob variações em degrau na geração das fontes alternativas. Nesse caso, as baterias funcionam com estados de carga diferentes, $S O C 1=0,7$ e $S O C 2=0,4$ logo, elas dividem as correntes de forma proporcional ao $S O C$, como definido no Capítulo 6, além de promoverem a restauração da tensão terminal dos UC em $85 \mathrm{~V}$.

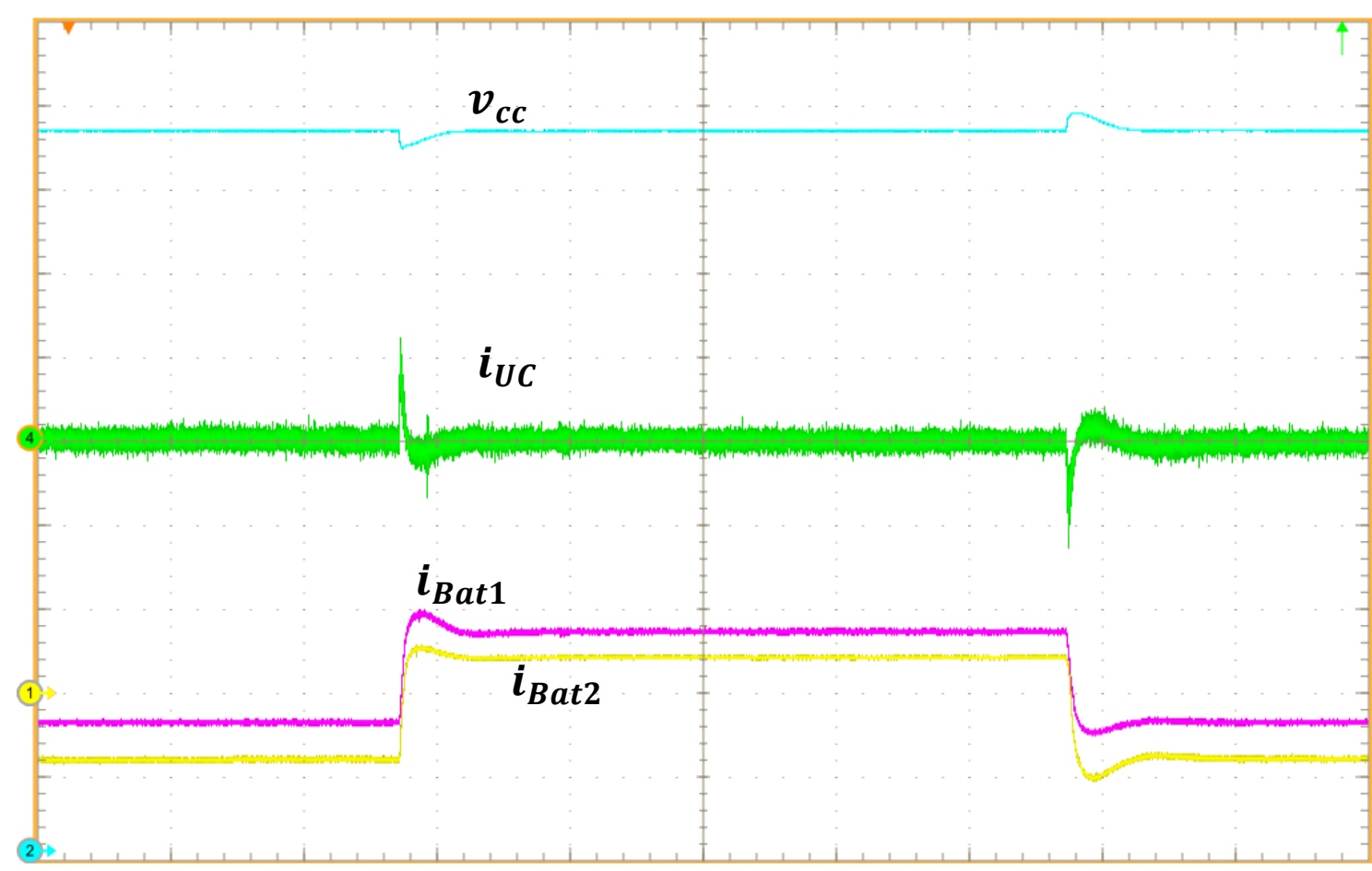

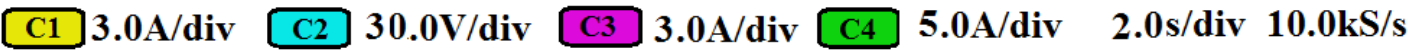

Figura 8.38 - Técnica de controle descentralizado com restauração do barramento CC dividindo a carga entre o UC e baterias para entrada em degrau de $i_{f a}$. Neste caso, as duas baterias possuem estados de carga diferentes, $S O C 1=0,7$ e $S O C 2=0,4$. 


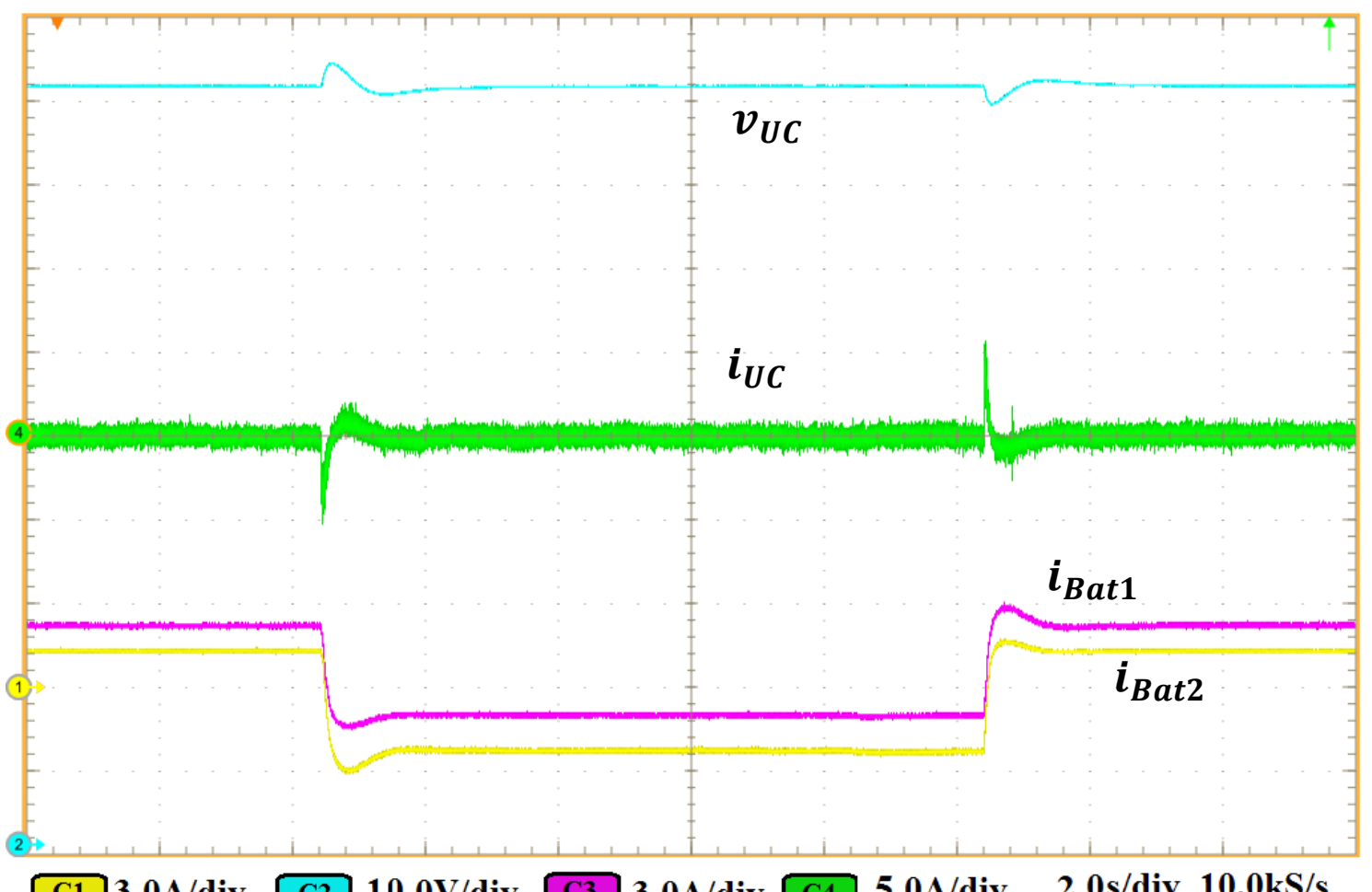

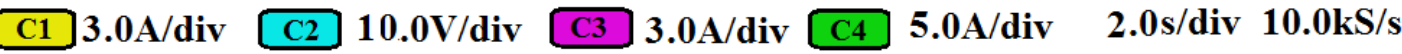

Figura 8.39 - Técnica de controle descentralizado com restauração do barramento CC dividindo a carga entre o UC e baterias dada entrada em degrau de $i_{f a}$. Neste caso, as duas baterias possuem estados de carga diferentes, $S O C 1=0,7$ e $S O C 2=0,4$.

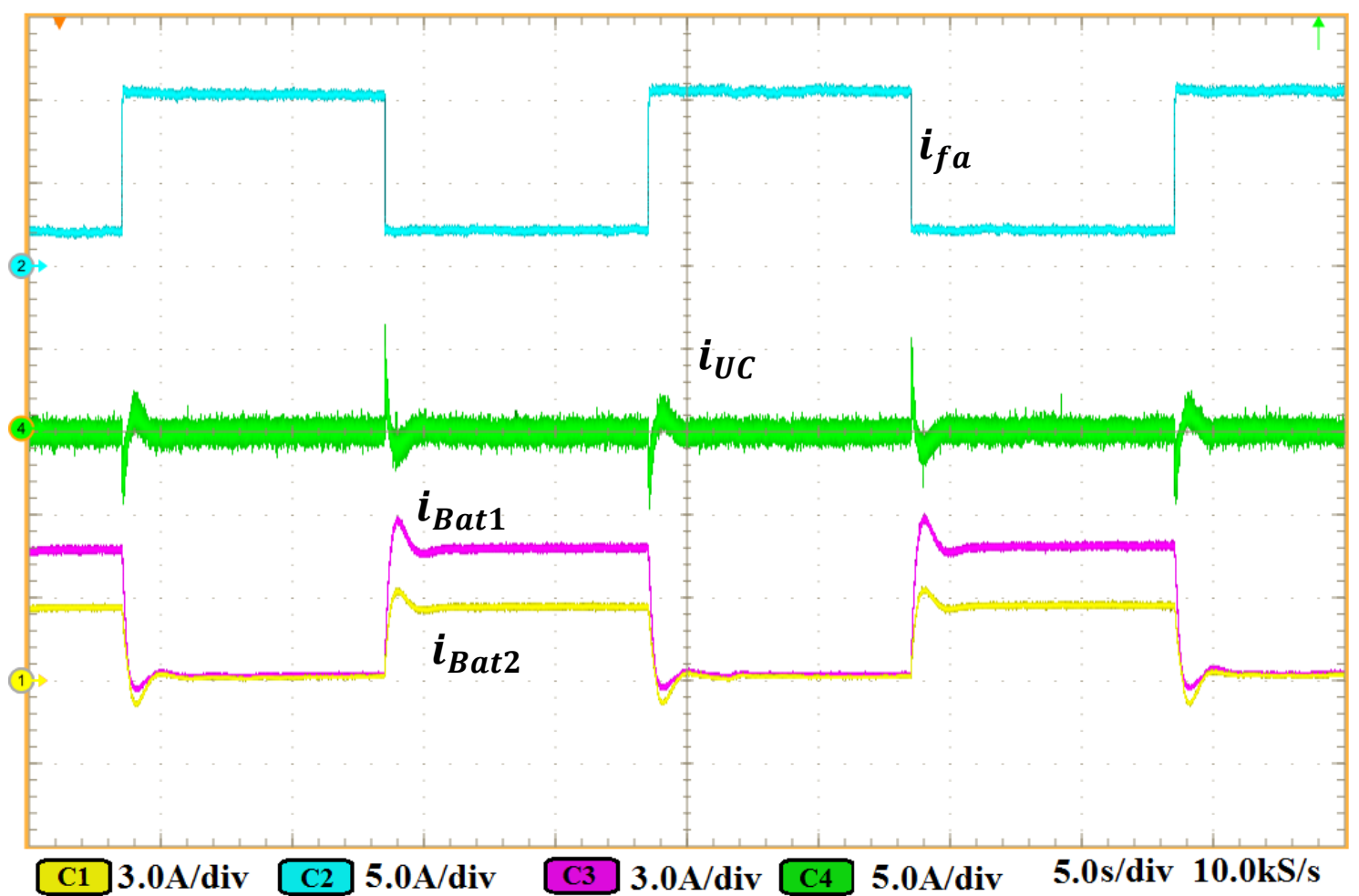

Figura 8.40 - Técnica de controle descentralizado com restauração do barramento CC dividindo a carga entre o UC e baterias para entrada em degrau de $i_{f a}$. Neste caso, as duas baterias possuem estados de carga diferentes, $S O C 1=0,7$ e $S O C 2=0,4$. 
A Fig. 8.41 apresenta o comportamento do UC e bateria dada uma entrada em degrau, além da soma das correntes dos armazenadores, mostrando que a ação combinada destes dispositivos compensa os transitórios com o objetivo de manter a tensão do barramento estável.

A Fig. 8.42 mostra o comportamento dos armazenadores quando a fonte alternativa emula o comportamento de uma $\mathrm{CaC}$, aumentando gradualmente a potência gerada. Nota-se que à medida que a potência gerada pela $\mathrm{CaC}$ aumenta, as baterias passam do modo de descarga para o modo carga, devido ao superávit de energia.

Contudo, diferentemente da metodologia sem restauração do barramento, a tensão se mantém estável em $250 \mathrm{~V}$ durante todo o processo. Nesse caso, foi considerado que as baterias possuíssem estados de carga diferentes, $S O C 1=0,7$ e $S O C 2=0,4$, dividindo assim a carga de forma proporcional ao $S O C$.

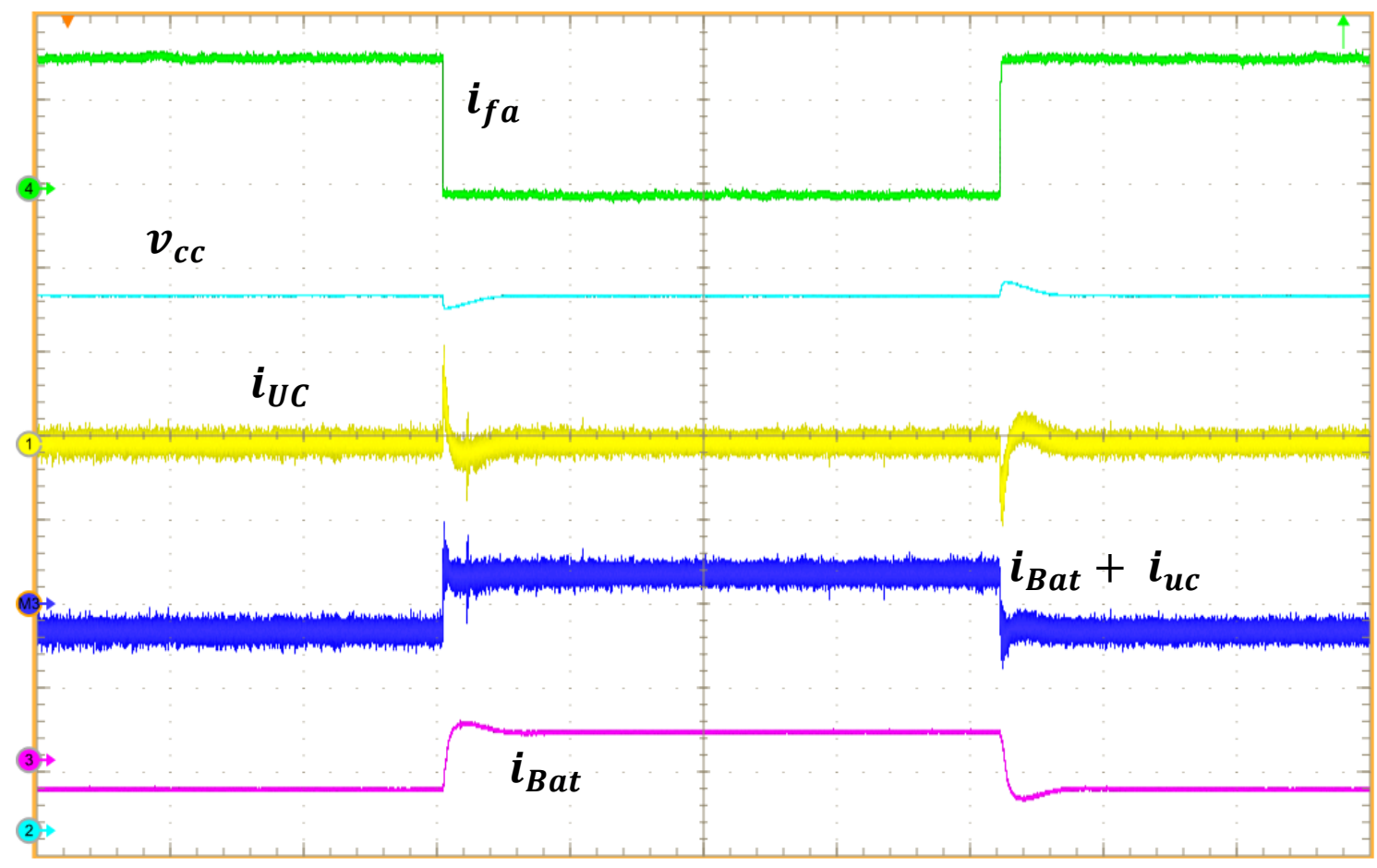

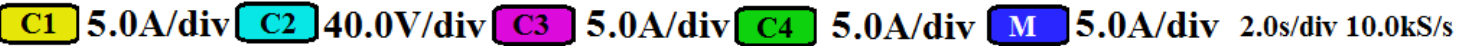

Figura 8.41 - Técnica de controle descentralizado com restauração do barramento CC dividindo a carga entre o UC e baterias para entrada em degrau de $i_{f a}$.

Assim como nas seções anteriores, de forma a analisar o comportamento dinâmico da equalização das baterias em relação ao $S O C$, é utilizada a equação (6.7) de forma a emular o comportamento de uma bateria de baixa capacidade. A Fig. 8.43 mostra a equalização de duas baterias graças à técnica de divisão de carga proporcionalmente ao SOC. Ao final do processo, ambas as baterias apresentam o mesmo estado de carga e fornecem a mesma corrente à 
microrrede enquanto que, o barramento CC é sempre restaurado para o valor de referência (250 V) após os transitórios.

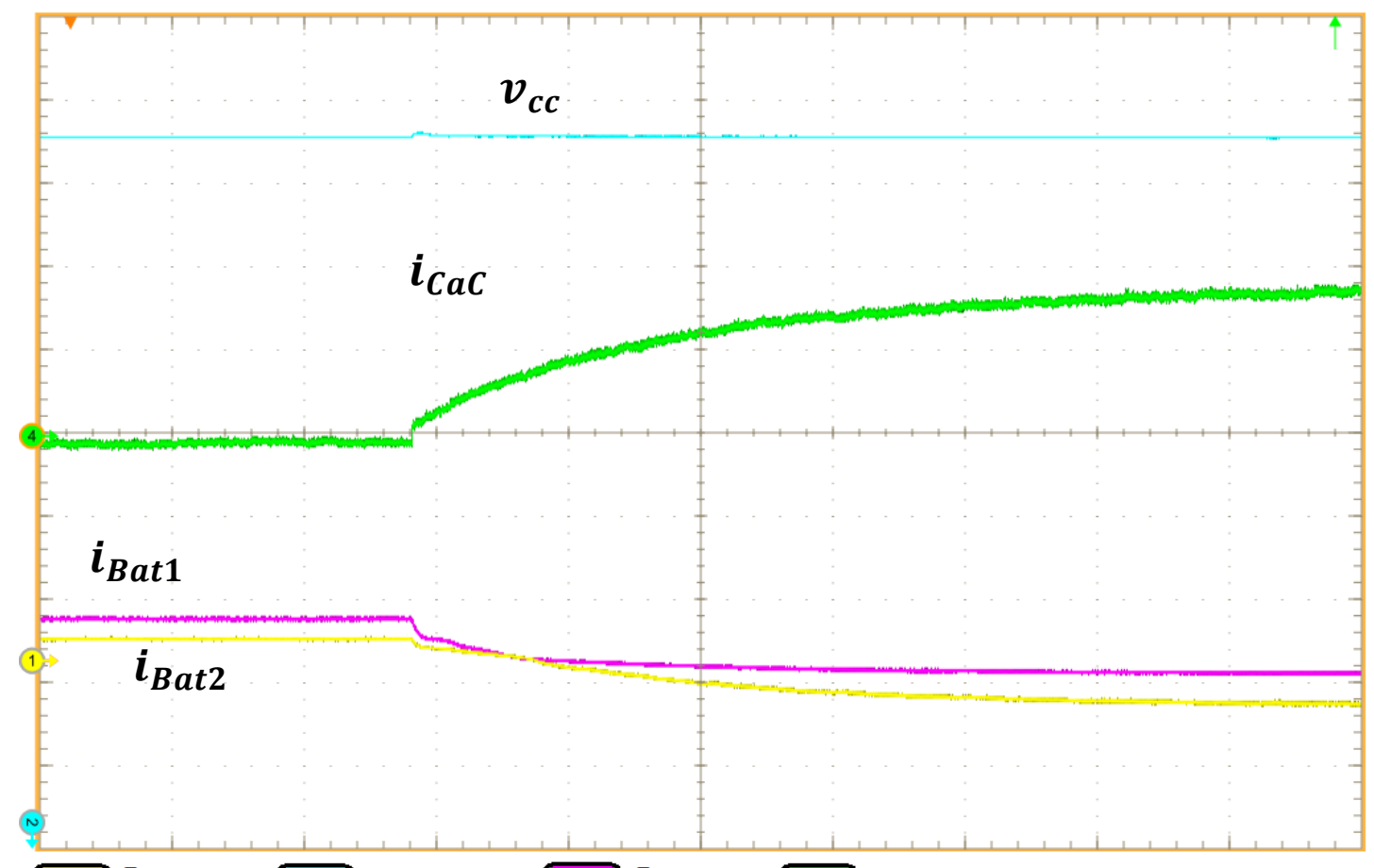

C1 5.0A/div C2 30.0 $3 / \mathrm{div} C \mathrm{C} 3.0 \mathrm{~A} / \mathrm{div} \mathrm{C} 45.0 \mathrm{~A} / \mathrm{div} \quad 5.0 \mathrm{~s} / \mathrm{div} 10.0 \mathrm{kS} / \mathrm{s}$

Figura 8.42 - Técnica de controle descentralizado com restauração do barramento CC dividindo a carga entre o UC e baterias para entrada em degrau de $i_{f a}$.

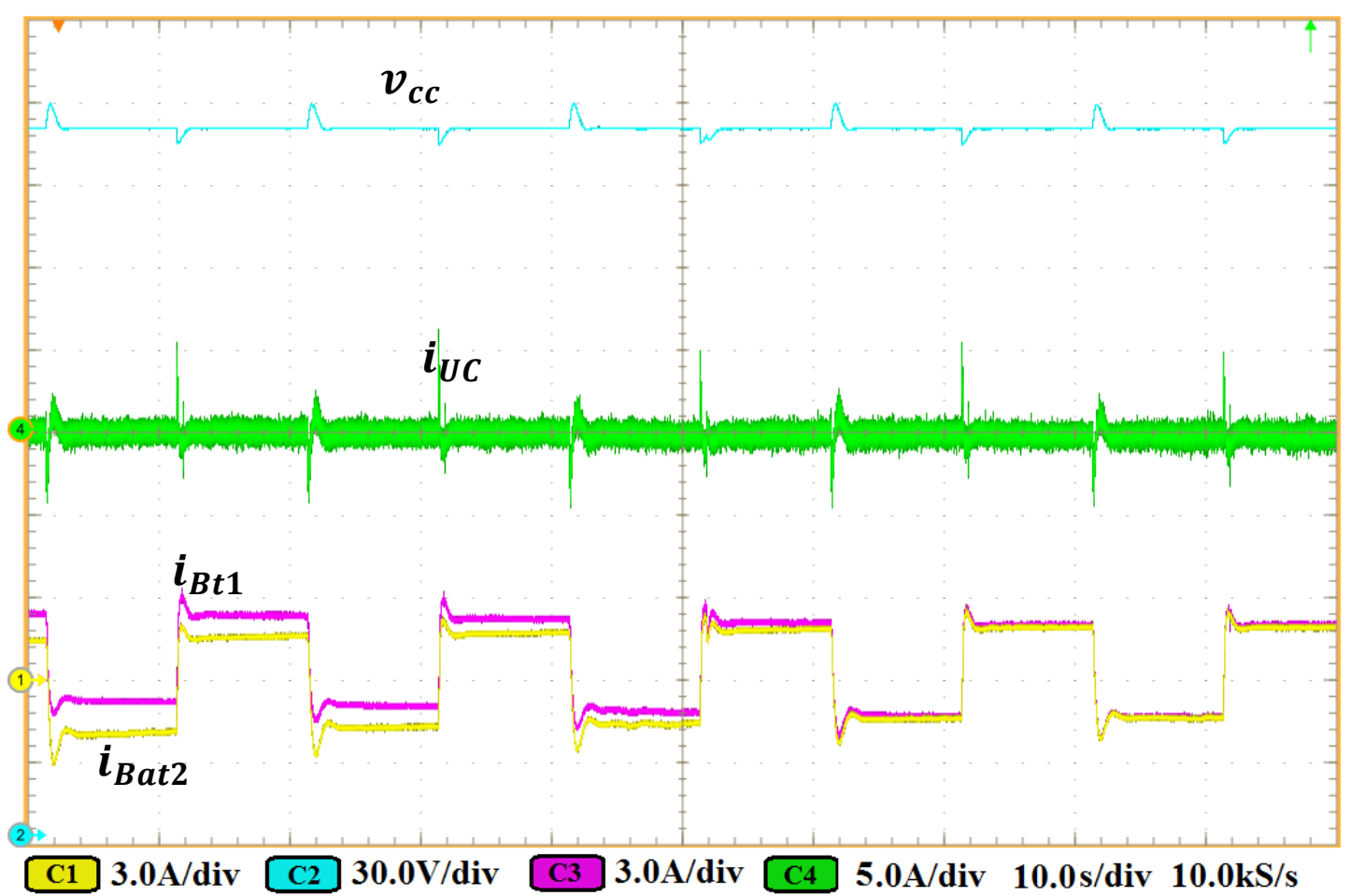

Figura 8.43 - Técnica de controle descentralizado com restauração do barramento CC dividindo a carga entre o UC e baterias para entrada em degrau de $i_{f a}$. Neste caso é mostrada a equalização das baterias de forma dinâmica usando a equação (6.7). 
De forma a comprovar a qualidade do sinal de corrente entregue à rede de distribuição pelo protótipo, a saída do inversor controlado em corrente foi amostrada (Fig. 8.44) e analisada em termos do conteúdo harmônico, de forma a comprovar que a microrrede atende os requisitos de qualidade definidos pelo IEEE1547.

A Fig. 7.45 mostra da FFT deste sinal, no qual nota-se a fundamental $(60 \mathrm{~Hz})$ próxima às baixas frequências e harmônicas múltiplas da frequência de chaveamento (12, 24 e 36 kHz).

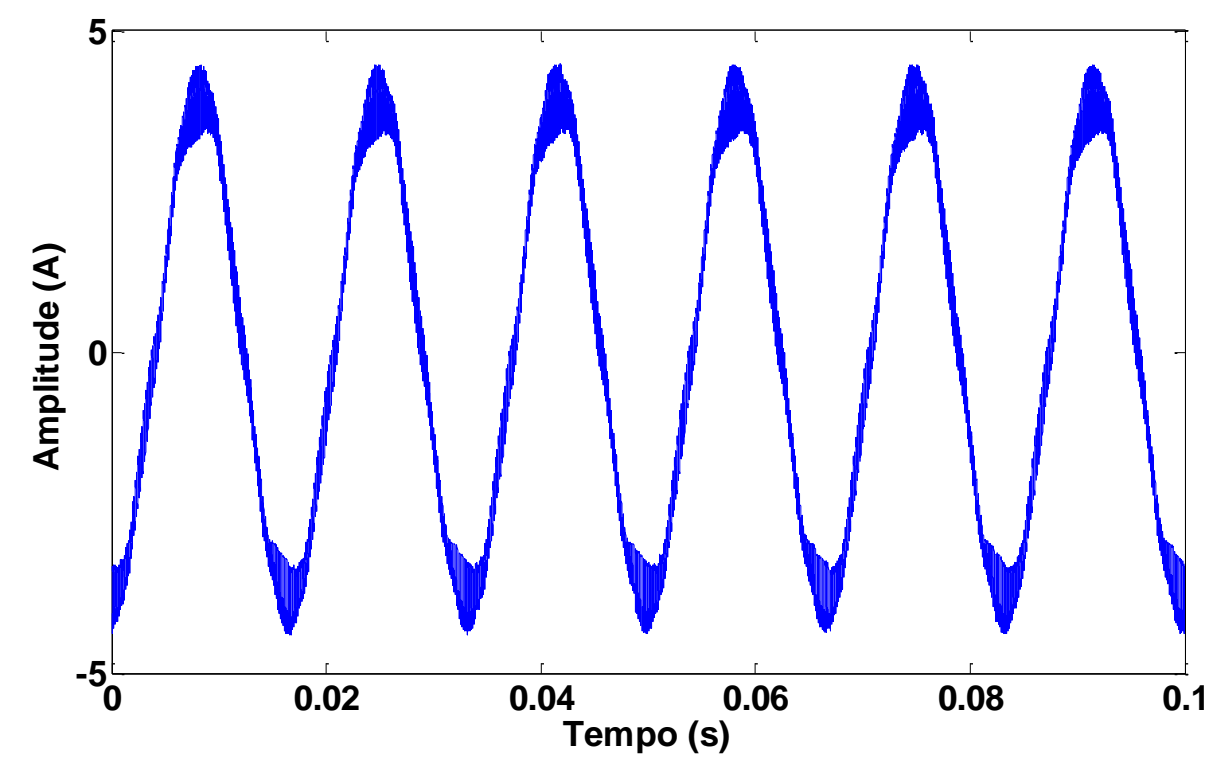

Figura 8.44 - Corrente entregue a rede pelo inversor.

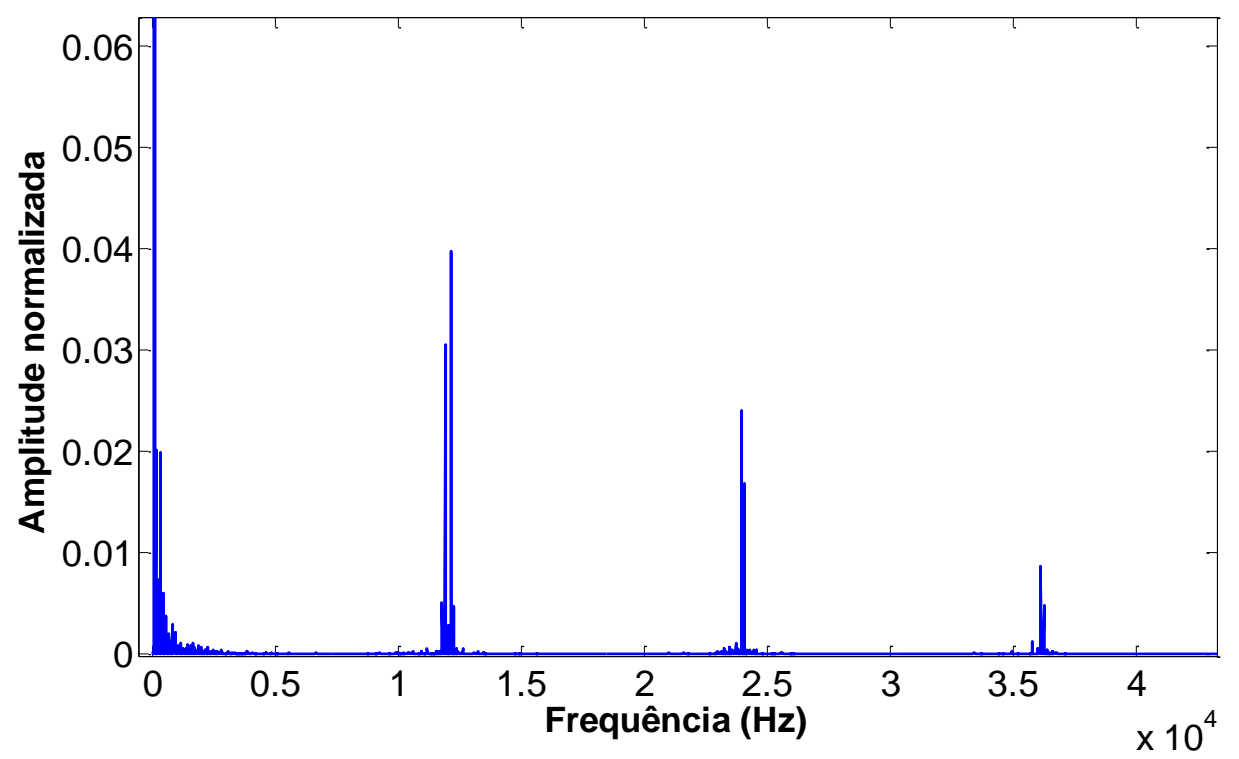

Figura 8.45- FFT do sinal de corrente na saída do inversor.

A Fig. 8.46 é obtida isolando apenas as harmônicas múltiplas da frequência fundamental $(60 \mathrm{~Hz})$ até a décima primeira, enquanto que a Fig. 8.47 mostra um zoom nas 
componentes de baixa amplitude. Nota-se uma baixa distorção harmônica, com as componentes sempre abaixo dos $2 \%$, o que contribui para a alta qualidade do sinal gerado.

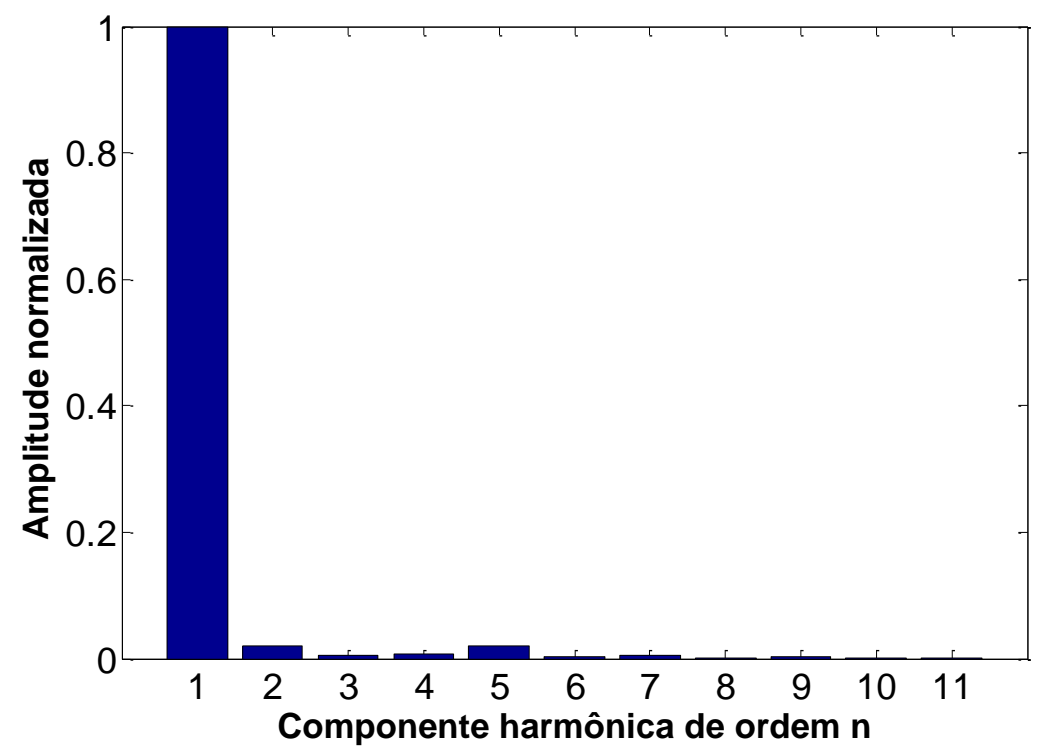

Figura 8.46 - Composição harmônica normalizada do sinal de corrente na saída do inversor.

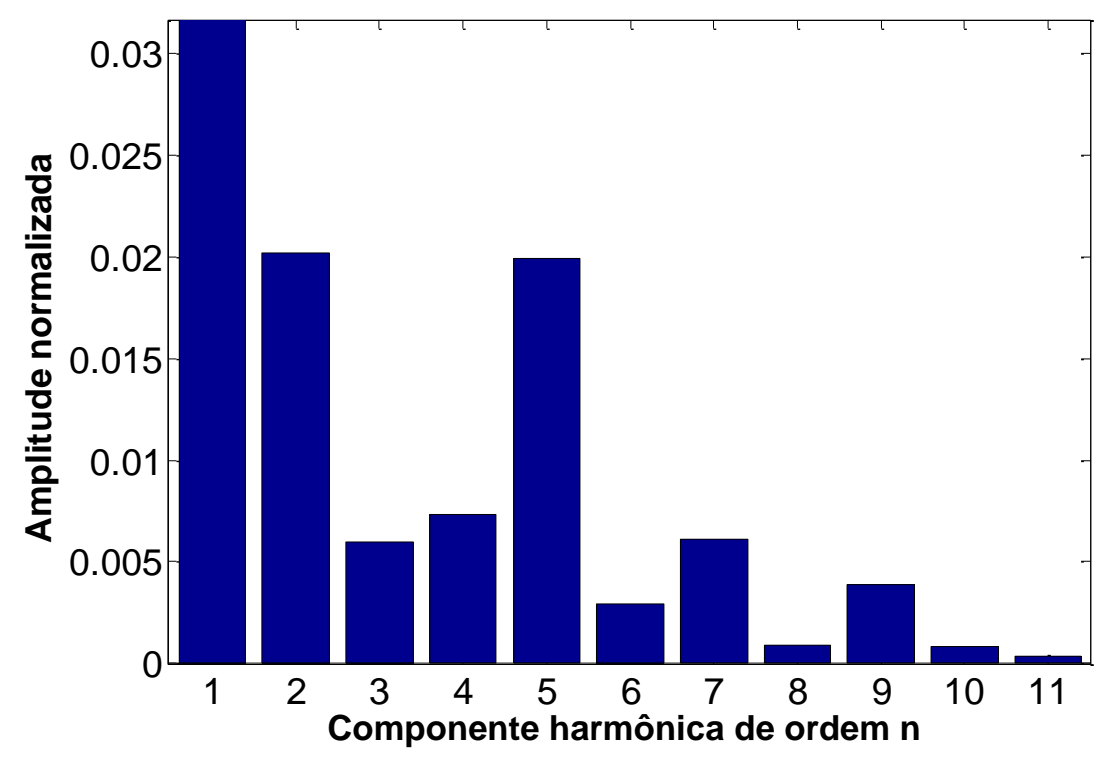

Figura 8.47 - Zoom na Fig. 8.45 mostrando a composição harmônica da corrente. 


\subsection{Considerações Finais do Capítulo 8}

Neste capítulo foram apresentados os resultados experimentais para as técnicas de gerenciamento propostas e simuladas no Capítulo 5, 6 e 7. Nota-se a concordância entre os resultados simulados e práticos, mesmo os resultados simulados sendo obtidos através de modelos médios e/ou modelos simplificados, comprovando assim a eficácia dos modelos e eficiências das técnicas propostas.

Assim como proposto no Capítulo 7 a técnica baseada no UC de alta capacidade permitiu a injeção de potência constante na rede de distribuição por intervalos, mesmo durante transitórios de potência nas fontes alternativas, cuja duração dos períodos de injeção constante é dependente do tamanho do UC e dos limites de tensão do algoritmo.

Para a técnica baseada na média da potência gerada, mostrou-se que mesmo sob fortes transitórios no barramento $\mathrm{CC}$, a corrente entregue à rede de distribuição não varia de forma brusca, evitando a entrega de degraus de potência no lado CA cujos transitórios, do lado CC, foram absorvidos pela técnica centralizada de gerenciamento, que dividia os transitórios entre bateria e UC, sendo a tensão do UC e tensão do barramento CC restauradas após cada transitório.

Para os resultados referentes às técnicas propostas no Capítulo 6, mostrou-se, a concordância com as simulações, sendo os armazenadores gerenciados de forma descentralizada, ou seja, sem comunicação entre eles e dividindo os transitórios entre bateria e UC. Foi apresentado que a técnica de divisão de carga, proporcionalmente ao $S O C$, leva as baterias à equalização, contudo, como discutido no Capítulo 6, para estados de carga reduzidos, o controlador deve limitar a ação da equalização em prol da estabilidade. Por fim, uma análise da qualidade do sinal de corrente no lado CA mostrou que a energia entregue a rede apresenta baixa distorção harmônica, com componentes abaixo de $2 \%$. 


\section{Conclusões Gerais}

Este trabalho apresentou o estudo e desenvolvimento de uma microrrede CC para integração de fontes alternativas e armazenadores híbridos conectados à rede distribuição. Foram apresentados os modelos das fontes alternativas, conversores, armazenadores de energia além das respectivas malhas de controle propostas.

Os circuitos eletrônicos utilizados nesta Tese de doutorado foram modelados de três formas distintas, por modelo chaveado, modelo médio e modelo simplificado, sendo cada modelo utilizado em um determinado momento, de forma a suprir necessidades distintas. Todas as modelagens se mostraram eficientes com resultados comprovados experimentalmente.

Como contribuições deste trabalho pode-se destacar a técnica de restauração contínua dos UCs, a técnica de divisão de carga descentralizada sem restauração do barramento, a técnica de divisão de carga descentralizada com restauração do barramento, o modelo simplificado de energias, a técnica de gerenciamento baseada no UC além da análise de energias apresentada no Capítulo 7.

A técnica de restauração contínua dos UCs permite o uso de capacitores de capacidade reduzida, uma vez que a energia média é sempre constante, evitando a necessidade de instantes exclusivos para a carga destes dispositivos.

As técnicas descentralizadas de gerenciamento e divisão de carga apresentam claras vantagens em relação a topologias centralizadas, uma vez que a expansão da microrrede é baseada simplesmente em plug and play uma vez que, os armazenadores não se comunicam entre si via rede de comunicação de alta velocidade, ou seja, eles só utilizam leituras locais e se ajustam dividindo as cargas de acordo com parâmetros como, tensão do barramento $\mathrm{CC}$, os ganhos dos controladores e ao próprio estado de carga.

Além disto, a técnica proposta alcança ao mesmo tempo, divisão de carga descentralizada com armazenadores híbridos (UC e bateria), restauração da tensão terminal, restauração da tensão do barramento CC e equalização das baterias, diferentemente das demais soluções da literatura.

Dentro da técnica de equalização das baterias proposta, mostrou-se que em estados de carga muito baixos a estabilidade do sistema é comprometida logo nestas ocasiões o ganho proporcional ao $S O C$ deve ser limitado, prejudicando a equalização, porém mantendo a estabilidade da microrrede. 
Assim como proposto, a técnica de gerenciamento baseada no UC de alta capacidade eliminou variações de potência de alta frequência na rede de distribuição, criando um perfil de entrega de energia de forma constante por intervalos, cujo comprimento destes intervalos pode ser ajustado pelo tamanho do UC e pelos limites de tensão da técnica. Logo, a microrrede apresenta um funcionamento mais suave (constante por intervalos), sem variações frequentes e oscilatórias de potência decorrentes de alterações climáticas aleatórias.

A técnica baseada na energia média gerada, assim como proposto, fornece à rede de distribuição um perfil filtrado em relação à potência gerada pelas fontes alternativas, evitando assim que transitórios na geração sejam transmitidos à rede de distribuição. Desta forma, alguns problemas de operação do sistema elétrico podem ser minimizados, como o chaveamento de reguladores de tensão, que são muito frequentes em redes com alta penetração de fontes alternativas, devido a intermitência das fontes e fluxos de potência reverso.

Foi também feita uma análise de energia utilizando o modelo simplificado da microrrede, cujos conversores são representados como ganhos. Nesta análise, foi apresentada uma metodologia para a entrega de potência constante à rede, independente das alterações climáticas. Foi também, estimada a capacidade mínima da bateria e os parâmetros da técnica de forma a manter a microrrede em funcionamento contínuo, evitando colapso energético. Com a aplicação desta técnica, é possível minimizar os problemas na distribuição, como o já citado chaveamento de reguladores de tensão, devido à ausência de transitórios de potência advindos das fontes alternativas.

Resultados experimentais permitiram a verificação da proposta dessa Tese de doutorado, tanto de desempenho dos controladores projetados quanto das estratégias de gerenciamento desenvolvidas, comprovando a precisão do modelo simplificado na análise dos fluxos de potência (energéticos) e do gerenciamento dos armazenadores (híbridos) pelos modelos médios. Foi analisada a qualidade da energia injetada na rede, apresentando baixa distorção harmônica, estando todas as componentes abaixo de 2\%, garantindo assim a qualidade da energia gerada. 


\section{Propostas para Pesquisas Futuras}

Como pode ser notado nas técnicas analisadas nesta Tese de doutorado, a grande parte delas se apoia tecnicamente em baterias eletroquímicas para o armazenamento energético, o que inviabiliza ou desestimula o uso em grande escala destas técnicas. Logo, a busca por soluções que realizem as mesmas funções propostas, mas que eliminem completamente o uso destes dispositivos seria de grande valia.

Além disso, foi proposta uma técnica que faz uso apenas de UCs de alta capacidade energética como armazenadores, contudo, como foi visto, a mesma permite apenas a entrega de potência constante por intervalos curtos e limitados. Assim, como pesquisas futuras deseja-se buscar uma técnica para redução ou eliminação dos transitórios rápidos de potência na rede, sem o uso de baterias, apenas utilizando dispositivos com elevada vida útil e baixo impacto ambiental, que no longo prazo sejam viáveis. Como opções de armazenadores pode-se mencionar os UCs, volantes de inércia e armazenamento a ar comprimido como possíveis candidatos. 


\section{Referências}

[1] V. M. Pereira, Estudo e Modelagem dinâmica de Gerador de Indução Acionado por Máquina de Combustão Interna com Controle de Tensão e de Frequência por meio de Inversor PWM, Tese de Doutorado, UNICAMP, Campinas, 2003.

[2] A. H. M. Santos, Conservação de energia: eficiência energética de equipamentos e instalações., Itajubá: 3 ed., 2006.

[3] C. T. Pan, M. C. Cheng e C. M. Lai, "A Novel Integrated DC/AC Converter With High Voltage Gain Capability for Distributed Energy Resource Systems," IEEE Transactions on Power Electronics, vol. 27, pp. 2385-2395, May 2012.

[4] F. Wang, J. L. Duarte, M. A. M. Hendrix e P. Ribeiro, "Modeling and Analysis of Grid Harmonic Distortion Impact of Aggregated DG Inverters," IEEE Transactions on Power Electronics, vol. 26, pp. 786-797, 2011.

[5] A. Camacho, M. Castilha, J. Miret, J. Vasquez e E. Alarcon-Gallo, "Flexible Voltage Support Control for Three-Phase Distributed Generation Inverters Under Grid Fault," IEEE Transaction on Industrial Electronics, vol. 60, pp. 1429-1441, Apr. 2013.

[6] BRASIL, Decreto $n$. 2003, Regulamenta a produção de energia elétrica por produtores independentes e por autoprodutor, e dá outras providências, 1996.

[7] BRASIL, Decreto n. 5.025/2004, Programa de Incentivo as Fontes Alternativas de Energia Elétrica - PROINFA, 2004.

[8] IEEE Std 1159-2009, IEEE Recommended Practice for Monitoring Electric Power Quality, Vol. 2009. 2009.

[9] IEEE Std 519-1992, IEEE Recommended Practices and Requirements for Harmonic Control in Electrical Power System, 1993.

[10] Agência nacional de energia elétrica, Procedimentos de Distribuição de Energia Elétrica no Sistema Elétrico Nacional-PRODIST, 2012.

[11] J. Rocabert, G. M. S. Azevedo, A. Luna e J. M. Guerrero, "Intelligent Connection Agent for ThreePhase Grid-Connected Microgrids," IEEE Transactions on Power Electronics, vol. 26, pp. 29933005, 2011.

[12] Agência nacional de energia elétrica, Resolução normativa n. 482, de 17 de abril de 2012.

[13] W. El-Khattam e M. Salama, "Distributed generation technologies, definitions and benefits," Electric Power Systems Research, vol. 71, pp. 119-128, Oct 2004. 
[14] E. Pouresmaeil, D. Montesinos-Miracle e O. Gomis-Bellmunt, "Control Scheme of Three-Level NPC Inverter for Integration of Renewable Energy Resources Into AC Grid," IEEE Systems Journal , vol. 6, pp. 242-253, June 2012.

[15] C. Ma e D. Huang, "Comparative study of PI controller and fuzzy logic controller for three-phase grid-connected inverter," in 2011 IEEE International Conference on Mechatronics and Automation, pp. 2067-2071, Aug. 2011.

[16] A. Cataliotti, G. Cocchiara, M. Ippolito e G. Morana, "Applications of the Fault Decoupling Device to Improve the Operation of LV Distribution Networks," IEEE Transaction on Power Delivery, vol. 23, pp. 328-337, Jan. 2008.

[17] R. Dugan e T. McDermott, "Distributed Generation," IEEE Industry Applications Magazine, vol. 8, pp. 19-25, 2002.

[18] A. Campoccia, G. Cocchiara, M. Ippolito e G. Morana, "Fault decoupling device: a new device to reduce the impact of distributed generation on electrical distribution systems," in 2003 IEEE Bologna Power Tech Conference Proceedings, vol. 4, pp. 684-690, 2003.

[19] S. Chaitusaney e A. Yokoyama, "Impact of protection coordination on sizes of several distributed generation sources," in 2005 Internacional Power Engineering Conference, vol. 2, pp. 669-674, 2005.

[20] E. Jauch, "Possible Effects of Smart Grid Functions on LTC Transformers," IEEE Trans. on Ind. Appl, vol. 47, n. 2, pp. 1013-1021, Apr. 2011.

[21] E.-M. Baerthlein, M. Hartung e A. Panosyan, "Variable voltage set point control of tap changers in distribution grids," in Innovative Smart Grid Technologies Conference Europe (ISGT-Europe), pp. 1-6, 12-15, Oct 2014.

[22] R. A. Kordkheili, B. Bak-Jensen, J. R. Pillai, M. Savaghebi e J. M. Guerrero, "Managing high penetration of renewable energy in MV grid by electric vehicle storage," in Smart Electric Distribution Systems and Technologies (EDST), 2015 International Symposium on, pp. 127-132, 811, Sept. 2015.

[23] S. Huang, J. Pillai, M. Liserre e B. Bak-Jensen, "Improving photovoltaic and electric vehicle penetration in distribution grids with smart transformer," in Innovative Smart Grid Technologies Europe (ISGT EUROPE), 2013 4th IEEE/PES, pp. 1-5, 6-9, Oct. 2013.

[24] J. D. Souza, B. B. Silva e J. C. Ceballos, "Estimativa da radiação solar global à superfície usando um modelo estocástico: caso sem nuvens," Revista Brasileira de Geofísica, vol. 26, n. 1, pp. 3144, 2008.

[25] N. E. M. Moçambique, "Aplicação de Algoritmos de Busca do Ponto de Máxima Potência e Controladores Lineares e/ou Fuzzy para a Regulação da Tensão Terminal de Painéis Fotovoltaicos,", Dissertação de Mestrado, USP, São Carlos, 2012. 
[26] R. F. Bastos, Sistema de Gerenciamento para Carga e Descarga de Baterias (Chumbo-Ácido) e para Busca do Ponto de Máxima Potência Gerada em Painéis Fotovoltaicos Empregados em Sistemas de Geração Distribuída, Dissertação de Mestrado - USP São Carlos, 2013.

[27] M. G. Villalva, "Conversor Eletrônico de Potência Trifásico para Sistema Fotovoltaico Conectado à Rede létrica,", Tese de Doutorado, Unicamp, Campinas, 2010.

[28] T. Dragičević, X. Lu, J. Vasquez e J. M. Guerrero., "DC Microgrids-Part I: A Review of Control Strategies and Stabilization Techniques," IEEE Transactions on Power Electronics, vol. 31, n. 7, pp. 4876-4891, july 2016.

[29] T. Dragičević, X. Lu, J. Vasquez e J. M. Guerrero., "DC Microgrids-Part II: A Review of Power Architectures, Applications, and Standardization Issues,", in IEEE Transactions on Power Electronics, vol. 31, n. 5, pp. 3528-3549, May 2016.

[30] R. Teodorescu, M. Liserre e P. Rodriguez, Grid Converters for Photovoltaic ans WInd Power SYstem, John Wiley \& Sons, 2011.

[31] Z. Lubosny, Wind Turbine Operation in Electric Power Systems, Berlin: Springer, 2003.

[32] T. Ackermann, Wind Power in Power Systems, New York: John Wiley \& Sons, 2005.

[33] S. Heier, Grid Integration of Wind Energy Conversion Systems, New York: Wiley \& Sons, 1998.

[34] A. Rolan, A. Luna, G. Vazquez, D. Aguilar e G. Azevedo, "Modeling of a variable speed wind turbine with a Permanent Magnet Synchronous Generator," ISIE 2009 Internacional Symposium on, pp. 734-739, 2009.

[35] J. L. Rodriguez, J. C. Burgos e L. Arnalte, Sistemas Eólicos de Producción de Energía Eléctrica, Madrid: Editorial Rueda S. L, 2003.

[36] M. Kesraoui, N. Korichi e A. Belkadi, "Maximum Power Point Tracker Of Wind Energy Conversion SYstem," Renewable Energy, vol. 36, pp. 2655-2662, Apr. 2010.

[37] N. Mocambique, R. Machado e V. Oliveira, "A fuzzy PD-PI control strategy to track the voltage references of photovoltaic arrays," Control and Automation (ICCA), 2011 9th IEEE International Conference on, pp. 1162-1167, 2011.

[38] M. Villalva, J. Gazoli e E. Filho, "Comprehensive Approach to Modeling and Simulation of Photovoltaic Arrays," Power Electronics, IEEE Transactions on, vol. 24, n. 5, pp. 1198-1208, 2009.

[39] D. B. Cândido, "Desenvolvimento de Sistemas estáticos Distribuídos - "Multi String", Para Aplicações em Sistemas Fotovoltaicos Autônomos", Dissertação de Mestrado, UFSM, Santa Maria, 2010.

[40] K. D. Coelho, "Estudo de uma Fonte Ininterrupta de Corrente contínua de Baixa Potência 
Gerenciada por um Microcontrolador", Dissertação de Mestrado, UFSC, Florianópolis, 2001.

[41] Moura, “Manual Técnico Moura Acumuladores," 2011.

[42] YUASA, "YUASA INC, Catálogo de Baterias," 1999.

[43] J. Aylor, A. Thieme e B. Johnso, "A battery state-of-charge indicator for electric wheelchairs," Industrial Electronics, IEEE Transactions on, vol. 39, n. 5, pp. 398-409, 1992.

[44] K.-S. Ng, C.-S. Moo, Y.-p. Chen e Y.-C. Hsieh, "State-of-Charge Estimation for Lead-Acid Batteries Based on Dynamic Open-Circuit Voltage," Power and Energy Conference, IEEE 2nd International, pp. 972-976, 2008.

[45] J. Alvarez, J. Marcos, A. Lago, A. Nogueiras, J. Doval e C. Penalver, "A fully digital smart and fast lead-acid battery charge system," Power Electronics Specialist Conference, PESC '03, vol. 2, pp. 913-917, 2003.

[46] G. Yifeng e H. Limin, "The Charging Technology for Lead-Acid Battery with a Negative Pulse," Power and Energy Engineering Conference (APPEEC), pp. 1-3, 2010.

[47] D. G. Fent, "An Automatic Universal Boost Charging Algorithm for Lead Acid Batteries," Telecommunications Energy Special Conference, TELESCON, pp. 453-456, 1994.

[48] R. Kotz e M. Carlen, "Principles and Applications of Electrochemical Capacitors," in Electrochimica Acta, vol. 45, pp. 2483-2498, May 2000.

[49] A. A. Ferreira, Sistema Supervisório de Gestão de Múltiplas Fontes de Suprimento para Aplicações em Veículos Elétricos, Tese de Doutorado, UNICAMP, 2007.

[50] MaxwelTechnologies, "Top 10 Reasons for Using Ultracapacitors in Your System Design," [Online]. Available: www.maxwell.com/ultracapacitors/support/papers.html. [Acesso em 12 Março 2005].

[51] A. Schneuwly, B. Maher e J. Auer, "Ultracapacitors, the New Thinking in Automotive World," [Online]. Available: www.maxwell.com/ultracapacitors/support/papers.html. [Acesso em 12 Março 2005].

[52] G. Prophet, "Supercaps for supercaches," [Online]. Available: www.edn.com/article/CA268379.html. [Acesso em 13 Março 2005].

[53] EPCOS, "UltraCap Technology," [Online]. Available: www.epcos.com/inf/20/35/ds/technology.pdf. [Acesso em 12 Março 2005].

[54] F. Belhachemi, S. Rael e B. Davat, "A Physical Based Model of Power Electronics Double-Layer Supercapacitors," Proceedings of the IEEE IAS Annual Meeting, vol. 5, pp. 3069-3076, Oct 2000. 
[55] M. A. Elgendy, B. Zahawi e D. J. Atkinson, "Analysis of the Performance of CC Photovoltaic Pumping Systems with Power Point Tracking," in 4th IET Conference on Power Electronics, Machines and Drives Renewable, pp. 426-430, April 2008.

[56] J. D. G. Liorente, Analysis of Optimal Matching between a CC Motor and Photovoltaic Modules Via CC-CC Power Converters, Disponivel em: http://search.proquest.com/docview/205436530, 2009.

[57] F. R. Bastos, N. E. M. Moçambique, R. Q. Machado e C. R. Aguiar, REDE NEURAL ARTIFICIAL APLICADA NA BUSCA DO PONTO DE MÁXIMA POTENCIA EM PAINÉIS FOTOVOLTAICOS, Congresso Brasileiro de Automatica - CBA2012, 2012.

[58] P. Thounthong, S. Pierfederici e B. Davat, "Analysis of Differential Flatness-Based Control for a Fuel Cell Hybrid Power Source," IEEE Transactions on Energy Conversion, vol. 25, pp. 909-920, 2010.

[59] R. M. Kamel, A. Chaouachi e K. Nagasaka, "Three Control Strategies to Improve The Microgrid Transient Dynamic Response During Isolated Mode: A Comparetive Study," IEEE Transactions on Industrial Electronics, vol. 60, pp. 314-322, 2013.

[60] C. R. Aguiar, Estudo e Análise de Algoritmos de Deteç̧ão de Ilhamento em Sistemas de Geração Distribuída Conectados a rede de distribuição, Dissertação de Mestrado - USP, São Carlos, 2013.

[61] G. G. Pozzebon, A. F. Q. Golçalves, G. G. Pena, N. E. M. Moçambique e R. Q. Machado, "Operation of a three-Phase Power Converter Connected to a Distribution System," IEEE Transactions on Industrial Electronics, vol. 60, pp. 1810-1818, May 2013.

[62] S. Buso e P. Mattavelli, Digital Control in Power Electronics - Sysnthesis Lectures on Power Electronics, Vol. 1. Morgan and Claypool Publisher, 2006.

[63] R. Q. Machado, Sistema de Geração Distribuída com Fontes CA e CC Conectados a Rede Monofásica e Controle Eletrônico da Qualidade da Energia Elétrica, Tese de Doutorado UNICAMP, Campinas, 2005.

[64] R. W. Erickson e D. Maksimovic, Fundamentals of Power Electronics, Springer, 2nd edition, 2001.

[65] R. Q. Machado, S. Buso, J. Pomilio e F. Marafao, "Three-phase to single-phase direct connection for rural co-generation systems," in Nineteenth Annual IEEE Applied Power Electronics Conference and Exposition - APEC 04, vol. 3, pp. 1547-1553, 2004.

[66] F. P. Marafao, S. M. Deckmann e J. A. Pomilio, "Metodologia de projeto e análise de algoritmos de sincronismo pll," Brasileira de Eletrônica de Potencia, vol. 10, pp. 7-14, 2005.

[67] H. Zhou, T. Bhattacharya, D. Tran, T. Siew e Khambadkone, "Composite Energy Storage System Involving Battery and Ultracapacitor With Dynamic Energy Management in Microgrid Applications," Power Electronics, IEEE Transactions on, vol. 26, n. 3, pp. 923,930, 2011. 
[68] X. Lu, J. Guerrero, K. Sun e J. Vasquez, "An Improved Droop Control Method for DC Microgrids Based on Low Bandwidth Communication With DC Bus Voltage Restoration and Enhanced Current Sharing Accuracy," in Power Electronics, IEEE Transactions on, vol. 29, n. 4, pp. 18001812, April 2014.

[69] K. Sun, L. Zhang, Y. Xing and J. M. Guerrero, "A distributed control strategy based on DC bus signaling for modular photovoltaic generation systems with battery energy storage," IEEE Trans. Power Electron., vol. 26, n. 10, pp. 3032-3045, 2011.

[70] Y. Gu, X. Xiang, W. Li e X. He, "Mode-Adaptive Decentralized Control for Renewable DC Microgrid With Enhanced Reliability and Flexibility," in Power Electronics, IEEE Transactions on, vol. 29, n. 9, pp. 5072-5080, sept. 2014.

[71] N. Tummuru, M. Mishra e S. Srinivas, "Dynamic Energy Management of Renewable Grid Integrated Hybrid Energy Storage System," in Industrial Electronics, IEEE Transactions on, vol. 62 n. 12, pp. 7728-7737, Dec. 2015.

[72] W. LI, C. XU, H. YU, Y. GU e X. HE, "Energy management with dual droop plus frequency dividing coordinated control strategy for electric vehicle applications," Journal of Modern Power Systems and Clean Energy, vol. 3, n. 2, pp. 212-220, May 2015.

[73] N. L. Diaz, T. Dragičević, J. Vasquez e J. M. Guerrero., "Intelligent Distributed Generation and Storage Units for DC Microgrids-A New Concept on Cooperative Control Without Communications Beyond Droop Control," in IEEE Transactions on Smart Grid, vol. 5, n. 5, pp. 2476-2485, sept 2014.

[74] NREL, "National Renewable Energy Laboratory (NREL)," [Online]. Available: http://www.nrel.gov/. [Acesso em 112 2014]. 


\section{Apêndice A}

\section{Placas de Condicionamento de Sinais e}

\section{Acionamento do Inversor}

Neste anexo são apresentadas as placas desenvolvidas e aplicadas no condicionamento dos sinais de corrente e tensão utilizados no protótipo, além da placa de acionamento do inversor. Estes circuitos são necessários uma vez que os sinais oriundos dos sensores de corrente e tensão tem polaridades tanto positiva quando negativa, enquanto os conversores analógico/digital do processador utilizado apenas faz a leitura de valores entre 0 e $3 \mathrm{~V}$. Desta forma os sinais devem ser escalonados para que se mantenham dentro deste universo. No caso do inversor, a placa de acionamento eleva o nível dos sinais oriundos do processador (3 V) ao valor mínimo necessário para o acionamento das chaves eletrônicas (15 V).

São apresentadas as placas e esquemáticos na seguinte ordem:

- Esquemático e pinagem do inversor Semikron;

- Esquemático do Driver de acionamento do Inversor;

- Placa de condicionamento de sinais de corrente;

- Placa de condicionamento de sinais de tensão. 


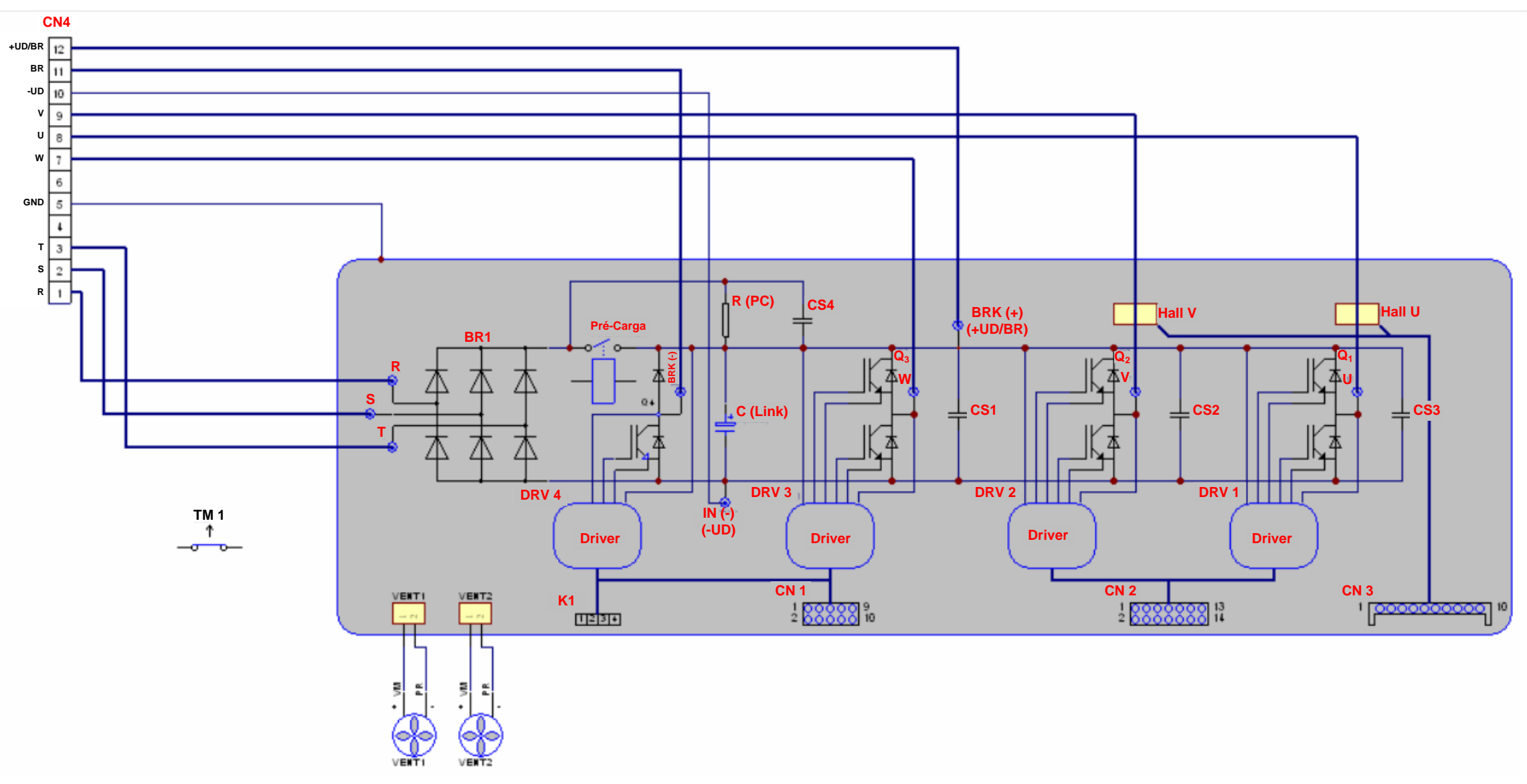




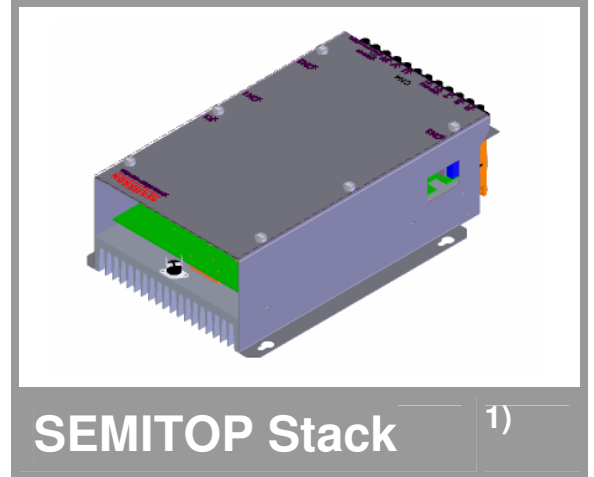

\section{Three-phase inverter}

SKS 21F B6U+E1CIF+B6Cl 12 V12

SK 60 GB 128

SK 30 GAL 123

SK 95 D 12

P 35/325F

\section{SKHI 20opA}

Preliminary Data

\section{Features}

- Compact design

- Hall Effect Current Sensor

- Circuit for soft charge the capacitors

- IGBT Braking chopper

- Vce monitoring

\section{Typical Applications}

- AC Motor Control

- Elevator

- Industrial

1) Photo non- contractual

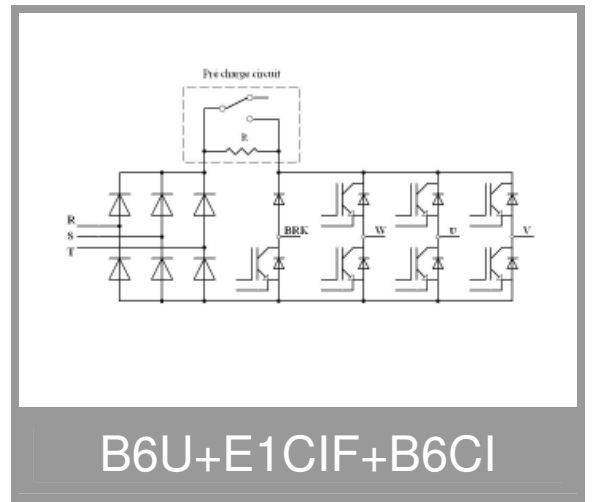

$\mathrm{B} 6 \mathrm{U}+\mathrm{E} 1 \mathrm{CIF}+\mathrm{B} 6 \mathrm{Cl}$

\begin{tabular}{|c|c|cc|c|}
\hline Circuit & $\mathrm{I}_{\mathrm{rms}}$ & \multicolumn{2}{|c|}{$\mathrm{V}_{\mathrm{ac}}\left(\mathrm{V}_{\mathrm{dc}}\right)$} & Types \\
$\mathrm{B} 6 \mathrm{Cl}$ & 30 & 380 & 750 & SKS 21F B6U+E1CIF+B6Cl 12 V12 \\
& & - & - & \\
\hline
\end{tabular}

\begin{tabular}{|l}
\hline \\
\hline \\
\hline \\
\hline
\end{tabular}

Symbol

\begin{tabular}{l|l}
$I_{\text {rms }} \max$ & No overload; $10 \mathrm{kHz}$
\end{tabular}

$\mathrm{T}_{\mathrm{amb}}=35^{\circ} \mathrm{C}$

$150 \%$ overload, 60 s every $10 \mathrm{~min}\left(\mathrm{I}_{\mathrm{ov}} / \mathrm{I}_{\mathrm{N}}\right)$

$200 \%$ overload, 10 s every $10 \mathrm{~min}\left(\mathrm{I}_{\mathrm{ov}} / \mathrm{I}_{\mathrm{N}}\right)$

\section{$\mathrm{V}_{\text {ce }} \max$}

$\mathrm{f}_{\mathrm{sw}} \max$

$\mathrm{f}_{\mathrm{sw}} \max \mathrm{Csl}$

C

$\mathrm{C}_{\text {eqvl }}$

$\mathrm{T}_{\mathrm{ds} \%}$

$\mathrm{V}_{\mathrm{DC}} \max$

Rectifier

$\mathrm{V}_{\text {net }} \max$

$T_{v j}$

$T_{\text {stg }}$

$T_{\text {amb }}$

$\mathrm{V}_{\text {isol }}$

w

Cooling

Absolute maximum switching frequency

Advise maximum switching frequency

Type EPCOS B43303A0687

Equivalent capacitor bank

Discharge time of the capacitor bank

Max DC voltage applied to capacitor bank

Values

Units

Losses

Max network voltage (line side)

Junction temperature for continous operation

without requirement of reforming of capacitors

30

$36 / 24$

$42 / 21$

1200

15

10

$680 / 400$

$1700 / 800$

A

A

A

A

$\mathrm{V}$

Current

sensor

Thermal trip

Others

$60 \mathrm{~Hz} / 1 \mathrm{~min}$

Aprox. total weight

Fan, DC power supply

Current Consumption (per fan)

Required air flow (per fan)

$\mathrm{B} 6 \mathrm{Cl}$, Converter at $\mathrm{P}_{\max }, \mathrm{T}_{\mathrm{amb}}=35^{\circ} \mathrm{C}$

Efficiency

Hall-type LEM LA 55-P

components

normally closed

Relay Metaltex J1NAC3

\section{Options}

Tests

\section{Functional Test}

Short Circuit Test

Visual Inspection 

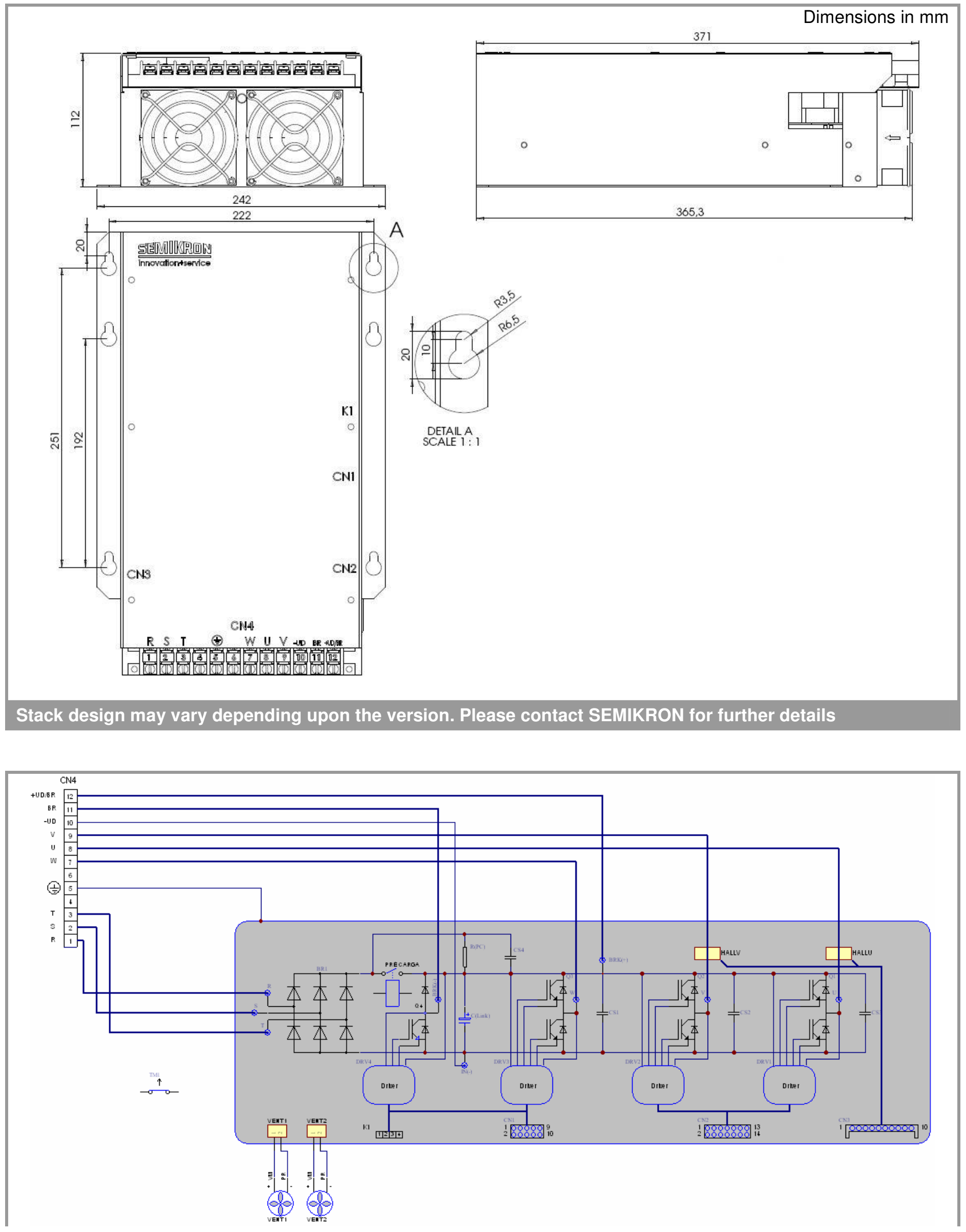
Electrical Data

\begin{tabular}{|c|c|c|c|c|c|c|}
\hline \multicolumn{7}{|c|}{ Connectors } \\
\hline \multirow{2}{*}{$\begin{array}{c}\text { Connector } \\
\text { Pin }\end{array}$} & \multirow[t]{2}{*}{ Symbol } & \multirow[t]{2}{*}{ Description } & \multicolumn{3}{|c|}{ Values } & \multirow[t]{2}{*}{ Units } \\
\hline & & & $\min$. & typical & $\max$. & \\
\hline CN1:1 & TOP W & Top phase W input signal & \multicolumn{3}{|c|}{$0 / 15$ (CMOS) } & $\mathrm{V}$ \\
\hline CN1:2 & ER W & Vce phase W error output signal & \multicolumn{3}{|c|}{$0 / 15$ (CMOS) } & $\mathrm{V}$ \\
\hline $\mathrm{CN} 1: 3$ & BOT W & Bot phase $\mathrm{W}$ input signal & \multicolumn{3}{|c|}{$0 / 15$ (CMOS) } & $\mathrm{V}$ \\
\hline CN1:4 & GND & Ground & \multicolumn{3}{|c|}{0} & $\mathrm{~V}$ \\
\hline CN1:5 & Vin(BRK) & Break input signal & \multicolumn{3}{|c|}{$0 / 15$ (CMOS) } & $\mathrm{V}$ \\
\hline CN1:6 & ER BRK & Vce Break error output signal & \multicolumn{3}{|c|}{$0 / 15$ (CMOS) } & $\mathrm{V}$ \\
\hline CN1:7 & $+\mathrm{Vs}$ & Supply voltage & 14,0 & & 15,6 & $\mathrm{~V}$ \\
\hline $\mathrm{CN1} 18$ & $+\mathrm{Vs}_{\mathrm{s}}$ & Supply voltage & 14,0 & & 15,6 & $\mathrm{~V}$ \\
\hline CN1:9 & GND & Ground & \multicolumn{3}{|c|}{0} & $\mathrm{~V}$ \\
\hline CN1:10 & GND & Ground & \multicolumn{3}{|c|}{0} & $\mathrm{~V}$ \\
\hline & & & \multirow{2}{*}{\multicolumn{3}{|c|}{$0 / 15$ (CMOS) }} & \\
\hline CN2:1 & TOP U & Top phase U input signal & & & & $\mathrm{V}$ \\
\hline CN2:2 & ER U & Vce phase U error output signal & \multicolumn{3}{|c|}{ 0/15 (CMOS) } & $\mathrm{V}$ \\
\hline CN2:3 & BOT U & Bot phase U input signal & \multicolumn{3}{|c|}{$0 / 15$ (CMOS) } & $\mathrm{V}$ \\
\hline CN2:4 & GND & Ground & \multicolumn{3}{|c|}{$\begin{array}{c}0 \\
0 / 15(\mathrm{CMOS})\end{array}$} & $\mathrm{V}$ \\
\hline CN2:5 & TOP V & Top phase V input signal & & $5(\mathrm{CMO}$ & & $\mathrm{V}$ \\
\hline CN2:6 & ER V & Vce phase $V$ error output signal & & $5(\mathrm{CMO}$ & & $\mathrm{V}$ \\
\hline CN2:7 & BOT V & Bot phase $V$ input signal & & $5(\mathrm{CMO}$ & & $\mathrm{V}$ \\
\hline CN2:8 & GND & Ground & & 0 & & V \\
\hline CN2:9 & $+\mathrm{Vs}$ & Supply voltage & 14,0 & 15 & 15,6 & $\mathrm{~V}$ \\
\hline CN2:10 & $+\mathrm{Vs}$ & Supply voltage & 14,0 & 15 & 15,6 & $\mathrm{~V}$ \\
\hline CN2:11 & GND & Ground & & 0 & & V \\
\hline CN2:12 & GND & Ground & & 0 & & $\mathrm{~V}$ \\
\hline CN2:13 & & NC & & & & \\
\hline CN2:14 & & $\mathrm{NC}$ & & & & \\
\hline & & & & & & \\
\hline CN3:1 & $+15 \mathrm{~V}$ & Supply Voltage (positive) & 14,5 & 15 & 15,5 & $\mathrm{~V}$ \\
\hline CN3:2 & $-15 \mathrm{~V}$ & Supply Voltage (negative) & $-14,5$ & -15 & $-15,5$ & $\mathrm{~V}$ \\
\hline CN3:3 & GND & Ground & & 0 & & $\mathrm{~V}$ \\
\hline CN3:4 & HALL U & Output Hall phase U & & & & \\
\hline CN3:5 & HALL V & Output Hall phase V & & & & \\
\hline CN3:6 & & NC & & & & \\
\hline CN3:7 & GND & Ground & & 0 & & $\mathrm{~V}$ \\
\hline CN3:8 & $+15 \mathrm{~V}$ & Supply Voltage (positive) & 14,5 & 15 & 15,5 & $\mathrm{~V}$ \\
\hline CN3:9 & $-15 \mathrm{~V}$ & Supply Voltage (negative) & $-14,5$ & -15 & $-15,5$ & V \\
\hline CN3:10 & & & & & & \\
\hline & & & & & & \\
\hline CN4:1 & $\mathrm{R}$ & Input Phase R & 176 & 220 & 253 & $\mathrm{~V}$ \\
\hline CN4:2 & $\mathrm{S}$ & Input Phase S & 176 & 220 & 253 & V \\
\hline CN4:3 & $\mathrm{T}$ & Input Phase T & 176 & 220 & 253 & $\mathrm{~V}$ \\
\hline CN4:4 & & $\mathrm{NC}$ & & & & \\
\hline CN4:5 & Earth & Earth & & & & \\
\hline CN4:6 & & NC & & & & \\
\hline CN4:7 & W & Output W Inverter Phase & & 220 & 253 & $\mathrm{~V}$ \\
\hline CN4:8 & $\mathrm{U}$ & Output U Inverter Phase & & 220 & 253 & $\mathrm{~V}$ \\
\hline CN4:9 & $\mathrm{V}$ & Output V Inverter Phase & & 220 & 253 & $\mathrm{~V}$ \\
\hline CN4:10 & $-U D$ & DC Link Negative & & & & \\
\hline CN4:11 & BR & Break Resistor Input & & & & \\
\hline CN4:12 & $+\mathrm{UD} / \mathrm{BR}$ & $\begin{array}{l}\text { DC Link Positive Reference and Break Resistor } \\
\text { Input }\end{array}$ & & & & \\
\hline $\mathrm{K} 1: 1$ & & NC & & & & \\
\hline K1:2 & $\mathrm{CIS}$ & $\begin{array}{l}\text { Charge Input Signal / Positive FAN Power } \\
\text { Supply }\end{array}$ & 0 & $0 / 18$ & 26,5 & $\mathrm{~V}$ \\
\hline $\mathrm{K} 1: 3$ & GND & Ground / Reference FAN Power Supply & & 0 & & $\mathrm{~V}$ \\
\hline $\mathrm{K} 1: 4$ & & NC & & & & \\
\hline
\end{tabular}

This technical information specifies semiconductor devices but promises no characteristics. No warranty or guarantee expressed or implied is made regarding delivery, performance or suitability. 


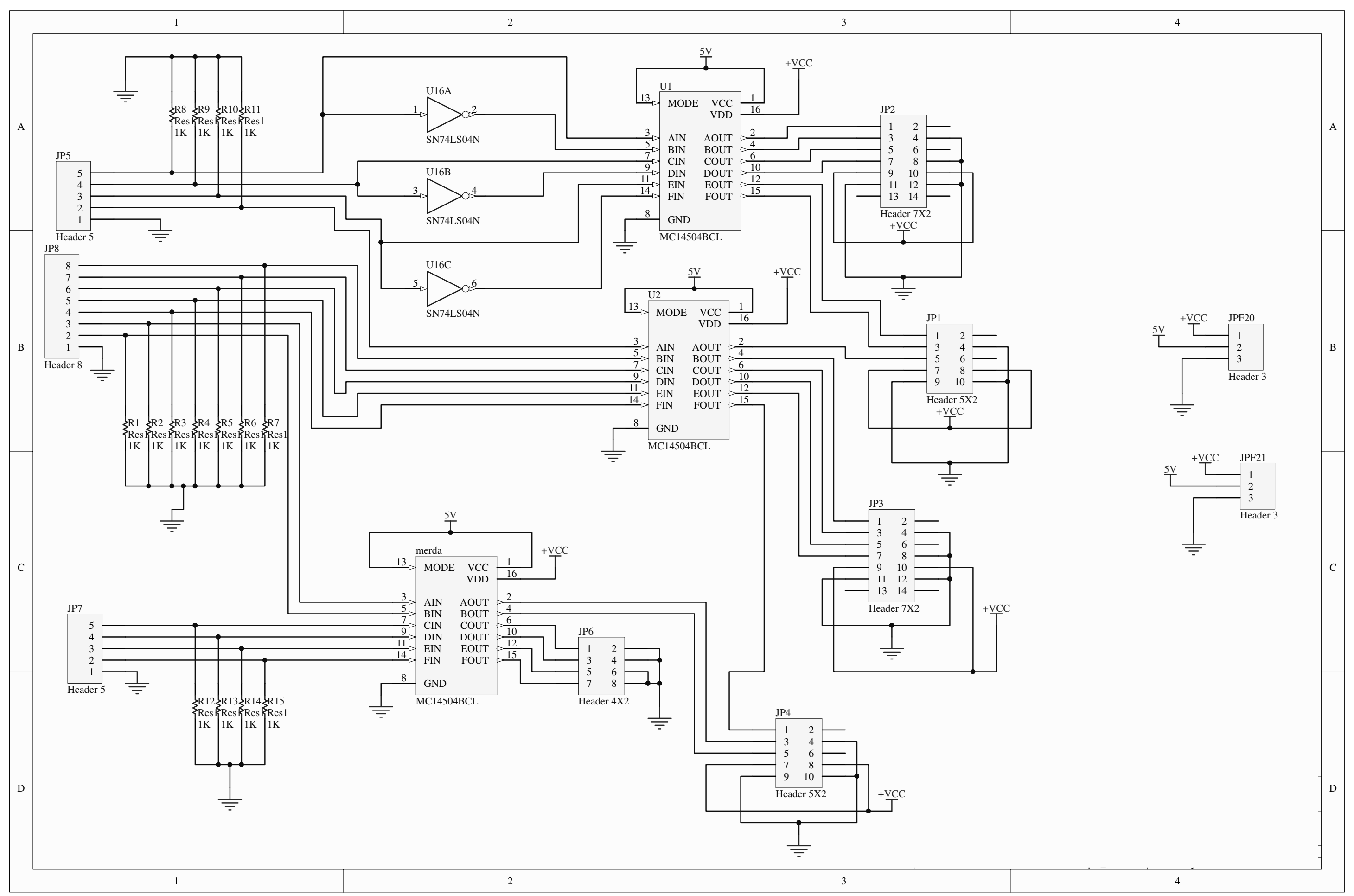


\begin{tabular}{l} 
Canal A \\
Canal A.SchDoc \\
\hline
\end{tabular}

$\underset{\text { Canal B. }}{\text { Cana B.Schboc }}$

\begin{tabular}{l} 
Canal C \\
Canal C.SchDoc \\
\hline
\end{tabular}

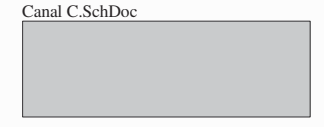

\begin{tabular}{l} 
Canal D \\
Canal D.SchDoc \\
\hline
\end{tabular}

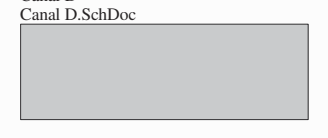

Protceao
Proctcano. Schboc

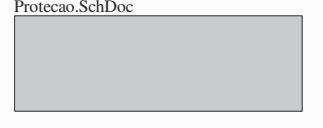

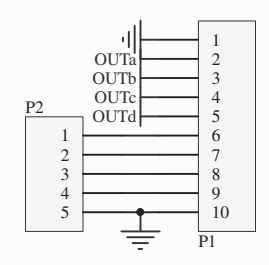

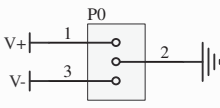




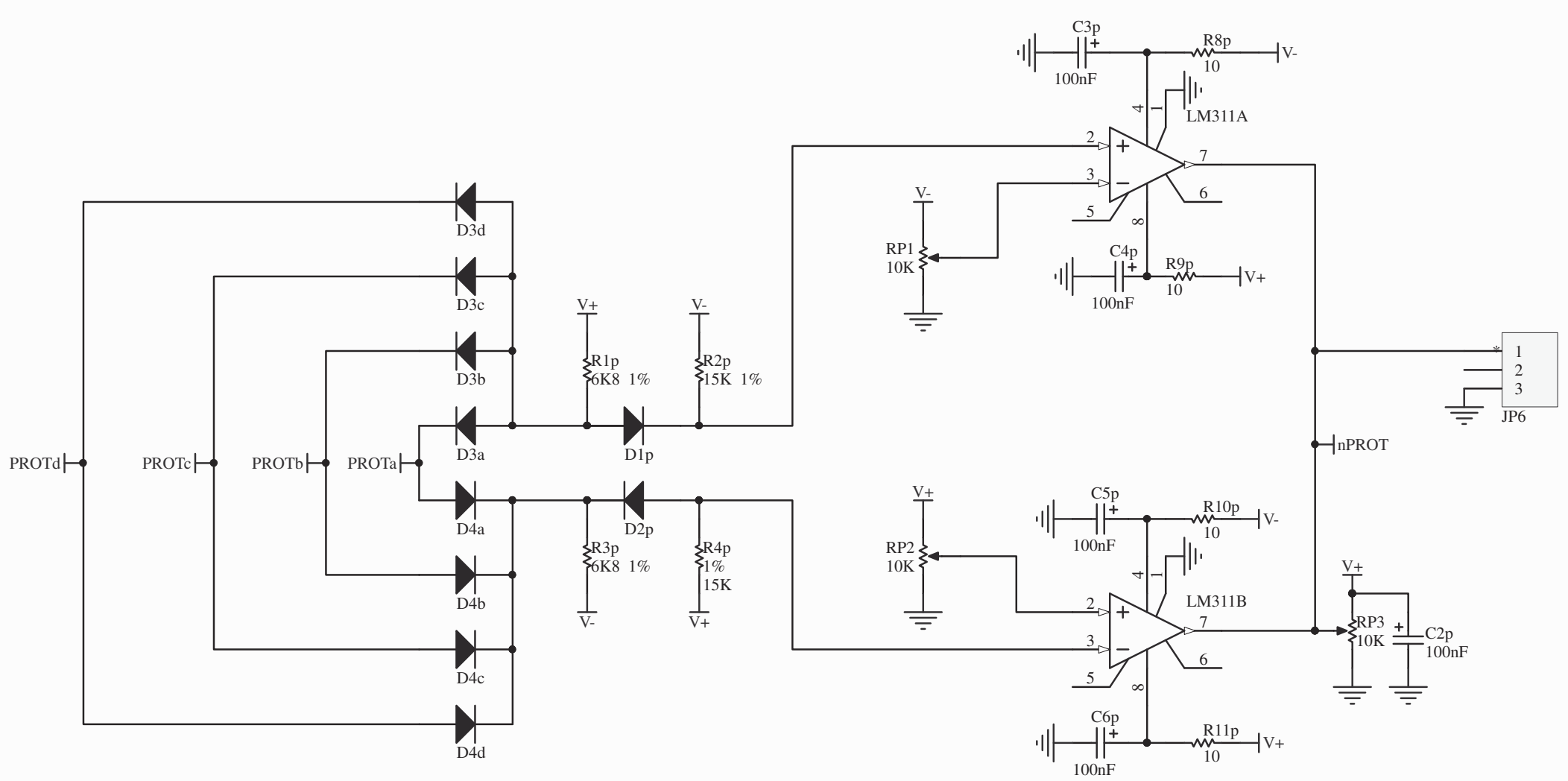




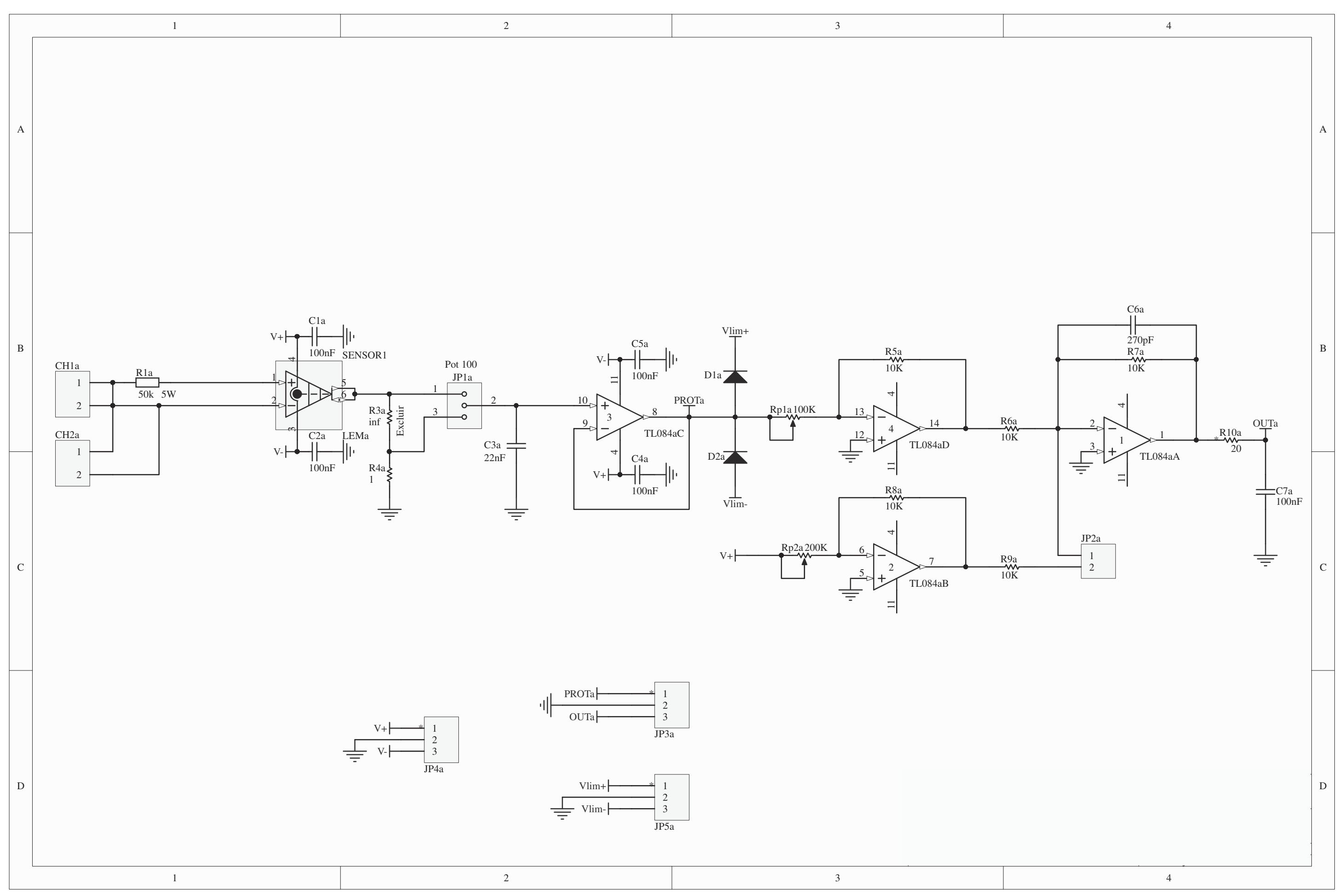


